\begin{abstract}
UNIVERSIDADE DE SÃO PAULO
ESCOLA DE ENGENHARIA DE SÃO CARLOS

CENTRO DE RECURSOS HÍDRICOS E ECOLOGIA APLICADA

PROGRAMA DE PÓS-GRADUAÇÃO EM CIÊNCIAS DA ENGENHARIA AMBIENTAL
\end{abstract}

\title{
TIAGO RODRIGUES
}

O ESTABELECIMENTO DE OBJETIVOS E INDICADORES DE SUSTENTABILIDADE PARA AVALIAÇÃO AMBIENTAL ESTRATÉGICA APLICADA A PLANOS DE DESENVOLVIMENTO URBANO

São Carlos - SP

2014 



\section{TIAGO RODRIGUES}

O ESTABELECIMENTO DE OBJETIVOS E INDICADORES DE SUSTENTABILIDADE PARA AVALIAÇÃO AMBIENTAL ESTRATÉGICA APLICADA A PLANOS DE DESENVOLVIMENTO URBANO

Dissertação apresentada à Escola de Engenharia de São Carlos, da Universidade de São Paulo, como parte dos requisitos para obtenção do título de mestre em Ciências da Engenharia Ambiental.

Orientador: Prof. Dr. Marcelo Montaño

São Carlos - SP

2014 
AUTORIZO A REPRODUÇÃO TOTAL OU PARCIAL DESTE TRABALHO, POR QUALQUER MEIO CONVENCIONAL OU ELETRÔNICO, PARA FINS DE ESTUDO E PESQUISA, DESDE QUE CITADA A FONTE.

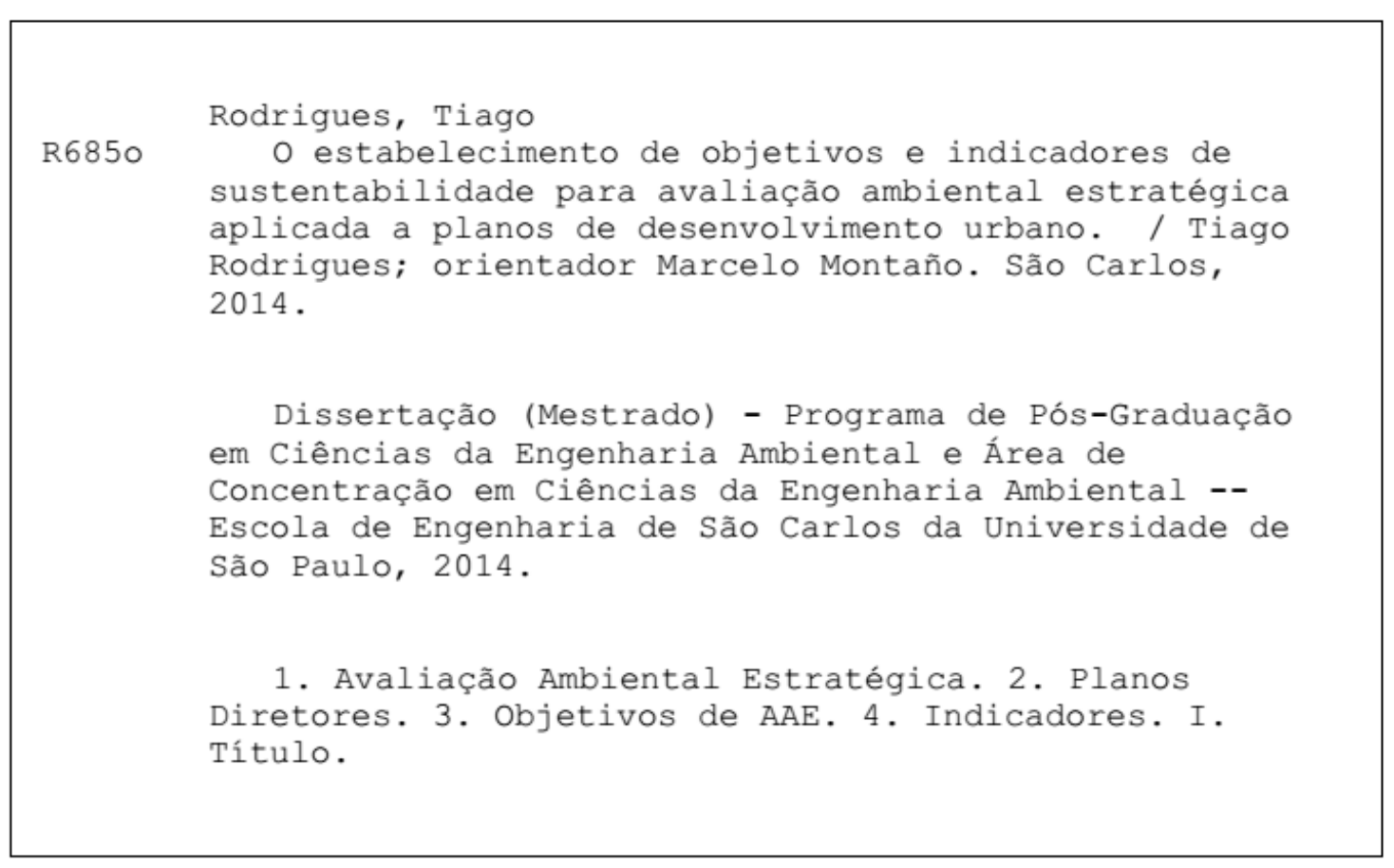




\section{FOLHA DE JULGAMENTO}

Candidato: Bacharel e Licenciado TIAGO RODRIGUES.

Título da dissertação: "Estabelecimento de objetivos e indicadores de sustentabilidade para a avaliação ambiental estratégica aplicada a planos de desenvolvimento urbano".

Data da defesa: $24 / 10 / 2014$

\section{Comissão Julgadora:}

Prof. Dr. Victor Eduardo Lima Ranieri (Presidente designado)

(Escola de Engenharia de São Carlos/EESC)

Prof. Titular Marcelo Pereira de Souza

(Escola de Artes, Ciências e Humanidades/EACH-USP)

Prof. Dr. Nemésio Neves Batista Salvador

(Universidade Federal de Sảo Carlos/UFSCar)
Resultado:

APROVADO

APROVADO

Coordenador do Programa de Pós-Graduação em Ciências da Engenharia Ambiental:

Prof. Associado Frederico Fabio Mauad

Presidente da Comissão de Pós-Graduação:

Prof. Associado Paulo César Lima Segantine 



\section{DEDICATORIA}

Dedico este trabalho aos meus pais, Gustavo e Rosária, que sempre me deram incentivo em todas as etapas da minha vida. Além dos amigos que ajudaram esta construção. 



\section{AGRADECIMENTOS}

Aos meus pais e meu irmão pelo suporte de sempre, pela confiança, pela paciência e por entenderem as minhas ausências mesmo estando tão perto.

Ao professor Marcelo Montaño, Mindu, o orientador da pesquisa, pela oportunidade que me foi dada, pela orientação, pela amizade, a paciência, pela compreensão e força nos momentos finais deste trabalho, por ser um bom exemplo como docente e contribuir ao meu amadurecimento profissional e pessoal.

A professora Clara Lemos e o Professor Marcelo Pereira que nos momentos finais deste trabalho muito contribuíram para o seu desenvolvimento.

Aos bons e velhos amigos da graduação, aqueles que resistiram a distância e ao tempo e que sempre se fazem presentes, em especial à Viviane (a nega), que até hoje passamos horas ao telefone, pelo carinho, pelos bons conselhos e por dividir a rotina e as discussões da Geografia. À Fran pelo carinho, conselhos e pelo jeito maduro e certeiro de decidir as coisas e a Virginia pelos palpites da vida e por sempre me ajudar nas decisões.

As amizades que conquistei em São Carlos, ao Alysson, ao Paulo de Sousa (o Paulette), ao Silvano e ao Paulo Arroio, que durante este percurso me acolheram bem e ajudaram me a adaptar a cidade e a rotina da pós-graduação, e ainda me trouxeram alegrias e bons momentos.

Ao André (Dédo), meu namorado, pelo companheirismo, o carinho, as risadas, a paciência, o senso de responsabilidade e, principalmente, por me incentivar e me ajudar a conciliar as diferentes atividades e os problemas que surgiram nos momentos finais deste trabalho.

Aos amigos de pesquisa, a Anne, a Priscila e a Mari, pelos conselhos e dicas de pesquisa, à Angela pela doçura e por ser um exemplo de pessoa guerreira, à Renata pela criatividade, criticidade e pelas boas risadas e, em especial, à Lilian, pela boa amizade, o carinho, os conselhos, a calma, as alegrias, o senso de responsabilidade e por ter se tornado uma grande amiga neste processo.

Aos amigos que conheci na Escola Natureza, em especial, a Cintia pela serenidade, pelo carinho e pelos os conselhos pedagógicos, a Fernanda e ao Cristiano por sempre me fazerem rir e me ajudarem nas dúvidas e minhas confusões.

Aos funcionários do SHS, do CCEAMA e PPG-SEA, pela disponibilidade e auxilio nos momentos de ajuda. A CAPES - Coordenação de Aperfeiçoamento de Pessoal de Nível Superior, pelo apoio financeiro durante o mestrado. A todas as pessoas não citadas aqui, mas que de alguma forma colaboraram para a construção deste trabalho. 


\section{RESUMO}

RODRIGUES, T. O Estabelecimento de objetivos e indicadores de sustentabilidade para avaliação ambiental estratégica aplicada a planos de desenvolvimento urbano. 2014. 163p. Dissertação (Mestrado) - Escola de Engenharia de São Carlos, Universidade de São Paulo, São Carlos, 2014

Nas últimas décadas do século XX as ações relacionadas a compatibilização das ações humanas com a qualidade do meio urbano passaram a fazer parte de agendas políticas e tratados internacionais. No Brasil, este processo se concretizou - no plano institucional - por meio do estabelecimento do Estatuto da Cidade e seus instrumentos de política urbana. Contudo, após mais de uma década de sua implementação ainda é notória a continuidade de um modelo de planejamento e gestão urbanos que nega a existência dos conflitos socioambientais inerentes ao processo de urbanização e, por sua vez, negligencia o desenvolvimento de ações de enfrentamento de seus problemas. No quadro internacional destaca-se a Avaliação Ambiental Estratégica (AAE), que tem como foco a avaliação dos potenciais efeitos ambientais decorrentes de ações estratégicas no âmbito de políticas, planos e programas de desenvolvimento, e que permite a identificação de alternativas para o desenvolvimento urbano e a incorporação de objetivos ambientais e de sustentabilidade junto aos objetivos inicialmente estabelecidos. A literatura profissional da AAE destaca que o sucesso do instrumento é decorrente do foco estabelecido por seus Objetivos e Indicadores, elementos substanciais para a sua aplicação. Sendo assim, considera-se relevante indagar sobre quais aproximações metodológicas seriam necessárias para assegurar a aplicabilidade da AAE ao planejamento urbano brasileiro por meio dos Planos Diretores. A partir desta perspectiva, esta pesquisa tem como objetivo geral apresentar e discutir procedimentos e aspectos metodológicos que envolvem a definição de objetivos e indicadores a serem empregados em uma AAE voltada ao planejamento do desenvolvimento urbano no contexto brasileiro.

Os resultados obtidos, orientados para o caso do município de São Carlos (SP), permitem visualizar o potencial de integração da AAE para promoção da sustentabilidade na elaboração de Planos Diretores no contexto brasileiro.

Palavras-chave: Avaliação Ambiental Estratégica, Planos Diretores, Objetivos de AAE e Indicadores. 


\begin{abstract}
RODRIGUES, T. The establishment of goals and indicators of sustainability for strategic environmental assessment applied to urban development plans. 2014. 163p. Master (MSc) (Master degree in Environmental Engineering Sciences) - Escola de Engenharia de São Carlos, Universidade de São Paulo, São Carlos, 2014.
\end{abstract}

In the last decades of the twentieth century the actions related to compliance of human actions with the quality of the urban environment became part of political agendas and international treaties. In Brazil, this process materialized - at institutional level - through the establishment of the City Statute and its instruments of urban policy. However, after more than one decade of its implementation is still noticeable continuity of a model of urban planning and management that denies the existence of environmental conflicts inherent in the process of urbanization and, in turn, overlooks the development of actions to confront their problems. On the international front there is the Strategic Environmental Assessment (SEA), which focuses on the assessment of potential environmental effects arising from strategic actions in development policies, plans and programs, and allows the identification of alternatives for urban development and the incorporation of environmental objectives and sustainability with the development goals initially set. The professional literature in the SEA emphasizes that the success of the instrument is due to the focus established by its Objectives and Indicators, substantial elements for your application. Hence it is relevant to inquire about which methodological approaches were needed to ensure the applicability of SEA to the Brazilian urban planning through the Master Plans. From this perspective, this research has the overall objective to present and discuss procedures and methodological aspects involved in setting objectives and indicators to be used in an SEA focused on urban development planning in the Brazilian context. The results, oriented to the case of São Carlos (SP), let you see the potential for integration of SEA to promote sustainability in the development of Master Plans in the Brazilian context.

Keywords. Strategic Environmental, Master Plans, SEA Objectives and Indicators. 


\section{LISTA DE FIGURAS}

Figura 1- Desenho geral da pesquisa

Figura 2 - O modelo de AAE centrada na decisão (a) versus modelo de AAE centrado na AIA de projetos (b). Fonte: Adaptado de Partidário, 2007. 16

Figura 3 - Abordagens metodológicas da AAE: (a) avaliando a solução: avaliação do impacto dos resultados de PPP; (b) avaliar a estratégia: avaliação do impacto da estratégia de PPP. Fonte: Adaptado de Partidário, 2007. 17

Figura 4 - Comparação entre diferentes tipos de critérios de avaliação 20

Figura 5 - As etapas básicas da AAE e a tomada de decisão estratégica, segundo Therivel (2004).

Figura 6 - Ações que devem ocorrer no momento do Scoping e sua relação com a tomada de decisão estratégica, segundo Therivel (2004).

Figura 7 - Etapas básicas do processo de AAE baseada na AIA de projetos. Fonte: adaptado de

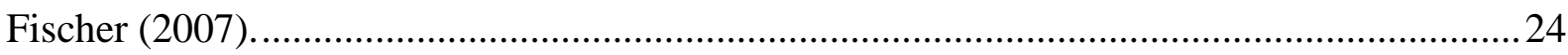

Figura 8 - A etapa de Scoping, segundo Fischer (2007)................................................ 25

Figura 9 - As etapas básicas para o desenvolvimento da AAE, segundo a OCDE.................26

Figura 10 - Ações que devem ocorrer no momento de Scoping segundo a OCDE ................227

Figura 11 - Elementos estruturantes que integram o modelo de pensamento estratégico em AAE.

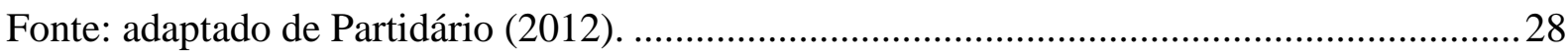

Figura 12 - Estrutura de desenvolvimento dos FCDs, segundo Partidário (2012) .................. 29

Figura 13 - Organização síntese da etapa de Scoping segundo alguns autores........................32

Figura 14 - Exemplo de objetivos, metas e indicadores na AAE ............................................ 33

Figura 15 - Relações entre indicadores, objetivos e demais elementos da AAE......................36

Figura 16 - Elementos do sistema de planejamento e gestão definidos pelo Estatuto da Cidade

Figura 17 - Os instrumentos disponíveis ao Plano Diretor. 39

Figura 18 - Exemplificação de como os Objetivos de AAE se inserem na ação estratégica ... 47 Figura 19 - Aumento da integração e equalização das questões ambientais, sociais e econômicas Fonte: Adaptado de OCDE, 2006.

Figura 20 - Representação das categorias utilizadas para classificação dos objetivos de AAE identificados. Adaptado de Bellen (2006).

Figura 21(A): Ligações entre os indicadores e outros aspectos da AAE; (B): Distinção entre informações contidas na etapa de Baseline e o Indicador de AAE. Fonte: Desenvolvido a partir

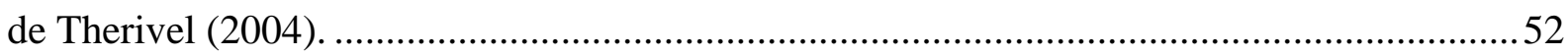

Figura 22 - Representação da organização hierárquica dos Indicadores de AAE coletados....53 
viii

Figura 23 - Exemplificação da organização hierárquica dos Indicadores de AAE para a descrição do Aspecto. Fonte: elaboração própria. 54

Figura 24 - Representação da distribuição dos Indicadores de AAE coletados e a representação dos indicadores coletados por dimensão. Fonte: elaboração própria........................................ 55

Figura 25- distribuição das informações nas tabelas 3, 4 e 5 58

Figura 26 - Descrição simplificada da estrutura de organização dos indicadores na dimensão Ambiental

Figura 27 - Descrição simplificada da estrutura de organização dos indicadores na dimensão Social

Figura 28 - Descrição simplificada da estrutura de organização dos indicadores na dimensão Econômica 70

Figura 29 - Procedimentos aplicados à análise da etapa scoping. ........................................ 75

Figura 30 - Localização de Thurrock Council ..................................................................... 78

Figura 31 - Articulação entre elementos e etapas da AAE/AS para formulação dos objetivos da avaliação. 79

Figura 32 - Elementos responsáveis pelo estabelecimento dos objetivos de AAE/AS 80

Figura 33- Localização do Council de Aberdeenshire 82

Figura 34 - Articulação entre elementos e etapas da AAE para formulação dos objetivos da avaliação. 83

Figura 35 - Localização da Área Metropolitana de Lisboa. 86

Figura 36 - Integração dos "Elementos Chave" para a formulação dos Fatores Críticos de Decisão..... 87

Figura 37 - Localização do Condado de Clare na Irlanda. 89

Figura 38 - Organização dos elementos responsáveis pela definição de objetivos ambientais estratégicos 91

Figura 39 - Modelo síntese representativo para o estabelecimento da etapa de Scoping segundo os casos analisados 103

Figura 40 - O modelo de AAE centrada na decisão (a) e o modelo de AAE baseado na AIA de projetos (b).

Figura 41 - Modelos de integração da AAE a tomada de decisão segundo Partidário (2012)

Figura 42 - Diagramas síntese da formulação teórica e prática da etapa de scoping. 109 Figura 43 - Diagrama síntese das concepções teóricas e práticas para o estabelecimento do scoping. 
Figura 44 - Ilustração de como se desenvolveria o processo de tomada de decisão para o desenvolvimento de planos diretores municipais considerando a aplicação da AAE ............117

Figura 45 - Localização do município de São Carlos em sua microrregião ............................. 118

Figura 46 - Esquema geral de articulações do Plano Diretor de São Carlos .......................... 121

Figura 47 - A promoção dos aspectos ambientais pela AAE. .............................................. 124

Figura 48 - Composição do elementos do scoping de uma AAE ao caso de São Carlos........128

\section{LISTA DE TABELAS}

Tabela 1: Vantagens e desvantagens das abordagens Baseline-led e Objective-led ................20

Tabela 2 - AAEs consultadas para identificação e coleta de Indicadores de AAE ...................44

Tabela 3 - Descrição dos indicadores da Dimensão Ambiental ...............................................59

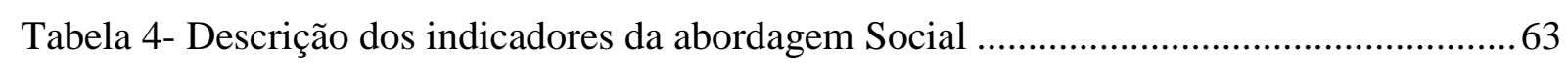

Tabela 5 - Descrição dos indicadores da abordagem econômica ............................................67

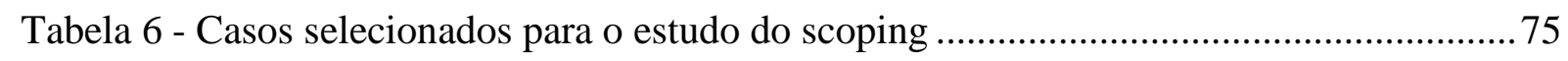

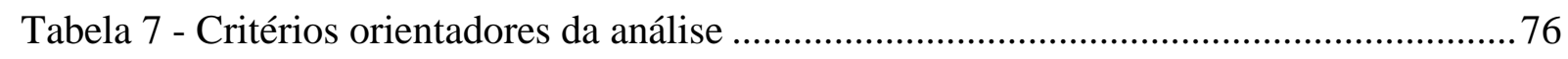

Tabela 8 - Considerações sobre a participação dos agentes envolvidos - (Stakeholders, participação Pública e Consultores) ......................................................................................95

Tabela 9 - Considerações sobre forma de apresentação das informações contextuais sobre o

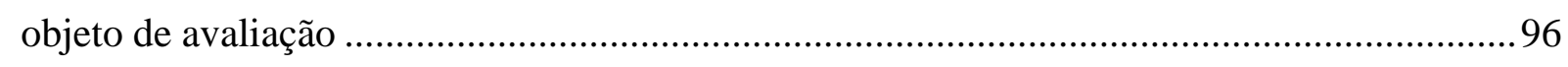

Tabela 10 - Considerações sobre a análise de outras Políticas, Planos e Programas - PPPs.... 97 Tabela 11 - Considerações sobre a importância da Baseline e a definição de Indicadores de

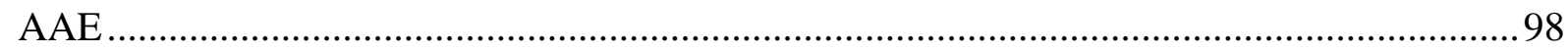

Tabela 12 - Considerações sobre como ocorre a consideração de aspectos voltados à promoção

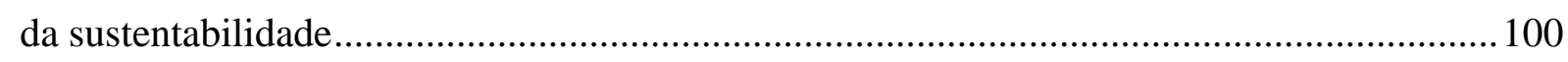

Tabela 13 - Relações verificadas entre os elementos do processo de scoping ....................... 101

Tabela 14 - A função da AAE segundo os casos analisados................................................. 105

Tabela 15 - Formas de integração da AAE a tomada de decisão nos casos analisados ..........108 Tabela 16 - Características dos elementos envolvidos no momento de scoping segundo o

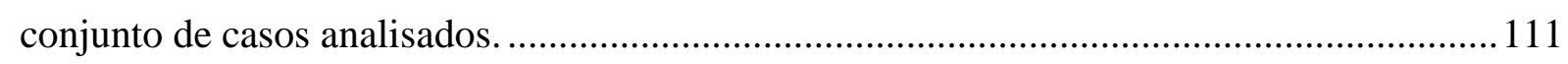

Tabela 17 - Expansão da área urbanizada do município de São Carlos (1857 - 2011) ......... 119

Tabela 18 - características dos elementos do scoping de uma AAE aplicada ao caso de São Carlos. 


\section{LISTA DE QUADROS}

Quadro 1 - Características dos modelos de AAE, segundo Partidário (2012)........................ 17

Quadro 2 - Objetivos do "Draft Plan” e os Objetivos de AAE/SA......................................... 80

Quadro 3 - Objetivos iniciais (intenções iniciais) da "Estrutura final do Plano" e os Objetivos

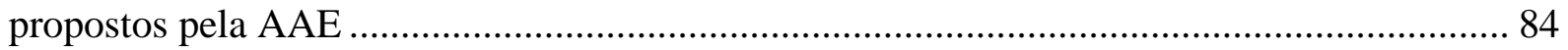

Quadro 4 - Objetivos de ação estratégica e os Objetivos de AAE para o caso 3..................... 88

Quadro 5 - Objetivos do Draft Plane os Objetivos Ambientais Estratégicos do caso 4 .......... 92

\section{LISTA DE GRÁFICOS}

Gráfico 1- Distribuição dos objetivos de AAE por tema e agrupados por países..................... 50

Gráfico 2 - Proporção dos temas em relação ao total de objetivos coletados.......................... 50

Gráfico 3 - Distribuição da quantidade de Objetivos de AAE coletados por tema ................. 51

Gráfico 4 - Distribuição dos indicadores da dimensão ambiental ......................................... 56

Gráfico 5 - Distribuição dos indicadores da dimensão social ................................................ 57

Gráfico 6 - Distribuição dos indicadores da dimensão econômica.......................................... 58

Gráfico 7 - Direcionamento temático dos Indicadores de AAE coletados. ............................. 71

Gráfico 8- Temas dos objetivos do Plano Diretor de São Carlos. ......................................... 122

Gráfico 9 - Comparação dos objetivos de AAE segundo a prática internacional, frente aos objetivos do plano diretor de São Carlos. ........................................................................... 122

\section{LISTA DE SIGLAS}

AAE

AIA

CETESB

DGOTDU

EEA

IBGE

NEPA

OECD

PD

PDSC

PPPs

SAAE

SEADE
Avaliação Ambiental Estratégica

Avaliação de Impacto Ambiental

Companhia Ambiental do Estado de São Paulo

Direcção Geral do Ordenamento do Território e

Desenvolvimento Urbano

European Environment Agency,

Instituto Brasileiro de Geografia e Estatística

National Environmental Policy Act

Organizaçtion for Economic Cooperations and Development

Plano Diretor

Plano Diretor Municipal de São Carlos

Políticas, Planos e Programas

Serviço autônomo de água e esgoto de São Carlos

Fundação Sistema Estadual de Análise de Dados 
SIMEC

SEA Indicators

SEA Objectives

SEA for Land Use Plan
Sistema de Indicadores do Ministério da Educação.

Strategic Environmental Indicators

Strategic Environmental Objectives

Strategic Environmental for Land Use Plan 


\section{SUMÁRIO}

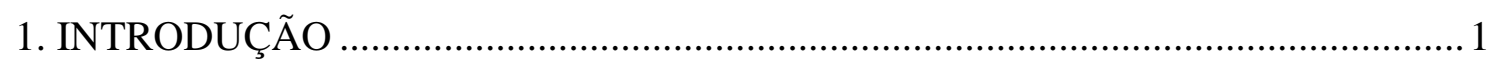

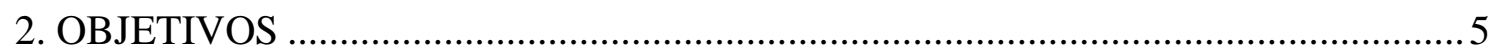

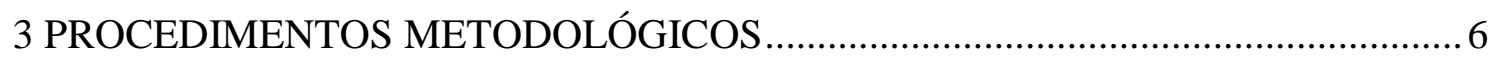

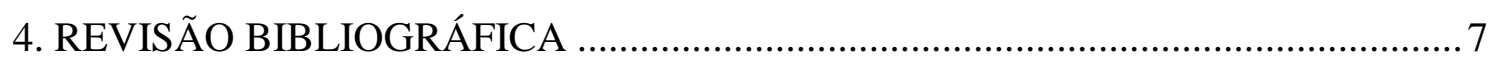

4.1 A Avaliação Ambiental Estratégica (AAE) ………………………………………... 8

4.2. A Avaliação Ambiental Estratégica aplicada ao planejamento urbano......................... 13

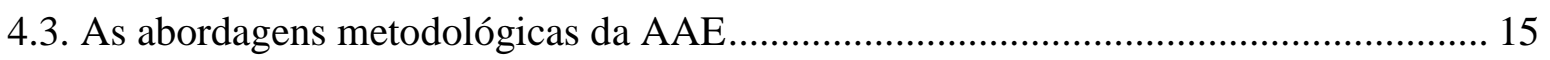

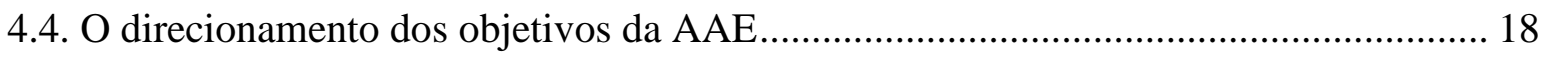

4.5. As Etapas Básicas da Avaliação Ambiental Estratégica e o papel do escopo. .............. 21

4.6. A elaboração da Baseline na Avaliação Ambiental Estratégica ……………………..... 33

4.7. O papel dos Indicadores na Avaliação Ambiental Estratégica ………………………... 34

4.8. O Estatuto da Cidade e o Plano Diretor ....................................................................... 37

4.9. O Plano Diretor e a política ambiental municipal ....................................................... 39

5. ANÁlISE DA PRÁtICA CORRENTE DE AAE: O USO DE OBJETIVOS E INDICADORES...

5.1. O direcionamento temático dos objetivos de AAE ................................................... 46

5.2. Caracterização dos indicadores de AAE na prática corrente........................................ 51

6. ANÁLISE DE CASOS SELECIONADOS: O PROCESSO DE SCOPING NA AAE.74

6.1 Análise dos casos selecionados - caracterização do processo de estabelecimento dos

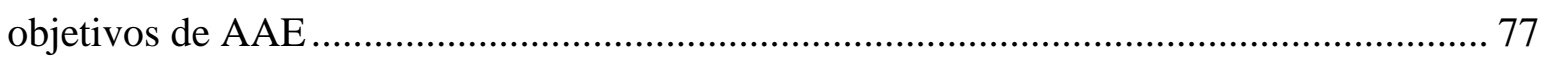

6.2 Discussões - os aspectos conceituais e práticos para a formulação do escopo da AAE 104

7. ILUSTRAÇÃO DO POTENCIAL DE CONTRIBUIÇÃO DA AAE AOS PLANOS DIRETORES MUNICIPAIS 116

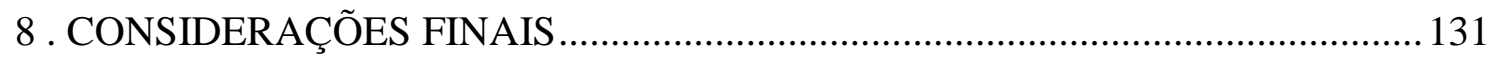

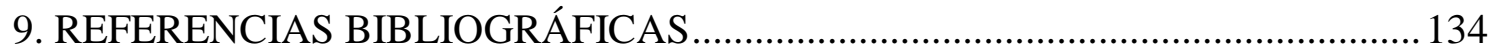

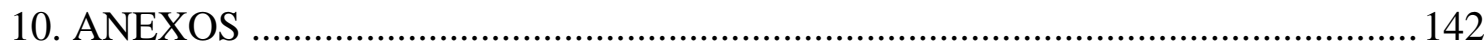




\section{INTRODUÇÃO}

A segunda metade do século XX foi marcada, no Brasil, por um intenso processo de industrialização e modernização das atividades no campo, que resultou no desenvolvimento de novas atividades produtivas, aumento da divisão social do trabalho, expansão do consumo e o aumento do número de pessoas vivendo nas cidades (SANTOS, 1993).

O modelo de urbanização brasileiro está associado a um aprofundamento das contradições entre os componentes ambiental e social dos espaços urbanos, de tal modo que as relações entre a urbanização do território e a resiliência do ambiente ocupado se tornam mais evidentes (SPÓSITO, 2003; SILVA \& TRAVASSOS, 2008).

Hogan (1995) lembra que os problemas ambientais nas cidades sempre existiram, mas devido à dimensão que atingiram passam a desencadear o interesse da sociedade em tomar medidas para o seu equacionamento. Deste modo, intensificam-se as discussões sobre a relação entre desenvolvimento e o meio ambiente, incorporando-se as questões ambientais ao conjunto de questões sociais, políticas e econômicas que pautam as decisões tomadas pelo conjunto da sociedade (SANTOS, 2004; RIBEIRO, 2010).

A partir do início da década de 1970, verifica-se um movimento de incorporação das questões ambientais na agenda político-institucional internacional que culmina na delimitação de um modelo de desenvolvimento que, ao pautar as decisões governamentais e de toda a sociedade, permitiria corrigir os rumos adotados até então em relação ao ritmo e modo de exploração dos recursos naturais. O relatório "Nosso Futuro Comum" (também conhecido como relatório Brundtland, divulgado em 1987), marco principal deste movimento, oferece a definição a ser aplicada para o que passa a ser denominado "desenvolvimento sustentável", sendo aquele que "satisfaz as necessidades do presente sem comprometer a capacidade das gerações futuras de suprir suas próprias necessidades" (CMMAD, 1988).

A Conferência das Nações Unidas para o Meio Ambiente e Desenvolvimento (CNUMAD), realizada em 1992 sob a influência do relatório Brundtland, reafirma como elementos-chave para a discussão dos problemas ambientais a questão do desenvolvimento e a noção de meio ambiente humano (CNUMAD, 1992). Como um dos principais documentos extraídos da conferencia, a Agenda 21 aponta que a concentração populacional nos assentamentos urbanos dos países em desenvolvimento tem exercido forte pressão sobre o meio ambiente e que a erradicação da pobreza junto à resolução de problemas habitacionais são requisitos essenciais para o alcance do desenvolvimento sustentável nas cidades (CNUMAD, 1992).

Segundo Pugh (2000), foi neste contexto em que a problemática relacionada ao crescimento desordenado dos centros urbanos, assume importância significativa a aqueles 
ligados a perda de recursos naturais. A Agenda 21 Brasileira, por exemplo, estabelece a introdução da dimensão ambiental nas políticas urbanas existentes como medida para a promoção do desenvolvimento sustentável nas cidades (MMA, 2004).

No plano institucional brasileiro, o Estatuto da Cidade (Lei Federal no 10.257/2001) é considerado um dos principais vetores para a promoção da compatibilização das ações humanas com a qualidade do meio urbano. Como bem destacam Fernandes (2013) e Rolnik (2013), o Estatuto é fruto de um movimento de reforma urbana pelo direito à cidade, que emergiu como contraposição a um modelo de urbanização excludente e espoliativo que vem prevalecendo ao longo de décadas de urbanização acelerada. Além do direito à cidade e à moradia, o Estatuto também inclui entre seus fundamentos a promoção do equilíbrio ambiental e da sustentabilidade, sendo o Plano Diretor um de seus instrumentos essenciais de política urbana (BRASIL, 2001).

Ainda assim, verifica-se uma distância considerável entre a realidade dos municípios brasileiros e a concretização dos princípios e objetivos de sustentabilidade já incorporados ao arcabouço institucional (SILVA \& TRAVASSOS, 2008). Nesse sentido, alguns autores têm procurado compreender as razões da permanência dos problemas socioambientais urbanos e os desafios que se apresentam para a sua superação (FERNANDES, 2013; ROLNIK, 2013).

A falta de integração da variável ambiental e/ou dos princípios de sustentabilidade ao conjunto de valores e referências que orientam o planejamento do desenvolvimento urbano encontra-se na raiz deste problema. É revelador, por exemplo, o fato de aproximadamente $80 \%$ dos municípios brasileiros contarem com órgãos com atribuições específicas voltadas para a gestão de aspectos ambientais (IBGE, 2014) ao mesmo tempo em que os Planos Diretores municipais têm reforçado a marginalização das questões ambientais frente às demais questões relacionadas ao desenvolvimento dos municípios (COSTA, CAMPANTE e ARAÚJO, 2011).

Via de regra, embora tenha ocorrido a assimilação de princípios e objetivos ambientais em grande parte dos planos diretores brasileiros, não há vinculação com estratégias de ordenamento territorial fundamentadas em princípios de sustentabilidade ambiental (ibid.). Mesmo havendo esforços significativos para a promoção da efetividade na aplicação dos instrumentos de planejamento territorial a partir do Estatuto da Cidade, ainda prevalece um modelo de planejamento e gestão urbanos que nega a existência dos conflitos socioambientais inerentes ao processo de urbanização e, por sua vez, negligencia o desenvolvimento de ações de enfrentamento de seus problemas (COSTA, CAMPANTE e ARAÚJO, 2011; ROLNIK, 2013).

A inserção da variável ambiental no planejamento tem sido impulsionada pela aplicação de instrumentos voltados para a avaliação dos efeitos sobre o meio ambiente 
derivados da implantação de empreendimentos e atividades, assim como da implementação de políticas, planos e programas. Este percurso se inicia com a promulgação, em 1969, da lei de Política Nacional do Meio Ambiente (National Environmental Policy Act - NEPA) nos Estados Unidos, que passa a exigir formalmente que as decisões governamentais tomadas nos diversos níveis do planejamento sejam submetidas a uma Avaliação de Impacto Ambiental, de tal modo que levem em consideração os efeitos sobre o meio ambiente que possam ser provocados, justificando a decisão tomada (WOOD, 2002; SANTOS, 2004; SÁNCHEZ, 2006). Segundo Fischer (2007), a partir de então as avaliações ambientais assumem importância significativa no planejamento das ações humanas, na medida em que promovem a inserção do aspecto ambiental e oferecem aos tocadores de decisão condições para a promoção da proteção ambiental e do desenvolvimento sustentável.

Ao longo da década de 1990 a literatura passa a reportar a aplicação da Avaliação de Impacto Ambiental em instâncias estratégicas do planejamento, por meio da Avaliação Ambiental Estratégica (AAE). Ainda que inicialmente as aplicações de AAE tenham sido orientadas pela abordagem metodológica aplicada à AIA de projetos, ao longo de seu desenvolvimento e maturação a AAE passa paulatinamente a incorporar visões e abordagens complementares em função do contexto em que é aplicada (BINA, 2007; TETLOW \& HANUSCH, 2012). Atualmente, a despeito de diferentes abordagens propostas para a condução da AAE e sua integração ao processo decisório, consolida-se a visão de que a AAE deve ter como foco/objetivo a promoção das considerações ambientais e de sustentabilidade a partir da integração dos aspectos sociais, econômicos e ambientais relevantes para a decisão a ser tomada, facilitando a busca da melhor alternativa estratégica (FISCHER, 2007; THERIVEL, 2010; LOBOS \& PARTIDÁRIO, 2014).

Conforme estabelecem Fischer (2007) e Therivel (2010), um dos fatores que asseguram a singularidade e especificidade da AAE em relação às suas contribuições para a formulação de PPPs é o seu potencial de ajuste ao contexto de aplicação, em função do objeto a ser analisado.

Esta capacidade de estabelecer para si o foco da avaliação com vistas à promoção de objetivos de sustentabilidade a serem incorporados às ações estratégicas, é realizada ao longo da etapa de scoping. Trata-se de uma das etapas essenciais do instrumento, pois ao ser aplicado em uma instancia estratégica de planejamento, permite identificar impactos que vão além da escala do projeto, atuando como ferramenta de promoção da sustentabilidade ao incorporar questões sociais, econômicas e ambientais (PARTIDÁRIO, 1996; SHEPHERD \& ORTOLANO, 1996; THERIVEL, 2010). 
Conforme Therivel (2010), ao longo desta etapa são estabelecidos os objetivos a serem perseguidos pela AAE, ou seja, a delimitação das questões que devem ser tratadas para o desenvolvimento da ação estratégica. Associados aos objetivos, definem-se quais serão os indicadores a serem considerados durante a avaliação dos efeitos induzidos pela ação estratégica.

São, portanto, essenciais à realização de uma AAE focada na promoção da sustentabilidade no planejamento de ações estratégicas. No caso brasileiro, entende-se que há um grande potencial de contribuição da AAE para o preenchimento das lacunas atualmente identificadas no planejamento do desenvolvimento urbano, justamente em relação à promoção da integração de princípios de sustentabilidade ao conjunto de valores e referências que orientam a formulação de Planos Diretores Municipais no país.

Apesar da existência de uma produção acumulada em torno das perspectivas de integração da $\mathrm{AAE}$ aos instrumentos de planejamento territorial e urbano, como ilustram os trabalhos de Souza (2003), Oliveira (2008), Fabbro Neto (2010, 2013), Angelieri (2011), Romanelli (2013), dentre outros, há claramente uma carência de produção científica voltada para a fundamentação da prática da AAE no planejamento do desenvolvimento urbano no Brasil. Sendo assim, o presente trabalho tem como objetivo apresentar procedimentos e aspectos metodológicos envolvidos na definição de objetivos e indicadores empregados na Avaliação Ambiental Estratégica voltada à promoção da sustentabilidade no planejamento do desenvolvimento urbano no contexto brasileiro.

A pesquisa é amparada pela revisão da prática internacional e interpretação do contexto de aplicação da AAE como instrumento de suporte à elaboração de Planos Diretores Municipais no Brasil. Para tanto, procedeu-se à análise dos objetivos e indicadores em 15 AAEs voltadas para planos de desenvolvimento territorial no contexto europeu, complementada pela verificação da fundamentação conceitual e metodológica que ampara a realização do scoping em quatro casos selecionados de modo a assegurar a representatividade em relação ao conjunto inicial. Em seguida, partiu-se para uma ilustração de procedimentos e aspectos metodológicos aplicados no estabelecimento de objetivos e indicadores de AAE para a promoção da sustentabilidade no planejamento urbano, utilizando o Plano Diretor do município de São Carlos (SP) como elemento de suporte. 


\section{OBJETIVOS}

A pesquisa tem como objetivo geral apresentar e discutir procedimentos e aspectos metodológicos que envolvem a definição de objetivos e indicadores a serem empregados em uma Avaliação Ambiental Estratégica voltada ao planejamento do desenvolvimento urbano no contexto brasileiro.

Para tanto, estabelecem-se os seguintes objetivos específicos:

i. Estabelecimento do modelo conceitual aplicado na etapa de scoping, de tal modo a assegurar a integração entre seus elementos essenciais;

ii. Identificar temas, procedimentos e aspectos metodológicos que têm direcionado o desenvolvimento de objetivos e indicadores para promoção da sustentabilidade em processos de AAE no contexto internacional, e a sua importância em relação ao modelo conceitual aplicado;

iii. Ilustrar a potencial contribuição da $\mathrm{AAE}$ em relação à promoção da sustentabilidade como elemento estratégico na elaboração de Planos Diretores de Desenvolvimento Urbano no Brasil, a partir do caso do município de São Carlos (SP). 


\section{PROCEDIMENTOS METODOLÓGICOS}

O presente trabalho foi desenvolvido a partir de uma perspectiva qualitativa de pesquisa, que orientou os procedimentos metodológicos aplicados para a definição de objetivos e indicadores aplicados em AAE no contexto do planejamento urbano. $\mathrm{O}$ desenvolvimento da pesquisa incluiu, portanto, as seguintes etapas:

\section{(i) Revisão bibliográfica}

Tem como princípio conhecer os principais aspectos conceituais e metodológicos que orientam a aplicação da AAE e também as questões conceituais que envolvem os instrumentos de planejamento urbano brasileiro e a questão ambiental. No presente trabalho, etapa permitiu estabelecer os fundamentos teóricos e conceituais que orientam as análises desenvolvidas sobre a prática de aplicação a AAE, tendo-se como base:

- a evolução conceitual da AAE e as linhas de discussão dominantes relacionadas às abordagens metodológicas e conceituais do instrumento;

- as diferentes concepções sobre as etapas processuais e o papel da etapa scoping na AAE, além da função de elementos como a baseline, os indicadores e objetivos da AAE;

i. o papel dos instrumentos de planejamento urbano no Brasil e sua relação com a questão ambiental e a sustentabilidade nos espaços urbanos.

(ii) Análise do estabelecimento de objetivos, emprego de indicadores e elaboração do scoping na prática corrente da AAE

A partir do embasamento teórico/conceitual apresentado, esta etapa trabalhou em aplicações da AAE no planejamento do uso do solo e/ou desenvolvimento urbano, incluindo:

$\checkmark$ Análise de temas, procedimentos e aspectos metodológicos que direcional o desenvolvimento de objetivos e indicadores para promoção da sustentabilidade em 15 relatórios de AAE elaborados segundo os procedimentos definidos para países da União Europeia. As saídas desta etapa permitiram verificar como se dá o alinhamento das questões almejadas por objetivos e indicadores nas AAEs estudadas;

$\checkmark$ Análise de elementos e procedimentos aplicados em quatro relatórios, para desenvolvimento da etapa de scoping. Esta etapa permitiu elaborar um modelo conceitual sintético referentes aos aspectos que orientam a definição do scoping.

(iii) Ilustração do potencial de aplicação da AAE no contexto brasileiro 
Nesta etapa, desenvolveu-se discussões sobre o potencial de contribuição da AAE em relação à promoção da sustentabilidade e como elemento estratégico na elaboração de Planos Diretores, tendo como objeto o atual plano diretor do município de São Carlos (SP). A partir daí, foi possível cotejar os objetivos e indicadores que instruem a prática atual de AAE em âmbito internacional diante dos temas contidos no plano diretor analisado, desenvolvendo-se uma ilustração dos elementos que estariam presentes em uma configuração hipotética do escopo da AAE, caso aplicada ao plano diretor de São Carlos.

A Figura 1 a seguir apresenta o desenho geral da pesquisa realizada. O detalhamento dos procedimentos metodológicos empregados em cada etapa, juntamente com os resultados e discussões estão dispostos nos capítulos a seguir.

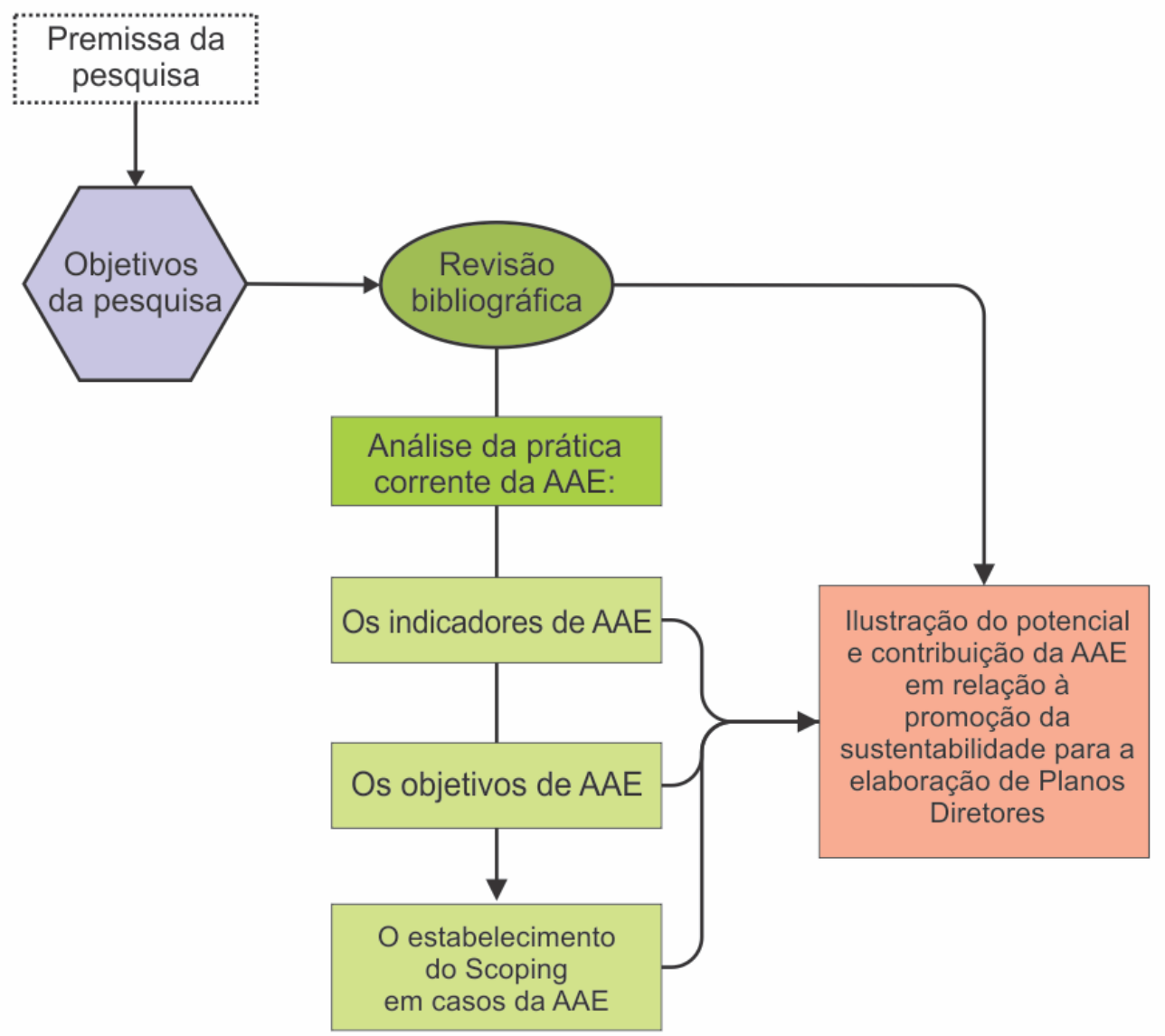

Figura 1- Desenho geral da pesquisa

\section{REVISÃO BIBLIOGRÁFICA}

A revisão bibliográfica foi estruturada em torno de dois elementos - a Avaliação Ambiental Estratégica, com foco em suas características, princípios, abordagens e procedimentos; e a inserção de aspectos ambientais a partir da aplicação dos instrumentos de planejamento urbano no Brasil, com maior enfoque sobre os Planos Diretores de desenvolvimento municipal. 


\subsection{A Avaliação Ambiental Estratégica (AAE)}

A inserção da variável ambiental no planejamento tem sido impulsionada pela aplicação de instrumentos voltados para a avaliação dos efeitos sobre o meio ambiente derivados da implantação de empreendimentos e atividades, assim como da implementação de políticas, planos e programas.

Um dos principais marcos para a disseminação de instrumentos voltados para a avaliação de impactos, a promulgação da lei de Política Nacional do Meio Ambiente (National Environmental Policy Act - NEPA) nos Estados Unidos, em 1969, passa a exigir formalmente que as decisões governamentais tomadas nos diversos níveis do planejamento sejam submetidas a uma Avaliação de Impacto Ambiental, de tal modo que levem em consideração os efeitos sobre o meio ambiente que possam ser provocados, justificando a decisão tomada (SANTOS, 2004; SÁNCHEZ, 2006).

A partir de então, a Avaliação de Impacto Ambiental (AIA) passa a ser adotada em diversos países de forma dirigida para projetos, aplicada de forma sistemática (FISCHER, 2007). Ao longo do tempo, a AIA voltada para projetos passa a ser direcionada a níveis estratégicos de planejamento integrando os aspectos sociais e econômicos aos biofísicos, e a literatura passa a reportar aplicações - a partir de meados da década de 1980 - de avaliações ambientais aplicadas às instâncias estratégicas de decisão, sobretudo para orientar a formulação de políticas, planos e programas (PPPs) (PARTIDARIO, 2000; BUCKLEY, 2000).

Um dos principais fatores que distinguem as avaliações de impacto voltadas para projetos das avaliações voltadas para ações estratégicas é a possibilidade que estas últimas têm de influenciar na definição de objetivos e alternativas para o desenvolvimento. Neste sentido, Pope (2004) e Therivel (2004) entendem que o caráter proativo da Avaliação Ambiental Estratégica (AAE) favorece a discussão de efeitos cumulativos, indiretos e sinérgicos, além de possibilitar o estabelecimento de alternativas que possam influenciar positivamente ao longo dos níveis de decisão (POPE, 2004; THERIVEL, 2004). Para Therivel (2004), inclusive, a AAE surge como uma ferramenta de integração das considerações ambientais e de sustentabilidade na tomada de decisão estratégica.

De acordo com Fischer (2007), a AAE deve apresentar três características que a distinguem dentre os demais instrumentos de Avaliação de Impactos:

i. A AAE deve ser estruturada em torno de um processo sistemático, de suporte ao processo de tomada de decisão estratégica e ser orientada para a inclusão de outros aspectos de sustentabilidade (além dos ambientais) durante a formulação de PPPs; 
ii. A AAE deve inserir rigor científico para formulação de PPPs, ao se basear em evidencias construídas por técnicas e métodos consistentes;

iii. $\quad$ A AAE deve formular um quadro estruturado de suporte à decisão de modo a tornar-se mais efetiva, por exemplo, ao definir com clareza as questões e alternativas que deverão ser consideradas em diferentes níveis de planejamento.

Conforme discorre Partidário (2007), enquanto a AIA aplicada a projetos tem como foco encontrar a solução para um problema específico (notadamente, o controle dos efeitos ambientais provocados pelos projetos) a AAE se atenta em compreender o contexto em que o problema se manifesta, integrando diferentes perspectivas e, assim, propor caminhos sustentáveis de desenvolvimento.

Assim, entende-se que a Avaliação Ambiental Estratégica tem raízes na Avaliação de Impacto Ambiental, mas se distancia da mesma na medida em que se qualifica como um processo sistematizado de avaliação ambiental com o objetivo de integrar as considerações ambientais e de sustentabilidade na tomada de decisão estratégica (THERIVEL, 2004).

Em termos de sua representatividade, o principal marco institucional da AAE é dado pela Diretiva Europeia de AAE, SEA DIRECTIVE (2001/42/CE), que torna obrigatório aos estados membros da União Europeia a aplicação da AAE na formulação de determinados planos e programas que possam provocar efeitos significativos sobre o meio, antes da tomada de decisão estratégica.

O objetivo da Diretiva é promover um alto nível de proteção ambiental e contribuir para a integração dos aspectos ambientais na preparação e adoção de planos e programas com vistas ao desenvolvimento sustentável e, dessa maneira, se impõe a setores de planejamento (por exemplo, transporte, energia, pesca, turismo, uso do solo, desenvolvimento urbano) cujas ações podem causar efeitos significativos no ambiente (DESMOND, 2007).

No Brasil a AAE tem sido exercida de maneira informal e desarticulada (MONTAÑO et al., 2014; MONTAÑO, MALVESTIO \& OPPERMANN, 2013), em grande medida direcionada ao licenciamento de grandes projetos e/ou empreendimentos estruturantes sem o devido respaldo estratégico (OLIVEIRA, MONTAÑO e SOUZA, 2013; MALVESTIO \& MONTAÑO, 2013). Uma deficiência associada às AAEs brasileiras decorre do fato de serem desenvolvidas sem a definição de objetivos estratégicos, princípios e diretrizes que orientem os procedimentos para a utilização do instrumento, ainda que uma série de iniciativas para institucionalização do instrumento tenham sido reportadas (MONTAÑO, MALVESTIO \& OPPERMANN, 2013; OLIVEIRA, MONTAÑO \& SOUZA, 2009). 
Alguns estudos acadêmicos têm se concentrado em avaliar potenciais aplicações da AAE em diferentes contextos e os benefícios decorrentes de sua incorporação ao quadro decisório brasileiro. Dentre os grupos de pesquisa que se dedicam ao tema da AAE, o Núcleo de Estudos de Política Ambiental - NEPA, ligado ao programa de pós-graduação em Ciências da Engenharia Ambiental da EESC/USP, se destaca pelo maior volume de Teses e Dissertações produzidas até o momento.

Neste contexto, os estudos desenvolvidos por Lemos (2007, 2011) desenvolvem aproximações para a aplicação da AAE ao planejamento do setor do turismo, bem como uma estrutura geral para a sua aplicação neste setor; os trabalhos de Neto $(2010 ; 2013)$ sobre a empregabilidade da AAE ao Estatuto da Cidade e ao Plano Diretor, e também sobre a integração do Plano Diretor ao Plano de Bacia Hidrográfica a partir da AAE; o estudo desenvolvido por Montaño (2014), que constrói um panorama comparativo entre a aplicação da AAE no Brasil em relação a diferentes países; e finalmente o trabalho desenvolvido por Malvestio (2013), que analisou a efetividade da prática brasileira de AAE no setor de energia.

Aspectos conceituais e fundamentos da AAE

Dentre as muitas definições encontradas na literatura quanto aos propósitos da Avaliação Ambiental Estratégica, Therivel (2004) destaca que estas se desenvolvem a partir da conceituação dada por Sadler \& Verheem (1996), que se refere à AAE como um:

"processo sistemático de avaliação das consequências ambientais de iniciativas propostas de política, plano ou programa, a fim de assegurar que elas sejam plenamente incluídas e apropriadamente tratadas no estágio inicial e apropriado do processo de tomada de decisão, juntamente com as considerações de ordem econômicas e sociais" (SADLER \& VERHEEM, 1996, p.27).

As diferentes conceituações que se desenvolvem a partir de então estão diretamente ligadas a mudanças no seu propósito de aplicação, tendo em vista os diferentes contextos em que são aplicadas (BROWN \& THERIVEL, 2000; THERIVEL, 2004). Tome-se, por exemplo, a Organização para Cooperação Econômica e Desenvolvimento (OECD, 2006) que classifica a AAE como um conjunto de abordagens analíticas e participativas que visam integrar considerações ambientais nas políticas, planos e programas e avaliar as interligações com as considerações econômicas e sociais.

A Diretiva Europeia sobre o uso da AAE em determinados planos e programas (Diretiva 2001/42/CE), coloca a AAE como um processo de avaliação ambiental em que se estabelece um nível elevado de proteção ambiental e que contribui para a integração das 
considerações ambientais na elaboração de planos e programas, com vistas à promoção do desenvolvimento sustentável.

Por sua vez, o protocolo relativo à aplicação da AAE no contexto transfronteiriço (UNECE, 2003) define a AAE como:

"A avaliação dos prováveis efeitos no ambiente, e na saúde, o que inclui a determinação do âmbito de um relatório ambiental e a sua elaboração, a participação e consulta do público e a tomada em consideração do relatório ambiental e dos resultados da participação e da consulta do público em um plano ou programa”. (UNECE, 2003)

No Brasil o Ministério do Meio Ambiente propõe a seguinte definição para AAE:

"Um procedimento sistemático e contínuo de avaliação da qualidade do meio ambiente e das consequências ambientais decorrentes de visões e intenções alternativas de desenvolvimento, incorporadas em iniciativas tais como: a formulação de políticas, planos e programas, de modo a assegurar a integração efetiva dos aspectos biofísicos, econômicos, sociais e políticos, o mais cedo possível, aos processos públicos de planejamento e tomada de decisão”. (MMA, 2002, p. 15)

Considerada a principal organização profissional no âmbito de aplicação da Avaliação de Impactos, a Associação Internacional de Avaliação de Impacto (IAIA, 2002) define a AAE como um processo que informa planejadores, tomadores de decisão e o público afetado a respeito da sustentabilidade das decisões estratégicas, facilitando a busca pela melhor alternativa e com capacidade de tornar o processo de tomada de decisão mais democrático. Considerando a própria natureza da associação, esta definição encontra amplo respaldo no âmbito acadêmico, como ilustram os trabalhos de Therivel (2004), Jones et al. (2005) e Fischer (2007).

É possível identificar, portanto, uma convergência nas definições a respeito da AAE, relacionada à sua aplicação em torno de um processo estruturado e proativo cuja finalidade é reforçar a influência das questões ambientais na tomada de decisões estratégicas, e ao reconhecimento da importância de seu caráter antecipatório. A partir daí, o papel e objetivos a serem assumidos pela AAE variam de acordo com o sistema de planejamento e o contexto da decisão a ser tomada (VERHEEM \& TONK, 2000; TETLOW \& HANUSCH, 2012).

Com relação à sua potencial contribuição ao processo de planejamento, é razoável admitir que os benefícios esperados da utilização da AAE estejam alinhados com os conceitos 
apresentados anteriormente. De fato, conforme Therivel (2004), a AAE apresenta um grande potencial para:

$\checkmark$ Lidar com impactos que são difíceis de serem considerados ao nível de projetos, como os sinérgicos e cumulativos;

$\checkmark$ Promover a melhor consideração de alternativas, pois afeta o processo de tomada de decisão em um estágio onde mais alternativas estão disponíveis para serem consideradas;

$\checkmark$ Permitir incorporar valores de proteção e sustentabilidade ambiental na tomada de decisão, ao adicionar outras dimensões ao processo de tomada de decisão;

$\checkmark$ Favorecer a hierarquização de tais valores e outros níveis de ação, como programas e projetos;

$\checkmark$ Facilitar a maior frequência de participação pública no processo de tomada de decisão.

Estes fatores, segundo a autora, permitem que o processo de tomada de decisão se torne mais robusto e transparente, de modo a permitir a implementação efetiva da ação estratégica.

Outro efeito decorrente da aplicação da AAE reportado na literatura remete à sua capacidade de atuar como um instrumento promotor da sustentabilidade. Segundo Fischer (2007) esta visão se estabelece a partir da década de 1980 com as discussões desenvolvidas por organismos internacionais como a OECD e por marcos da política ambiental internacional como a Agenda 21.

Estas discussões desenvolviam-se sobre o nível de atuação do instrumento, as políticas, planos e programas, o que permitiria transmitir os valores de sustentabilidade apresentada e, principalmente, pelo fato da AAE integrar em seu processo as considerações ambientais, sociais e econômicas de modo equilibrado, o que por sua vez constitui o tripé básico da sustentabilidade (FISCHER, 2007; WALLINGTON, 2007). O enfoque estratégico voltado para a promoção da sustentabilidade tem sido amplamente defendido, como ilustram ainda os trabalhos de Bina (2011) e Lobos \& Partidário (2014).

Para Shepherd \& Ortolano (1996) a perspectiva da promoção da sustentabilidade pela AAE é algo notório em planos de desenvolvimento urbano, sendo alcançada por meio da realização do potencial intrínseco ao instrumento, tal como a promoção do alinhamento entre os níveis estratégicos de decisão (Tiering), e a integração das questões de sustentabilidade em diferentes níveis de PPPs. 
Segundo White \& Bram (2012), o potencial da AAE em promover a sustentabilidade está relacionado à sua capacidade de adaptação a diferentes contextos e da existência de princípios de sustentabilidade bem estabelecidos. Além disso, os autores argumentam que os novos desafios no campo da AAE estão alinhados com a necessidade de assumi-la como um instrumento indutor da sustentabilidade e, portanto, com um propósito claramente estabelecido, o que permitiria distinguir a AAE de outros instrumentos de avaliação estratégica.

De modo específico a Sustainability Appraisal (SA), em tradução livre - Avaliação de Sustentabilidade, se estabelece no Reino Unido junto à AAE em conformidade com a Diretiva Europeia e a legislação inglesa (Planning and Compulsory Purchase Act) e ocorre durante a preparação ou revisão de Planos Locais e estratégias regionais de desenvolvimento (LONDON, 2005).

Trata-se de um instrumento de avaliação de impacto com enfoque específico na promoção do desenvolvimento sustentável por meio da integração de os objetivos ambientais, sociais e econômicas durante a avaliação de um plano em elaboração (PLANNING PRATICE GUINDACE, 2014) ${ }^{1}$.

Em teoria as abordagens se diferem, pois no âmbito da Diretiva Europeia a AAE visa assegurar que um plano de desenvolvimento considere adequadamente as questões ambientais, enquanto que a Sustainability Appraisal tem como objetivo integrar questões ambientais, econômicas e sociais (THERIVEL \& MINAS, 2002). Mas segundo os autores, na prática a Avaliação de Sustentabilidade é muitas vezes uma AAE com algumas questões sociais e econômicas adicionada, contudo é preciso reconhecer as diferenças metodológicas e o propósito claro da $S A$ frente à $\mathrm{AAE}$.

\subsection{A Avaliação Ambiental Estratégica aplicada ao planejamento urbano.}

A AAE apresenta um leque amplo de aplicação, mas segundo Jones (2005) a forma mais praticada de AAE é, provavelmente, aquela voltada ao planejamento territorial e do uso do solo ${ }^{2}$, e em específico para o planejamento do desenvolvimento urbano ${ }^{3}$.

\footnotetext{
${ }^{1}$ O Pplanning Practice Guidance é um portal web do Ministério das comunidades e governo local (Department for Communities and Local Government) do Reino Unido e tem como proposito disponibilizar o acesso a informações e bem como a consulta de processos de planejamento governamental. Mais informações em $<\mathrm{http}: / /$ planningguidance.planningportal.gov.uk/about/>.

${ }^{2}$ De acordo com FAO (1993), esta modalidade de planejamento visa orientar o desenvolvimento de todas as formas de uso do solo, como a agricultura, pecuária, áreas de conservação, industrial e urbano, bem como os conflitos decorrentes destes usos. No presente trabalho, tendo em vista o foco em planos de desenvolvimento urbano, as diferenças metodológicas e de objetivos entre as modalidades de planejamento são desconsideradas, empregandose como sinônimos os termos planejamento espacial, de uso do solo, e territorial.

${ }^{3} \mathrm{Na}$ Irlanda, por exemplo, o emprego da AAE para o planejamento do uso do solo corresponde a cerca de $80 \%$ das aplicações do instrumento (EPA, 2012)
} 
Segundo a Agência Portuguesa do Ambiente (APA, 2008) a experiência acumulada a partir da institucionalização do uso da AAE no planejamento territorial permitiu verificar diversas contribuições do instrumento. Neste sentido, destaca-se que a AAE tem se mostrado:

$\checkmark$ Fomentadora da interatividade entre entidades com responsabilidades ambientais especificas com aquelas que intervêm na elaboração e acompanhamento de um plano;

$\checkmark$ Otimizadora do processo de planejamento, com capacidade de integrar as considerações de ordem ambiental, social, cultural e econômica nas alternativas dos planos e no desenvolvimento das respectivas soluções técnicas;

$\checkmark$ Avaliadora dos efeitos decorrentes da execução do plano, com capacidade de inserir com maior agilidade outros procedimentos que necessitam ser verificados antes da aprovação de um plano;

$\checkmark$ Criadora de plataformas de articulação e compartilhamento de diferentes tipos de conhecimento especializado e setorial, que permitem inserir decisões mais fundamentadas e colaborativas.

É consenso na literatura que um instrumento da natureza da AAE se mostra suscetível ao contexto em que é aplicado. Neste sentido, o trabalho de Gazzola (2008) pode ser apontado como relevante, ao refletir sobre os aspectos que influenciam na efetividade da AAE tomando como base duas culturas bastante distintas em termos de planejamento. $\mathrm{O}$ trabalho conclui que a efetividade do instrumento é fortemente influenciada por elementos contextuais, tendo encontrado diferenças significativas em termos da sua efetividade quando integrada a um sistema "flexível" de planejamento, em comparação com sistemas mais "rígidos" como o praticado no Reino Unido.

Neste sentido, ainda que o cenário europeu seja predominante dentre os artigos que reportam o uso da AAE no processo de planejamento do uso do solo, verifica-se também um significativo volume de comunicações de aplicações da AAE em sistemas de planejamento operados por países emergentes e em desenvolvimento, podendo-se mencionar os trabalhos de Elling (2000); Tao, Tan \& He (2007); Leng, Ng \& Obbard (2005) e Wirutskulshai, Sajor e Coowanintwong (2011). Os trabalhos mencionados relatam diferentes experiências de introdução da $\mathrm{AAE}$ em seus respectivos sistemas de planejamento, com enfoque na flexibilização e adaptação do instrumento, bem como a importância dos elementos contextuais ao longo do processo.

A qualidade dos relatórios que instruem o processo de AAE também se mostra determinante para a efetividade do instrumento quando aplicado ao planejamento do uso do solo, como bem aponta o trabalho de Fischer (2009) ao aplicar critérios para revisão da 
qualidade de relatórios de AAE elaboradas para as core strategies ${ }^{4}$ que orientavam o processo de planejamento espacial na Inglaterra. Os resultados apresentados pelo autor permitem traçar um panorama qualitativo a respeito dos problemas e pontos positivos da utilização da AAE no planejamento espacial.

\subsection{As abordagens metodológicas da AAE}

A literatura tem apontado para um debate acerca do papel da AAE para a tomada de decisão estratégica, que se rebate em diferentes visões a respeito do modo de se conduzir o processo de AAE.

Assim, a partir dos trabalhos de Therivel (2004), Partidário (2007) e Fischer (2007), verifica-se a predominância de duas concepções a respeito de como o processo de AAE pode ser desenvolvido:

- Uma delas compreende a AAE como um instrumento a ser aplicado estrategicamente em relação à tomada de decisões, de modo que AAE tenha capacidade de oferecer suporte para o desenvolvimento da ação estratégica. Trata-se de um modelo de AAE centrada na tomada de decisão (Figura 2 - a), que propõe a compreensão do contexto de aplicação, a capacidade de identificar fatores críticos para a decisão estratégica e a configuração de um quadro de referências para a sua implementação. Assim, a AAE se aplicaria de forma flexível através de um quadro de funções e atividades que se moldam às tendências e oportunidades, com liberdade para a escolha de alternativas mais adequadas para o processo e para a definição de ações próprias de monitoramento e gerenciamento. Estando alinhada, portanto, a um processo não sistematizado e não padronizado, que idealmente seria totalmente adaptado a cada situação de aplicação.

- A segunda concebe a AAE como um processo avaliativo estruturado e rigoroso baseado na AIA de projetos, que a literatura descreve como "EIA-based SEA", em que o processo conta com etapas pré-definidas (screening, avaliação de escopo, recomendações para mitigações e monitoramento/acompanhamento), aplicada para planos e programas sob responsabilidade de autoridades públicas de planejamento. Neste caso, a AAE reafirma suas raízes na AIA de projetos

\footnotetext{
${ }^{4}$ Até a recente reforma do sistema de planejamento inglês, as core strategies eram responsáveis por vincular as estratégias de desenvolvimento espacial ao nível regional, fornecendo subsídios para o planejamento local.
} 
com papel paralelo à tomada de decisão estratégica (Figura 2 - b), cujo objetivo é assegurar que as questões ambientais sejam considerados no planejamento.

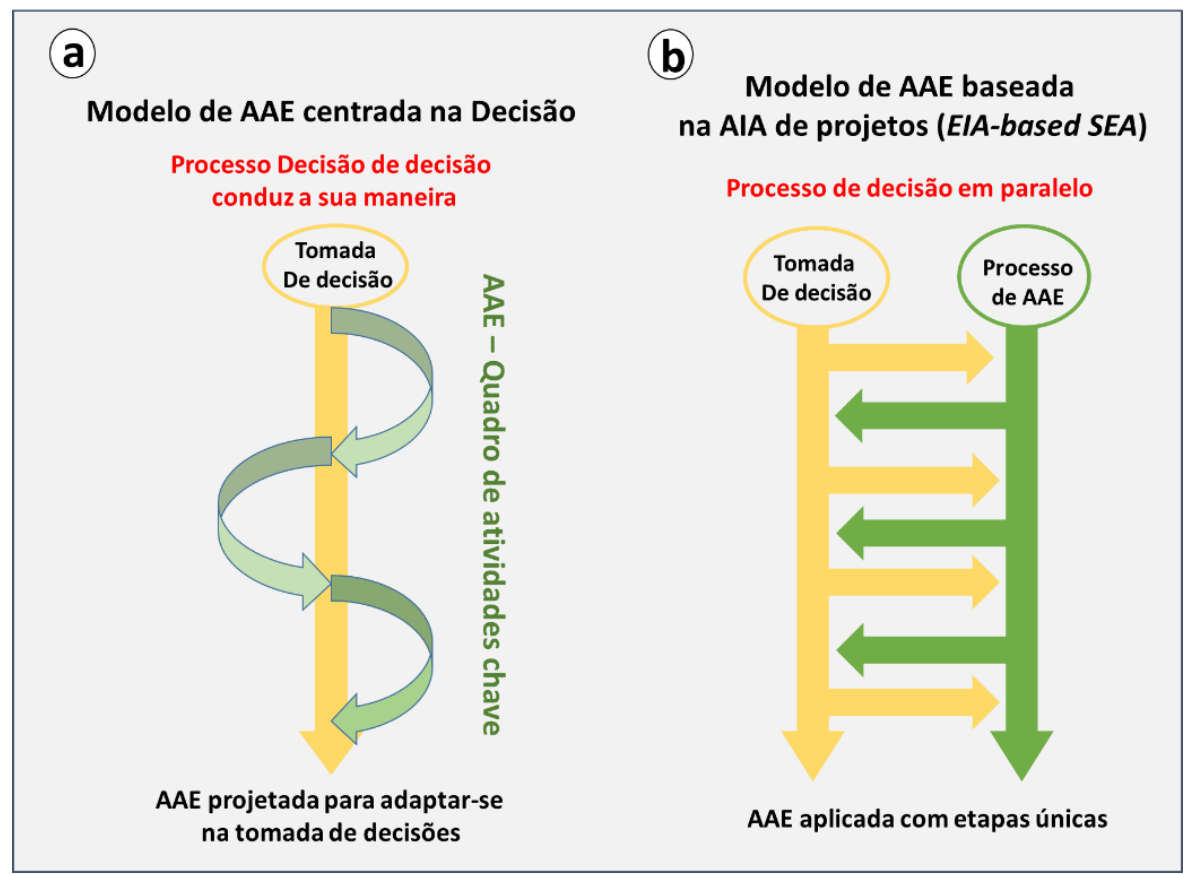

Figura 2 - O modelo de AAE centrada na decisão (a) versus modelo de AAE centrado na AIA de projetos (b). Fonte: Adaptado de Partidário, 2007.

Fischer (2007) argumenta que, na prática, não há fronteiras que delimitem estas duas concepções admitindo, inclusive, construções híbridas. No entanto, o autor é enfático ao afirmar que o modelo de AAE centrada na tomada de decisão apresenta deficiências importantes por não se estabelecer como um processo sistematizado, o que tornaria esta abordagem associada a um menor rigor metodológico e sujeita a um enfraquecimento em pontos centrais, como por exemplo, a especificação das questões sobre as quais a AAE deverá se debruçar, a configuração de objetivos e metas, a coleta de informações, entre outros.

Em contraposição, Partidário (2007) afirma que ao se desenvolver a AAE com uma roupagem baseada na AIA de projetos se está na verdade dando um novo nome a uma velha prática, mas aplicada a um nível diferente de planejamento. A autora afirma que esta nova abordagem deve avaliar os impactos ambientais em um contexto de sustentabilidade, integrar fatores que permitam verificar como os impactos ambientais podem afetar a sustentabilidade de decisões estratégicas e, para tal, a AAE deve ser estruturada para operar no processo de planejamento colaborando para o desenvolvimento de uma visão clara do que se deseja futuramente.

Ainda segundo a autora, um aspecto importante que diferencia as duas concepções é justamente o motivador para o desenvolvimento da AAE (Figura 3). Enquanto o modelo 
baseado na AIA de projetos (ilustrado em "a") coloca a ação estratégica sujeita à AAE no centro da avaliação, que por sua vez estará voltada para a verificação das consequências para o meio ambiente associadas às ações estratégicas, o modelo de AAE centrada na decisão (ilustrado em "b") coloca os problemas a serem resolvidos no centro da avaliação, buscando-se encontrar opções adequadas para resolver o problema e cumprir com os objetivos pretendidos de sustentabilidade.

Em outras palavras, o foco da AAE passa a ser as propostas e consequências da ação estratégica, de forma semelhante à AIA de projetos (Figura 3 - a), ou então o foco da AAE são os problemas ou objetivos para os quais a estratégia se destina, procurando-se verificar se esta (a estratégia) é a mais adequada ou mesmo verificar se existem outras ações que a complementem (Figura 3 - b).

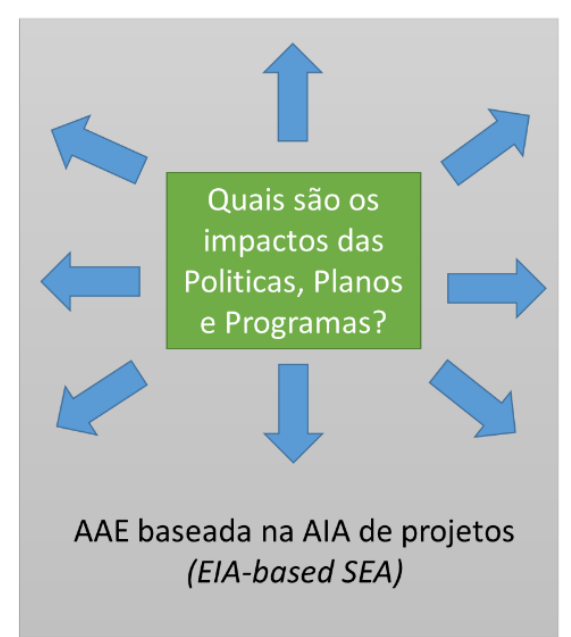

a

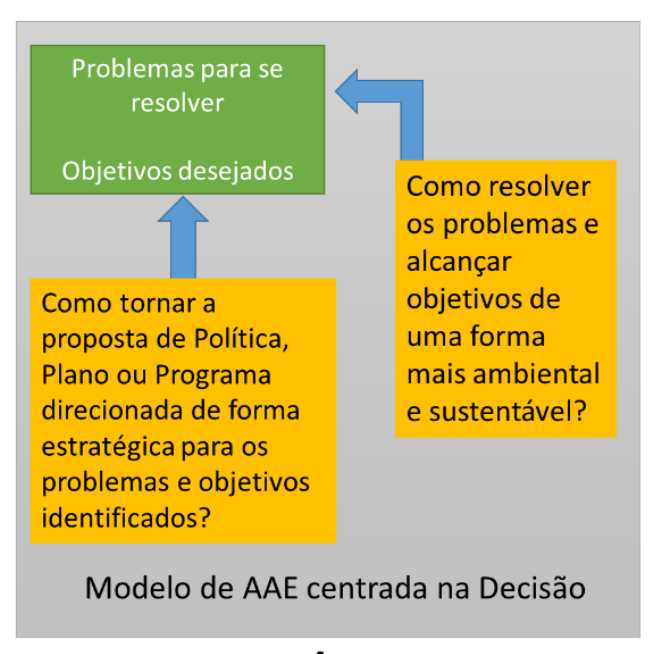

b

Figura 3 - Abordagens metodológicas da AAE: (a) avaliando a solução: avaliação do impacto dos resultados de PPP; (b) avaliar a estratégia: avaliação do impacto da estratégia de PPP. Fonte: Adaptado de Partidário, 2007.

As principais diferenças entre estas duas concepções podem ser sintetizadas a partir das características de cada uma, como indica o quadro a seguir.

Quadro 1 - Características dos modelos de AAE, segundo Partidário (2012).

Modelo de AAE centrada na AIA de projetos (EIA-based $\boldsymbol{S E A}$ )
Modelo de AAE centrada na decisão. 


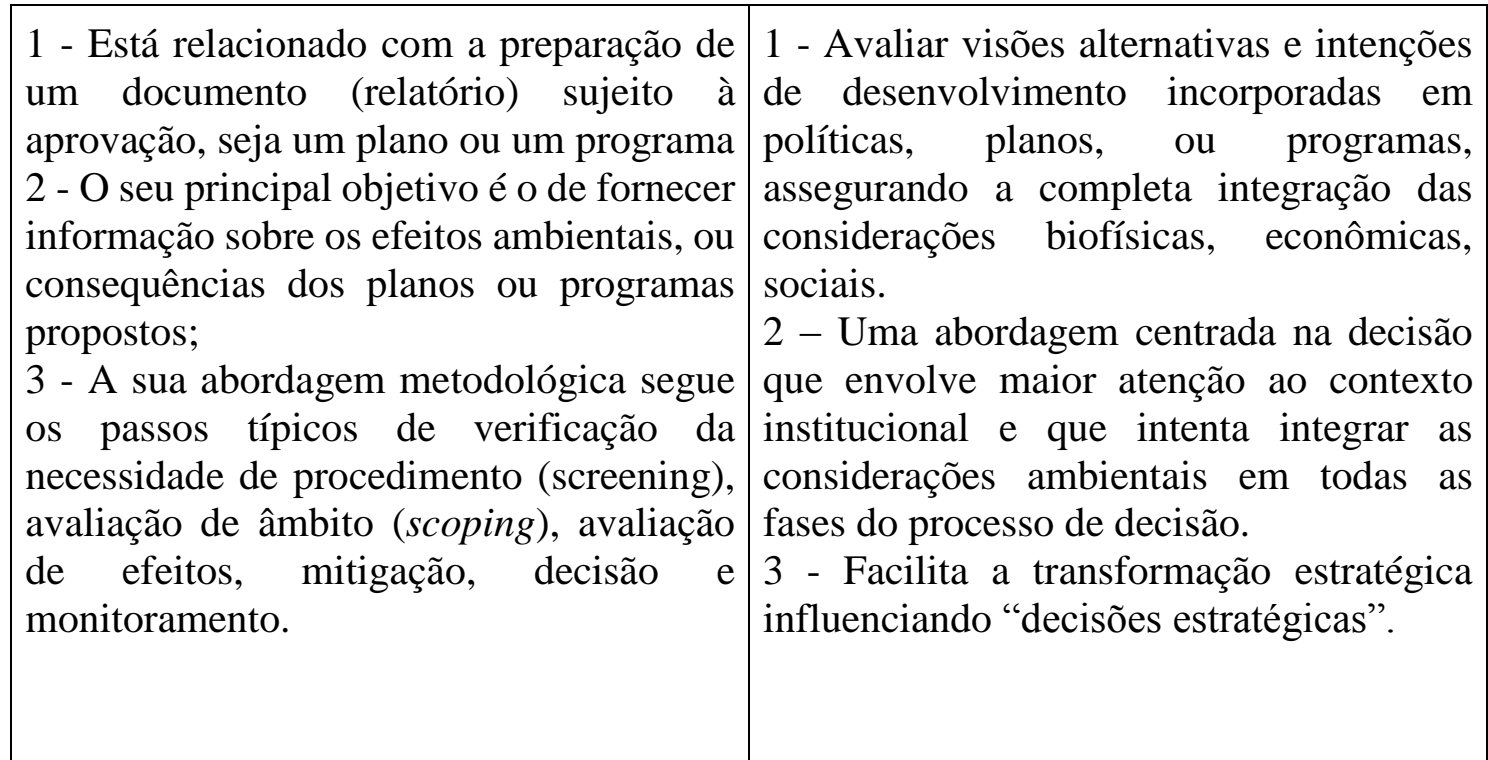

Fonte: extraído de Partidário, 2012.

É valido ressaltar, que segundo Lobos \& Partidário (2014) existem contradições entre as correntes teóricas e a prática da AAE, pois apesar da forte evolução conceitual do papel da AAE como uma abordagem proativa e integradora a pratica tem demonstrado que, mesmo vestindo esta roupagem, ainda predominam as aplicações da AAE baseada na AIA de projetos.

\section{4. $O$ direcionamento dos objetivos da $\mathrm{AAE}$}

Além destas concepções procedimentais a literatura tem explorado como a Avaliação de Impacto Ambiental (AIA) pode contribuir para alcançar o desenvolvimento sustentável e isto recai sobre o debate voltado para a avaliação de sustentabilidade, "Sustainability Assessment", a AIA de projetos e principalmente a AAE (POPE, 2004).

Cabe destacar que, a capacidade de promover a sustentabilidade por meio da avaliação de impacto, se deve às características deste instrumento, isto é, o seu caráter antecipatório, integrativo, flexível, que permitem inserir aspectos de sustentabilidade na tomada de decisão (POPE, 2004; THERIVEL, 2004).

Assim, no caso da AAE, segundo Hacking \& Guthrie (2006) e Therivel (2004) destacam-se duas abordagens metodológicas que envolvem a forma com que as avaliações ambientais, em especial a AAE, podem balizar a importância dos impactos ambientais, trata-se da:

\section{- "Baseline-led";}

- "Objective-led".

A abordagem "Baseline-led" preconiza o emprego de técnicas originalmente formuladas na AIA de projetos. Em termos práticos, tal modelo baseia-se na seleção de um 
conjunto de parâmetros ambientais, objetivos e indicadores, que serão utilizados para descrever a situação do ambiente e identificar conflitos, esperando-se que os resultados obtidos influenciem os objetivos da ação estratégica (THERIVEL, 2004; JACKSON \& ILLSLEY, 2007). Esta abordagem se caracteriza por ser reativa, pois busca resolver uma problemática atual ao avaliar os impactos ambientais de uma PPP frente a uma linha de base ambiental, que por sua vez, tem o papel de avaliar impactos e identificar possíveis modificações para melhorar os resultados ambientais (POPE, 2004; THERIVEL, 2004). Uma limitação apontada, segundo Pope (2004), é que esta visão torna o escopo da AAE limitado para se considerar alternativas, mesmo tratando-se de um nível estratégico de decisão.

A abordagem "Objective-led" se desenvolve tendo como referência um quadro futuro de promoção da sustentabilidade, ou seja, um modelo de objetivos e metas a serem atingidas pelo objeto da AAE e que serão utilizados para avaliação e comparação de alternativas (THERIVEL, 2004). Segundo Pope (2004) trata-se de uma abordagem proativa, pois pode ser articulada ao processo de tomada de decisão ao invés de apenas avalia-lo e reflete um desejo de se alcançar resultados definidos por objetivos ambientais, sociais e econômicos e não mediar impactos baseados em uma linha de base.

A Figura 4, adaptada de Hacking \& Guthrie (2006), permite compreender as diferenças entre as abordagens, no exemplo, uma determinada ação estratégica ou projeto se desenvolve, no qual:

- A seta "A" tem como referência os padrões aplicados a um determinado indicador em relação à situação esperada com a ação desenvolvida. Por exemplo um efluente pode ser comparado aos padrões de qualidade de água, como uma forma de avaliar o provável impacto sobre o corpo receptor.

- A seta "B" reflete as condições em que um indicador pode se desenvolver com e sem a iniciativa; é a visão estabelecida pela abordagem "Baseline-led". Por exemplo, a comparação entre os níveis de desemprego com e sem a ação.

- A seta "C" descreve a visão "Objective-led", que faz referência aos níveis desejados para um indicador, sinalizando o quanto um determinado indicador deverá idealmente variar com o desenvolvimento da ação. 


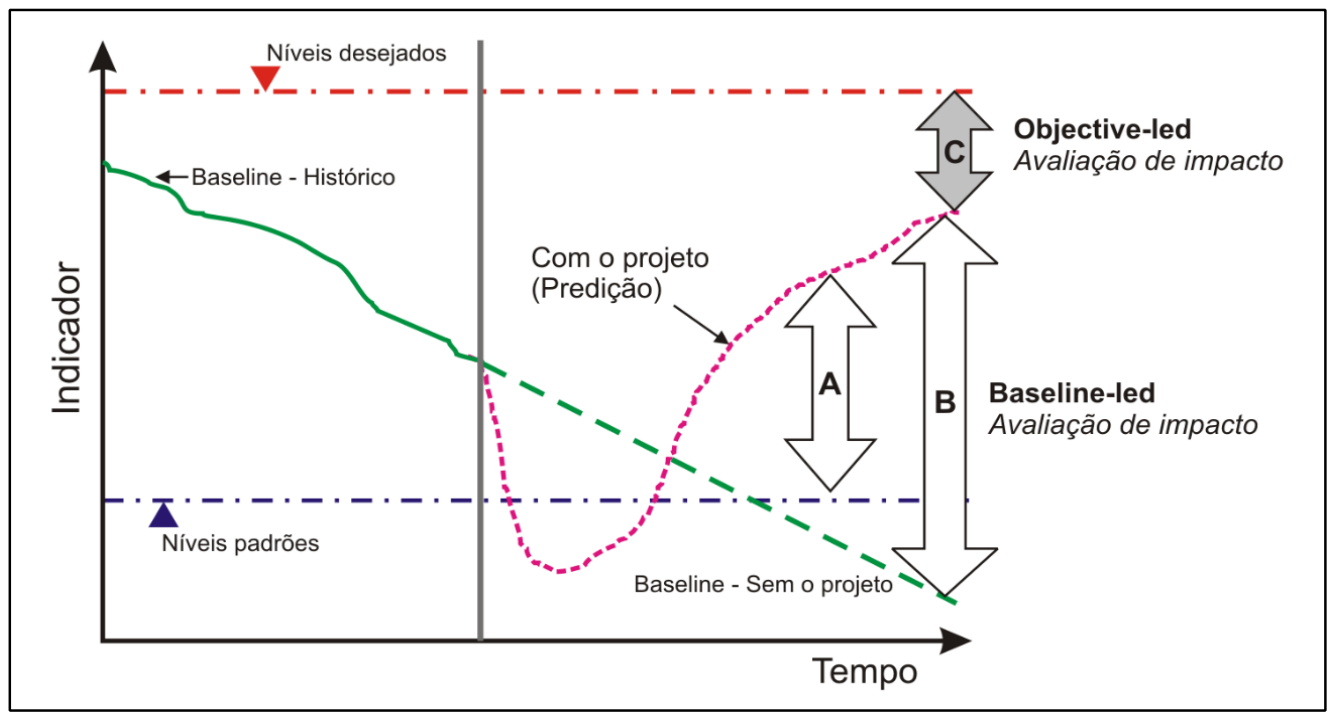

Figura 4 - Comparação entre diferentes tipos de critérios de avaliação Fonte: Adaptado de Hacking \& Guthrie, 2006.

É evidente que cada uma das abordagens apresenta vantagens e desvantagens, como indica a Tabela 1. No entanto, entende-se que as mesmas não são conflitantes e sim complementares, podendo ser combinadas de modo a se extrair o máximo benefício dos pontos fortes de cada uma (THERIVEL, 2004; FISCHER, 2007).

Tabela 1: Vantagens e desvantagens das abordagens Baseline-led e Objective-led

\begin{tabular}{|c|c|c|}
\hline & Vantagens & Desvantagens \\
\hline 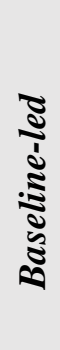 & $\begin{array}{l}\text { Pode ser rigorosa, ao atuar como } \\
\text { ponto de direção para a proteção } \\
\text { ambiental ou mesmo a } \\
\text { sustentabilidade; } \\
\text { - Tem o foco em identificar os } \\
\text { problemas ambientais; } \\
\text { Torna mais fácil a identificação de } \\
\text { impactos cumulativos. }\end{array}$ & $\begin{array}{l}\text { - Atua como um "teste" em vez de um } \\
\text { método de integração da } \\
\text { sustentabilidade na tomada de decisões; } \\
\text { - } \quad \text { Pode tornar a AAE muito diversificada. }\end{array}$ \\
\hline$\frac{0}{0}$ & $\begin{array}{l}\text { Objetiva integrar totalmente as } \\
\text { considerações de sustentabilidade na } \\
\text { tomada de decisões; } \\
\text { Tem a capacidade de reduzir os } \\
\text { dados desnecessários da baseline, } \\
\text { pois direciona quais dados são } \\
\text { realmente necessários de serem } \\
\text { levantados. }\end{array}$ & $\begin{array}{l}\text { Pode se tornar um mero teste de } \\
\text { compatibilidade interna, em vez de } \\
\text { assegurar que a ação estratégica se } \\
\text { torne sustentável; } \\
\text { - Indicadores econômicos podem } \\
\text { dominar, promover objetivos não } \\
\text { relacionados a questão ou trazer para } \\
\text { avaliação um conjunto maior de } \\
\text { obstáculos ambientais. }\end{array}$ \\
\hline
\end{tabular}

Fonte: THERIVEL, 2004. 


\subsection{As Etapas Básicas da Avaliação Ambiental Estratégica e o papel do escopo.}

As discussões apresentadas permitiram visualizar a AAE como um instrumento sujeito a diversas concepções teóricas e metodológicas, que garantem a flexibilidade e ajustes às particularidades dos diversos contextos de planejamento em que pode ser empregada.

No entanto, independente da abordagem aplicada, a AAE é um processo de avaliação estruturado, organizado e que possui etapas básicas consideradas essenciais para boa prática do instrumento (THERIVEL, 2004; JONES, 2005; FISCHER, 2007).

Em qualquer estrutura processual da AAE existe o desenvolvimento da etapa de Scoping - o escopo da avaliação, que de maneira genérica, trata da identificação das questõeschave que deverá abranger, de modo a cumprir com os objetivos da avaliação (THERIVEL, 2004).

As etapas processuais da AAE podem ser expressas, conforme Therivel (2004), a partir estruturação disposta na Figura 5, que demonstra a necessidade da avaliação em alimentar e integrar os estágios do processo de tomada de decisão como um todo, em que cada etapa da AAE se relaciona com a construção da decisão estratégica conforme indicado. Segundo argumenta a autora, este aspecto permite que o processo de tomada de decisão se torne mais transparente, robusto e assegura maior probabilidade de que a decisão será efetivamente implementada levando em consideração seus impactos. 


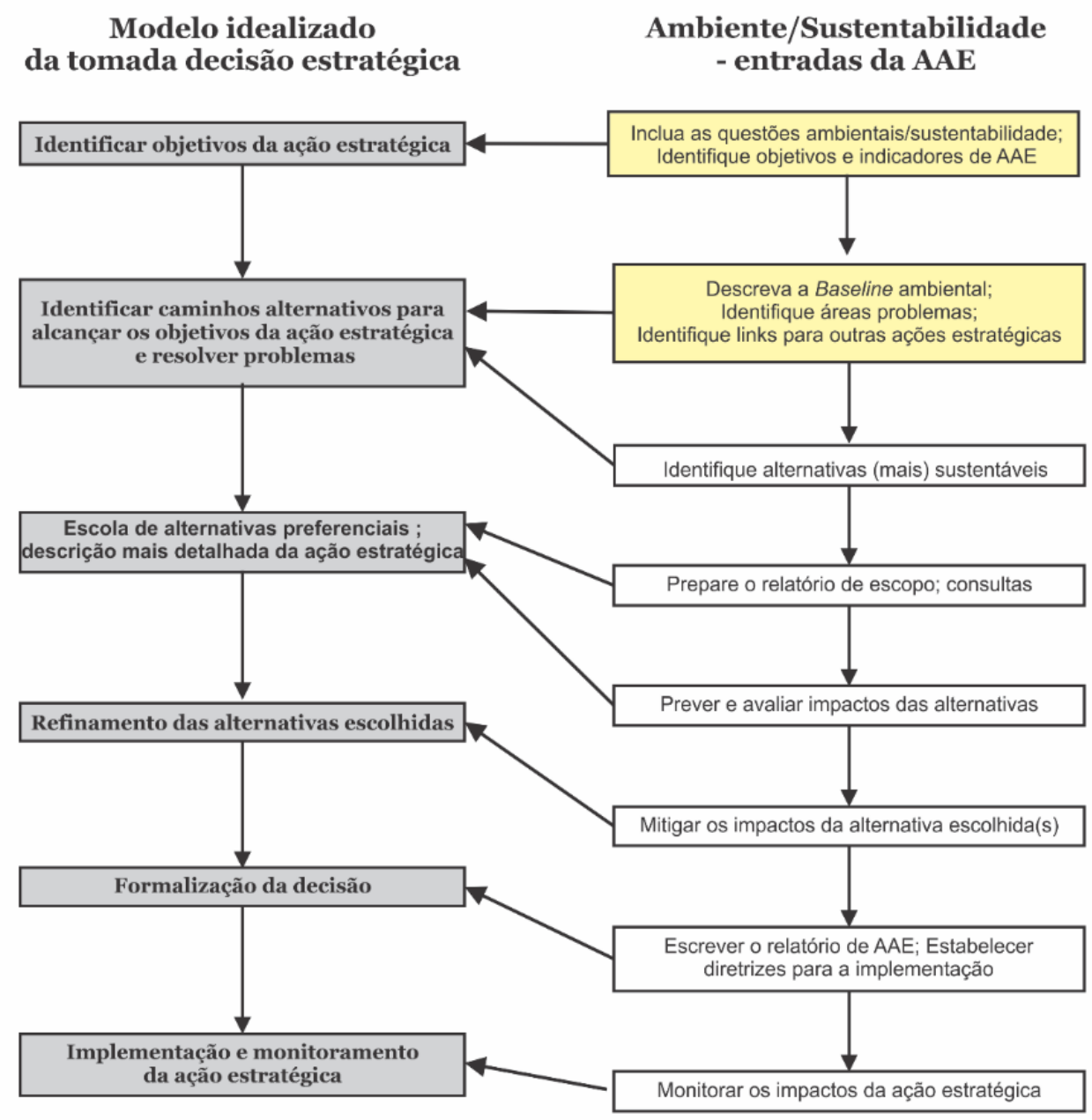

Figura 5 - As etapas básicas da AAE e a tomada de decisão estratégica, segundo Therivel (2004).

No que se refere ao Scoping, a autora reconhece tratar-se de uma tarefa complexa devido à quantidade de informações que precisam ser reunidas, mas que é central para o desenvolvimento da avaliação.

Neste sentido, o momento é voltado para a descrição dos dados ambientais de base, a identificação de problemas e tendências futuras que servirão de base para os demais estágios da avaliação, além de se observar as relações da ação estratégica com outras Políticas, Planos e Programas, as quais permitem identificar obstáculos e também possíveis caminhos para enfrenta-los. Assim, são levantadas perspectivas ambientais, sociais e econômicas com vistas à proteção ambiental e à promoção da sustentabilidade e expressas por meio do estabelecimento de objetivos, indicadores e metas.

Ainda de acordo com Therivel (2004), na definição de objetivos, indicadores e metas deve-se atentar para que estes: 
- Traduzam o que realmente significam, isto é, a situação real e não tenham abertura para manipulações;

- Estejam em escala adequada para serem desenvolvidos, ou seja, possíveis de serem alcançados no nível de atuação da ação estratégica;

- Apresentem dados e informações coerentes ao nível de desenvolvimento da AAE;

- Apresentem total relação com a AAE e necessidade de serem desenvolvidos, no sentido de se evitar a sobreposição com outros objetivos, dados e informações;

- Apresentem compatibilidade entre um e outro, ou seja, os objetivos devem estar correlacionado aos seus indicadores.

Esta concepção de Scoping pode ser representada pela Figura 6. Deve-se destacar que não há propriamente uma "ordem" ou "sequência" para que as ações ocorram, mas sim que estas são necessárias para a efetividade do próprio processo AAE tendo em vista a perspectiva de introduzir a dimensão da sustentabilidade entre os objetivos iniciais da ação estratégica.

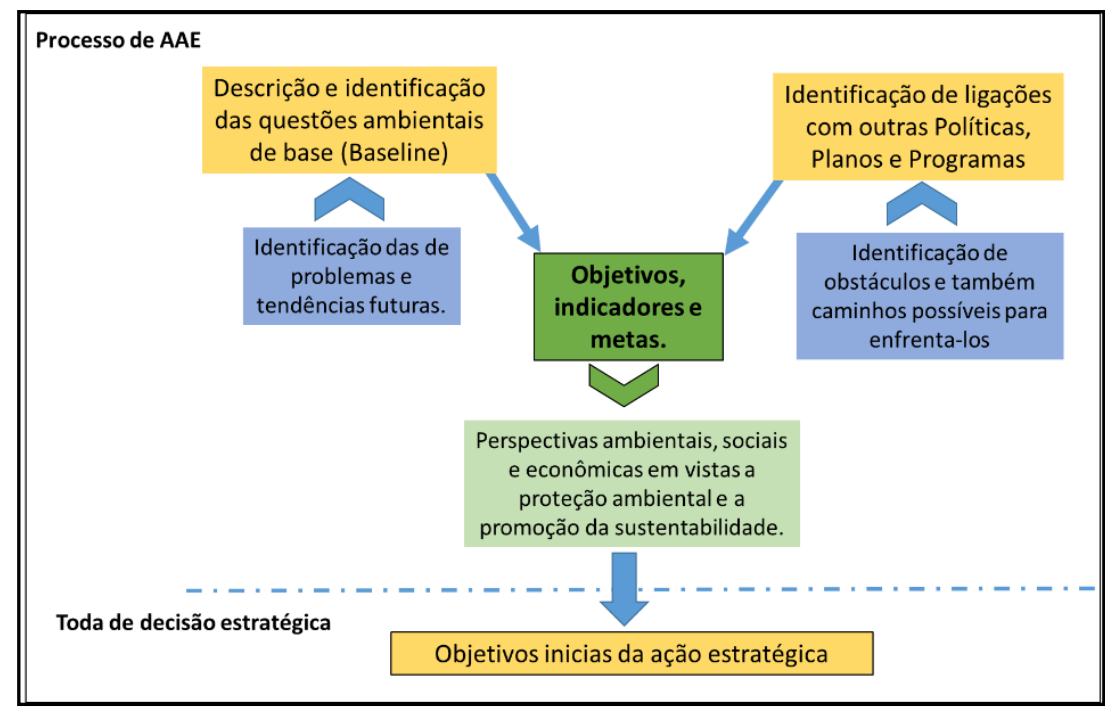

Figura 6 - Ações que devem ocorrer no momento do Scoping e sua relação com a tomada de decisão estratégica, segundo Therivel (2004).

Para Fischer (2007) as etapas processuais da AAE requerida pela Diretiva Europeia (2001/42 CE) têm base na AIA de projetos e apresentam capacidade de se conectar à tomada de decisão de forma contínua e integrada. As principais etapas da AAE podem ser observadas na Figura 7 a seguir. 


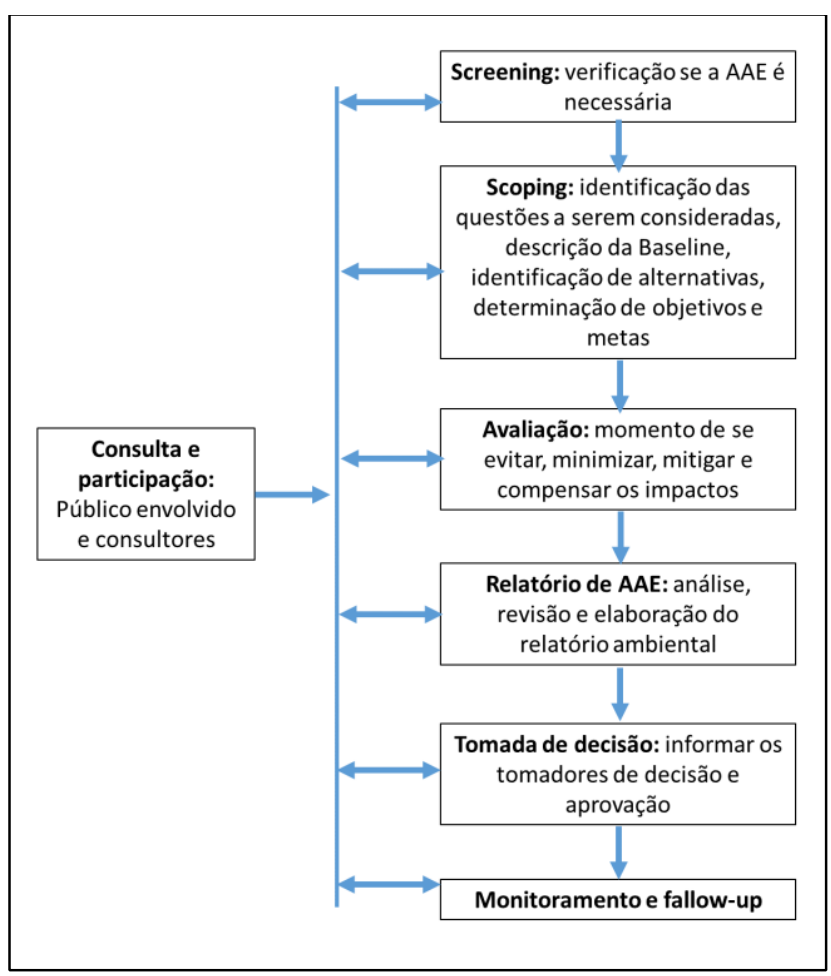

Figura 7 - Etapas básicas do processo de AAE baseada na AIA de projetos. Fonte: adaptado de Fischer (2007).

De acordo com Fischer (2007), o Scoping é o estágio onde se determina a extensão temática, temporal, geográfica e o nível de detalhe da avaliação, portanto, são estabelecidas quais informações serão avaliadas e reportadas.

Neste momento, as informações de Baseline são reunidas, as potencialidades e lacunas são identificadas, os problemas e objetivos de proteção ambiental devem ser descritos, procurando-se desenhar uma pintura realística da situação corrente. $\mathrm{O}$ autor afirma que, neste estágio, não são considerados apenas os aspectos ambientais, mas também os sociais e econômicos.

Neste momento, a avaliação pode incorporar objetivos e indicadores prescritos em requerimentos legais ou estratégias de desenvolvimento, os objetivos de outras PPPs relacionadas e checar os objetivos e metas de sustentabilidade (FISCHER, 2007).

O autor ressalta que ainda na etapa de Scoping devem-se discutir as alternativas de desenvolvimento a serem avaliadas pela AAE para objetivos ambientais, sociais e econômicos, bem como os métodos e técnicas a serem utilizadas na avaliação, além da identificação dos Stakeholders com ênfase para o público envolvido, cujo envolvimento é fundamental para o sucesso desta etapa. A etapa de Scoping, conforme Fischer (2007), é ilustrada pela Figura 8 a seguir 


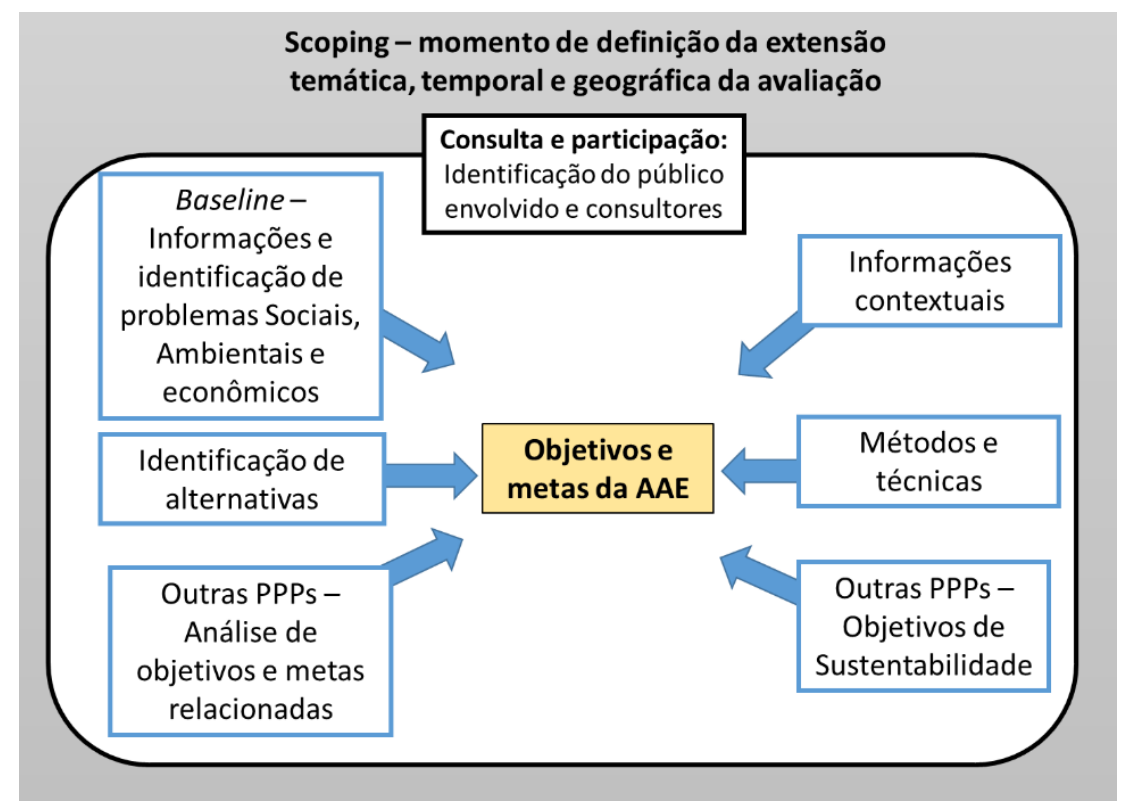

Figura 8 - A etapa de Scoping, segundo Fischer (2007).

O Comitê de Auxílio para o Desenvolvimento, da Organização para Cooperação e Desenvolvimento Econômico - OCDE, desenvolveu orientações de boas práticas para uma aplicação mais eficiente da AAE na formulação e avaliação das políticas, planos e programas de desenvolvimento, a partir de um modelo consensual de AAE que advoga a flexibilidade no desenvolvimento de aplicações do instrumento em diversas necessidades.

Segundo a OCDE (OCDE, 2006), a boa prática procedimental do instrumento deve envolver quatro etapas, Figura 9, subdivididas em tarefas não sequenciais. 


\section{Etapas básicas da AAE}

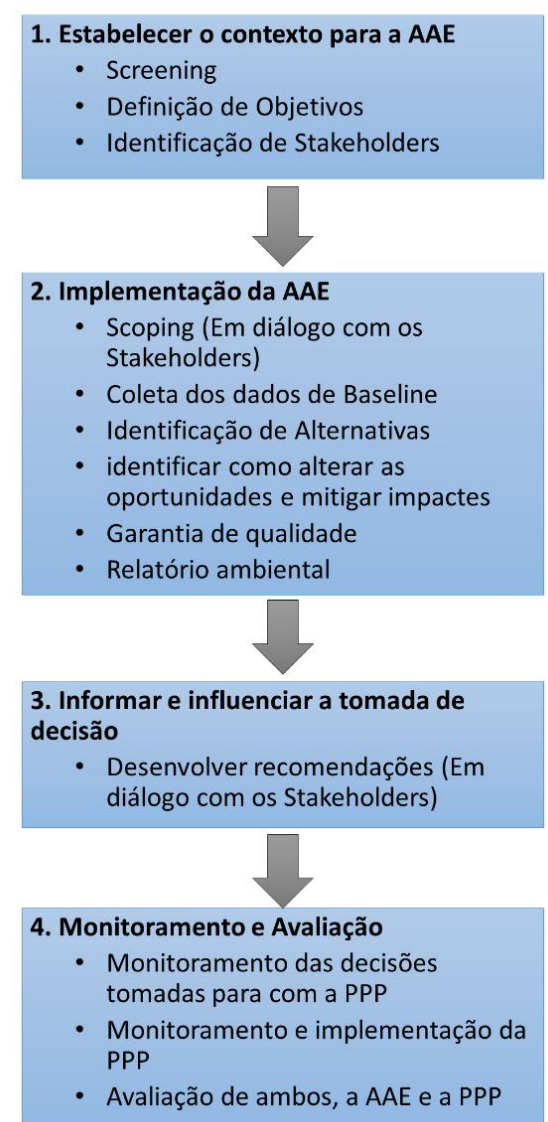

Figura 9 - As etapas básicas para o desenvolvimento da AAE, segundo a OCDE.

Com relação à etapa de Scoping, as orientações de boas práticas da OCDE indicam tratar-se de um processo de definição de competências para o conteúdo da AAE, que devem ser dispostas em um relatório de escopo (Scoping Report). Ao longo desta etapa, deve-se envolver ativamente as principais partes interessadas, os Stakeholders e o público diretamente envolvido, para a identificação de problemas significativos associados à proposta e suas principais alternativas. A partir daí, os objetivos, os critérios de decisão e os indicadores deverão ser identificados, bem como quais os métodos adequados para a análise de questões-chave e as fontes de dados relevantes (OCDE, 2006). Ainda conforme as orientações da OCDE, esta etapa também pode envolver a análise de relações entre diferentes planos ou programas específicos, e a identificação das implicações ambientais de outras políticas ou estratégias.

Logo, a definição do momento de Scoping depende diretamente da participação e consulta das partes interessadas e devem resultar em uma definição do foco da AAE, em termos de seus objetivos e indicadores. Cabe destacar que, segundo a OCDE (2006), a AAE deve ser baseada em um entendimento completo do ambiente e dos sistemas sociais potencialmente afetados. Contudo, o momento de desenvolvimento da Baseline se dá após a formulação do 
relatório de escopo, ou seja, a Baseline é direcionada para a descrição dos indicadores definidos na etapa anterior. A Figura 10, a seguir, ilustra o descrito.

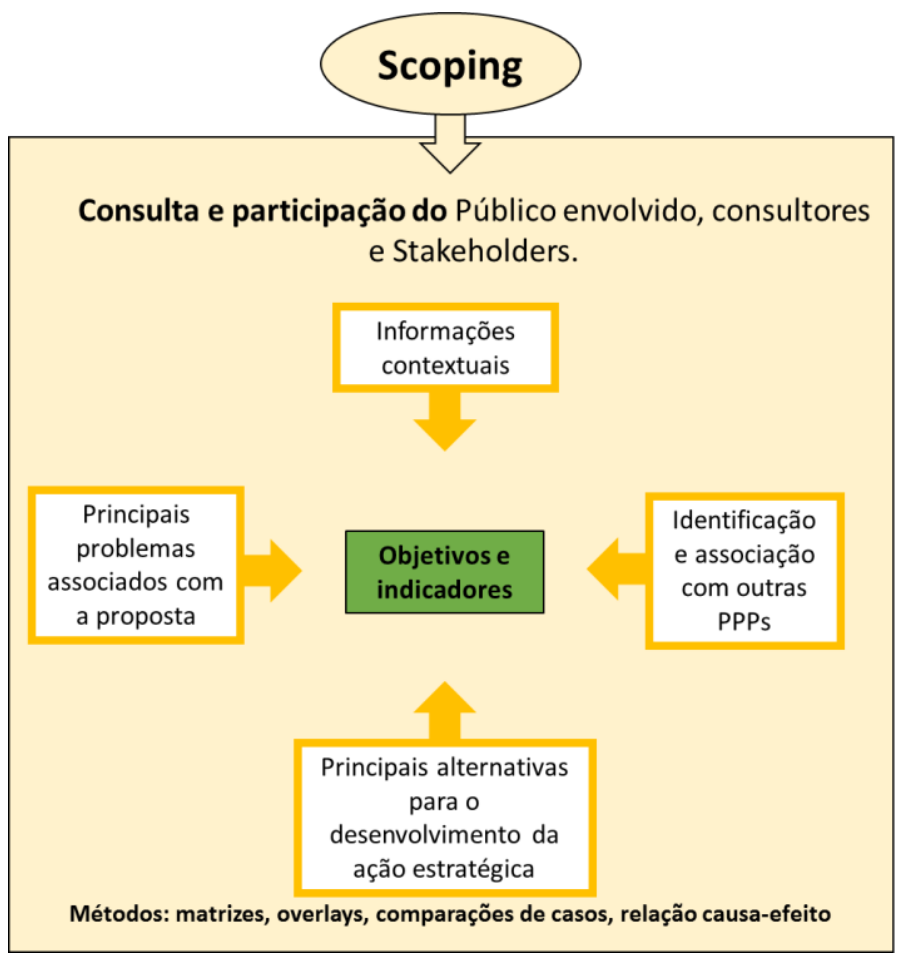

Figura 10 - Ações que devem ocorrer no momento de Scoping segundo a OCDE

A abordagem de Avaliação Ambiental Estratégica defendida por Partidário (2012) é baseada no pensamento estratégico e voltada para o desenvolvimento integrado do processo de AAE junto à tomada de decisão. Desta forma, a AAE não está estruturada em torno de um esquema sequencial de etapas para o desenvolvimento da avaliação, mas sim por um conjunto de elementos considerados fundamentais para o processo de AAE, que se combinam de forma diversa conforme as necessidades do contexto em que será aplicada. Para a autora, tais elementos seriam interdependentes e não necessariamente sequenciáveis, de tal modo que prevalece um processo amplamente flexível e adaptável a diferentes sistemas de tomada de decisão.

Os elementos processuais para o desenvolvimento da AAE, de acordo com Partidário (2012), estão sintetizados na Figura 11. 


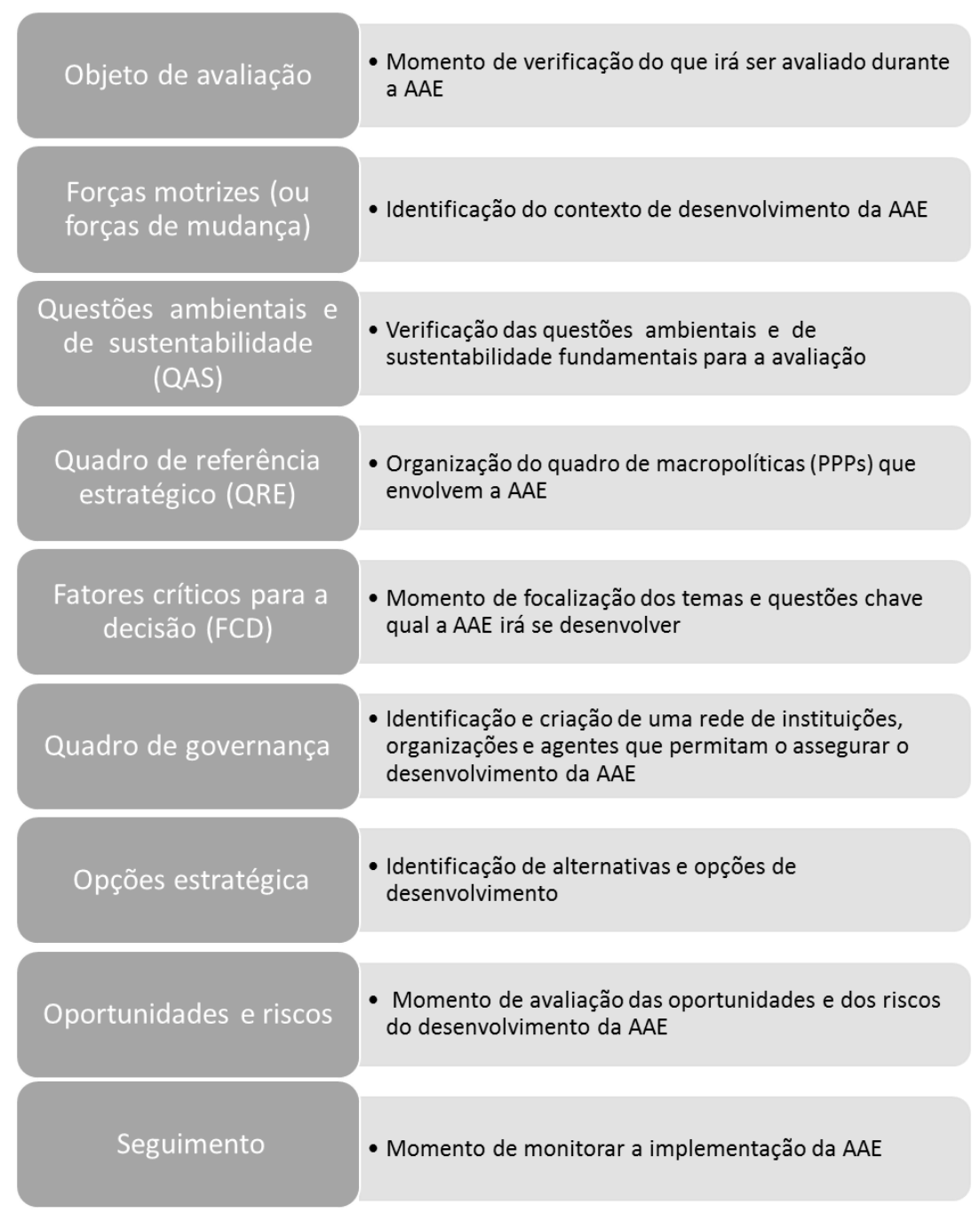

Figura 11 - Elementos estruturantes que integram o modelo de pensamento estratégico em AAE. Fonte: adaptado de Partidário (2012).

Ao analisar estes elementos, percebe-se que a etapa de Scoping segundo a abordagem de Partidário (2012) está associada à definição dos Fatores Críticos para Decisão (FCD), quando se estabelecem os temas chave do processo, ou seja, o foco da AAE. Os fatores críticos são determinados por meio do estabelecimento de prioridades, identificadas fundamentalmente a partir do desenvolvimento do diálogo entre os envolvidos sobre a finalidade da ação e os principais problemas e potencialidades para determinar o sucesso da ação, além disso, são reunidas as questões ambientais e de sustentabilidade relacionadas às prioridades da decisão estratégica (PARTIDÁRIO, 2012).

A estrutura para definição dos FCDs, segundo a autora, pode ser observada na Figura 12, cabendo ressaltar que esta materializa o conceito de definição de âmbito exigida nos requisitos da Diretiva Europeia de AAE (2001/42 CE). 


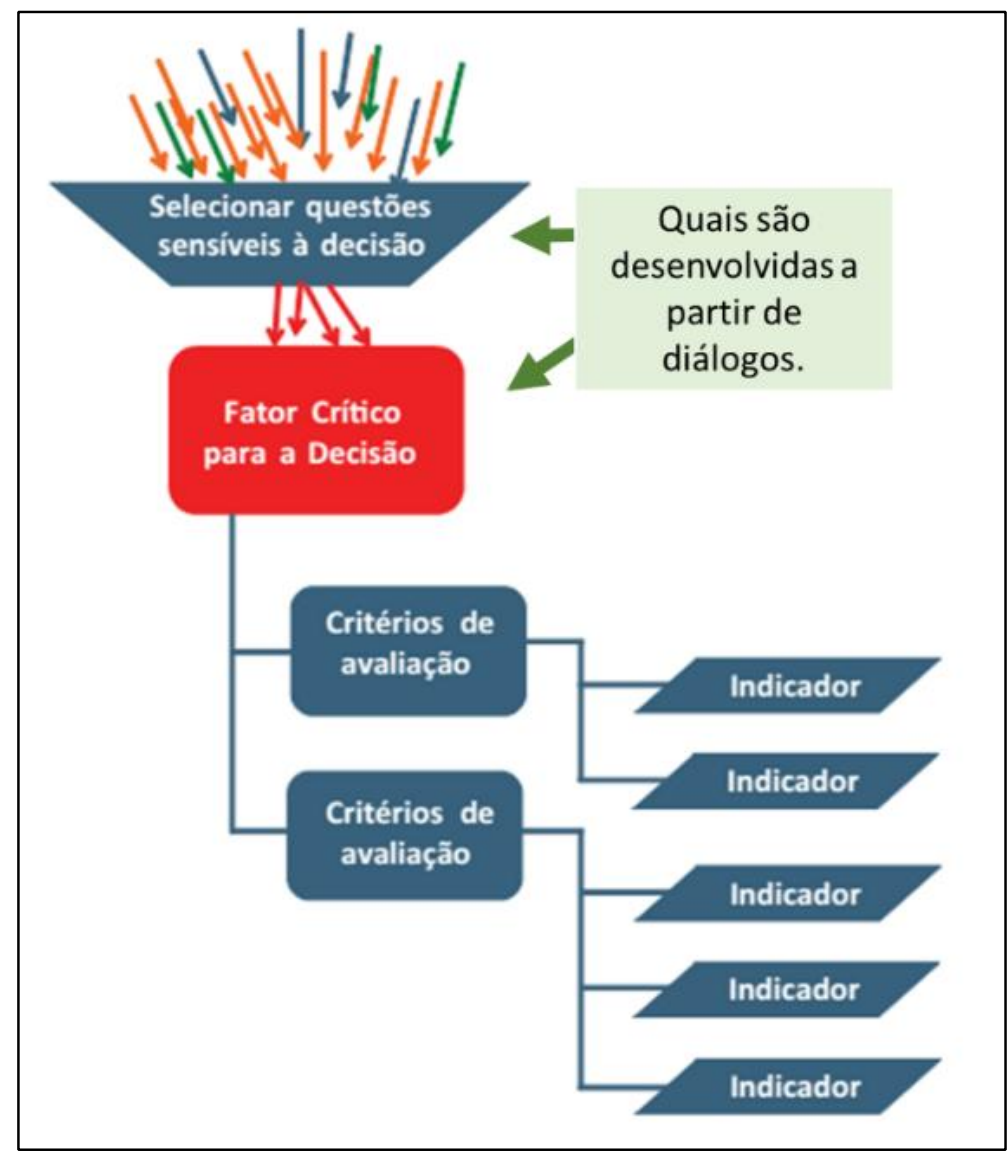

Figura 12 - Estrutura de desenvolvimento dos FCDs, segundo Partidário (2012). Fonte: Adaptado de Partidário (2012).

As concepções sobre o momento de estabelecimento do foco da AAE representada pela figura, permite compreender que a seleção das questões sensíveis a decisão depende fundamentalmente do diálogo entre os interessados e não necessariamente do desenvolvimento sequencial de outros elementos da avaliação, pois estas se desenvolvem conforme a necessidade do contexto de aplicação do instrumento.

Tendo como base as diferentes conceituações sobre a etapa de Scoping na AAE apresentadas, é possível elaborar uma síntese dos fundamentos que conduzem esta etapa.

Em primeiro lugar, deve-se lembrar que a AAE constitui um processo de avaliação que ocorre antes da tomada da decisão estratégica de políticas, planos e programas, e portanto encontram-se em um nível de planejamento que direciona ações futuras de desenvolvimento. Diferentemente da AIA de projetos, a AAE tem por natureza se colocar como um instrumento proativo que influencia a construção de objetivos com visão futura e de promoção da sustentabilidade nas ações estratégicas (SNELL \& COWELL, 2006).

Neste sentido, Fischer (2007) argumenta que poucas alternativas estão disponíveis em situações de projeto, sobretudo porque um “conjunto de questões especificas do local” estão mais detalhadas e se concentram em torno de questões especificas, locacionais e operacionais. 
Contudo, mais alternativas estão acessíveis de serem discutidas na escala de políticas ou planos, porque o objeto tratado por estes são mais amplos e ligados a questões políticas, reguladoras, tecnológicas, fiscais e econômicas, e consequentemente o escopo da AAE se encarrega de tratar de questões desta natureza (FISCHER, 2007).

Assim, por lidar com um conjunto de incertezas, a AAE promove a construção de objetivos, metas e indicadores de sustentabilidade como forma de direcionar a avaliação e confere à etapa de Scoping o momento para se definir quais questões e aspectos (ambientais, sociais e econômicos) serão trabalhadas, incluindo a abrangência espacial e temporal.

Esta etapa se constrói a partir de um conjunto de elementos que evidenciam aspectos relevantes para a avaliação. A partir das conceituações dadas pelos autores trabalhados entendese que tais procedimentos podem ser descritos como segue:

- Organização das informações contextuais e objetivos iniciais da ação estratégica: os autores tratam a reunião de informações prévias da ação estratégica como inerente ao processo de AAE como um todo e consequentemente à etapa de Scoping, pois servirão de suporte para o desenvolvimento das demais ações;

- Definição e identificação das questões ambientais de base (Baseline): se refere à reunião de informações ambientais, sociais e econômicas referentes ao contexto de ação da AAE, contudo foi encontrada uma divergência importante na revisão da literatura, que a aponta como o momento de construção detalhada da Baseline (THERIVEL, 2004) ou como um momento em que apenas se reúne informações prévias sobre este aspecto (OCDE, 2006);

- Identificação de relações com outras políticas, planos e programas (PPPs): trata-se da ação de verificar se os objetivos de outras PPPs sobrepõem ou contemplam a ação estratégica, de modo que permita o desenvolvimento mais amplo e direcionado da AAE (THERIVEL, 2004).

- Perspectivas com vistas à proteção ambiental e promoção da sustentabilidade: trata-se da forma com que a AAE assegura a inserção de aspectos de sustentabilidade, que pode ser elaborada por meio da observação de outras PPPs ou mesmo de elementos normativos (leis, protocolos, acordos, etc.) voltados à promoção da sustentabilidade e com relação direta com o objeto a AAE.

- Métodos e técnicas para avaliação: segundo Fischer (2007) a etapa de Scoping pode ser útil para se definir quais métodos e técnicas serão empregadas pela AAE, como matrizes, sobreposição de mapas e comparações de casos, mas que 
também podem ser empregadas para a própria definição do Scoping. Por exemplo, para identificar inconsistências nos objetivos estabelecidos para a AAE, questões que requerem atenção e/ou o impacto potencial da aplicação da proposta, de modo a melhor qualificar esta etapa.

- Identificação de alternativas para a ação estratégica: a concepção apresentada por Fischer (2007) e OCDE (2006) colocam o momento do Scoping como aquele que pode evidenciar e discutir alternativas para o desenvolvimento da ação estratégica, ainda que a discussão efetiva destas alternativas ocorra em um estágio subsequente, logo trata-se de um momento importante para subsidiar a avaliação de alternativas;

- Identificação das questões chave para decisão: conforme a abordagem apresentada por Partidário (2012), a etapa de definição do âmbito da AAE deve conter a identificação de questões chave, principalmente, pela consulta e diálogo entre os agentes envolvidos com a ação estratégica;

- Consultas e Participação (Stakeholders, público envolvido e consultores): procedimentos de consulta e envolvimento da sociedade é destacada como um fator essencial para o sucesso da etapa de Scoping, de modo que a identificação e participação destes agentes devem conduzir o desenvolvimento das demais ações. Segundo Fischer (2007), durante a AAE a "consulta" se refere ao engajamento de agentes externos às questões tratadas pela ação estratégica, como especialistas, autoridades ou mesmo o público indiretamente afetado, enquanto que por "participação", se trata da contribuição daqueles com total relação e envolvimento com o desenvolvimento da ação estratégica, que produzem informações, opiniões, interesses e valores.

Os elementos apresentados como síntese da etapa de Scoping podem ser visualizados na Figura 13 a seguir. Ainda que não seja adequado propor um conjunto ordenado de atividades que orientem a etapa de Scoping entende-se, contudo, que todos os elementos apresentados são necessários para o desenvolvimento do Scoping, que deverá culminar na definição de Objetivos, Metas e Indicadores para a AAE. 


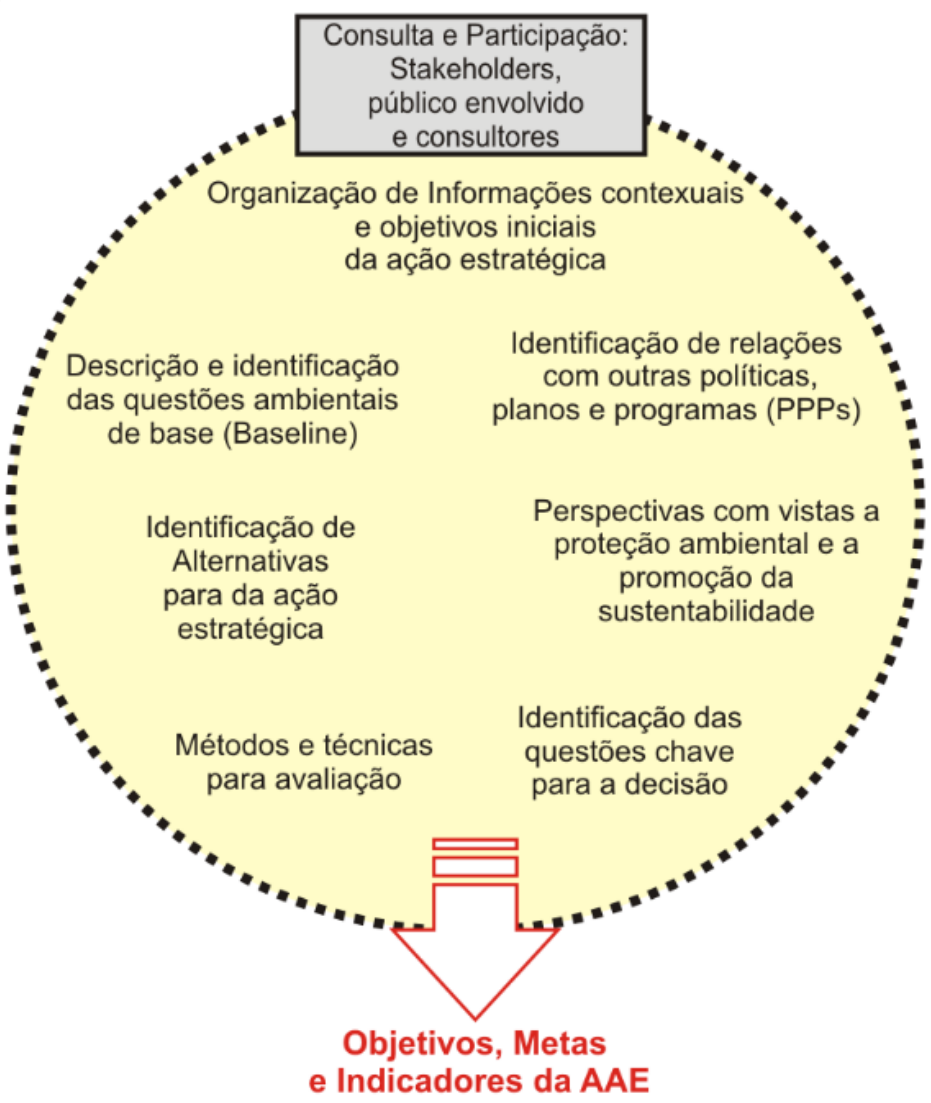

Figura 13 - Organização síntese da etapa de Scoping segundo alguns autores.

Os Objetivos, Metas e Indicadores de Avaliação Ambiental Estratégica são tidos por Therivel (2004) como elementos centrais da AAE pois influenciam em praticamente todas as demais fases da avaliação e por isso a importância desta etapa.

A autora explica que os Objetivos de AAE significam a descrição de uma situação pretendida, a ser alcançada, como por exemplo "reduzir a poluição do ar" ou "melhorar a saúde humana". Outro ponto é que não se deve confundir os objetivos da AAE com os da ação estratégica, pois estes últimos se referem aos objetivos adotados por uma PPPs e os primeiros se referem a uma forma eficaz de desenvolver a ação considerando seus efeitos sobre o meio ambiente e a sustentabilidade (THERIVEL, 2004).

Os indicadores, por sua vez, encontram-se associados aos objetivos. São parâmetros que se alteram com o tempo e servem para mensurar o alcance dos objetivos ou não (SANTOS, 2004; THERIVEL, 2004 e PARTIDÁRIO, 2012). Por exemplo, indicadores de qualidade do ar podem ser aplicados como forma de monitorar o objetivo de "reduzir a emissão de $\mathrm{CO}_{2}$ em uma determinada região". Já as metas podem ser traduzidas como situações ideais que precisam ser alcançadas, como a redução de um parâmetro ambiental até determinado nível, que podem ter como referência as agendas ambientais ou marcos legais, como a Agenda 21 (THERIVEL, 2004; PARTIDÁRIO, 2012). 
Donnelly (2006) também explica que para determinar se um impacto de um plano ou programa é positivo ou negativo metas e indicadores precisam ser estabelecidas e exemplifica na Figura 14 esta relação entre objetivos-metas-indicadores.

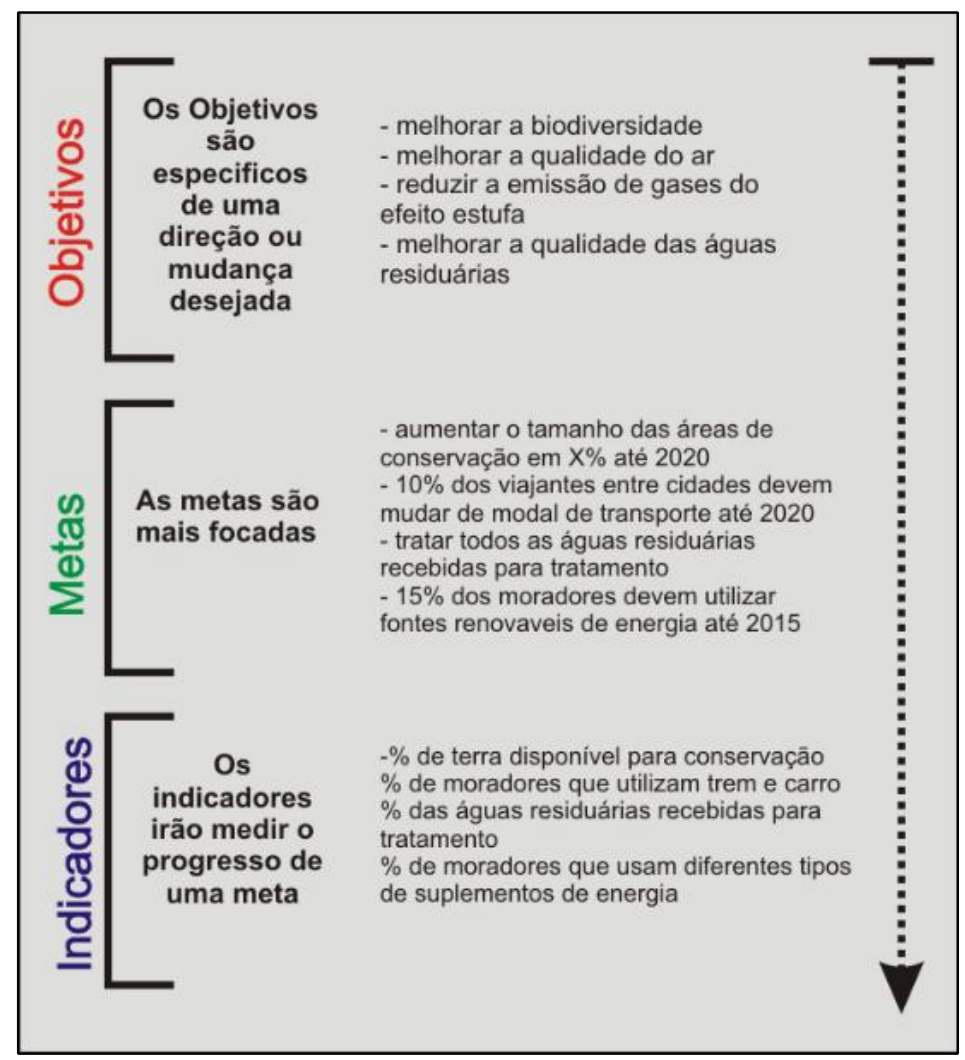

Figura 14 - Exemplo de objetivos, metas e indicadores na AAE Fonte: Adaptado de Donnelly (2006).

\subsection{A elaboração da Baseline na Avaliação Ambiental Estratégica}

Diante das abordagens processuais da AAE e do conceito de Scoping discutidos anteriormente, torna-se importante destacar as características do que seria a Baseline, visto que alguns autores a consideram como parte integrante do Scoping e outros como uma etapa isolada do processo.

Desta forma, Baseline ou linha de base ambiental, em tradução livre, é tratada por Therivel (2004) como o instante em que são reunidas informações sobre o estado corrente do ambiente e como este deverá evoluir no caso da não implementação da ação estratégica.

Para OCDE (2006) a baseline da AAE deve ser voltada para o entendimento completo do ambiente potencialmente afetado e os sistemas sociais envolvidos. A baseline deve ter particular atenção aos sistemas e serviços ecológicos importantes, sua resiliência e 
vulnerabilidade e à importância para o bem-estar humano; também deve-se verifica a existência de instrumentos normativos e medidas de proteção ambiental existentes (OCDE, 2006).

A baseline permite gerar informações sobre os impactos que uma ação estratégica poderá causar sobre o ambiente, a partir da diferença entre o estado do ambiente futuro, sem e com a ação estratégica. Deste modo, reúne informações sobre o ambiente que servem para o desenvolvimento das demais etapas do processo de avaliação, ou seja, que orientam a previsão e o monitoramento dos efeitos ambientais e, ainda, subsidiam a busca de medidas alternativas para lidar com tais efeitos.

As fontes de dados para a construção da baseline incluem informações advindas de websites, relatórios, pesquisas governamentais, de universidades, ONGs, mapas e, também, entrevistas com o público diretamente afetado e especialistas (THERIVEL, 2004). Estas informações podem ser de teor qualitativo ou quantitativo, onde a temporalidade e espacialidade devem ser as mais apropriadas quanto possível para a escala de avaliação. Além disso, devem abranger aspectos ambientais, sociais e econômicos, dispostos em tópicos como biodiversidade, população, saúde humana, fauna, flora, solos, ar, água, fatores climáticos, bens materiais, patrimônio cultural, paisagem, bem como as suas interrelações (THERIVEL, 2004).

Quanto aos métodos e técnicas para elaboração da baseline, estes podem incluir indicadores, checklists, matrizes de impacto, participação/comunicação do público afetado e consulta a especialistas, sendo que a escolha destas devem ser de modo apropriado à complexidade da tarefa de avaliação (FISCHER, 2007); THERIVEL, 2004).

\subsection{O papel dos Indicadores na Avaliação Ambiental Estratégica}

O termo indicador é originário do Latin Indicare, que significa descobrir, apontar, anunciar, estimar (HAMMOND et al., 1995 apud BELLEN, 2006). A sua utilização é ampla e abrange diversos campos científicos, de modo, que existem diversas conceituações acerca de sua definição, papel e funcionalidade.

Para Santos (2004), os indicadores são parâmetros, ou funções derivadas deles, que têm a capacidade de descrever um estado ou uma resposta de fenômenos que ocorrem. Esta definição é compatível com a apresentada pela OECD (2008), segundo a qual os indicadores ambientais são parâmetros que apontam ou fornecem informações sobre o estado do meio ambiente, cujo valor numérico se estende para além e adquire um significado.

A EEA (European Environment Agency) (2005) estabelece que um indicador é uma medida, em geral quantitativa, que pode ser usada para ilustrar e comunicar fenômenos complexos e simples ao incluir as tendências e sua evolução ao longo do tempo. A agência ainda reforça que um indicador tem como função fornecer pistas para uma questão de maior 
importância ou tornar perceptível uma tendência ou fenômeno que não se mostre imediatamente detectável.

Para Bellen (2006), os indicadores têm o papel de agregar informações para que uma significância fique mais aparente, pois eles proporcionam a simplificação das informações de fenômenos complexos e logo promovem a comunicação destes.

Estas características permitem a comunicação e visualização das mudanças e condições no ambiente e assim promovem a sua principal função, que é a capacidade de auxiliar os tomadores de decisão e a sociedade. Podem ser utilizados para avaliar, comparar e projetar tendências e ações, de modo a serem úteis para prognosticar cenários e nortear ações preventivas (SANTOS, 2004).

Deve-se compreender que os indicadores se distinguem dos dados primários, pois estes referem-se a valores, medidas ou observações brutas, já os indicadores remontam a uma variável, que apresenta significação (SANTOS, 2004; BELLEN, 2006).

Tendo como base estes fundamentos compreende-se que os indicadores exercem importante função para a Avaliação Ambiental Estratégica. Segundo Fischer (2007) os indicadores são utilizados em todos os estágios, como por exemplo, para indicar se a avaliação é necessária ou não, para definir a Baseline, para a discussão e estabelecimento da etapa de scoping, para a identificação de impactos, identificação de alternativas e finalmente estabelecimento do monitoramento. Em outras palavras, eles providenciam importantes evidencias para se tomar decisões.

Segundo Therivel (2004) eles são mais comumente empregados para descrever e monitorar o estado de base do ambiente e predizer impactos, mas, principalmente, firmam-se como um elemento fundamental ao processo de AAE, pois, como esquematiza a Figura 15, apresentam-se totalmente associados aos objetivos de AAE e logo firmam-se como um elemento que permite visualizar o alcance dos objetivos da avaliação.

De acordo com a figura os indicadores desempenham sua função por meio da sua ligação com as demais etapas do processo de avaliação, dispondo também de uma alça de retroalimentação com a baseline, que estabelece uma relação comum de construção e complementação entre ambos. 


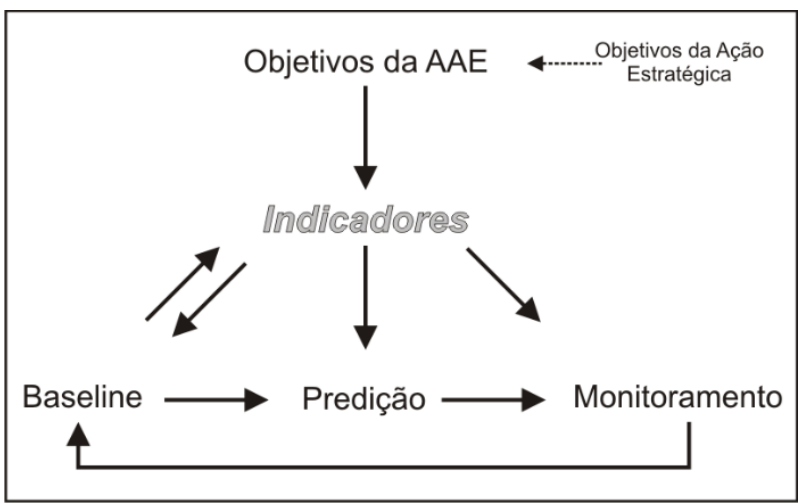

Figura 15 - Relações entre indicadores, objetivos e demais elementos da AAE Fonte: Adaptado de Therivel (2004).

Para Wang (2013), os indicadores apresentam um conjunto de funções chave para o processo de $\mathrm{AAE}$, das quais:

- Os indicadores podem manter informados os planejadores e tomadores de decisão acerca do estado corrente do meio nos domínios sob sua responsabilidade, pois eles não descrevem apenas o estado atual mas também providenciam uma imagem prospectiva do ambiente;

- Os indicadores podem facilitar o acompanhamento da AAE, o monitoramento e antecipar futuros problemas de implementação das ações estratégicas. Tal capacidade é potencializada quando a situação retratada pelos indicadores são comparadas a um estágio anterior ou a metas de desenvolvimento;

- Os indicadores podem facilitar a disseminação da informação, isto é, eles podem ser facilmente compreendidos pelo público envolvido e facilitar uma comunicação efetiva entre diferentes stakeholders. Logo um indicador é uma importante fonte de informação para guiar os planejadores para a tomada de decisão, como também para o monitoramento e avaliação.

De forma análoga, Ezequiel \& Ramos (2011) afirmam que os indicadores têm papel central na AAE, porque melhoram e facilitam o processo de avaliação da sustentabilidade, a comunicação, formulação do relatório ambiental, contribuem para melhor participação pública e o processo de tomada de decisão. No entanto, alertam que há casos em que este potencial não é utilizado totalmente e muitas vezes, na realidade, terminam por empobrecer o processo de avaliação.

No que refere à capacidade de comunicação dos indicadores na AAE Gao, Kornov \& Christensen (2013) discutem o seu papel na construção de um processo avaliativo mais envolvente e deliberativo a partir do diálogo entre o público e os tomadores de decisão. Os 
autores evidenciam casos em que este aspecto tornou o processo de AAE mais dinâmico, com menos barreiras e com melhor capacidade de construção.

Por sua vez, o trabalho desenvolvido por Moldan, Janouska \& Hák (2012) analisa as diferentes abordagens e tipos de indicadores desenvolvidos, utilizados para a avaliação da sustentabilidade ambiental. Segundo os autores, a principal dificuldade está na forma de selecioná-los, interpretá-los e utilizá-los de forma adequada. Os autores chamam a atenção sobre a necessidade de se dispor de metas mais concisas e especificas por parte de órgãos internacionais, de modo que isso permitiria um melhor estabelecimento de metas para as ações estratégicas.

O trabalho de Donnelly et al. (2007) objetiva orientar a melhor seleção de indicadores ambientais em processos de AAE por meio da aplicação de um conjunto de critérios que facilitam a seleção de indicadores pela equipe de especialistas. Em outro trabalho, o autor apresenta um uma metodologia teórica para o desenvolvimento de objetivos, metas e indicadores para uso em AAEs (DONNELLY et al. 2006). Para os autores, o quadro apresentado sugere uma maneira simples, lógica, transparente e sistemática de organizar ou alinhar o foco de um processo de AAE e permite evitar a subjetividade no processo de tomada de decisão. Finalmente, Donnelly, Prendergast \& Hanush (2008) apresentam um conjunto de critérios para examinar a qualidade de objetivos, metas e indicadores ambientais em relatórios de AAE, procurando verificar se estes refletem a melhor prática em AAE e apontar as deficiências encontradas.

Em síntese, a literatura é recorrente em relação à importância dos indicadores e sua relação com os objetivos da $\mathrm{AAE}$, sendo apontados como elementos fundamentais para a efetividade na aplicação do instrumento.

\subsection{O Estatuto da Cidade e o Plano Diretor}

A Política Urbana ${ }^{5}$ ou comumente conhecida como Estatuto da Cidade é uma conquista social de um processo importante de reforma urbana iniciado na década de 1980, que estabelece o governo democrático da cidade, a justiça urbana, o bem estar dos cidadãos e o equilíbrio ambiental como princípios para o planejamento urbano. Adota como diretriz o direito a cidades sustentáveis, ou seja, o direito à terra urbana, ao saneamento ambiental, à infraestrutura urbana, aos serviços públicos, o trabalho e ao lazer de forma adequada às presentes e futuras gerações (BRASIL, LEI No 10.257, DE 10 DE JULHO DE 2001).

\footnotetext{
${ }^{5}$ Lei 10.257 , de 10 de julho de 2001, que regulamenta o capítulo da política urbana da Constituição Federal (arts. 182 e 183), estabelecendo suas diretrizes e regulamentando a aplicação de importantes instrumentos de gestão e reforma urbana, dentre os quais se destacam o Plano Diretor.
} 
Assim, para desenvolver os objetivos previstos, o Estatuto encadeia suas disposições em torno de um sistema de planejamento e gestão de desenvolvimento territorial (Figura 16), que dispõe de um conjunto de instrumentos jurídicos, tributários, financeiros e de planejamento a ser em articulados pelos agentes do poder público municipal através do Plano Diretor. Logo, o objetivo de garantir o equilíbrio ambiental deve ser buscado a partir da aplicação dos diversos instrumentos da política urbana, orientados pelo que estabelece o Plano Diretor e implementados pelos agentes do poder público.

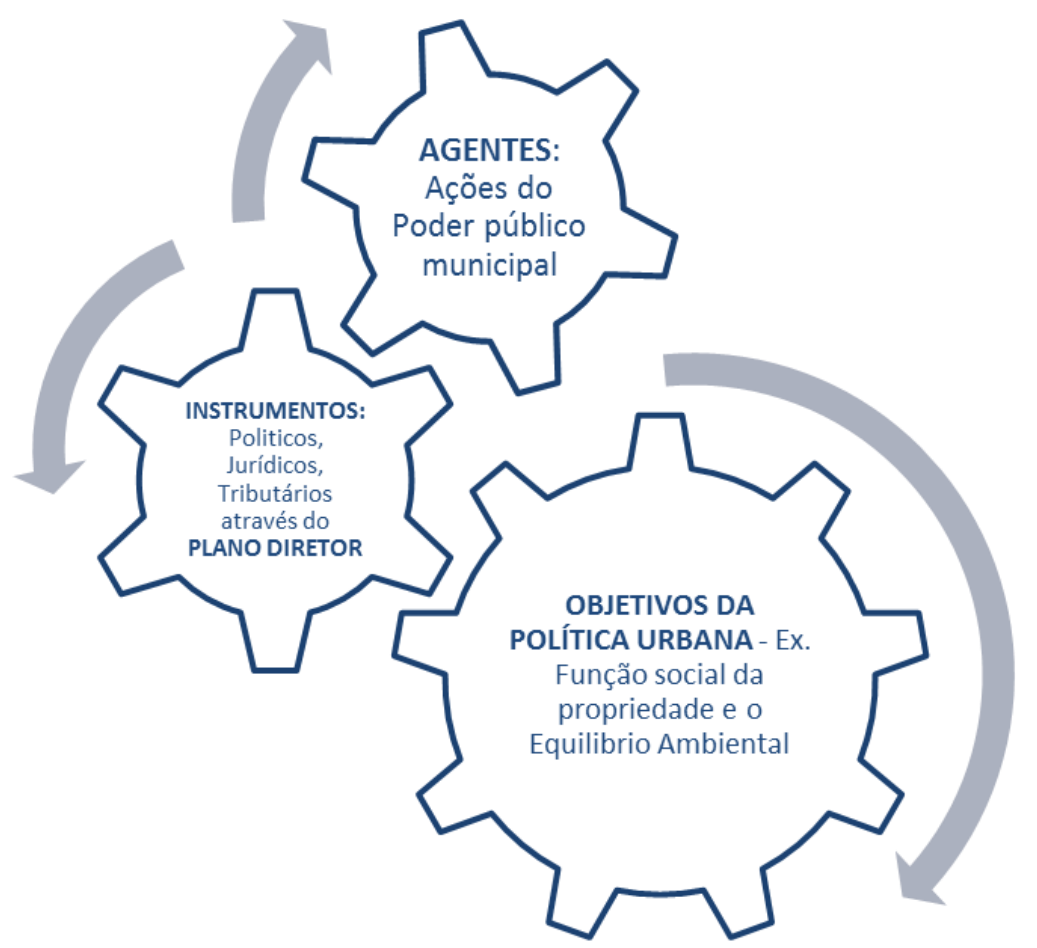

Figura 16 - Elementos do sistema de planejamento e gestão definidos pelo Estatuto da Cidade

Desta forma, o estatuto se propõe a dar um suporte jurídico às ações governamentais e da sociedade para a administração dos processos de uso, ocupação, parcelamento e desenvolvimento urbano e assim subsidiar o enfrentamento das graves questões urbanas, sociais e ambientais que afetam diretamente a vida nas cidades (FERNANDES, 2010).

Neste sentido, o Plano Diretor é o instrumento básico de ordenamento do território, previsto no Estatuto das Cidades e pode ser definido: “[...] como um conjunto de princípios $e$ regras orientadoras da ação dos agentes que constroem e utilizam o espaço urbano." (BRASIL, 2002, p. 40).

Em outras palavras, pode ser entendido como um conjunto de diretrizes, normas legais e objetivos que abarcam o desenvolvimento econômico-social, o meio ambiente e o uso e ocupação do solo, projetados para um determinado período. 
Além disto, ele é um documento que deve tratar suas questões de modo explícito, que devem ser fruto de uma discussão democrática e consensual sobre que tipo de cidade querem desenvolver, ou seja, os objetivos do plano não são "dados" ou definidos a priori e sim um produto complexo (SABOYA, 2008). Esse aspecto torna o Plano Diretor uma ferramenta extremamente valiosa ao seu contex to de aplicação.

Para sua elaboração e implementação, o Plano Diretor dispõe de um conjunto de instrumentos (Figura 17) que irão permitir à cidade alcançar seus objetivos específicos ao mesmo tempo em que assumem os objetivos estabelecidos na Política Urbana. Assim, entendese que passa a ser função dos planos diretores, após a promulgação do Estatuto das Cidades, orientar o desenvolvimento do território para a proteção do ambiente e para a sustentabilidade.

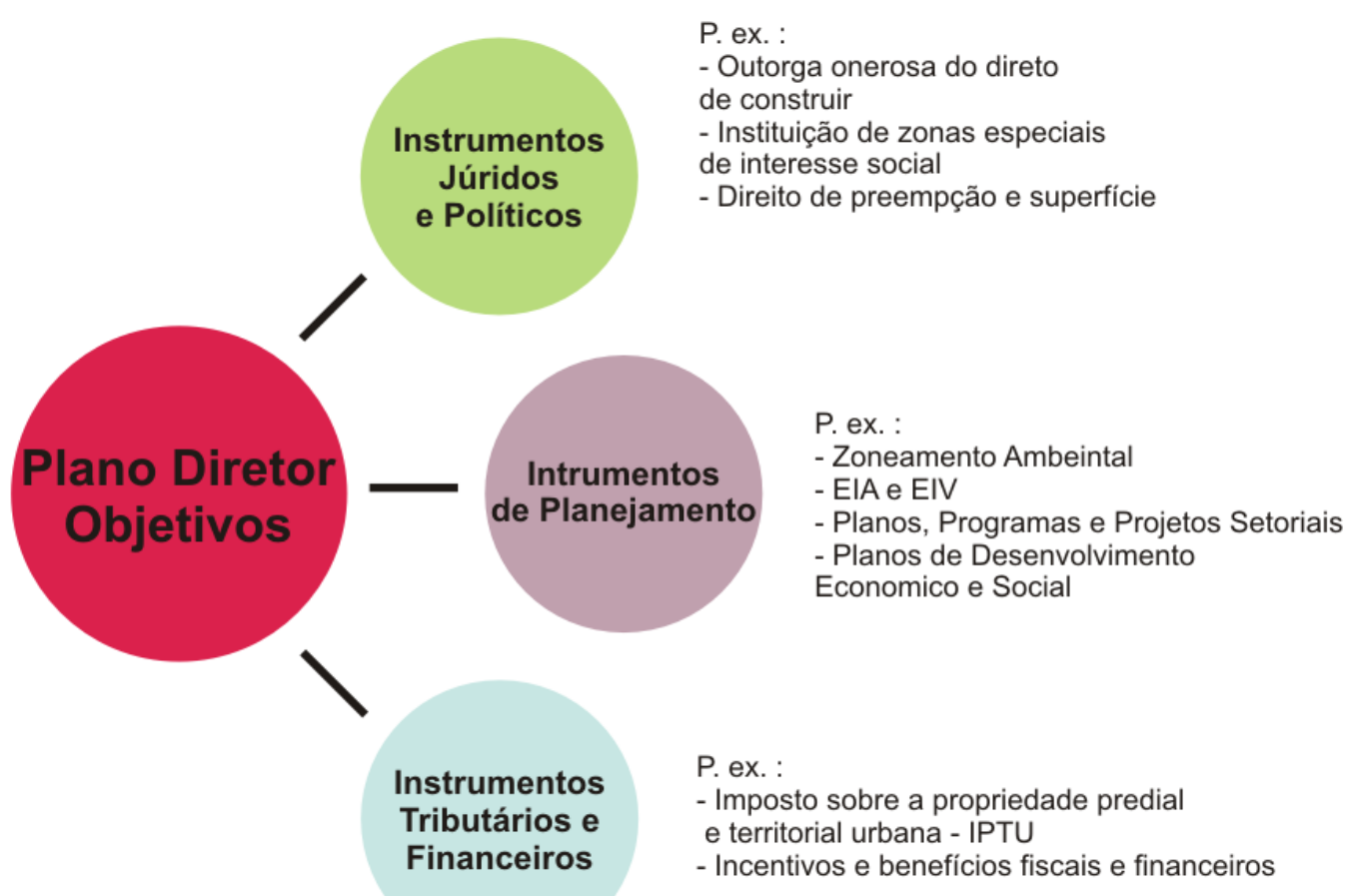

Figura 17 - Os instrumentos disponíveis ao Plano Diretor

\subsection{O Plano Diretor e a política ambiental municipal}

A concepção de plano diretor evoluiu bastante durante o século XX. Inicialmente este apresentava preocupações ligadas a aspectos estéticos, ao desenho da cidade; em seguida dedicou-se à distribuição espacial de edificações de acordo com suas funções econômicas; depois firmou-se a conceituação de Plano Diretor de Desenvolvimento Integrado, em que o plano é um instrumento de planejamento destinado a alcançar objetivos integrados nos campos físico, econômico, social e administrativo (SILVA, 2006). 
A concepção proposta por Villaça, (1999) pode ser compreendida como ilustrativa desta visão. Segundo o autor, o Plano Diretor:

"Seria um plano que, a partir de um diagnóstico científico da realidade fisica, social, econômica, política e administrativa da cidade, do município e de sua região, apresentaria um conjunto de propostas para o futuro desenvolvimento socioeconômico e futura organização espacial dos usos do solo urbano, das redes de infraestrutura e de elementos fundamentais da estrutura urbana, para a cidade e para o município, propostas estas definidas para curto, médio e longo prazos, e aprovados por lei municipal." (VILLAÇA, 1999, pg. 238)

Conforme Saboya (2013), o principal elemento que caracteriza um "plano" é a definição de um caminho a ser percorrido para que se alcance um objetivo ou um conjunto de objetivos, caminho este que é percorrido através de ações que devem ser realizadas pelos diversos atores que participam do desenvolvimento urbano. Desta forma, o plano diretor deve indicar quais são essas ações, e como elas se integram para constituir o direcionamento que levaria da situação atual à situação desejada.

No entanto, para o autor, os planos diretores brasileiros têm apresentado pouca orientação quanto às ações que devem ser desenvolvidas, seja por adotarem objetivos muito genéricos que, apesar de darem uma indicação do rumo que se deseja seguir, não permite de indicar e organizar a sequência de ações a serem tomadas, seja porque se atentam essencialmente ao estabelecimento dos elementos normativos como base para o ordenamento territorial, estabelecendo limites para o que pode e o que não pode ser realizado, mas dizendo pouco sobre o que deve ser feito, em qual ordem ou grau.

Neste sentido, o autor explica que:

"Por isso, para que se possa chamar de plano ele deve conter orientações explícitas para guiar as ações futuras. Assim podemos entender um plano diretor como um documento que sintetiza e explicita os objetivos consensuados para o Município e estabelece princípios, diretrizes e normas a serem utilizadas como base para que as decisões dos atores envolvidos no processo de desenvolvimento urbano convirjam, tanto quanto possível, na direção desses objetivos." (SABOYA, 2013, p. 1)

Outro ponto destacado pelo autor é quanto à credibilidade dos planos diretores, pois se o plano é orientador de ações futuras ele deve passar credibilidade aos tomadores de decisão e ao público afetado de que as orientações são legítimas e representativas. Legítimas, no sentido do plano ter sido concebido dentro de um de um processo transparente de debates, discussões 
e negociação, em que as informações foram amplamente divulgadas sem distorções ou manipulações de nenhum tipo, e representativas, porque as decisões tomadas teriam sido construídas a partir da representação social e da participação pública.

Assim, Saboya (2013) reflete que:

"Temos aí um círculo que pode ser vicioso ou virtuoso. Se, por um lado, o plano precisa ser utilizado como referência para construir credibilidade, por outro lado ele precisa ter credibilidade para ser efetivamente utilizado como referência. A história dos planos no Brasil nos mostra que o que tem predominado é o círculo vicioso: falta de credibilidade gera desrespeito ao plano, e vice-versa." (SABOYA, 2013, p. 1)

Conforme Silva (2006), o planejamento urbano deve buscar a complementaridade e integração de políticas, planos e programas setoriais ao nível regional, assegurando o respeito à realidade local. Portanto, deve-se então considerar as relações interurbanas com as demais esferas governamentais (nacional, regional, estadual), e também intraurbana, isto é, no nível local (SILVA, 2006).

Como visto anteriormente a política urbana estabelece instrumentos para que seus objetivos sejam desenvolvidos através do Plano Diretor. No entanto, após mais de uma década da instituição do Estatuto das Cidades, ainda existem muitas lacunas relacionadas aos problemas urbanos.

Dentre estes pode-se fundamentar a subutilização dos instrumentos disponíveis aos Planos Diretores para articular o alcance de objetivos relacionados ao meio ambiente urbano. Neste sentido, considera-se revelador os resultados da mais ampla análise realizada até o momento voltada para a inserção da dimensão ambiental nos planos diretores de municípios brasileiros, realizado por meio da Rede Nacional de Avaliação e Capacitação para Implementação de Planos Diretores Participativos e com o apoio do Ministério das Cidades.

O trabalho de Costa, Campante e Araújo (2011) investigou a existência de diretrizes, instrumentos e propostas vinculadas a políticas específicas de meio ambiente stricto sensu, ou seja, excluindo-se aspectos setoriais e claramente imbricados com a sustentabilidade urbana como saneamento ambiental, habitação e mobilidade urbana. O estudo foi elaborado a partir da síntese organizada para os 27 estados brasileiros, que envolveu o universo de 526 relatórios municipais de planos diretores.

Dentre as considerações apresentadas, verificou-se uma enorme heterogeneidade sobre o tratamento da questão ambiental nos planos diretores, não sendo possível identificar sequer uma semelhança de princípios e fundamentos entre os diferentes estados e/ou regiões. Dentre 
os resultados sobre o panorama nacional descrito pelo estudo, pode-se destacar as seguintes considerações:

$\checkmark$ Existe o predomínio de incorporação de um discurso ambiental entre os objetivos e princípios fundamentais, através dos conceitos de sustentabilidade e qualidade ambiental;

$\checkmark$ Há ainda pouca ou nenhuma inovação no uso dos instrumentos previstos no Estatuto em prol das questões ambientais e tampouco há vinculação com estratégias de ordenamento territorial fundamentadas em princípios de sustentabilidade ambiental;

$\checkmark$ Os planos não expressam uma abordagem integrada para as questões ambientais e demais políticas setoriais;

$\checkmark$ Predomina um tratamento genérico quanto a diretrizes ambientais, ou seja, excluindo-se questões especificas, locais ou regionais;

$\checkmark$ As questões intermunicipais são em maioria tratadas através de diretrizes genéricas, sem identificação de instrumentos de gestão compartilhada de problemas e serviços de interesse comuns, tais como consórcios, comitês ou agências intermunicipais;

ii. Marca-se a ausência de autoaplicabilidade dos dispositivos. Embora ditos participativos é predominante a ausência de pactos que possibilitassem avanços na definição de parâmetros e critérios voltados para o cumprimento da função social da propriedade e, portanto, maior controle do uso e na ocupação do solo, conforme preconizado pelo Estatuto da Cidade.

O estudo revela que predomina uma visão de meio ambiente como algo ligado à preservação e proteção de áreas verdes, de modo desvinculado das demais questões de desenvolvimento municipal e, assim, encobrindo a existência de conflitos socioambientais que caracterizam a temática, bem como o desenvolvimento de ações de enfrentamento destes problemas (COSTA, CAMPANTE \& ARAÚJO, 2011).

Além disto, conceitos relacionados a sustentabilidade ambiental, preservação ambiental, desenvolvimento econômico e melhoria da qualidade de vida, não são visualizados como princípios de articulação da maioria dos planos, de modo que se mantém a ação compartimentalizada de políticas setoriais e a ausência de propostas efetivas de consolidação de sistemas de planejamento e gestão urbana e ambiental (COSTA, CAMPANTE \& ARAÚJO, 2011). 


\section{ANÁlise dA PRÁtica CORRENTE DE AAE: O USO DE OBJETIVOS E INDICADORES}

As análises que se desenvolvem a seguir têm como prioridade identificar temas, procedimentos e aspectos metodológicos que têm direcionado o desenvolvimento de objetivos e indicadores para promoção da sustentabilidade em processos de AAE no contexto internacional, e a sua importância em relação ao modelo conceitual aplicado.

Assim as análises a seguir se desenvolvem em duas partes:

- A caracterização dos temas abordados pelos objetivos estabelecidos na prática da AAE e sua relação com a temática da sustentabilidade;

iii. A caracterização do uso de indicadores de AAE em casos da prática internacional.

\section{Critérios de seleção dos relatórios.}

A busca pelos relatórios ambientais se deu a partir de indicações referenciadas e discutidas em trabalhos acadêmicos, como o de Silva (2012), Jones (2005), Fischer (2007), além das avaliações recomendadas e disponibilizadas em sites especializados como o da consultoria de Levett-Therivel ${ }^{6}$, os bancos de dados de relatórios de AAEs do governo da Escocia $^{7}$ e da região de governo da Lombardia na Italía ${ }^{8}$, bem como os relatórios já integrados ao banco de dados elaborado pelo Núcleo de Estudos de Política Ambiental - NEPA 9 .

Assim, foram identificados inicialmente 42 relatórios de AAEs aplicadas no planejamento do uso do solo e/ou ao desenvolvimento urbano que foram pré-analisados em relação aos seguintes requisitos:

- a existência de indicadores de AAE associados aos seus objetivos;

- apresentação clara dos Indicadores de AAE segundo a sua função, ou seja, deveria permitir a verificação do seu uso nas diversas etapas do processo;

$\checkmark$ a possibilidade de acesso a documentos complementares que possibilitassem o maior possibilidade de compreensão do contexto em que foram aplicados;

\footnotetext{
${ }^{6} \mathrm{O}$ site http://www.levett-therivel.co.uk/SEArec11.htm apresenta uma listagem anual de casos recomendados de aplicação da AAE que apresentam características especiais em seu desenvolvimento.

${ }^{7} \mathrm{O}$ site < http://www.scotland.gov.uk/Topics/Environment/environmental-assessment/sea/SEAG $>$ permite acesso a um banco de dados que disponibiliza para consulta e donwload diversos relatórios de AAE desenvolvidos em território escocês.

8 O Site < http://www.cartografia.regione.lombardia.it/sivas/jsp/home.jsf $>$ apresenta informações sobre a aplicação da AAE na região da Lombardia e disponibiliza o acesso aos relatórios desenvolvidos em todas as cidades ou microrregiões.

${ }^{9}$ O Núcleo de Estudos de Política Ambiental - NEPA, ligado ao programa de pós-graduação em Ciências da Engenharia Ambiental da EESC/USP que tem desenvolvido pesquisas ligadas a AAE tem organizado diversos relatórios que já foram objetos de estudo.
} 
A partir de um conjunto variado de relatórios, optou-se por adotar uma amostra homogênea quanto à estrutura de procedimentos aplicada na elaboração da AAE, decidindo-se por aquelas avaliações ambientais regidas pela Diretiva Europeia de AAE (2001/42/CE). Ao mesmo tempo, procurou-se estabelecer um conjunto de relatórios que incluísse diferentes contextos de aplicação e, principalmente, diferentes realidades em termos das prioridades para o planejamento do uso do solo e desenvolvimento urbano.

Foram selecionados um total de 15 relatórios, elaborados em 5 países distintos, que agregam uma parcela diversificada de aplicações do instrumento, como detalha a tabela a seguir.

Tabela 2 - AAEs consultadas para identificação e coleta de Indicadores de AAE

\begin{tabular}{|c|c|c|c|}
\hline Nome da AAE & $\begin{array}{l}\text { Objeto de avaliação } \\
\text { (Ação estratégica) }\end{array}$ & Ano & País \\
\hline $\begin{array}{l}\text { Aberdeenshire Local } \\
\text { Development Plan } 2009 \\
\text { Strategic Environment } \\
\text { Assessment: Interim } \\
\text { Environmental Report }\end{array}$ & \multirow{3}{*}{$\begin{array}{l}\text { As avaliações se referem a "Local Development Plans", } \\
\text { que são estratégias a nível de condado (Counties), mas } \\
\text { também a unidades autônomas como áreas protegidas, } \\
\text { por exemplo, parques nacionais. Estas ações organizam } \\
\text { políticas, estratégias e ações para o desenvolvimento e } \\
\text { uso da terra em sua área de autoridade local. }\end{array}$} & $\begin{array}{l}2 \\
0 \\
0 \\
9\end{array}$ & \multirow{3}{*}{$\begin{array}{l}\mathrm{E} \\
\mathrm{s} \\
\mathrm{c} \\
\mathrm{o} \\
\mathrm{c} \\
\mathrm{i} \\
\mathrm{a}\end{array}$} \\
\hline $\begin{array}{c}\text { The Local Development Plan } \\
\text { for Glasgow - Main issues } \\
\text { report - Interim } \\
\text { Environmental Report. }\end{array}$ & & $\begin{array}{l}2 \\
0 \\
1 \\
0\end{array}$ & \\
\hline $\begin{array}{c}\text { Cairngorms National Park - } \\
\text { Deposit Local Plan Strategic } \\
\text { Environmental Assessment/ } \\
\text { Environmental Report }\end{array}$ & & $\begin{array}{l}2 \\
0 \\
0 \\
7\end{array}$ & \\
\hline $\begin{array}{c}\text { (SEA) / (SA) of Thurrock } \\
\text { Council - Local Development } \\
\text { Framework /Scoping Report }\end{array}$ & \multirow{2}{*}{$\begin{array}{c}\text { As avaliações consultadas se referem tanto para } \\
\text { estratégias de desenvolvimento (frameworks) quanto } \\
\text { para planos que visam responder a estratégias especificas } \\
\text { de desenvolvimento do uso do solo a nível local e } \\
\text { setorial, como planos de transporte, os "Local } \\
\text { Implementation Plan”. }\end{array}$} & $\begin{array}{l}2 \\
0 \\
0 \\
5\end{array}$ & $\begin{array}{l}\text { I } \\
\mathrm{n} \\
\mathrm{g}\end{array}$ \\
\hline $\begin{array}{l}\text { The London Borough of } \\
\text { Barking and Dagenham - } \\
\text { Local Implementation Plan - } \\
\text { Strategic Environmental } \\
\text { Assessment/ Environmental } \\
\text { Report }\end{array}$ & & $\begin{array}{l}2 \\
0 \\
0 \\
5\end{array}$ & $\begin{array}{l}\mathrm{a} \\
\mathrm{t} \\
\mathrm{e} \\
\mathrm{r} \\
\mathrm{r} \\
\mathrm{a}\end{array}$ \\
\hline
\end{tabular}




\begin{tabular}{|c|c|c|c|}
\hline Nome da AAE & $\begin{array}{l}\text { Objeto de avaliação } \\
\text { (Ação estratégica) }\end{array}$ & Ano & País \\
\hline $\begin{array}{l}\text { Oxford City Council - } \\
\text { Scoping Report for the } \\
\text { Local Development } \\
\text { Framework }\end{array}$ & & $\begin{array}{l}2 \\
0 \\
1 \\
1\end{array}$ & \\
\hline $\begin{array}{l}\text { Clare County Development } \\
\text { Plan 2011-2017 - } \\
\text { Environment Appraisal of } \\
\text { the Plan /Part I: Strategic } \\
\text { Environmental Assessment } \\
\text { (SEA) }\end{array}$ & \multirow{3}{*}{$\begin{array}{l}\text { Os "Development Plans" se referem a estratégias a nível } \\
\text { de condado "Counties", que incluem políticas para o uso } \\
\text { do solo e o desenvolvimento controlado destes e, } \\
\text { também um zoneamento para os tipos de uso. }\end{array}$} & $\begin{array}{l}2 \\
0 \\
1 \\
1\end{array}$ & I \\
\hline $\begin{array}{l}\text { Appropriate Assessment Of } \\
\text { Draft Galway County } \\
\text { Development Plan }\end{array}$ & & $\begin{array}{l}2 \\
0 \\
0\end{array}$ & $\begin{array}{l}\mathrm{l} \\
\mathrm{a} \\
\mathrm{n}\end{array}$ \\
\hline $\begin{array}{c}\text { Cork County Council } \\
\text { Planning Policy Unit - } \\
\text { Strategic Environmental } \\
\text { Assessment - Environmental } \\
\text { Report }\end{array}$ & & $\begin{array}{l}2 \\
0 \\
0 \\
7\end{array}$ & \\
\hline $\begin{array}{c}\text { Comune di Romano di } \\
\text { Lombardia - Valutazione } \\
\text { Ambientale Strategica (VAS) } \\
\text { del Piano di Governo del } \\
\text { Territorio (PGT) }\end{array}$ & \multirow{3}{*}{$\begin{array}{c}\text { Piano Urbanistico Comunale - refere-se a uma } \\
\text { ferramenta de gestão a nível municipal, que a partir de } \\
\text { dispositivos legais regem a gestão da transformação } \\
\text { urbana e territorial. }\end{array}$} & $\begin{array}{l}2 \\
0 \\
0 \\
8\end{array}$ & \multirow{3}{*}{$\begin{array}{l}\mathrm{I} \\
\mathrm{t} \\
\mathrm{a} \\
1 \\
\mathrm{i} \\
\mathrm{i} \\
\mathrm{a}\end{array}$} \\
\hline $\begin{array}{c}\text { Comuni di Bergamo - } \\
\text { Valutazione Ambientale } \\
\text { Strategica (VAS) del Piano di } \\
\text { Governo del Territorio (PGT) }\end{array}$ & & $\begin{array}{l}2 \\
0 \\
0 \\
8\end{array}$ & \\
\hline $\begin{array}{l}\text { Comune di Acerra Piano } \\
\text { Urbanistico Comunale - } \\
\text { Valutazione ambiental } \\
\text { estrategica - Rapporto } \\
\text { Ambientale }\end{array}$ & & $\begin{array}{l}2 \\
0 \\
0 \\
8\end{array}$ & \\
\hline $\begin{array}{l}\text { Avaliação Ambiental } \\
\text { Estratégica da Alteração do } \\
\text { Plano Regional de } \\
\text { Ordenamento do Território da } \\
\text { Área Metropolitana de Lisboa }\end{array}$ & $\begin{array}{l}\text { Planos Regionais de Ordenamento do Território, que } \\
\text { tratam de objetivos relativos ao planejamento em nível } \\
\text { de região. Surgem como resposta a planos de nível } \\
\text { nacional ou setorial. }\end{array}$ & $\begin{array}{l}2 \\
0 \\
1 \\
0\end{array}$ & $\begin{array}{l}\mathrm{P} \\
\mathrm{o} \\
\mathrm{r} \\
\mathrm{t} \\
\mathrm{u}\end{array}$ \\
\hline
\end{tabular}




\begin{tabular}{|c|c|c|c|}
\hline Nome da AAE & $\begin{array}{c}\text { Objeto de avaliação } \\
\text { (Ação estratégica) }\end{array}$ & Ano & País \\
\hline $\begin{array}{c}\text { Avaliação Ambiental } \\
\text { Estratégica do Plano Regional } \\
\text { de Ordenamento do Território } \\
\text { dos Açores }\end{array}$ & & $\begin{array}{l}2 \\
0 \\
0 \\
9\end{array}$ & $\begin{array}{l}\mathrm{g} \\
\mathrm{a} \\
\mathrm{l}\end{array}$ \\
\hline $\begin{array}{c}\text { Avaliação Ambiental } \\
\text { Estratégica do Plano Regional } \\
\text { de Ordenamento do Território } \\
\text { dos Oeste e Vale do Tejo. }\end{array}$ & & $\begin{array}{l}2 \\
0 \\
0 \\
8\end{array}$ & \\
\hline
\end{tabular}

* As referências sobre estes relatórios encontram-se na seção de Referências Bibliográficas.

\subsection{O direcionamento temático dos objetivos de AAE.}

Esta análise tem por objetivo verificar, na prática corrente da AAE, quais temas têm direcionado o estabelecimento dos objetivos das AAEs, bem como identificar como têm sido aplicados para a promoção da sustentabilidade nos planos de desenvolvimento urbano.

Neste momento, cabe estabelecer a diferenciação entre a noção de objetivos de ação estratégica, que se referem aos objetivos adotados para o favorecimento de uma determinada PPPs sem ter a noção dos seus possíveis efeitos, da noção de objetivos de AAE, que providenciam uma forma eficaz de desenvolver a ação considerando seus efeitos sobre o meio ambiente e a sustentabilidade (THERIVEL, 2004).

Ainda que o processo de AAE possa ser envolvido de diversas maneiras no desenvolvimento da ação estratégica, como advoga Partidário (2012), em qualquer abordagem de AAE os objetivos estabelecidos na etapa de scoping representam o âmbito de discussão ao qual a avaliação vai se dedicar. Portanto, em relação ao processo de tomada de decisão, estes objetivos são interpretados como os inputs da AAE para a ação estratégica.

Além disso, independentemente da forma pela qual a tomada de decisão integra as considerações e recomendações decorrentes do processo de AAE, estes inputs estarão presentes ao final da tomada de decisão estratégica, ou seja, os objetivos de $\mathrm{AAE}$ deverão ser considerados na construção dos objetivos finais da ação, como exemplifica a Figura 18. 


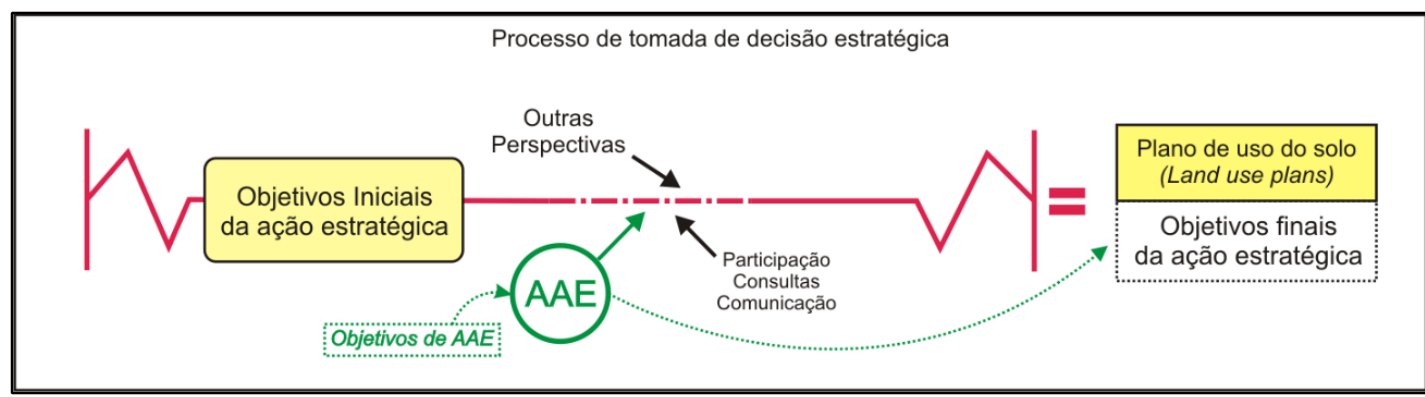

Figura 18 - Exemplificação de como os Objetivos de AAE se inserem na ação estratégica

Cabe destacar que, como um dos principais propósitos do processo de AAE, deve-se procurar promover a questão ambiental a um mesmo patamar de influência que as questões sociais e econômicas, como exemplifica a Figura 19.

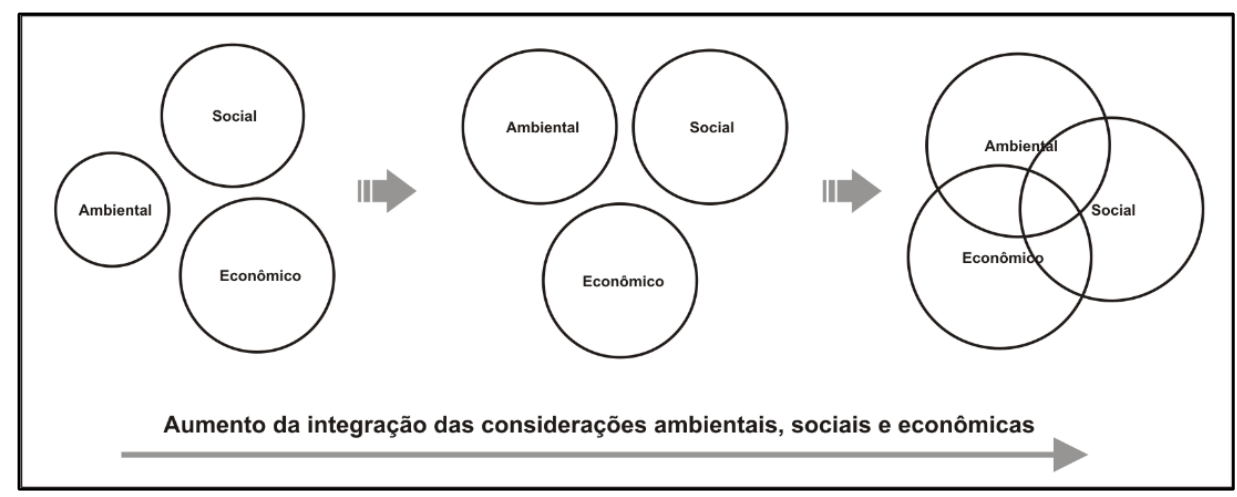

Figura 19 - Aumento da integração e equalização das questões ambientais, sociais e econômicas Fonte: Adaptado de OCDE, 2006.

A figura indica o aumento do "peso" atribuído as questões ambientais, até o momento de sua integração plena. Esta perspectiva atribuída ao instrumento acarreta em reflexos diretos nas características dos objetivos de AAE, ou seja, no direcionamento dos temas abordados por estes.

Em outras palavras, não apenas as questões ambientais são abordadas nos objetivos de AAE, mas também as perspectivas sociais e econômicas se fazem pertinentes, dado que garantem o alcance dos propósitos do instrumento para com a ação estratégica, além da inserção da variável ambiental e a promoção da sustentabilidade nos planos e programas.

Assim, a presente análise se desenvolve no sentido caracterizar os temas que têm sido apresentado como inputs às respectivas ações estratégicas na prática corrente da AAE aplicada ao planejamento do desenvolvimento do território. 


\section{Processo de coleta e organização dos objetivos de AAE}

A identificação dos objetivos de $\mathrm{AAE}$ se deu através da leitura e interpretação dos relatórios de AAE selecionados, e sua posterior organização conforme os temas retratados.

Para tanto, foram definidas categorias para classificação dos objetivos levando-se em conta aspectos localizados na literatura voltada à construção e aplicação de sistemas indicadores de sustentabilidade, como a de Bellen (2006), que apresenta conceitos relacionados à capacidade dos indicadores em medir a sustentabilidade e discute o potencial de diversos outros sistemas e em estruturas conceituais. De modo complementar, optou-se por agregar as definições dos sistemas de indicadores desenvolvido pelo IBGE (2010) e pela Agência Ambiental Europeia (EEA, 2005). Este procedimento é amparado pelo principio da relação direta entre indicadores e objetivos de AAE defendido por Donelly et al. (2006) e Therivel (2004).

A partir daí, estabeleceram-se as seguintes categorias (Figura 20) para classificação dos temas empregados pelos Objetivos de AAE coletados:

Objetivos voltados à temática Ambiental: se referem a todos objetivos voltados à promoção da qualidade e preservação do meio ambiente em decorrência dos impactos das atividades humanas;

Objetivos voltados à temática Social: Trata-se de objetivos que visem a promoção do bem estar humano, a condição humana e os meios utilizados para melhorar a qualidade de vida;

Objetivos voltados à temática Econômica: se voltam a objetivos ligados a melhoria $\mathrm{e}$ incentivos das atividades econômicas.

Além disso, para os objetivos voltados à combinação de dois ou mais temas, estabeleceu-se as seguintes categorias:

$\checkmark$ Ambiental e Social (A/S);

$\checkmark$ Ambiental e Econômica (A/E);

$\checkmark$ Social e Econômica (S/E);

$\checkmark$ Ambiental, Social e Econômica (A/S/E). 


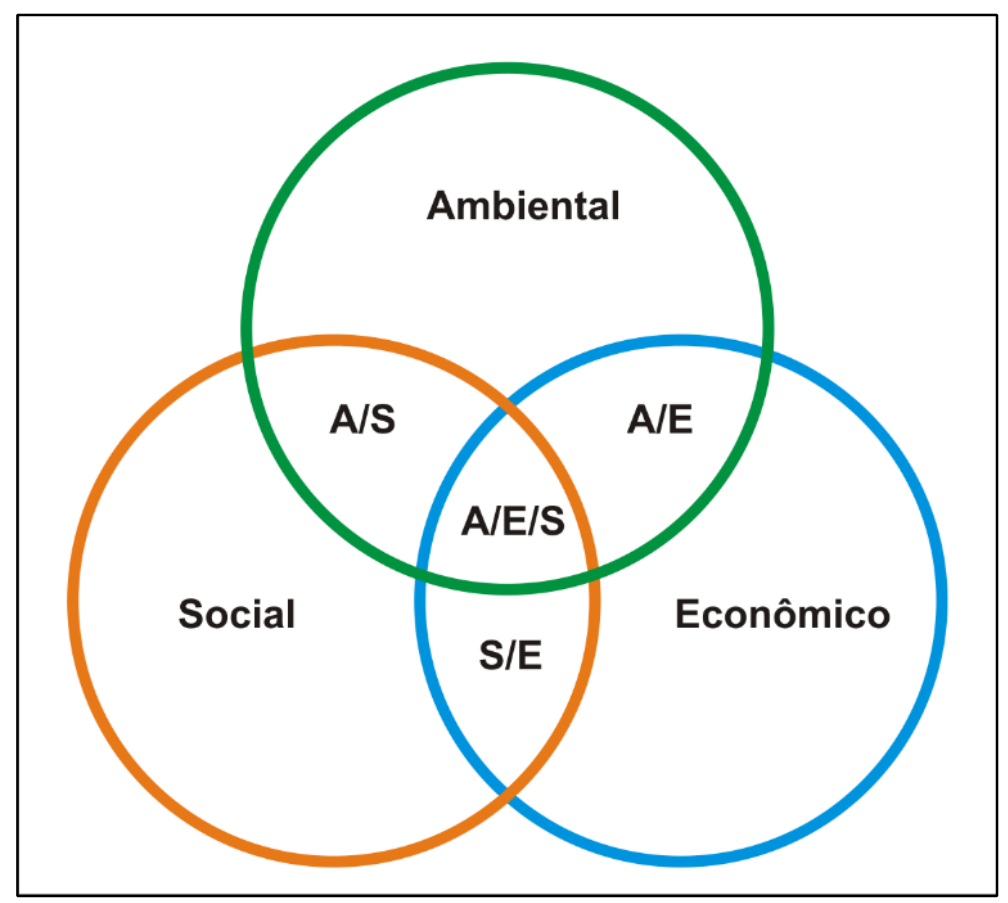

Figura 20 - Representação das categorias utilizadas para classificação dos objetivos de AAE identificados. Adaptado de Bellen (2006).

A categorização efetuada permitiu obter um panorama sobre os principais temas retratados nos processos de AAE, a partir da interpretação de seus objetivos. Vale dizer que a organização dos dados coletados não se propõe a apresentar informações detalhadas acerca dos conteúdos dos objetivos de AAE, mas sim identificar sua amplitude temática.

\section{Sistematização dos dados coletados}

Foram identificados nos relatórios amostrados um total de 264 objetivos de Avaliação Ambiental Estratégica, que foram posteriormente organizados conforme a sua classificação temática, como indica o Gráfico 1. 


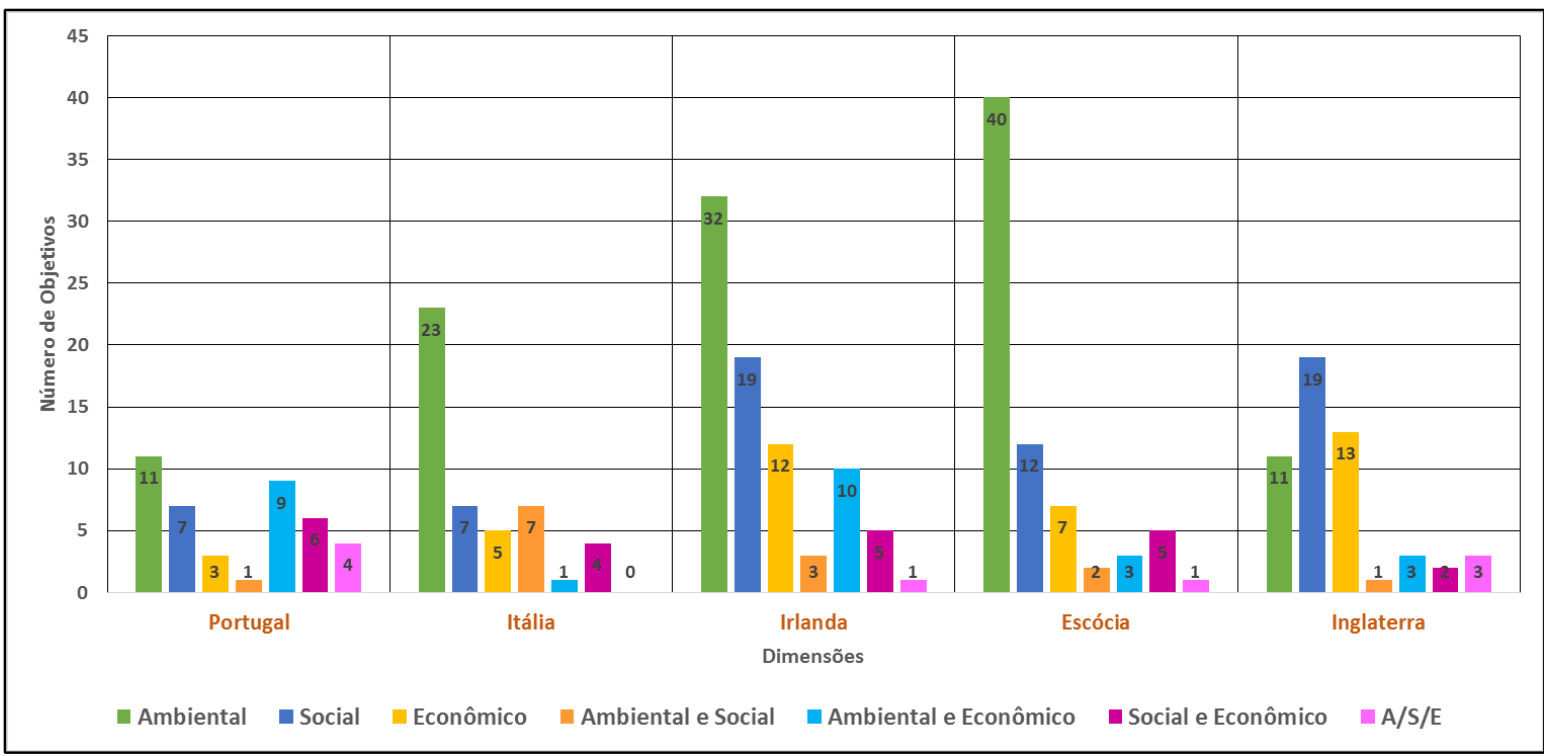

Gráfico 1- Distribuição dos objetivos de AAE por tema e agrupados por países

O Gráfico 2 a seguir apresenta o número de objetivos coletados e a proporção destes em relação ao total coletado em seus respectivos temas.

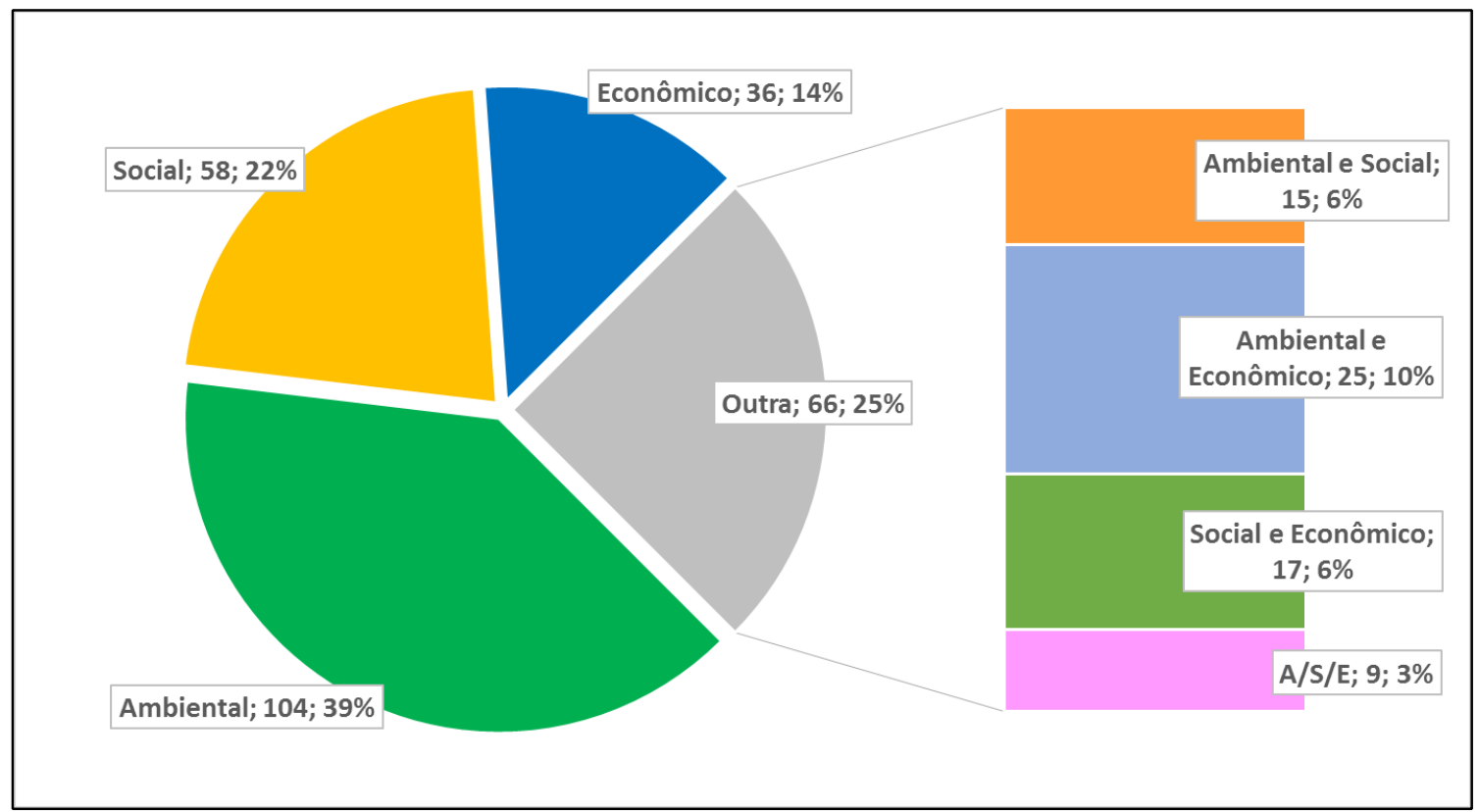

Gráfico 2 - Proporção dos temas em relação ao total de objetivos coletados.

Esta distribuição permite inferir sobre o peso de cada um dos temas, no qual os temas Ambiental, Social e Econômico correspondem, respectivamente, a 39\%, 22\% e 14\% dos objetivos identificados, enquanto os temas combinados somam $25 \%$ a partir de uma distribuição pouco uniforme, com direcionamento maior a temática Ambiental e Econômico.

O Gráfico 3 permite visualizar de modo mais claro o direcionamento que decorre da natureza da AAE (FISCHER, 2007), ou seja, uma promoção do aspecto ambiental ao mesmo 
nível que as demais, ilustrada pela presença do tema Ambiental como o mais influente do que os demais.

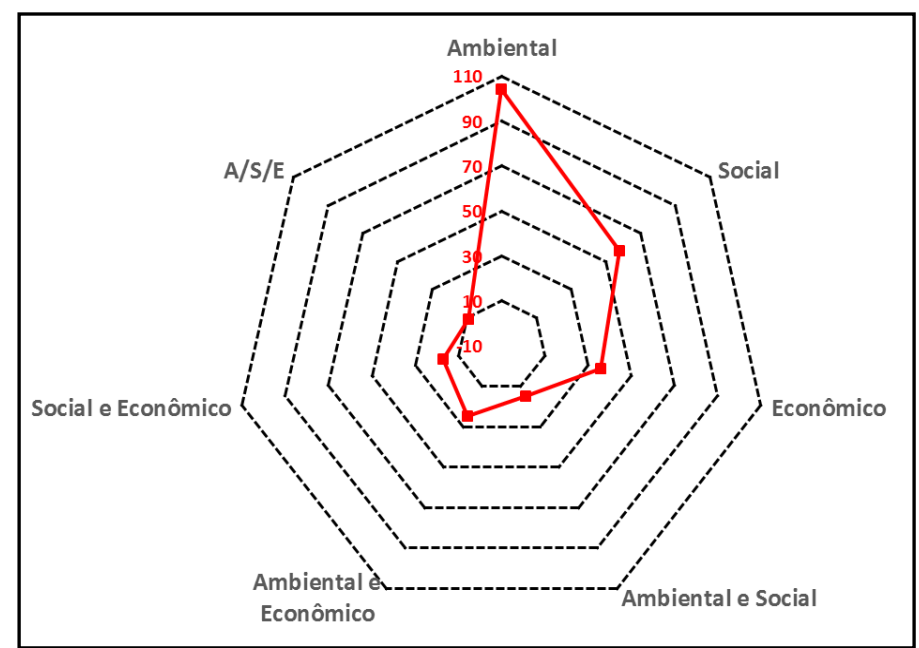

Gráfico 3 - Distribuição da quantidade de Objetivos de AAE coletados por tema

Lobos e Partidário (2014) argumentam que a literatura recente tem apontado para o potencial da AAE em contribuir para mudanças significativas na racionalidade que orienta o processo decisório e sustentam que a prática se mostra distante desta perspectiva, sugerindo que a AAE esteja sendo praticada eminentemente para o cumprimento de requisitos legais. Ainda que os relatórios analisados no presente trabalho indiquem que, de fato, o escopo da avaliação tem se voltado prioritariamente para aspectos biofísicos, uma possível interpretação para este comportamento estaria justamente no papel destinado à $\mathrm{AAE}$ de introduzir elementos de modo a equilibrar a influência dos aspectos ambientais diante dos sociais e econômicos. Neste sentido, as deficiências notadas pelos autores relacionadas ao uso da AAE no processo decisório têm suas origens no próprio processo em si, e não necessariamente no instrumento como querem sugerir.

\subsection{Caracterização dos indicadores de $\mathrm{AAE}$ na prática corrente.}

A análise realizada nesta etapa tem como pressuposto a discussão apresentada por Therivel (2004) sobre a função desempenhada pelos indicadores de AAE, que se estabelecem como parâmetros para verificação do alcance dos objetivos da avaliação e atuam de modo integrado às etapas do processo, como indica a Figura 21 - A.

Sendo assim, entende-se que durante o processo de avaliação as informações que compõem a baseline são consideradas na forma de indicadores de AAE, sendo esta a forma como adquirem importância e conectam-se com as demais etapas do processo (Figura 21 - B). 
Desta forma, o conceito abordado por Therivel (2004) prescreve o indicador de AAE como as funções ou ligações exercidas por uma determinada informação disposta pela baseline dentro do processo de avaliação.

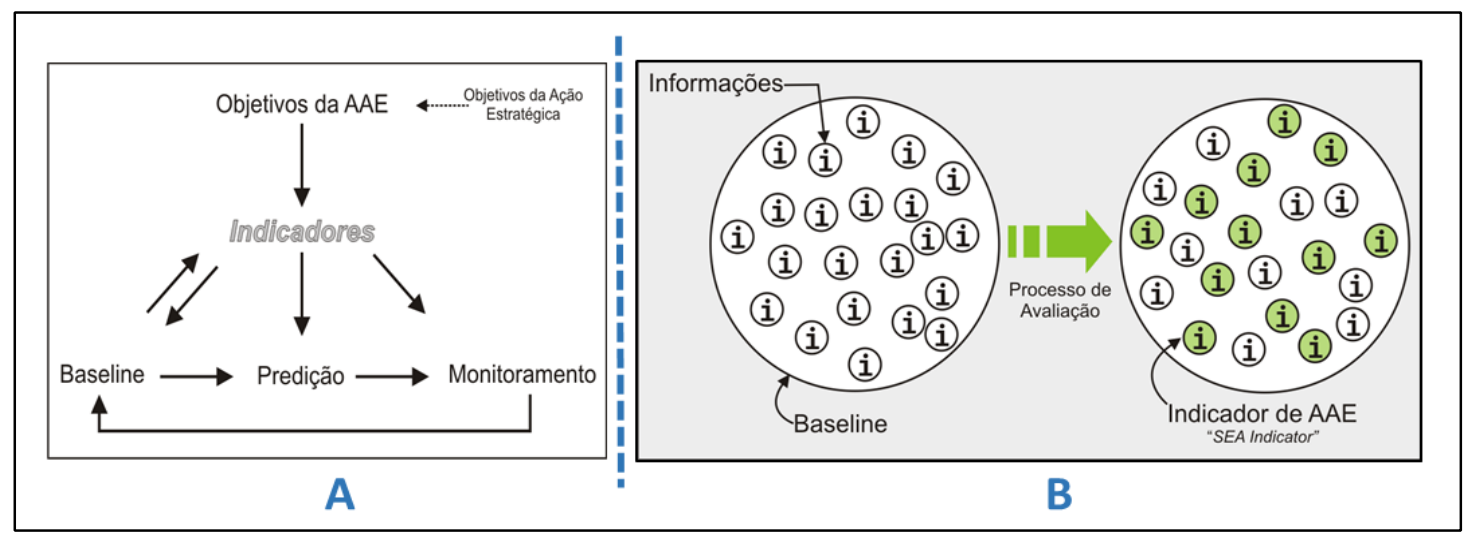

Figura 21(A): Ligações entre os indicadores e outros aspectos da AAE; (B): Distinção entre informações contidas na etapa de Baseline e o Indicador de AAE. Fonte: Desenvolvido a partir de Therivel (2004).

Dessa maneira, a análise tem como tarefa identificar, a partir dos indicadores de AAE em casos da prática corrente, quais questões têm sido abordadas. Para tanto, a foi estruturada como segue.

\section{Identificação, coleta e organização dos Indicadores de $A A E$}

A análise dos casos selecionados se deu por meio da leitura e interpretação dos respectivos relatórios ambientais cujo o foco era a identificação dos Indicadores de AAE, conforme fundamentação conceitual descrita anteriormente.

Este procedimento se baseia nos trabalhos de Silva (2012), que verificou de forma exploratória o emprego de indicadores de sustentabilidade em processos de AAE por meio da análise de conteúdo de 28 relatórios ambientais de diferentes países, e Donnelly (2007), que apresenta uma metodologia de seleção de indicadores para uso em AAEs.

Para tanto, os dados coletados foram dispostos em uma estrutura hierárquica, cuja organização foi baseada no sistema de indicadores para processos de AAE proposto por Wang (2013) e no trabalho de Lee \& Huang (2007), que elaborou um Index de 51 indicadores de sustentabilidade que fora dividido e organizado em quatro dimensões (Econômica, Social, Ambiental e Institucional).

Além disso, os termos e definições utilizadas foram baseadas no sistema de indicadores para o acompanhamento da sustentabilidade e o padrão de desenvolvimento do 
Brasil elaborado pelo IBGE (2010), bem como nos temas ambientais destacados no Anexo I da Diretiva Europeia de AAE (2001/42/CE).

A partir dos trabalhos mencionados, foi elaborada uma estrutura hierárquica para a organização dos Indicadores de AAE coletados, de tal modo que permitisse identificar as questões recorrentemente tratadas estes. Tal estrutura é esquematizada pela Figura 22.

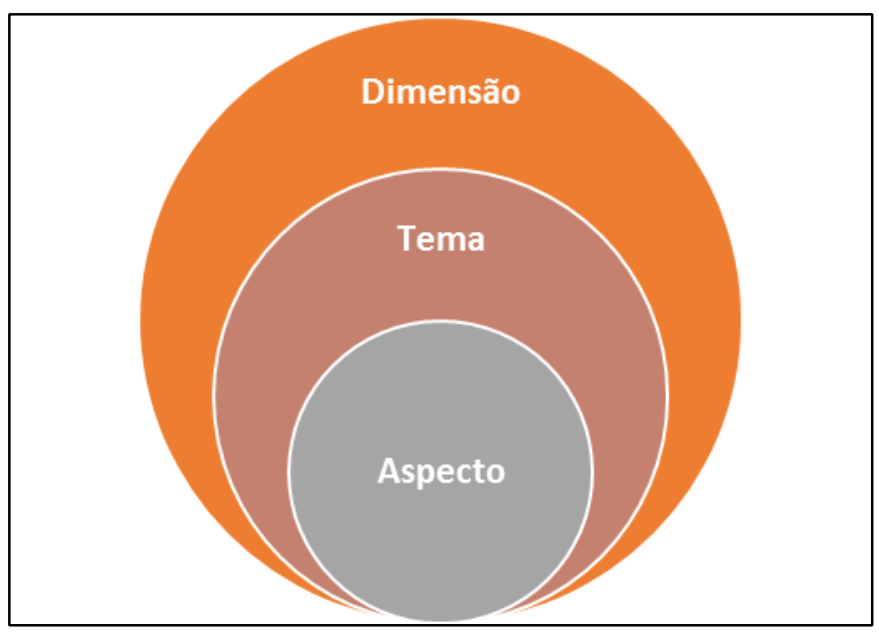

Figura 22 - Representação da organização hierárquica dos Indicadores de AAE coletados

Em que:

$\checkmark$ Dimensão, se refere ao direcionamento do indicador coletado tendo como principio os pilares de sustentabilidade Ambiental, Social e Econômica;

$\checkmark$ Tema, se desenvolvem a partir dos temas destacados pelo sistema de indicadores de sustentabilidade do IBGE (2010) e pelo Anexo I da Diretiva Europeia de AAE, que são descritos como essenciais para a avaliação dos efeitos significativos no ambiente. Estes se referem especificamente sobre a Biodiversidade, a população, a saúde humana, a fauna, a flora, o solo, a água, a atmosfera, os fatores climáticos, os bens materiais, o patrimônio cultural, arquitetônico, arqueológico, a paisagem e a interrelação destes.

- Aspecto, pode ser compreendido como o direcionamento pelo qual um tema pode se desenvolver, ou seja, o detalhamento do tema em questão. Por exemplo, o "tema" "Recursos Hídricos", cujo "aspecto" se refere a "qualidade da água"

\section{Análise da recorrência.}

Para a identificação e descrição das questões recorrentes houve a distribuição dos dados coletados na estrutura definida. Desse modo, foram primeiramente classificados conforme as 
questões retratadas nas "Dimensões" - Ambiental, Social e Econômico - e direcionada para seus respectivos “Temas” conforme a especificação da temática abordada.

A partir daí, os Indicadores de AAE foram distribuídos conforme o seu "aspecto", ou seja, em grupos formados de acordo com as questões que retratavam e, dessa forma, foi possível identificar de maneira precisa quais questões eram abordadas com maior recorrência.

Vale dizer que o procedimento aplicado é sensível à recorrência e homogeneidade dos indicadores para cada aspecto, ou seja, quando o conjunto tratado em nível de "Aspecto" se colocava com maior heterogeneidade, logo, com baixa recorrência, não foi possível detalhar o aspecto tratado. A Figura 23 ilustra o procedimento aplicado.

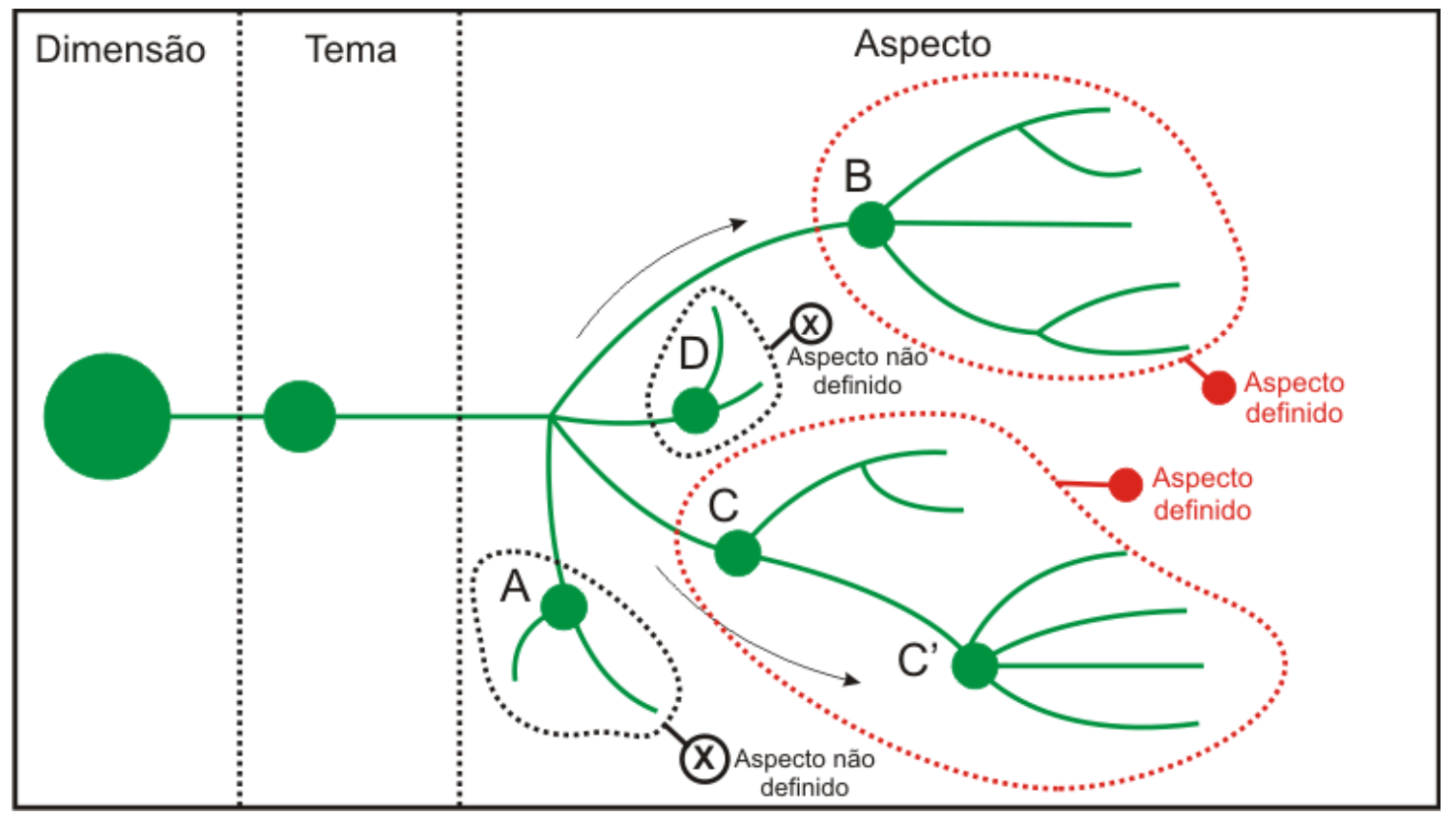

Figura 23 - Exemplificação da organização hierárquica dos Indicadores de AAE para a descrição do Aspecto. Fonte: elaboração própria.

\section{Caracterização geral dos indicadores de AAE coletados.}

No total, foram coletados 550 Indicadores de AAE, que foram associados às dimensões Ambiental, Social e Econômica, Figura 24 (A) e (B). 


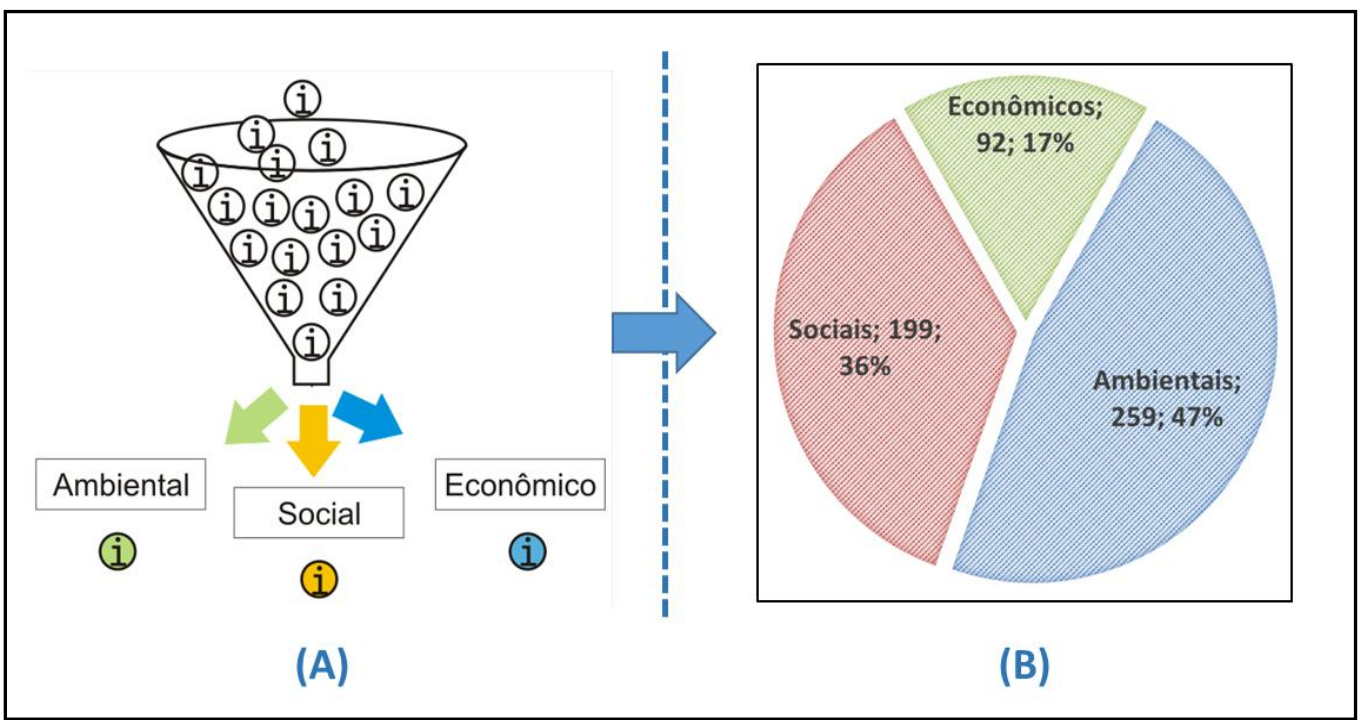

Figura 24 - Representação da distribuição dos Indicadores de AAE coletados e a representação dos indicadores coletados por dimensão. Fonte: elaboração própria.

\section{Indicadores da Dimensão Ambiental}

Os 259 indicadores da dimensão ambiental foram agrupados em sete Temas:

$\checkmark$ Atmosfera: informações ligadas a qualidade do ar e a poluição atmosférica;

$\checkmark$ Recursos Hídricos: toda informação relacionada a cursos d'agua, as águas continentais, as subterrâneas e costeiras, bem como aos parâmetros hidrológicos e de qualidade das águas;

$\checkmark$ Biodiversidade: refere-se essencialmente à identificação de áreas verdes e protegidas e à qualidade ambiental da fauna e flora destas;

$\checkmark$ Saneamento: toda informação relacionada com o abastecimento de água potável, o manejo de água pluvial, a coleta e tratamento de esgotos;

$\checkmark$ Resíduos Sólidos: refere-se a informações relativas à geração, coleta e disposição de resíduos sólidos urbanos ou industriais;

$\checkmark$ Riscos Ambientais: refere-se a informações que visam a identificação e ao monitoramento de processos, situações ou eventos que ocasionem em impactos físicos no ambiente, climáticos, mas alavancados de forma natural, antrópica ou mista. Por exemplo, enchentes, alagamentos, desmoronamentos, movimentos de massa, sismos, incêndios florestais e etc.;

- Solo: trata-se de informações voltadas à identificação e/ou monitoramento de impactos ligados à poluição do solo.

Neste sentido, o Gráfico 4 indica a quantidade e proporção dos indicadores coletados distribuídos pelos sete temas. 


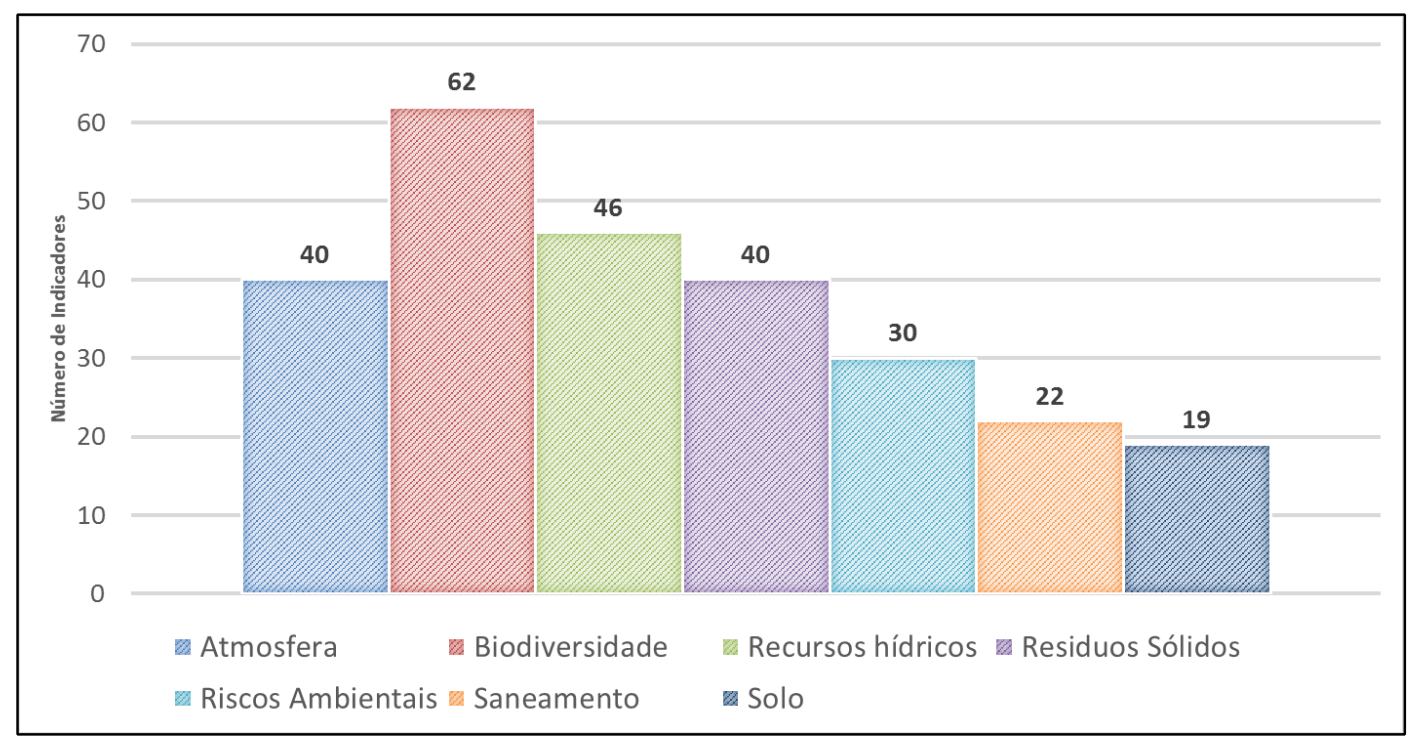

Gráfico 4 - Distribuição dos indicadores da dimensão ambiental

\section{Indicadores da Dimensão Social}

A Dimensão Social apresenta 199 indicadores distribuídos por seis Temas, como indica o Gráfico 5, que se definem como:

$\checkmark$ Educação: representações sobre o nível de escolaridade da população;

$\checkmark$ Paisagem: trata-se de informações que visam identificar situações que alterem as características dos elementos da paisagem natural;

$\checkmark$ População: informações que procuram expressar as características e o ritmo de crescimento populacional;

$\checkmark$ Mobilidade: se referem a parâmetros voltados a identificar e monitorar a facilidade ou dificuldade de deslocamento das pessoas por diferentes modais de transporte na área urbana;

$\checkmark$ Patrimônio Cultural e Arquitetônico: trata-se de informações que visam identificar situações que projetem alterar as características de elementos arquitetônicos e histórico-culturais;

- Saúde Humana: informações que procuram identificar e monitorar a qualidade da saúde e longevidade da população. 


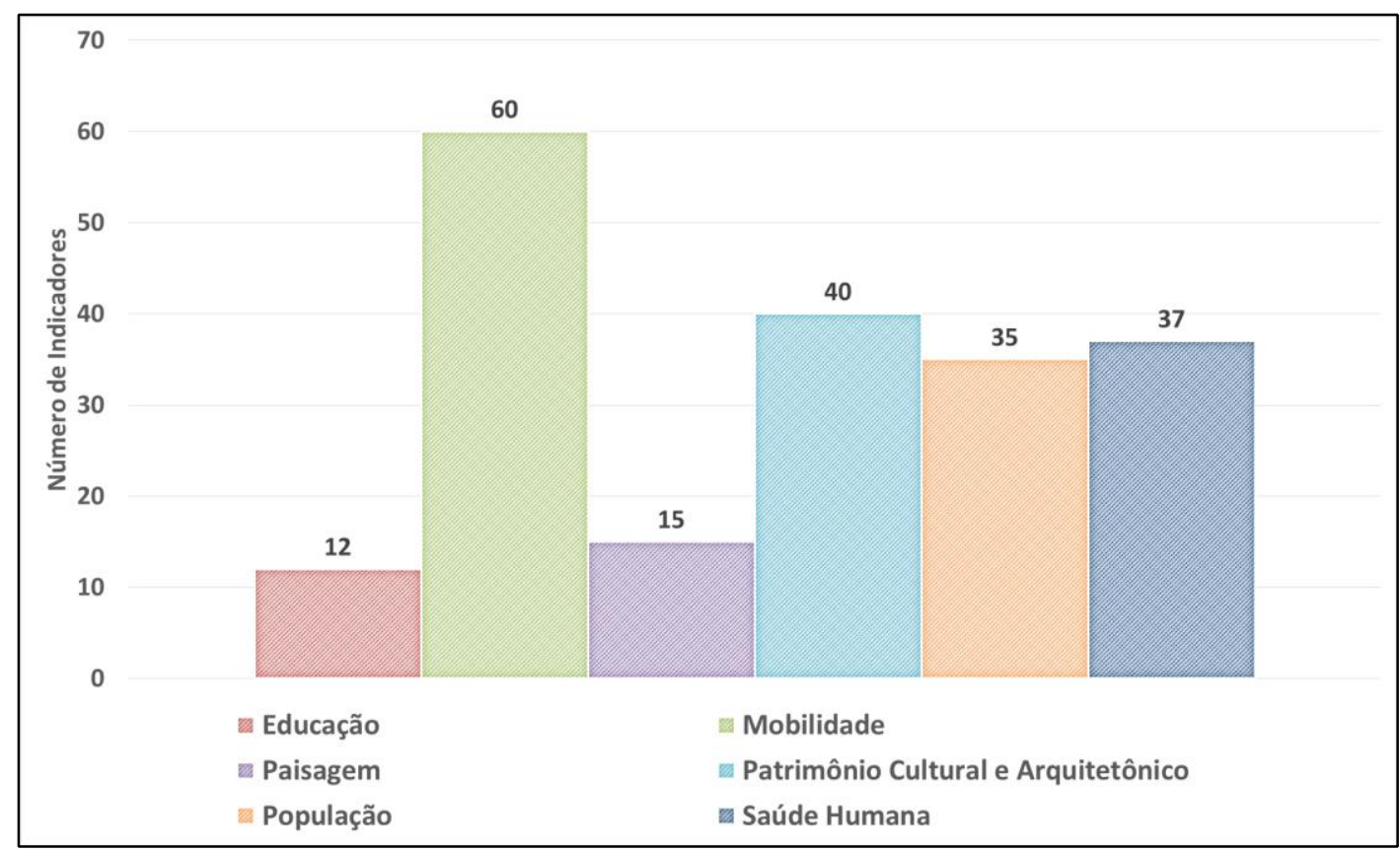

Gráfico 5 - Distribuição dos indicadores da dimensão social

\section{Indicadores da Dimensão Econômica}

A Dimensão Econômica apresenta a menor expressividade no total coletado, são 92 Indicadores de AAE, Gráfico 6, distribuídos pelos seguintes Temas:

$\checkmark$ Bens Materiais: se refere a novos e existentes desenvolvimentos que favoreçam a infra-estrutura logística existente;

$\checkmark$ Emprego: procura identificar e monitorar a relação entre emprego e desemprego, além da ocupação destes por setores da economia;

$\checkmark$ Habitação: identificar e monitorar os novos desenvolvimentos em habitação, bem como as condições de moradia;

- Uso do Solo: trata-se essencialmente do levantamento de informações sobre a localização e tipologias de uso do solo. 


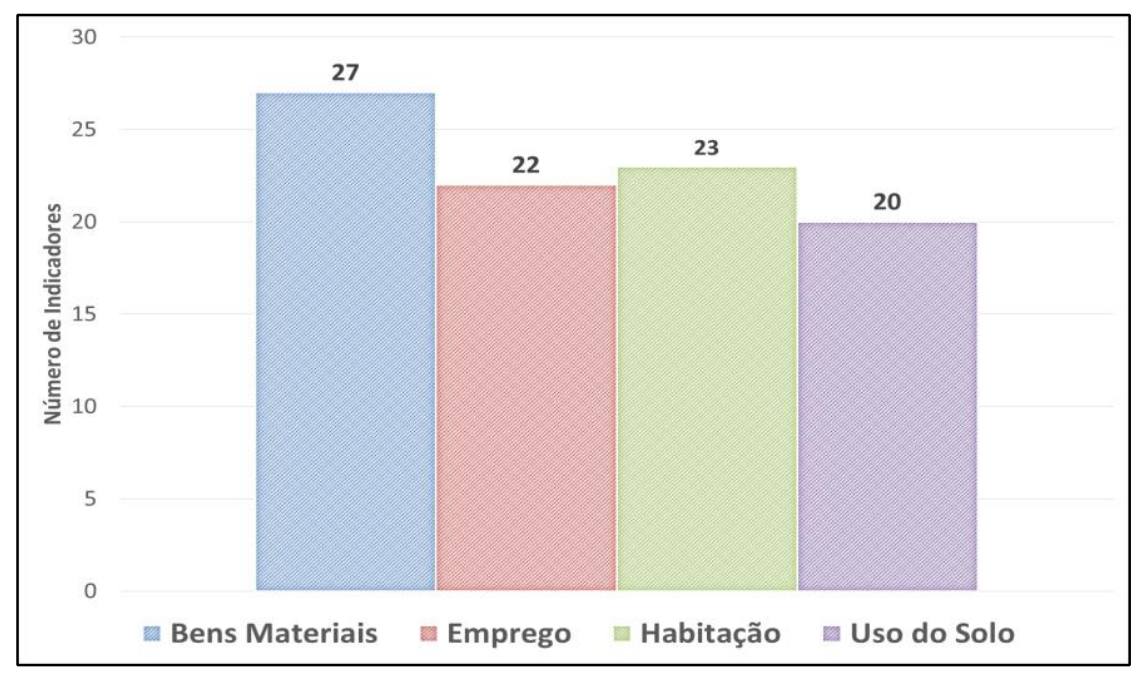

Gráfico 6 - Distribuição dos indicadores da dimensão econômica.

Torna-se importante destacar que a definição dos Temas elencados para cada dimensão, foram propostos com base nas referências bibliográficas que orientaram a organização procedimental desta etapa, mas principalmente nas características dos indicadores coletados, ou seja, as definições dos temas foram construídas tendo como princípio representar as características dos grupos de indicadores mais recorrentes.

\section{Descrição dos indicadores de AAE mais recorrentes}

As Tabelas 3, 4 e 5 a seguir descrevem de forma detalhada as características dos Indicadores de AAE recorrentes. Para tal, destacam, respectivamente, as dimensões Ambientais, Sociais e Econômicas - os seus respectivos "Temas" e a descrição detalhada dos agrupamentos com maior recorrência no campo "Aspectos". A Figura X apresenta o esquema utilizado para a organização das tabelas mencionadas.

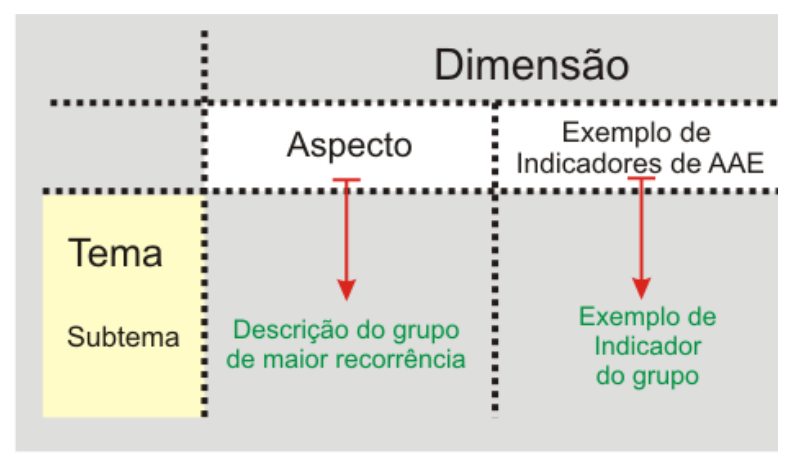

Figura 25- distribuição das informações nas tabelas 3, 4 e 5. 
Tabela 3 - Descrição dos indicadores da Dimensão Ambiental

\begin{tabular}{|c|c|c|c|}
\hline & Temas & & Exemplo de Indicadores de \\
\hline & Subtemas & & $\boldsymbol{A} A \boldsymbol{E}$ \\
\hline & 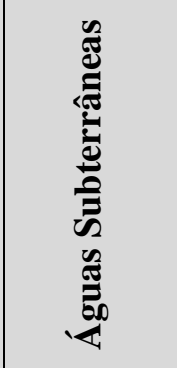 & $\begin{array}{l}\text { Seis (6) dos } 12 \text { indicadores coletados, procuram } \\
\text { averiguar questões acerca dos padrões e de } \\
\text { mudanças no nível de qualidade das águas dos } \\
\text { aquíferos, além de questões relativas à } \\
\text { disponibilidade hídrica e áreas de recarga. }\end{array}$ & $\begin{array}{l}\text { - Áreas de vulnerabilidade de } \\
\text { contaminação de aquíferos; } \\
\text { - Mudanças nos níveis de } \\
\text { qualidade de água } \\
\text { subterrânea; } \\
\text { - Níveis de qualidade de água } \\
\text { dos aquíferos. }\end{array}$ \\
\hline & 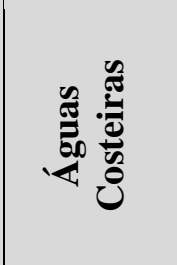 & $\begin{array}{c}\text { Toda as quatro (4) aplicações apresentam } \\
\text { questionamentos sobre a qualidade e condições } \\
\text { de espécies aquáticas. }\end{array}$ & $\begin{array}{l}\text {-Taxa de } \\
\text { conservação/condição } \\
\text { favoráveis de espécies } \\
\text { aquáticas (Mexilhões e } \\
\text { Salmão). }\end{array}$ \\
\hline 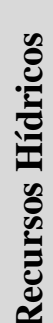 & 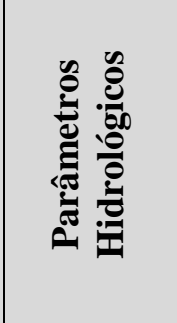 & $\begin{array}{c}\text { Das sete (7) aplicações, cinco (5) se referem a } \\
\text { preocupações relativas a quantidade do fluxo de } \\
\text { água e das características gerais dos cursos } \\
\text { d'água. }\end{array}$ & $\begin{array}{l}\text { - Consumo de água per } \\
\text { capita; } \\
\text { - Níveis de escoamento } \\
\text { superficial; } \\
\text { - Nível médio do fluxo de } \\
\text { água; }\end{array}$ \\
\hline & 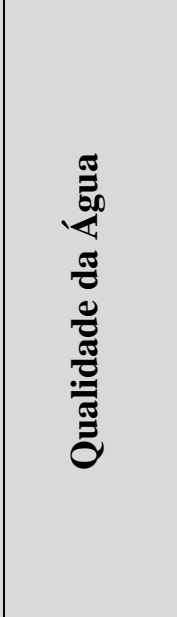 & $\begin{array}{c}\text { Todas as } 23 \text { aplicações inferem sobre a } \\
\text { observação de parâmetros físico-químicos e } \\
\text { bióticos da qualidade da água ao longo de um } \\
\text { determinado período. } \\
\text { Também se preocupa em identificar situações de } \\
\text { poluição e ou degradação em virtude de uma } \\
\text { atividade. }\end{array}$ & $\begin{array}{l}\text { - Níveis de qualidade química } \\
\text { e biológica da água; } \\
\text { - Qualidade física e biótica } \\
\text { dos corpos d'água; } \\
\text { - Mudanças em parâmetros de } \\
\text { qualidade de água durante o } \\
\text { período de implementação; } \\
\text { - Avaliação Biótica qualidade } \\
\text { das águas de rios; } \\
\text { - Nível de poluição das águas } \\
\text { - DBO - produtos de óleos - } \\
\text { Metais pesados. }\end{array}$ \\
\hline & & & \\
\hline
\end{tabular}




\begin{tabular}{|c|c|c|c|}
\hline \multicolumn{2}{|r|}{ } & \multirow[b]{2}{*}{$\begin{array}{l}\text { Apesar da heterogeneidade das } 37 \text { aplicações, há } \\
\text { um conjunto de } 18 \text { indicadores que de modo } \\
\text { geral procuram tratar sobre a qualidade e } \\
\text { preservação da biodiversidade do ambiente. } \\
\text { Por exemplo: ao verificar o número de espécies } \\
\text { e/ou habitats em estado de preservação, a } \\
\text { existência e condições de habitats únicos e, } \\
\text { principalmente, sobre a qualidade/condições da } \\
\text { biodiversidade das áreas verdes e protegidas. }\end{array}$} & \multirow[b]{2}{*}{$\begin{array}{c}\text {-Número de Espécies em } \\
\text { estado de proteção ou } \\
\text { preservação; } \\
\text {-Número e extensão de } \\
\text { ecossistemas fragmentados; } \\
\text {-\% De habitats únicos e } \\
\text { espécies perdida em locais } \\
\text { não designados durante a vida } \\
\text { útil do Plano; } \\
\text {-Número e tipo de espécies } \\
\text { com potencial de perda em } \\
\text { relação a novos } \\
\text { desenvolvimentos; } \\
\text { - Total de sítios de vida } \\
\text { silvestre perdida /vs/ área } \\
\text { recuperada; } \\
\text {-Porcentagem das áreas de } \\
\text { conectividade de } \\
\text { biodiversidade resultante da } \\
\text { ação estratégica. }\end{array}$} \\
\hline & 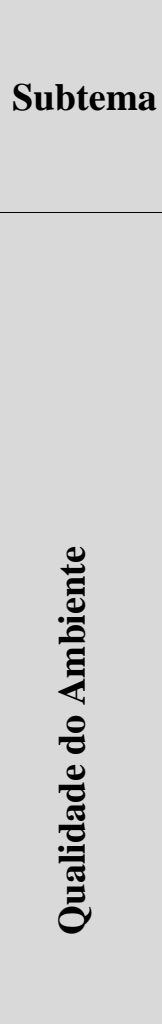 & & \\
\hline 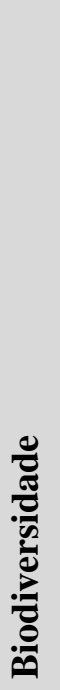 & 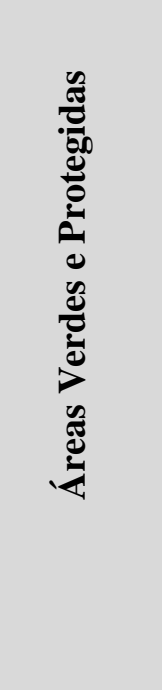 & $\begin{array}{l}\text { Quatorze (14) das } 25 \text { aplicações procuram } \\
\text { representar uma quantificação da extensão de } \\
\text { áreas verdes e protegidas. Ou seja, buscam, } \\
\text { principalmente, contabilizar a extensão do total } \\
\text { de áreas verdes e/ou sob proteção especial (Como } \\
\text { por exemplo APP, RPPN, reservas florestas), a } \\
\text { identificação de áreas verdes e de uso comum na } \\
\text { cidade e também, monitorar o incremento ou } \\
\text { diminuição do total destas áreas. }\end{array}$ & $\begin{array}{l}\text {-Total de terras ambientais } \\
\text { especialmente protegidas (ha) } \\
\text {-Proporção de áreas naturais } \\
\text { e selvagens aumentadas; } \\
\text {-Número e extensão de áreas } \\
\text { protegidas; } \\
\text {-Total de Áreas verdes } \\
\text { recuperadas /por/ total de } \\
\text { áreas a serem recuperadas; } \\
\text {-Total de áreas verdes - \% Da } \\
\text { área municipal / capita. }\end{array}$ \\
\hline
\end{tabular}




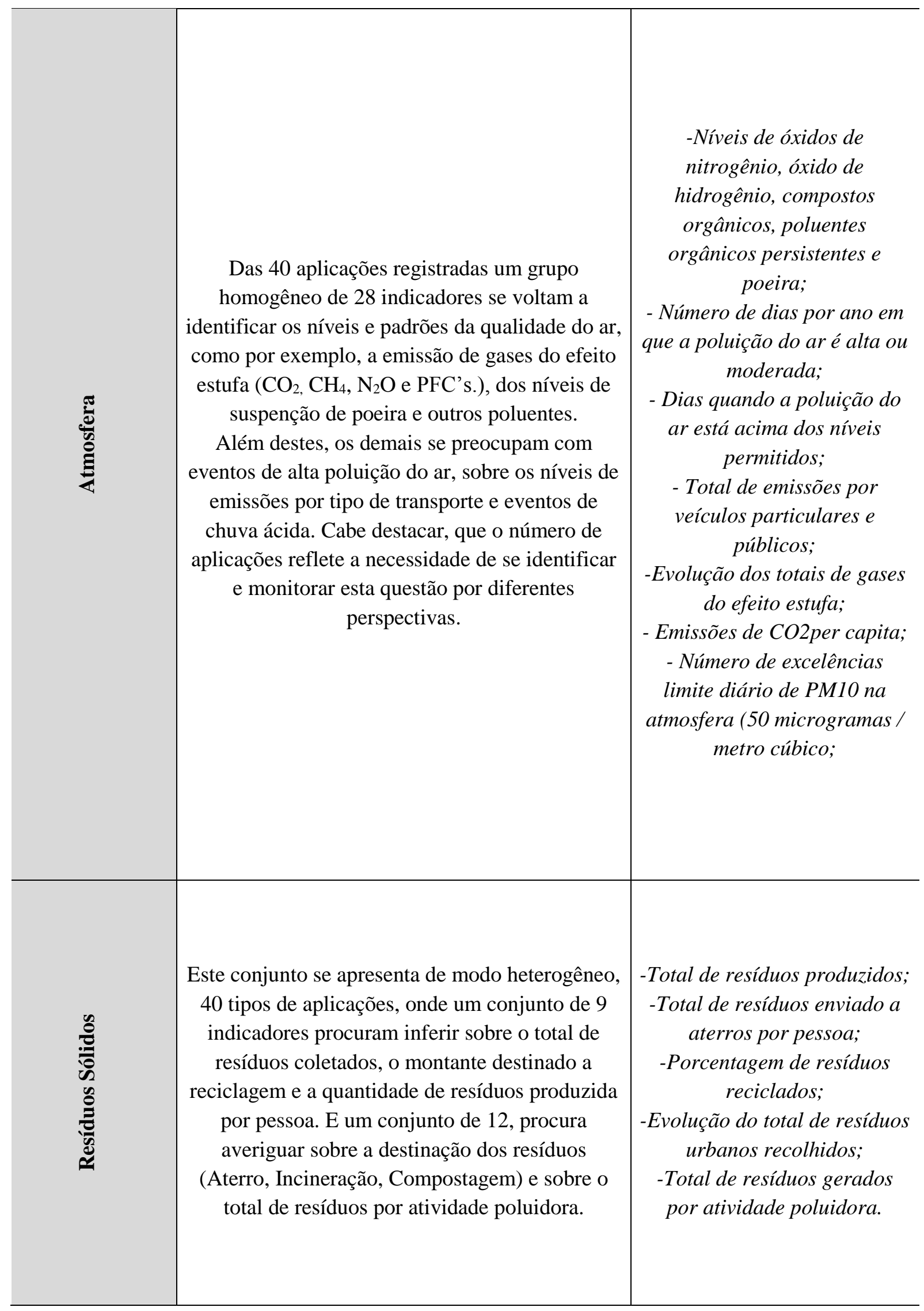




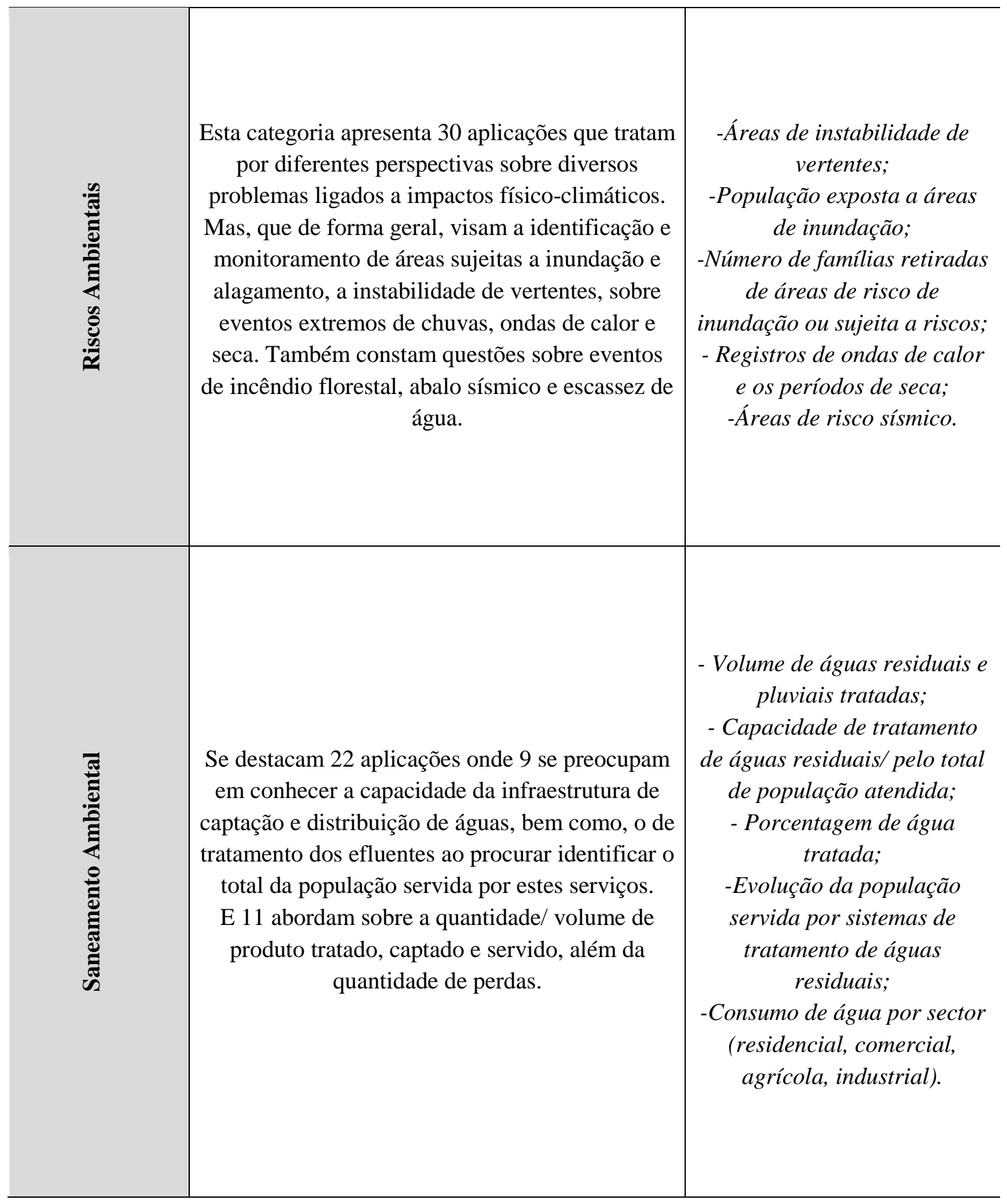




\begin{tabular}{|c|c|c|}
\hline 응 & $\begin{array}{l}\text { Dez (10) das } 19 \text { das aplicações procuram } \\
\text { identificar a localização de áreas contaminadas e } \\
\text { bem como os níveis de poluição destas. } \\
\text { Especificamente: A proximidade destas áreas as } \\
\text { de novos desenvolvimentos; O número de } \\
\text { incidentes relacionados; e o total de áreas } \\
\text { contaminadas. }\end{array}$ & $\begin{array}{l}\text {-Total de áreas contaminadas; } \\
\text {-Nível de contaminação do } \\
\text { solo; } \\
\text {-Número de terrenos } \\
\text { contaminados e ou } \\
\text { potencialmente; } \\
\text {-Área de territórios altamente } \\
\text { poluídas (ha, porcentagem). }\end{array}$ \\
\hline
\end{tabular}

Tabela 4- Descrição dos indicadores da abordagem Social

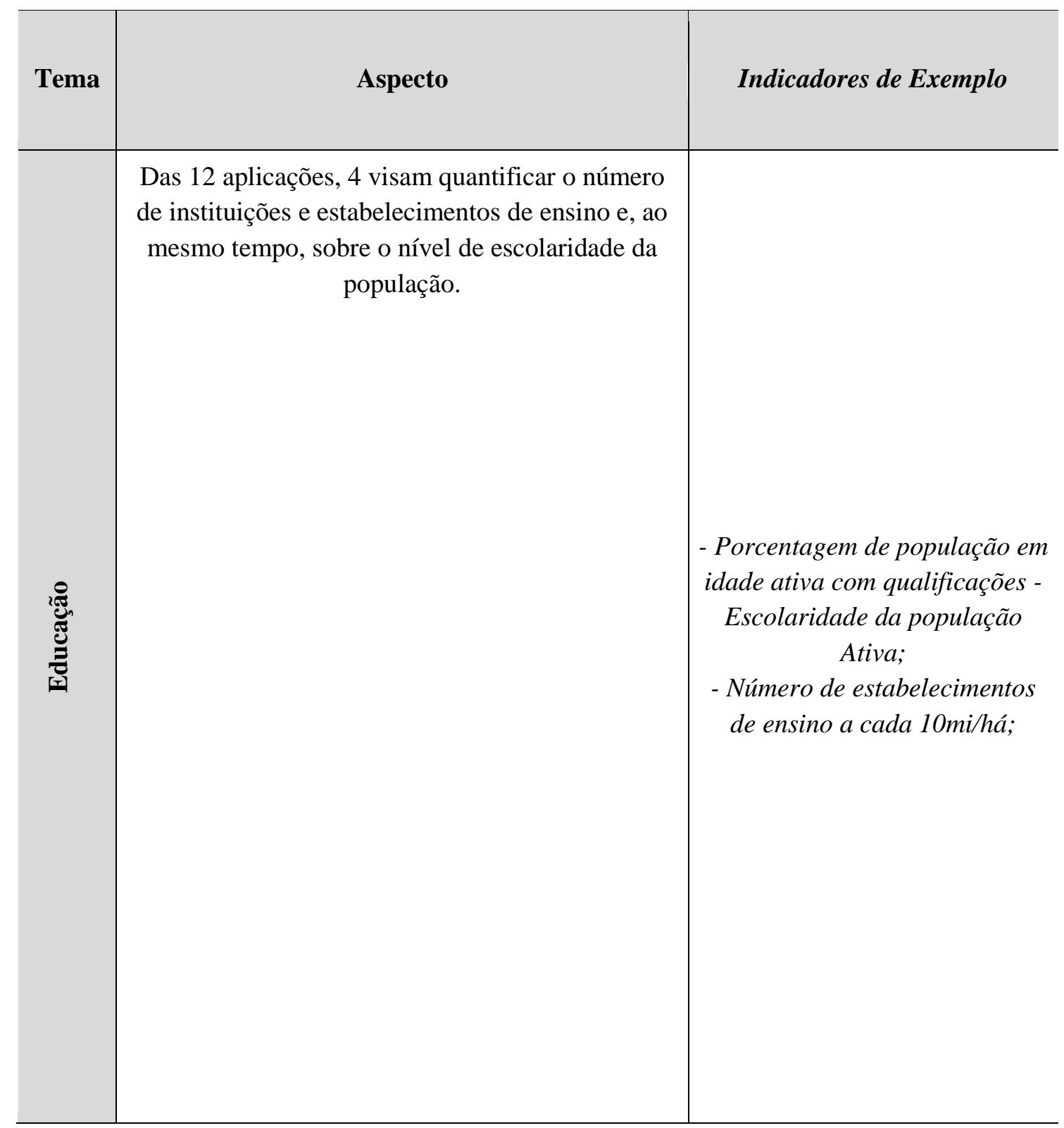




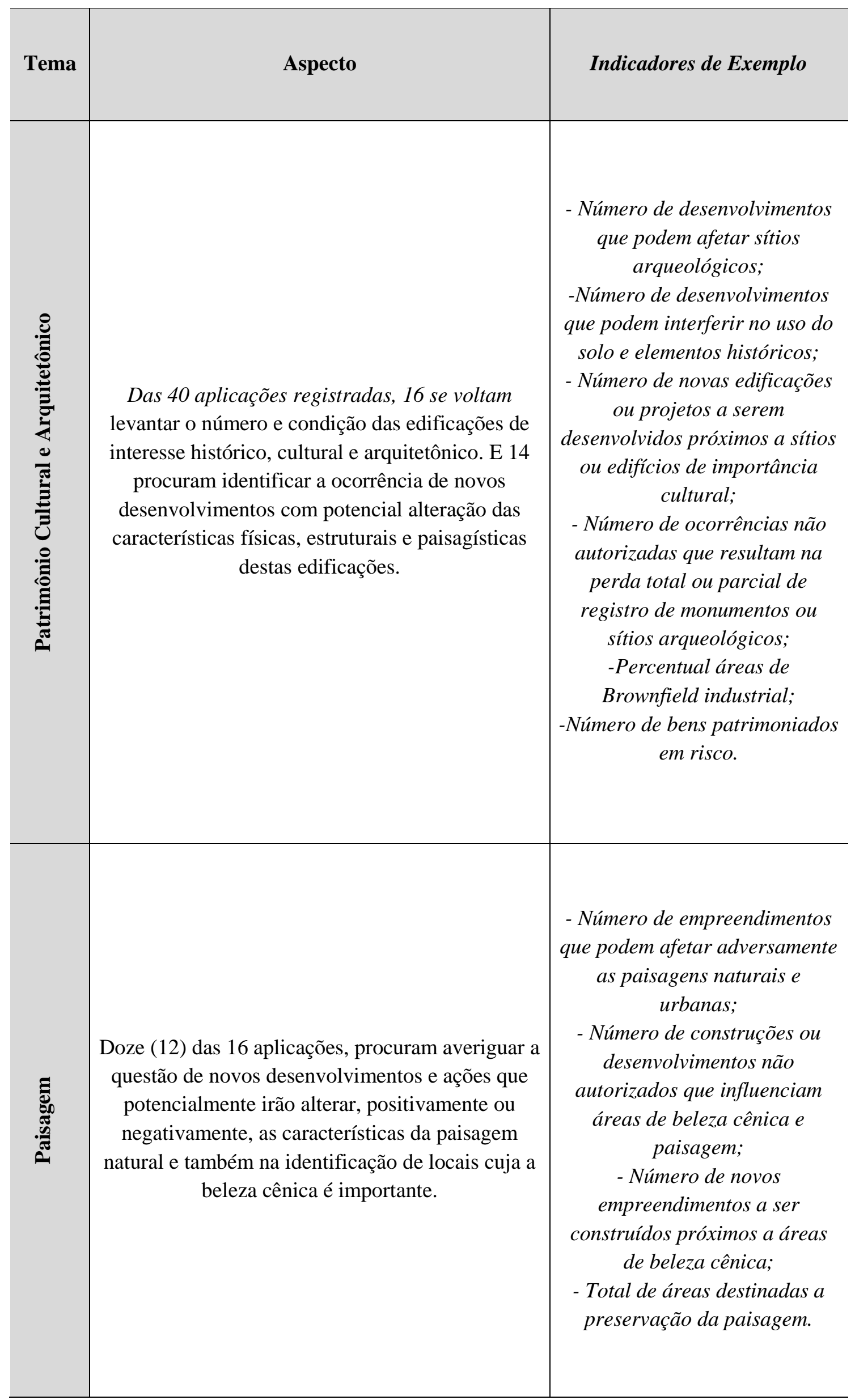




\begin{tabular}{|c|c|c|}
\hline Tema & Aspecto & Indicadores de Exemplo \\
\hline 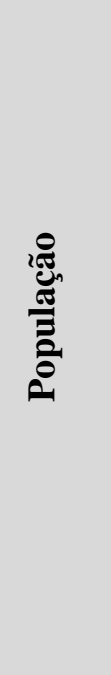 & $\begin{array}{l}\text { Este conjunto contêm } 35 \text { aplicações e se organiza } \\
\text { em três grupos principais onde: Doze (12) } \\
\text { procuram levantar o número de habitantes } \\
\text { residentes, seja de forma geral ou por faixa etária; } \\
\text { Cinco (5) ligados a densidade habitacional por área } \\
\text { (Zona ou Bairro); e Oito (8) procuram averiguar a } \\
\text { evolução do número de habitantes ao longo do } \\
\text { tempo. Nestes conjuntos, se destacam a } \\
\text { averiguação de questões especificas, como por } \\
\text { exemplo, identificar o número de estudantes, os } \\
\text { estrangeiros, a população flutuante e até questões } \\
\text { mais especificas como variação da densidade por } \\
\text { área. }\end{array}$ & $\begin{array}{c}\text {-Total da população residente } \\
\text { por faixa etária; } \\
\text {-Total da população; } \\
\text {-Pirâmide etária atual e } \\
\text { histórica; } \\
\text {-A densidade populacional - } \\
\text { prevista e atual; } \\
\text {-Total da população Flutuante; } \\
\text {-Total da população } \\
\text { estrangeira; } \\
\text {-Histórico/mudanças de } \\
\text { Densidade e total da população. }\end{array}$ \\
\hline 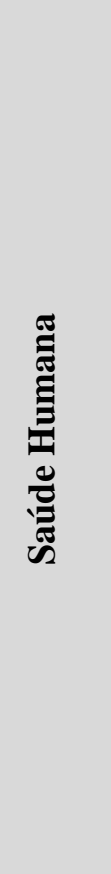 & $\begin{array}{l}\text { O conjunto se apresenta um total de } 35 \text { aplicações, } \\
\text { onde cinco (5) visam levantar a infraestrutura } \\
\text { presente voltada a serviços de saúde. Quinze (15) } \\
\text { em compreender situações e eventos específicos, } \\
\text { como por exemplo, taxas de mortalidade, número } \\
\text { de acidentes em estradas, as reincidências de } \\
\text { epidemias, os casos de doenças respiratórias, a } \\
\text { mortalidade por tipo de enfermidade e entre } \\
\text { outros. } \\
\text { E sete (7) em verificar níveis de criminalidade, } \\
\text { especificamente a taxa de roubo por habitante e a } \\
\text { percepções sobre o medo da criminalidade. }\end{array}$ & $\begin{array}{c}\text { - Mortalidade por Doenças } \\
\text { Respiratórias e Cardíacas; } \\
\text {-As taxas de mortalidade por } \\
\text { doenças do aparelho } \\
\text { circulatório, câncer, acidentes e } \\
\text { suicídios; } \\
\text {-Número de doenças atribuíveis } \\
\text { à poluição transporte; } \\
\text {-Número de Médicos e } \\
\text { enfermeiros por } 1000 \text { hab; } \\
\text { - Total de Centros de Saúde; } \\
\text { - Número acidentes rodoviários } \\
\text { por ano; } \\
\text { - violência contra a pessoa, } \\
\text { habitação e veículos (taxa por } \\
1000 \text { população); } \\
\text { - Crime e medo do crime. }\end{array}$ \\
\hline & & \\
\hline
\end{tabular}




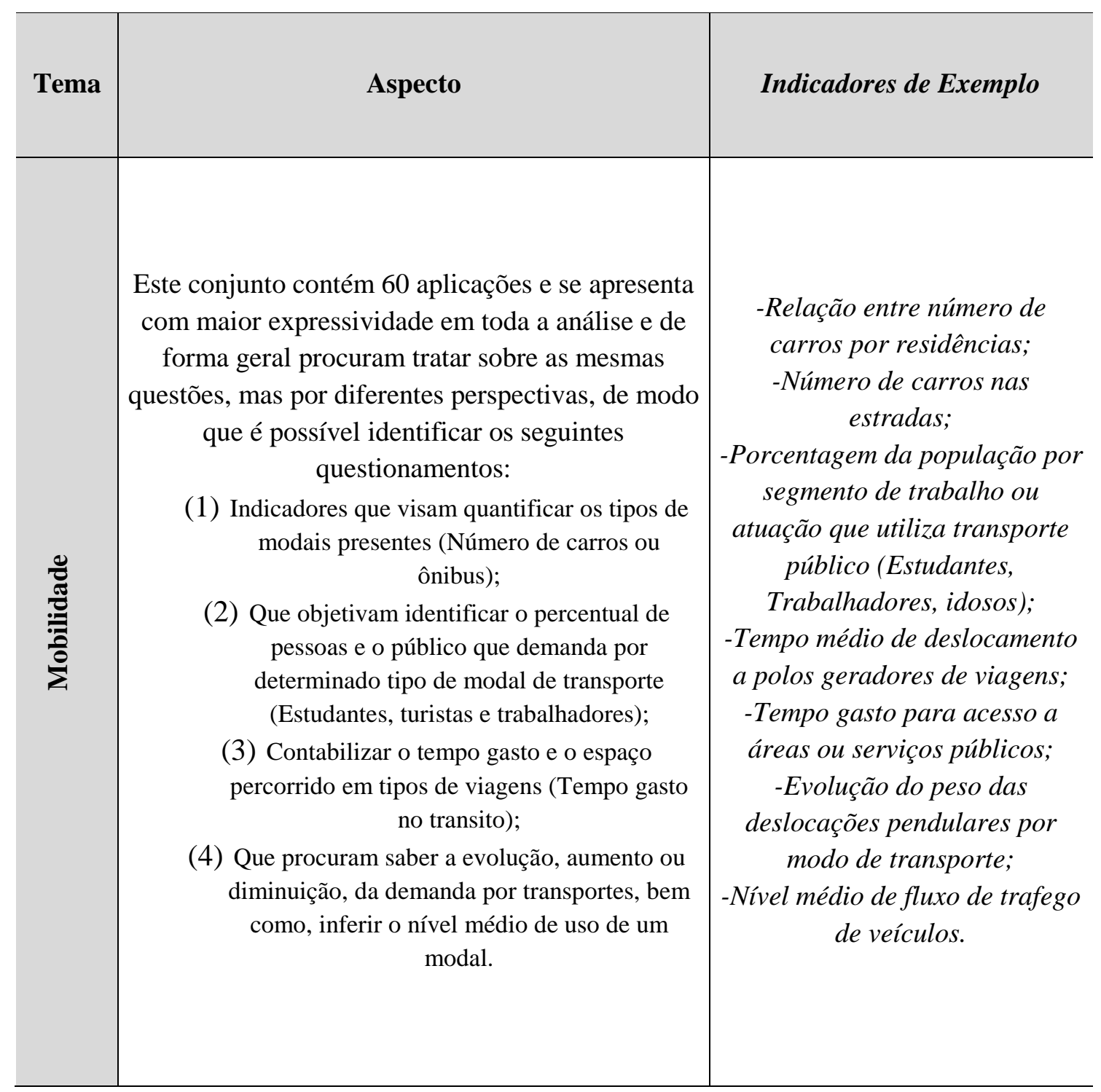


Tabela 5 - Descrição dos indicadores da abordagem econômica

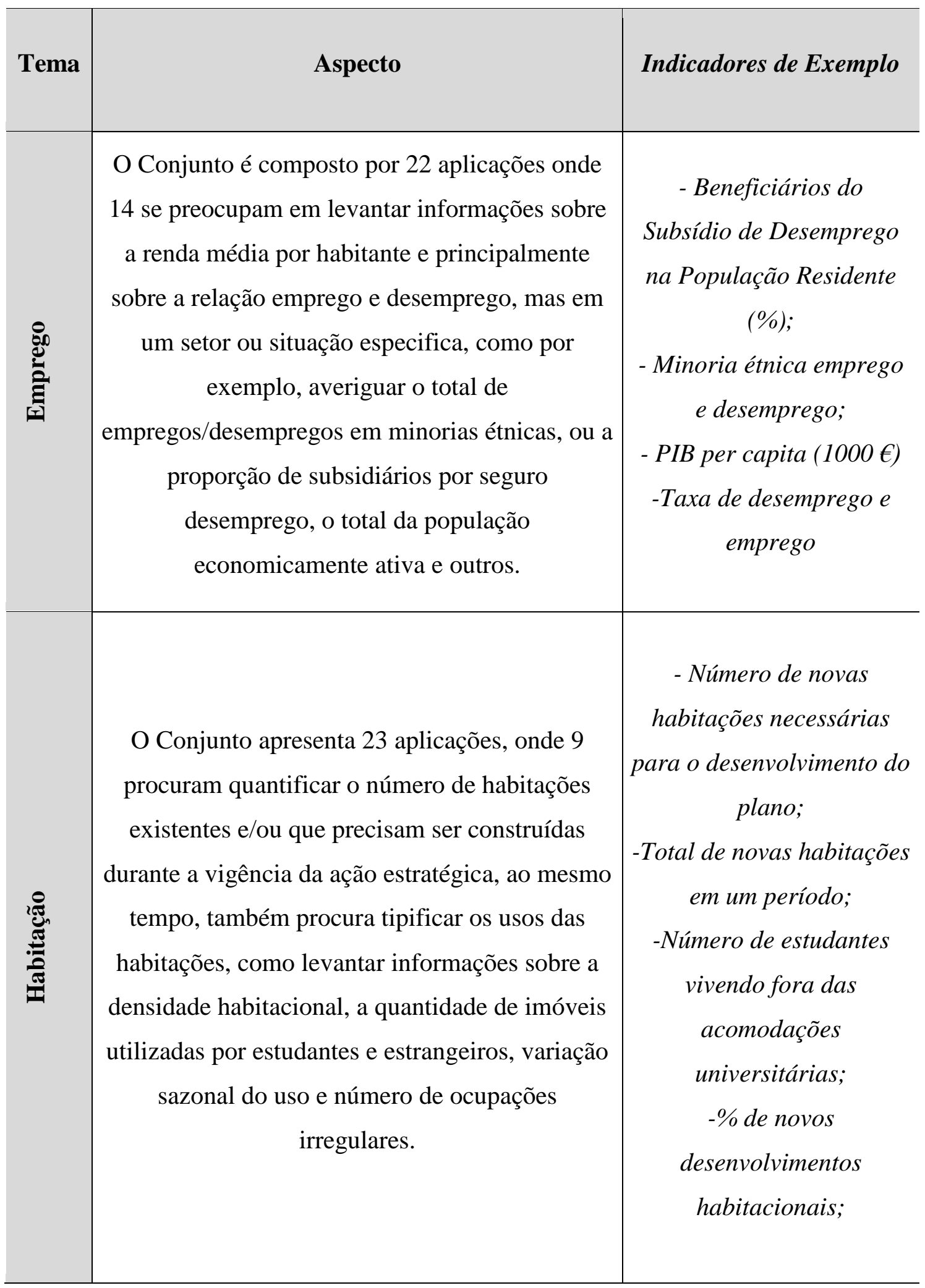




\begin{tabular}{|c|c|c|}
\hline Tema & Aspecto & Indicadores de Exemplo \\
\hline 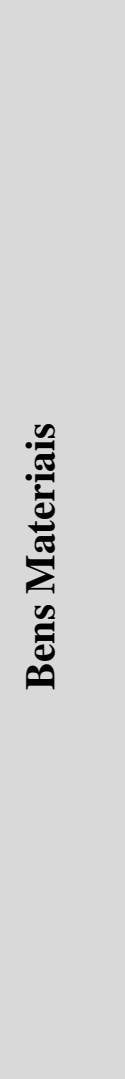 & $\begin{array}{l}\text { Este grupo contêm } 27 \text { aplicações, onde } 13 \\
\text { procuram levantar essencialmente informações } \\
\text { sobre quais as infraestruturas existentes e } \\
\text { também averiguar a previsão de novos } \\
\text { desenvolvimentos em infraestrutura (Logística, } \\
\text { Transporte e produção de energia elétrica), bem } \\
\text { como valorar os gastos previstos. E quatro a } \\
\text { saber o Total de energia elétrica consumida (por } \\
\text { localidade ou setor da economia. }\end{array}$ & $\begin{array}{c}\text {-Extensão em Km's de } \\
\text { novas vias rodoviárias } \\
\text { previstas; } \\
\text { - Novas estruturas e } \\
\text { concessões - Estradas / } \\
\text { viadutos / linhas férreas } \\
\text { de transporte público e } \\
\text { rodoviário; } \\
\text { - Total de Investimento em } \\
\text { novas vias de } \\
\text { comunicação. } \\
\text {-Consumo de energia } \\
\text { elétrica por setor } \\
\text { (doméstico, indústria, } \\
\text { terciário, etc.) }\end{array}$ \\
\hline 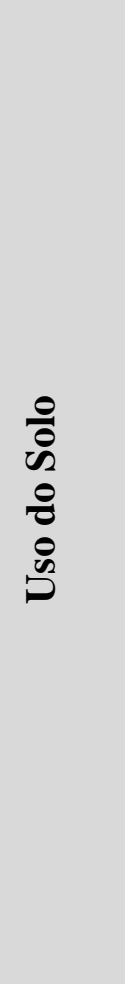 & $\begin{array}{c}\text { O conjunto de } 20 \text { aplicações busca } \\
\text { essencialmente espacializar os tipos de uso do } \\
\text { solo no sentido de identificar suas formas de } \\
\text { ocupação, como por exemplo, a espacialização } \\
\text { de infraestruturas logísticas, áreas industriais } \\
\text { abandonadas, vazios urbanos, espaços verdes, } \\
\text { prédios e etc. }\end{array}$ & $\begin{array}{c}\text {-Zoneamento urbano atual } \\
\text { - alocação e localização } \\
\text { das zonas; } \\
\text {-Espacialização da } \\
\text { Ocupação urbana - áreas } \\
\text { industriais, comercio, } \\
\text { lazer, Tecido descontinuo } \\
\text { e infraestruturas } \\
\text { logísticas; } \\
\text { - Variação dos Padrões de } \\
\text { Ocupação do Solo; } \\
\text { - Espacialização da } \\
\text { Ocupação Urbana do Solo } \\
\text { por tipologia de serviço. }\end{array}$ \\
\hline
\end{tabular}


As Figuras 26, 27 e 28 a seguir, ilustram de modo simplificado o detalhamento descrito na coluna "Aspecto" de cada "Tema" das tabelas acima.

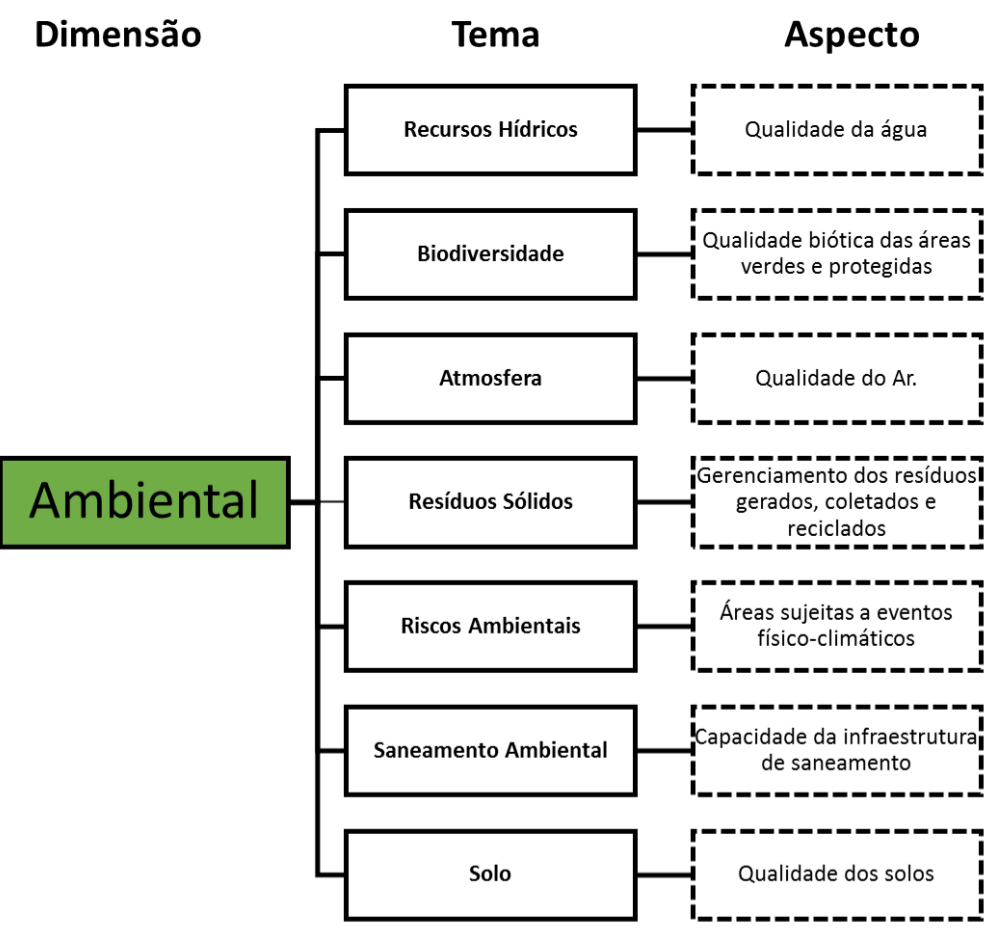

Figura 26 - Descrição simplificada da estrutura de organização dos indicadores na dimensão Ambiental

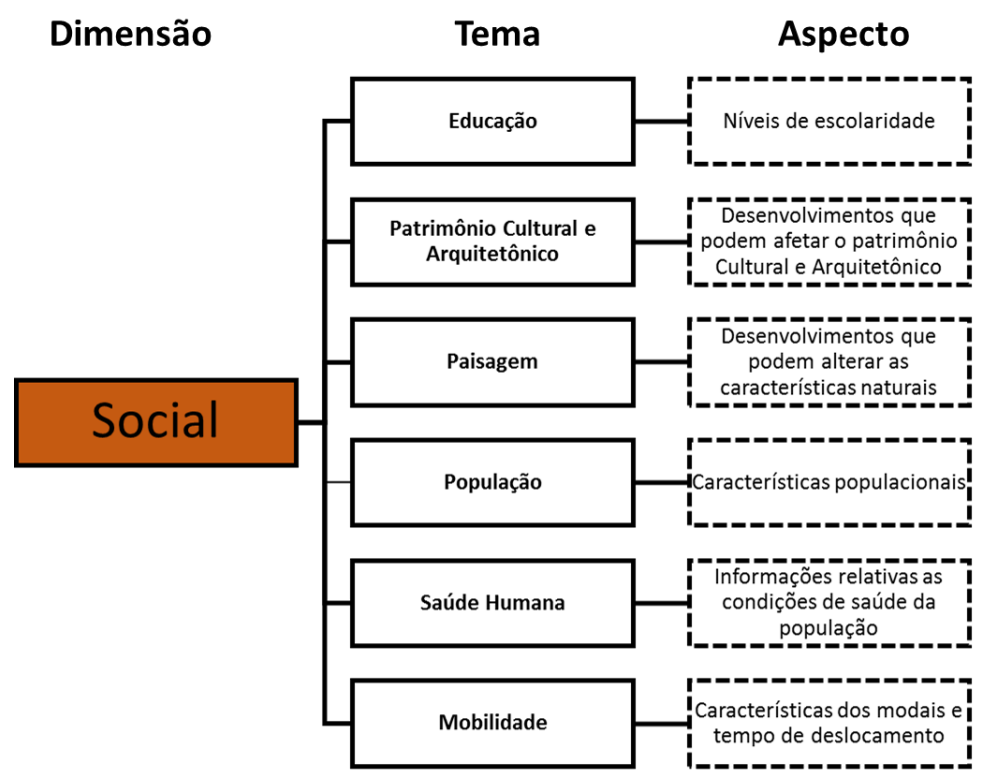

Figura 27 - Descrição simplificada da estrutura de organização dos indicadores na dimensão Social 


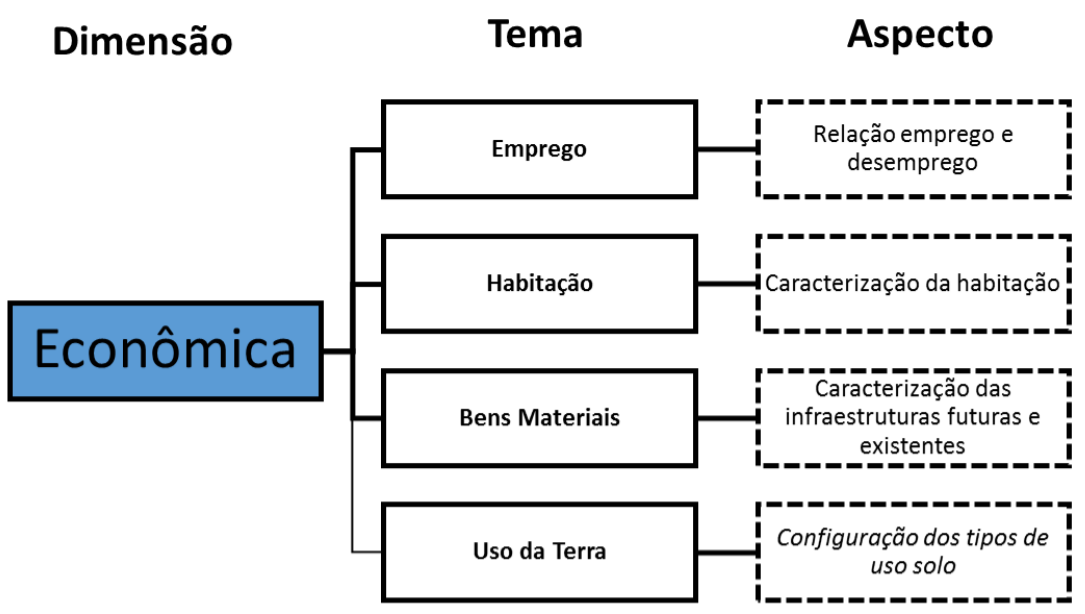

Figura 28 - Descrição simplificada da estrutura de organização dos indicadores na dimensão Econômica

\section{Pontos importantes a serem destacados:}

\section{A relação entre numero de indicadores e a confluência de dimensões e temas.}

É preciso reforçar que esta análise não tem a pretensão de demonstrar as características da prática corrente por meio de um viés estatístico, mas sim discorrer obre as características de uma parcela especifica da prática de aplicação da AAE para o planejamento do uso do solo e/ou desenvolvimento urbano.

Assim, ao observar-se a figura x, sobre o número de indicadores por dimensão, é possível verificar que grande parte do total de indicadores amostrados se encontra direcionado à dimensão ambiental, seguidos pelas dimensões social e econômica. Tal desproporção revela a importância relativa desta dimensão frente às demais, sugerindo confirmar os objetivos da AAE de promover a variável ambiental na tomada de decisão.

Ao analisarmos esta diferenciação entre o número de indicadores coletados pelos temas específicos de cada dimensão é possível identificar traços específicos da aplicação da AAE voltada ao Planejamento do Uso do Solo, como ilustram os gráficos a seguir. 


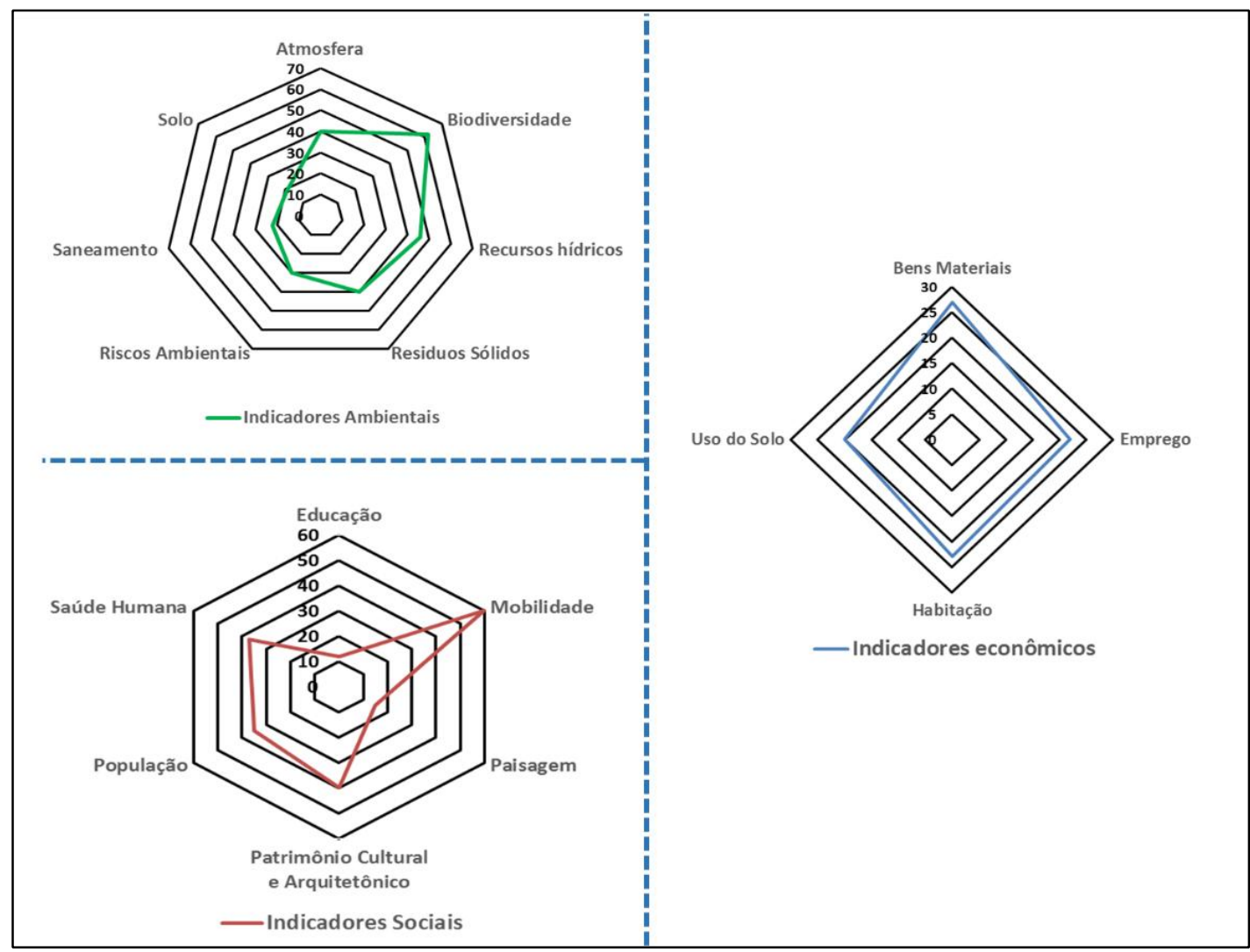

Gráfico 7 - Direcionamento temático dos Indicadores de AAE coletados.

Verifica-se, por exemplo, que os indicadores direcionados à dimensão ambiental, indicam a maior relevância dos temas Biodiversidade, Recursos Hídricos e, de modo equilibrado, Atmosfera e Resíduos Sólidos, o que sugere a importância destes frente aos demais temas. Por sua vez, em relação à dimensão social a questão da Mobilidade aparece como prioritária, seguidamente do tema Patrimônio Cultural e Arquitetônico, ao mesmo tempo, que os temas relativos à Saúde Humana e População aparecem de forma equiparada.

Para a dimensão econômica, verifica-se pouca variação para os indicadores por tema. Por outro lado, ainda que se considere que naturalmente os planos e programas voltados para o uso do solo e desenvolvimento urbano integrem os aspectos econômicos entre seus objetivos, verifica-se que ainda assim a AAE encontra oportunidade para a incorporação de indicadores voltados para este pilar da sustentabilidade, sobretudo considerando-se a sua relação com os demais temas e indicadores.

Observando-se as Tabelas 3, 4 e 5 é possível verificar na coluna que indica a descrição do "Aspecto" a quantidade de indicadores que possibilitaram a definição do conjunto, ao mesmo tempo, se percebe que houve indicadores que se encontravam desassociados dos demais e que não contribuíram para homogeneizar o conjunto de aspectos já identificados ou mesmo 
formular outro conjunto. Esta situação foi verificada para indicadores relacionados a temas como Resíduos Sólidos, Mobilidade e Habitação.

Assim, a heterogeneidade ou homogeneidade encontrada nos conjuntos de indicadores dos "Aspectos" em cada Tema sugere uma necessidade dos processos avaliativos em procurar tratar, ao mesmo tempo, de várias questões por diferentes perspectivas.

Por outro lado, é importante destacar que o processo de configuração de um “Aspecto", conforme a estrutura hierárquica utilizada, é na verdade a reunião de um conjunto de Indicadores de AAE com similaridades o suficientes para formular um determinado "Aspecto" ou seja, sua definição depende do conjunto de indicadores levantados.

Finalmente, considera-se que as evidências geradas cumprem com o objetivo da análise, ou seja, representam as características recorrentes dos Indicadores de AAE empregados em AAEs aplicada ao planejamento do uso do solo e/ou desenvolvimento urbano. Estes indicadores, portanto, devem ser compreendidos como os mais substanciais para as etapas dos processos de AAE.

Entende-se também que o conjunto de "Aspectos" descrito para cada "Tema" reflete quais questões necessitam ser desenvolvidas nas avaliações. Desta maneira, refletem de maneira geral quais objetivos os processos de AAE estabelecem para serem alcançados.

Por fim, alinhado à discussão realizada por Gao (2013) sobre a capacidade de comunicação dos indicadores nos processos de AAE, pode-se assumir que a prática da AAE tem revelado que é necessário discutir com os Stakeholders envolvidos na AAE para o planejamento do uso do solo e/ou o desenvolvimento urbano, aspectos relativos a Mobilidade, Atmosfera, Saneamento Ambiental, Patrimônio Cultural e Arquitetônico, Uso do Solo, Riscos Ambientais, Resíduos Sólidos, Saúde Humana e os demais aspectos detalhados nas tabelas acima.

Assim, de maneira consoante ao sistema de indicadores proposto por Wang (2013), os aspectos descritos têm potencial para servir de referência para a elaboração de sistemas de indicadores para esta modalidade de aplicação da AAE, porque sugere de forma direta questões primordiais a serem tratadas e também a utilização de indicadores que permitam a avaliação, o monitoramento, a definição de objetivos e metas.

Outro ponto de destaque é que este pode servir de norte para futuras construções de indicadores de AAE, de modo a evitar problemas semelhantes ao alertado por Ezequiel \& Ramos (2011) em que o potencial dos indicadores na AAE não é totalmente utilizado.

A literatura destaca que a promoção da sustentabilidade por meio a AAE encontra respaldo no fato do instrumento discutir questões de âmbito ambiental, social e econômico no momento do planejamento de ações estratégicas voltadas à proteção ambiental e/ou a 
sustentabilidade (DESMOND, 2007; FISCHER, 2007). A capacidade de promoção da sustentabilidade está no foco estratégico desenvolvido pela $\mathrm{AAE}$, de modo que o que determina o sucesso da avaliação é muito mais uma circunstância particular de apropriação do instrumento pela ação estratégica do que um fator metodológico (WALLINGTON, 2007).

Neste sentido, existe uma relação entre a forma estratégica que AAE pode ser apropriada e o contexto ou circunstância que ela se desenvolve, sendo assim, em um contexto favorável à apropriação estratégica da $\mathrm{AAE}$ o detalhamento dos aspectos mais recorrentes dos indicadores de AAE tem grande potencial para a promoção da sustentabilidade. 


\section{ANÁLISE DE CASOS SELECIONADOS: O PROCESSO DE SCOPING} NA AAE.

A etapa de Scoping da Avaliação Ambiental Estratégica é apontada como uma das etapas fundamentais para o processo de avaliação, pois é neste momento em que se estabelecem os objetivos, temas, indicadores e procedimentos a serem aplicados na avaliação. $\mathrm{O}$ arcabouço teórico estabelecido para orientar o presente trabalho indica que a etapa de scoping também é, ela mesma, sujeita ao contexto em que a AAE ocorre, incorporando diferentes procedimentos e agentes que variam conforme a abordagem metodológica aplicada na construção da AAE.

Tal fato reforça as considerações já referenciadas por Fischer (2007) e Lobos \& Partidário (2014) sobre o distanciamento entre as concepções teóricas e a construção prática da AAE. Assim, a presente análise volta-se para a verificação da prática corrente da AAE no que diz respeito à etapa de Scoping. O intuito é compreender o papel desempenhado pelos diversos elementos que compõem esta etapa.

A partir do estabelecimento do arcabouço conceitual que orienta a análise pretendida, partiu-se para a verificação de seu alinhamento aos casos selecionados. Ao final desta etapa foi possível estabelecer a síntese do que representa a etapa de Scoping em AAE e os principais elementos encontrados nos casos analisados, que orientam o estabelecimento de objetivos, indicadores e por meio de um diagrama.

Para isso, o trabalho se desenvolveu nas etapas dispostas na Figura 29, a seguir. 
Critérios de seleção e análise dos casos.

-Definição dos critérios para seleção e análise dos casos

Descrição dos casos selecioanados

-Descrição dos critérios de analise em cada caso.

Caracterização do Scoping segundo a prática

- Caracterização dos elementos essenciais para o desenvolvimento da etapa

de Scoping e elaboração de um diagrama síntese representativo dos casos

da prática.

Discussão dos aspectos conceituais e práticos para a

formulação do scoping.

-Discusões entre aspectos identificados em casos da prática e os aspectos

conceituais e metodológicos destacados na literatura sobre e a elaboração

do diagrama síntese da etapa de Scoping que represente ambos os

aspectos.

Figura 29 - Procedimentos aplicados à análise da etapa scoping.

\section{Critérios de seleção e análise dos casos}

Para alcançar os objetivos desta etapa pretendia-se trabalhar com um estudo de AAE de cada país dentre os 15 relatórios selecionados anteriormente. Devido à necessidade de acesso a um maior detalhamento sobre o desenvolvimento de cada etapa processual da avaliação e também acesso a documentos complementares, optou-se por descartar os casos italianos de AAE. Desta maneira, foram selecionados quatro casos representantes da prática da AAE desenvolvidas para o planejamento do desenvolvimento urbano na Inglaterra, Escócia, Portugal e Irlanda.

Os casos selecionados estão dispostos na Tabela 6, a seguir.

Tabela 6 - Casos selecionados para o estudo do scoping

\begin{tabular}{c|l|c|c}
\hline Caso & \multicolumn{1}{|c|}{ Nome da Avaliação } & País & Ano \\
\hline 1 & $\begin{array}{l}\text { Strategic Environmental Assessment / Sustainability } \\
\text { Appraisal of Thurrock Council Local Development } \\
\text { Framework. }\end{array}$ & Inglaterra & 2006 \\
\hline 2 & $\begin{array}{l}\text { Aberdeenshire Local Development Plan 2009 - Strategic } \\
\text { Environment Assessment: Interim Environmental Report }\end{array}$ & Escócia & 2009 \\
\hline
\end{tabular}




\begin{tabular}{l|l|l|l|l}
\hline 3 & $\begin{array}{l}\text { Avaliação Ambiental Estratégica da alteração do Plano } \\
\text { Regional de Ordenamento do Território da Área } \\
\text { Metropolitana de Lisboa }\end{array}$ & Portugal & 2011 \\
\hline 4 & $\begin{array}{l}\text { Clare County Development Plan 2011-2017/Environment } \\
\text { Appraisal of the Plan/Part I: Strategic Environmental } \\
\text { Assessment (SEA) }\end{array}$ & Irlanda & 2011 \\
\hline
\end{tabular}

Inicialmente, a partir da análise do conteúdo dos relatórios, foram identificados os procedimentos aplicados para elaboração do scoping, com foco na definição dos objetivos estabelecidos para a AAE. Entende-se que, a partir do conteúdo dos relatórios, tem-se uma descrição, ainda que simplificada, que descreve todo o processo de scoping e permite compreender como se concatenam os procedimentos aplicados em sua elaboração, em direção ao estabelecimento dos elementos perseguidos nesta etapa (notadamente, os objetivos de AAE e a promoção da sustentabilidade no planejamento do desenvolvimento urbano). Ao final, foi possível elaborar um diagrama ilustrativo do processo de scoping, destacando a correlação entre os aspectos conceituais e aquilo que revela a análise da prática para os casos selecionados.

Os critérios orientadores da análise efetuada nesta etapa da pesquisa, estabelecidos com base no referencial teórico, estão dispostos na Tabela 7 a seguir.

Tabela 7 - Critérios orientadores da análise

\begin{tabular}{|c|c|}
\hline Pergunta orientadora da análise & Propósito \\
\hline Qual o objeto da AAE? & $\begin{array}{l}\text { Detalhar a que se refere a ação estratégica } \\
\text { avaliada }\end{array}$ \\
\hline $\begin{array}{l}\text { Quais são os objetivos da ação } \\
\text { estratégica? }\end{array}$ & $\begin{array}{l}\text { Apresentar o propósito da ação } \\
\text { estratégica }\end{array}$ \\
\hline Qual a função do processo de avaliação? & $\begin{array}{l}\text { Apresentar o porquê do desenvolvimento } \\
\text { da AAE para a ação estratégica }\end{array}$ \\
\hline $\begin{array}{c}\text { De que forma a AAE se liga à tomada de } \\
\text { decisão estratégica? }\end{array}$ & $\begin{array}{l}\text { Identificar a abordagem empregada pelo } \\
\text { processo de AAE para se desenvolver } \\
\text { junto à ação estratégica }\end{array}$ \\
\hline Quais objetivos foram formulados? & $\begin{array}{l}\text { Apresentação dos objetivos iniciais da } \\
\text { ação estratégica e dos objetivos } \\
\text { formulados para a AAE no processo de } \\
\text { Scoping. }\end{array}$ \\
\hline $\begin{array}{l}\text { Como se desenvolveu o processo de } \\
\text { estabelecimento do Scoping? }\end{array}$ & $\begin{array}{l}\text { Apresentar de forma descritiva e } \\
\text { esquematizada o papel desempenhado } \\
\text { pelos elementos processuais } \\
\text { desenvolvidos neste momento, portanto: } \\
\checkmark \text { Considerações sobre a } \\
\text { participação dos agentes } \\
\text { envolvidos - (stakeholders, } \\
\text { participação pública e } \\
\text { consultores); }\end{array}$ \\
\hline
\end{tabular}




\begin{tabular}{|l}
\hline$\checkmark \begin{array}{l}\text { Considerações sobre a forma de } \\
\text { apresentação das informações }\end{array}$ \\
contextuais sobre o objeto de \\
avaliação; \\
$\checkmark \begin{array}{l}\text { Considerações sobre a análise de } \\
\text { outras Políticas, Planos e } \\
\text { Programas - PPPs; }\end{array}$ \\
$\checkmark \quad \begin{array}{l}\text { Considerações sobre a } \\
\text { importância da etapa de baseline; }\end{array}$ \\
$\checkmark \begin{array}{l}\text { Considerações sobre a definição } \\
\text { de indicadores de AAE; }\end{array}$ \\
$\checkmark \quad \begin{array}{l}\text { Considerações sobre como ocorre } \\
\text { a promoção de aspectos voltados } \\
\text { à sustentabilidade. }\end{array}$ \\
Além disso, procurar descrever como \\
estes elementos se interrelacionam e \\
contribuem para o estabelecimento desta \\
etapa.
\end{tabular}

6.1 Análise dos casos selecionados - caracterização do processo de estabelecimento dos objetivos de AAE

A seguir segue a descrição dos casos selecionados, tendo como base os cinco primeiros critérios de orientação apresentados. A seção seguinte apresenta a análise detalhada do scoping conduzida pelo sexto critério, valendo-se da compreensão de seus elementos fundamentais.

Caso 1: AAE e Avaliação de Sustentabilidade do Quadro de Desenvolvimento Local do Council de Thurrock - Reino Unido, 2006

"Strategic Environmental Assessment/Sustainability Appraisal of Thurrock Council Local Development Framework. Interim SA Report (Core Strategy and Policies for Control of Development \& Site Specific Allocations and Policies DPDS), UK, 2006”

Thurrock Council é uma autoridade unitária e autônoma da Inglaterra, com sua população por volta 160.000 habitantes à época em que o estudo foi elaborado, localizada a Leste do rio Tamisa e que faz parte do cinturão suburbano de Londres (Figura 30). 


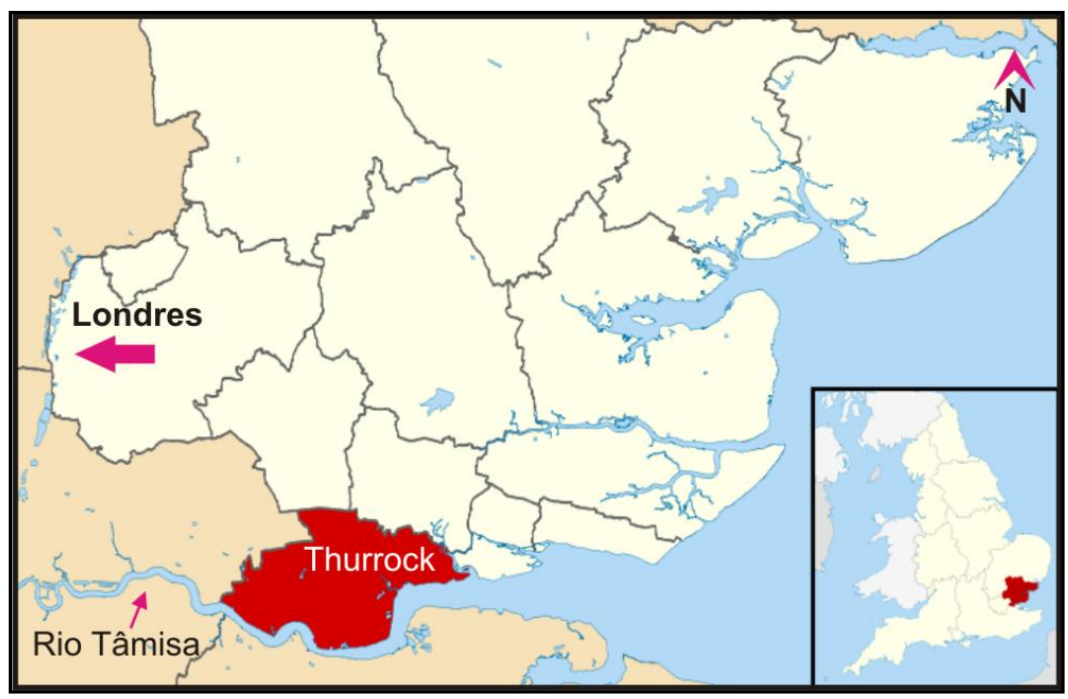

Figura 30 - Localização de Thurrock Council

Em 2006, o Conselho de Thurrock iniciou os trabalhos de elaboração de seu futuro Quadro de Desenvolvimento Local (Local Development Framework), uma estratégia de planejamento espacial composta por dois documentos específicos, a "Core Strategy" que representa os princípios a serem observados em relação a novos desenvolvimentos e usos da terra, e o "Site Specific Allocations" que contém as políticas que se aplicam a locais ou áreas específicas. Como requisito legal e supranacional foi necessário a elaboração, respectivamente, de uma Avaliação de Sustentabilidade (Sustainability Appraisal-SA) e de uma Avaliação Ambiental Estratégica (AAE).

Cabe destacar que o Quadro de Desenvolvimento Local (Local Development Framework) responde a uma ação estratégica em nível superior de planejamento regional e ao mesmo tempo fornece subsídios essenciais para o planejamento local.

Assim, a abordagem da avaliação incorpora as elementos sistematizados da AAE junto ao processo de Avaliação de Sustentabilidade (SA), que se desenvolveram juntas sobre o "Draft Plan", documento que sintetiza as intenções iniciais do processo de elaboração do Quadro de Desenvolvimento Local do Council de Thurrock.

Dentre as funções desta avaliação integrada, entre SA e AAE, se destacam:

$\checkmark$ Promover o desenvolvimento sustentável;

$\checkmark$ Assegurar um elevado nível de proteção do ambiente;

$\checkmark$ Integrar a sustentabilidade e as considerações ambientais na elaboração de planos e programas;

$\checkmark$ Fornecer um mecanismo para assegurar que os objetivos de sustentabilidade se traduzam nas políticas de planejamento;

$\checkmark$ Refletir preocupações globais, nacionais, regionais e locais; 
$\checkmark$ Fazer parte integrante de todas as fases da elaboração do plano.

A Figura 31 esquematiza a articulação verificada entre os agentes intervenientes do processo de tomada de decisão e do processo de AAE/SA, para o estabelecimento dos objetivos da avaliação.

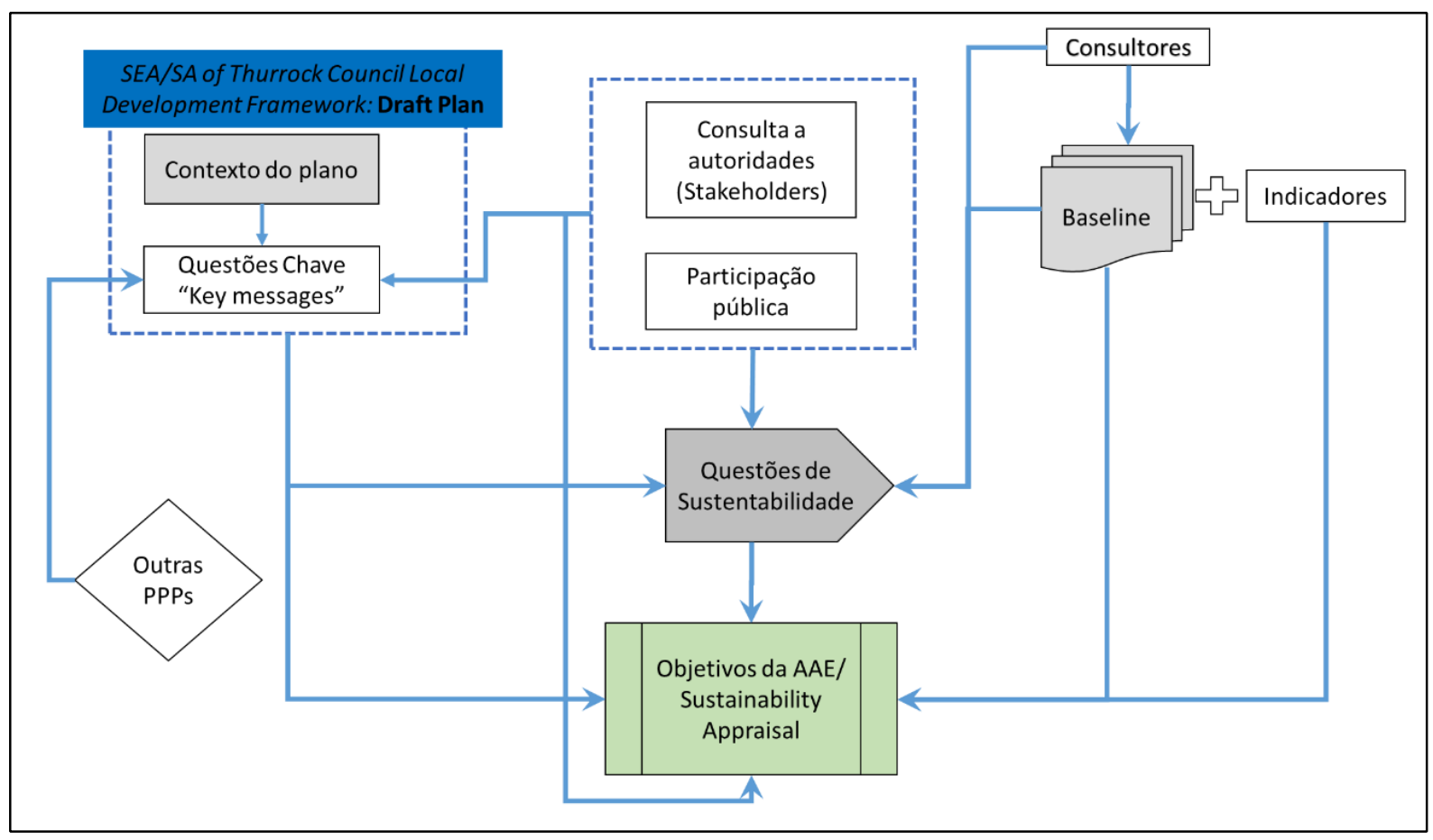

Figura 31 - Articulação entre elementos e etapas da AAE/AS para formulação dos objetivos da avaliação

Inicialmente, o "Draft Plan" fornece informações referentes ao contexto local, econômico, social e ambiental, que juntamente com os aspectos identificados em outras políticas, planos e programas e inputs provenientes dos processos de participação pública e demais stakeholders são utilizadas para delinear as questões-chave (relevantes para o refinamento das questões prioritárias a serem abordadas no futuro Quadro de Desenvolvimento Local).

Paralelamente, a elaboração da baseline ocorre por meio da reunião de informações mais detalhadas sobre o contexto em que a ação estratégica se desenvolve, a partir de temas pré-definidos pelas regulamentações que orientam o processo de AAE/SA na Inglaterra, complementados por um conjunto de indicadores que descrevem a situação de base antes da implementação do plano.

Em seguida, baseline e questões-chave, novamente influenciadas pela ação dos stakeholders e participação do público, são empregadas na definição das "Questões de 
Sustentabilidade". Esta etapa se volta para a identificação dos problemas relacionados à sustentabilidade que a localidade enfrenta e consequentemente definir objetivos e opções sustentáveis para o futuro Quadro de Desenvolvimento Local.

O relatório analisado apresenta este processo de modo conciso, sintetizado conforme a Figura 32 (extraída do próprio documento), destacando a participação de stakeholders e público como elementos essenciais para a definição de questões relevantes para a formulação do Quadro de Desenvolvimento.

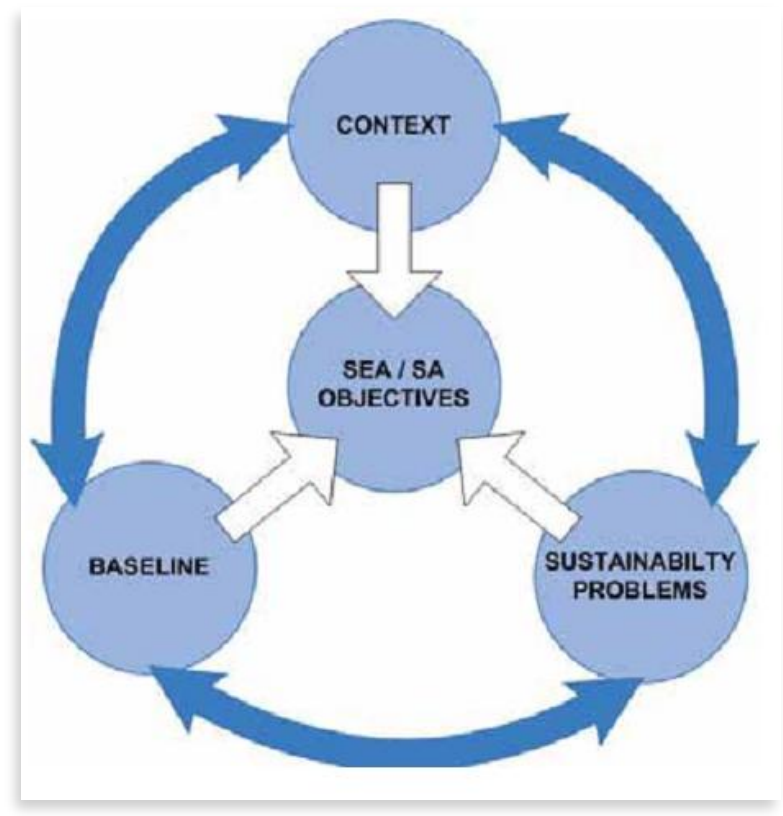

Figura 32 - Elementos responsáveis pelo estabelecimento dos objetivos de AAE/AS Fonte: Extraído de SEA/ SA of Thurrock Council Local Development Framework - Interim SA Report

Quanto à capacidade de promoção da sustentabilidade na ação estratégica, o Quadro 2 apresenta as questões iniciais estabelecidas pelo draft plan e os objetivos sugeridos pelo processo de AAE/SA após reformulação dos anteriores e direcionamento para uma visão de sustentabilidade e maior proteção ambiental.

Quadro 2 - Objetivos do "Draft Plan" e os Objetivos de AAE/SA.

\section{Objetivos do "Draf Plan"}

- Usar os recursos naturais, especialmente da água, de forma eficiente, e devem ser reutilizados sempre que possível, a fim de proteger os recursos ambientais fundamentais (terra agrícola, os habitats ameaçados, recursos minerais, patrimônio histórico, etc)

- Preservar e valorizar o Green Grid de espaços abertos 
- Proteger e melhorar paisagens valiosas, árvores, incluindo árvores individuais e a biodiversidade

- Aumentar a proporção de energia gerada a partir de fontes renováveis

- Reduzir a produção de resíduos e aumentar a reutilização/reciclagem/valorização de resíduos

- Usar áreas urbanas para o desenvolvimento habitacional, sempre que possível, a não ser em casos de se necessitar de áreas rurais

- Administrar o local dos desenvolvimentos, a fim de reduzir o risco de inundação, como áreas que requerem sistemas de drenagem urbana sustentáveis especificando o desenho e localização do desenvolvimento

- Aumentar a oferta de habitação e proporcionar uma melhor distribuição de tamanhos e tipos de habitação com uma gama de densidades habitacionais

- Fornecer acomodação adicional para as populações viajantes

- Auxiliar na redução do crime e no comportamento social ante o medo do crime

- Promover uma vida saudável, sensação de bem-estar e reduzir o risco de poluição ambiental

\section{Objetivos definidos pelo processo AAE/AS}

- Alcançar níveis sustentáveis de prosperidade e crescimento econômico

- Aumentar a diversidade econômica e aumentar a proporção de habilidades representadas

- Incentivar o investimento para garantir que os moradores atuais e futuros vivam e trabalhem dentro do município

- Promover padrões sustentáveis de desenvolvimento local, incluindo emprego e habitação

- Fazer o melhor uso da terra no município, incluindo a reutilização de terrenos previamente desenvolvidos

- Proteger e valorizar a biodiversidade e geodiversidade de Thurrock, incluindo todos os locais designados

- Proteger e melhorar o meio ambiente através da redução das emissões de poluentes

- Proteger e melhorar as características da paisagem, distinção local e patrimônio histórico construído

- Certificar que o consumo de água e fontes de água possam acomodar o desenvolvimento futuro

- Reduzir o consumo de fontes de energia não-renováveis e utilizar os recursos naturais disponíveis de forma mais eficiente e sustentável

- Conseguir uma partilha mais equitativa dos benefícios da prosperidade em todos os setores da sociedade

- Garantir acesso mais equitativo aos serviços, com foco nas áreas mais necessitadas

- Proporcionar a habitação a todos aqueles que necessitam

- Reduzir o crime e o medo do crime

- Reduzir as desigualdades na saúde e garantir que todos os moradores atuais e futuros tenham acesso aos serviços de saúde

- Reduzir a quantidade de resíduos produzidos e a quantidade de resíduos que está sendo importada

\section{Caso 2: AAE do Plano de desenvolvimento local do Council de Aberdeenshire - Escócia}

"Aberdeenshire Local Development Plan 2009 - Strategic Environment Assessment: Interim Environmental Report" 
Aberdeenshire é um Council que abrigava, à época, 250 mil habitantes, localizado na porção leste da Escócia, como indicado da figura 33.

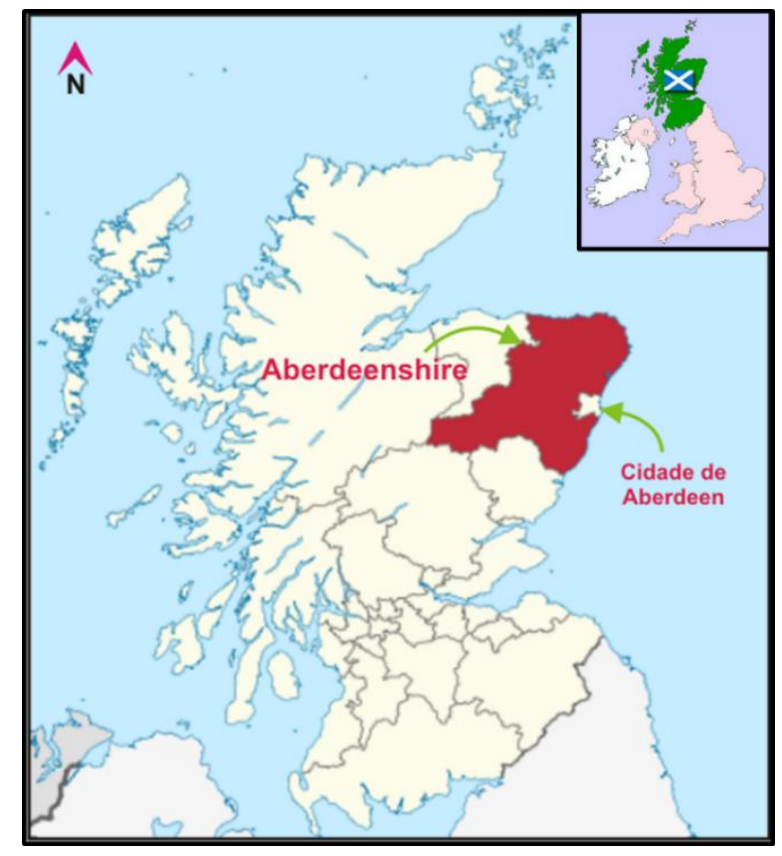

Figura 33- Localização do Council de Aberdeenshire

Por sua autonomia, o Council de Aberdeenshire elaborou seu Plano de Desenvolvimento Local (“Local Development Plan”), com a finalidade de fornecer uma estratégia de planejamento do uso do solo aos futuros desenvolvimentos.

No entanto, sua elaboração está ligada às condições dispostas no Relatório das Questões Principais ("Main Issues Report”), que surge como parte fundamental para sua elaboração. Este tem por função retratar a visão política, as questões prioritárias, as alternativas preferenciais e consideradas, bem como as características contextuais (Culturais, Sociais, Ambientais e Econômicas) sobre a localidade.

De modo prático o Relatório de Questões Principais apresenta a "Estrutura Final do Plano de Desenvolvimento Local", que é onde se inserem os "Objetivos do Plano" e sua "Visão Estratégica" - políticas e alternativas que a ação estratégica pressupõe.

Sendo assim, estes componentes do Relatório de Questões Principais tornam-se objeto do processo de AAE, que por sua vez tem a função de:

$\checkmark$ Proporcionar um elevado nível de proteção do meio ambiente;

$\checkmark$ Tornar as considerações ambientais de modo integrado na preparação de planos e, bem como, a sua adoção;

$\checkmark$ Promover o desenvolvimento sustentável; 
- Aumentar a participação pública na tomada de decisão ambiental.

O processo de AAE ocorre em um momento único, isto é, em conjunto com a construção do Relatório de Questões Principais, que por sua vez é suporte para o desenvolvimento da ação estratégica.

Os elementos que configuram os objetivos, indicadores e metas do processo de AAE podem ser observados na Figura 34.

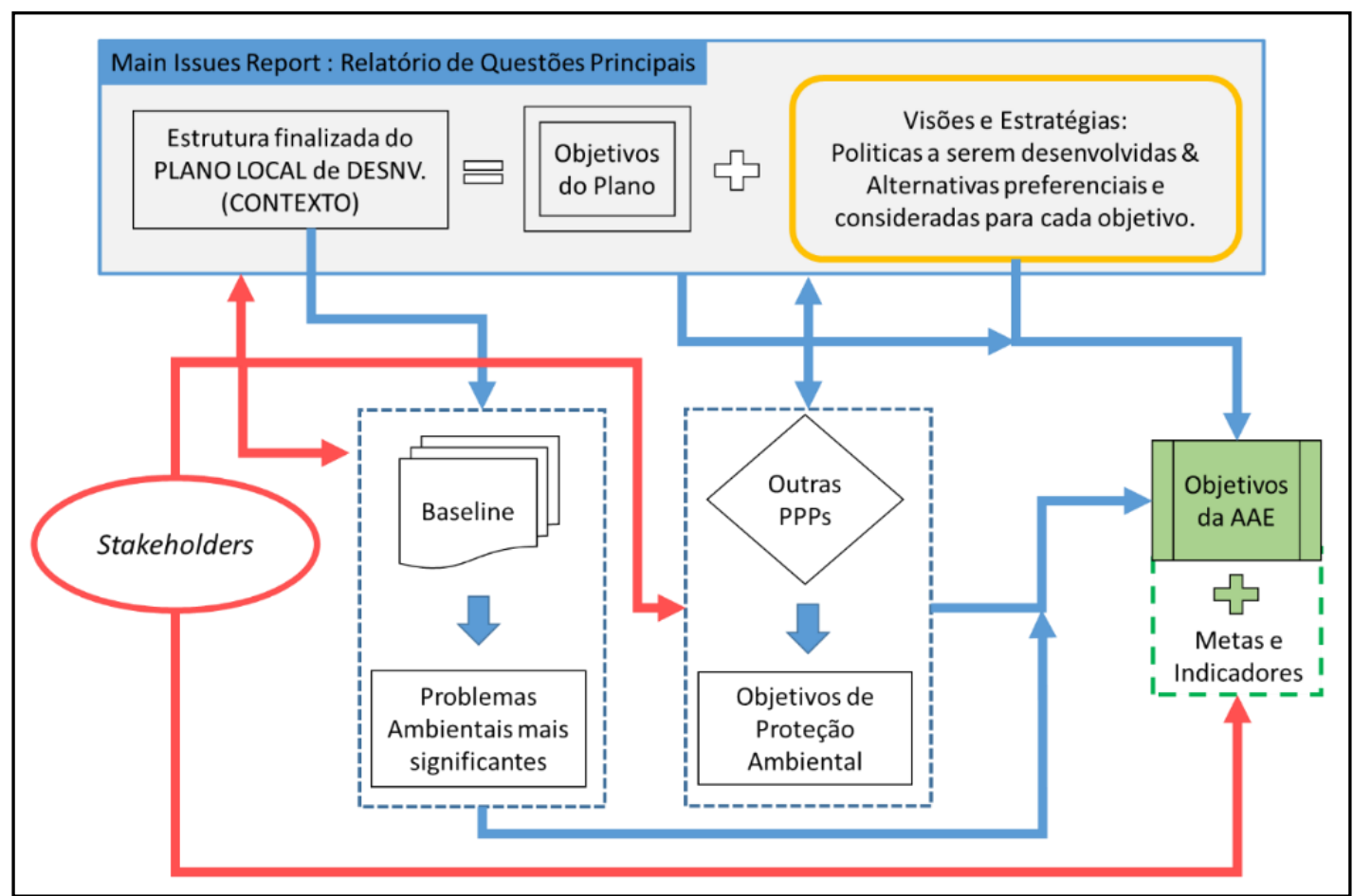

Figura 34 - Articulação entre elementos e etapas da AAE para formulação dos objetivos da avaliação.

Neste caso, inicialmente ocorre a associação entre as questões dispostas pelo "Relatório de Questões Principais", e consequentemente os "Objetivos do Plano", com as diferentes Políticas, Planos e Programas que apresentam influência direta sobre os objetivos do plano, definindo assim os objetivos de proteção ambiental. Estes, por sua vez, remetem a questões e objetivos que o plano deve levar em consideração ao ser desenvolvido.

A baseline se desenvolve a partir de temas pré-estabelecidos pela regulação de AAE em vigor na Escócia e se constitui com base nas informações contextuais dispostas na "Estrutura Finalizada do Plano", que destacam os "problemas ambientais mais significantes", ou seja, os principais problemas relacionados aos temas ambientais estabelecidos.

Os stakeholders e demais atores sociais envolvidos têm o papel de influenciar no momento de estruturação do "Relatório de Questões Principais" e todos os elementos derivados. 
Por sua vez, os objetivos da AAE - juntamente com um conjunto de metas e indicadores - são definidos a partir da contribuição dos processos de consulta e participação de stakeholders e pelo aporte da questões ambientais estratégicas (visões e estratégias, problemas ambientais mais significantes e objetivos de proteção ambiental) definidas ao longo das demais etapas.

Cabe destacar que a contribuição de atores como "Consultores" e a "Participação Pública" , ainda que apresentada como sendo influente e de fundamental importância nesta etapa do processo de $\mathrm{AAE}$, não é claramente detalhada no relatório.

A capacidade do processo de AAE em promover a sustentabilidade nas ações estratégicas pode ser verificada ao se cotejar os objetivos iniciais, dispostos na "Estrutura finalizada do Plano Local de Desenvolvimento", diante dos objetivos produzidos ao longo do processo de AAE, como representado no Quadro 3. Cabe lembrar que, embora os objetivos propostos pela AAE não sejam de adoção compulsória pelo futuro Plano Local de Desenvolvimento, a sua presença ilustra a liberdade que a AAE tem em dar luz a questões mais amplas a serem abordadas pela ação estratégica.

Quadro 3 - Objetivos iniciais (intenções iniciais) da "Estrutura final do Plano" e os Objetivos propostos pela AAE

Objetivos iniciais (intenções iniciais) da "Estrutura final do Plano"

- Crescer e Diversificar a Economia

- Tornar possíveis os desafios do desenvolvimento sustentável

- Certificar-se de que a área tem número suficiente de pessoas, casas e postos de trabalho para serviços de apoio e instalações

- Proteção e melhoria dos bens e recursos

- Promover comunidades mistas sustentáveis com os mais altos padrões de projeto

- Fazer uso eficiente da rede de transportes 
- Proteger e melhorar a qualidade do ar local.

- Manter e melhorar a qualidade da água para um bom estado ecológico.

- Melhorar e garantir a qualidade do solo

- Reduzir a quantidade de resíduos nos aterros sanitários

- Conservar, proteger, manter e melhorar a biodiversidade (incluindo os ecossistemas, habitats e espécies endêmicas)

- Reduzir as causas das mudanças do climáticas adversas ( Ex. redução dos níveis de CO2).

- Reduzir a vulnerabilidade aos efeitos das mudanças climáticas, (Ex. cuidados a áreas de inundações e melhoria na prestação de serviços públicos)

- Proteger e melhorar a acessibilidade aos espaços abertos.

- Diminuir a privação / exclusão social.

- Melhorar a oferta de terra a habitação, a fim de para acomodar a imigração, o envelhecimento da população e o aumento previsto da necessidade de novos domicílios.

- Proteger e, se necessário, melhorar o ambiente histórico.

- Proteger, melhorar e se necessário restaurar a qualidade e singularidade da paisagem da área

- Promover a criação de ativos imobiliários, comercias e industriais

- Regenerar terrenos abandonados, vagos ou contaminados

- Promover o uso de materiais sustentáveis e adoção de padrões de vida

Caso 3: Avaliação Ambiental Estratégica da Alteração do Plano Regional de Ordenamento do Território da Área Metropolitana de Lisboa

A Área Metropolitana de Lisboa (Figura 35) é uma região que engloba 18 municípios da Grande Lisboa e da Península de Setúbal, sendo o maior centro populacional português, com quase 3 milhões de habitantes e que representa pouco mais de $20 \%$ da população. 


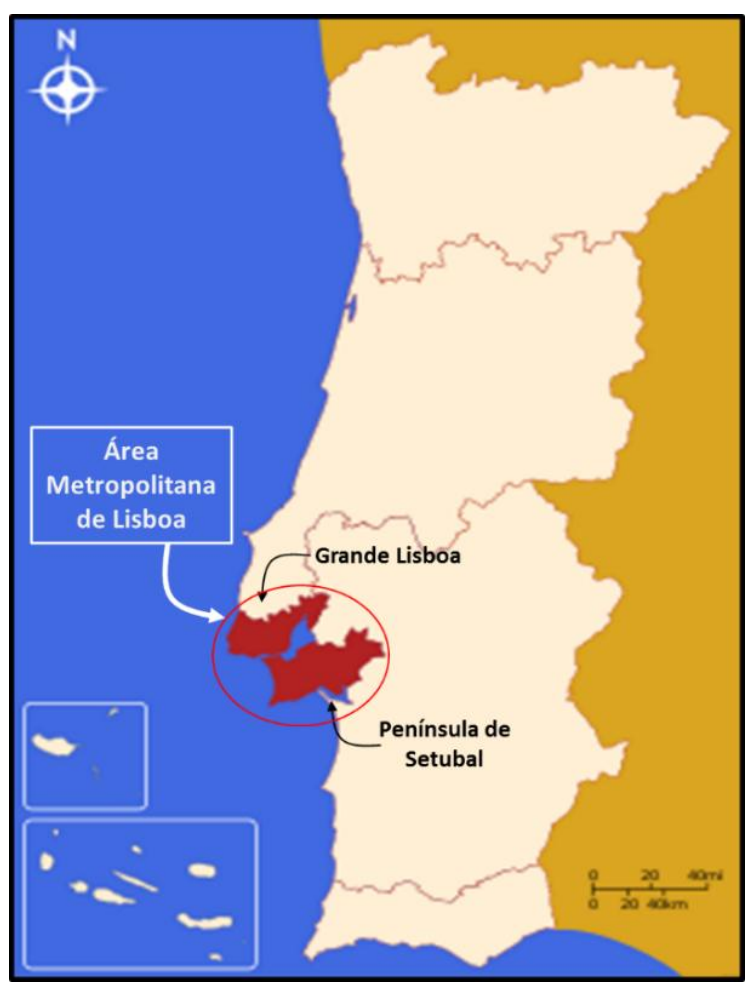

Figura 35 - Localização da Área Metropolitana de Lisboa

A área constitui uma entidade de nível intermediário da administração pública, de natureza associativa e que visa desenvolver os interesses comuns dos municípios que a integram. Assim, o caso em destaque se refere à alteração do Plano Regional de Ordenamento Territorial da Área Metropolitana de Lisboa (PROT-AML). Tal plano regional tem como função principal a de traduzir, em termos espaciais e regionais, os objetivos de desenvolvimento formulados em ações estratégicas de níveis superiores, como o Programa Nacional da Política de Ordenamento do Território e o Quadro de Referência Estratégico Nacional.

Além disto, o plano em questão estabelece as grandes orientações para o ordenamento e ocupação urbanística do território metropolitano, define as redes regionais de infraestruturas e transportes e, também, a estrutura ecológica fundamental do sistema urbano. Estas orientações se constituem como um quadro de referência para a elaboração dos planos municipais de ordenamento do território.

A “Alteração do PROT-AML”, objeto da AAE em questão, se refere a modificações estratégicas derivadas da inserção de novos desenvolvimentos, que prevêem a implantação de infraestruturas logísticas e, assim, a reestruturação do território metropolitano.

A AAE baseia-se na metodologia desenvolvida por Partidário $(2007)^{10}$, amplamente aplicada em Portugal, cuja função dada ao processo é a de direcionar a formulação do plano a

\footnotetext{
${ }^{10}$ PARTIDÁRIO, M.R. (2007). “Guia de boas práticas para Avaliação Ambiental Estratégica - orientações metodológicas", $1^{\text {a }}$ ed. Lisboa. Agência Portuguesa do Ambiente.
} 
partir da consideração de opções estratégicas e de um contexto de sustentabilidade. Além disso ela ocorre de modo orientado para a tomada de decisão e, portanto, deve se relacionar com todos os momentos da elaboração da ação estratégica. Dessa maneira, a AAE objetiva avaliar de que forma as propostas estratégicas do plano respondem aos problemas ambientais e de sustentabilidade da região e quais as oportunidades e riscos podem estar envolvidos sua implementação.

A metodologia apresentada no relatório é organizada em diversas etapas, sendo a de "Focalização" a responsável por consolidar o escopo da avaliação a partir de elementos-chave que, sobrepostos, desenvolvem os Fatores Críticos para Decisão (FCD) como esquematizado na Figura 36.

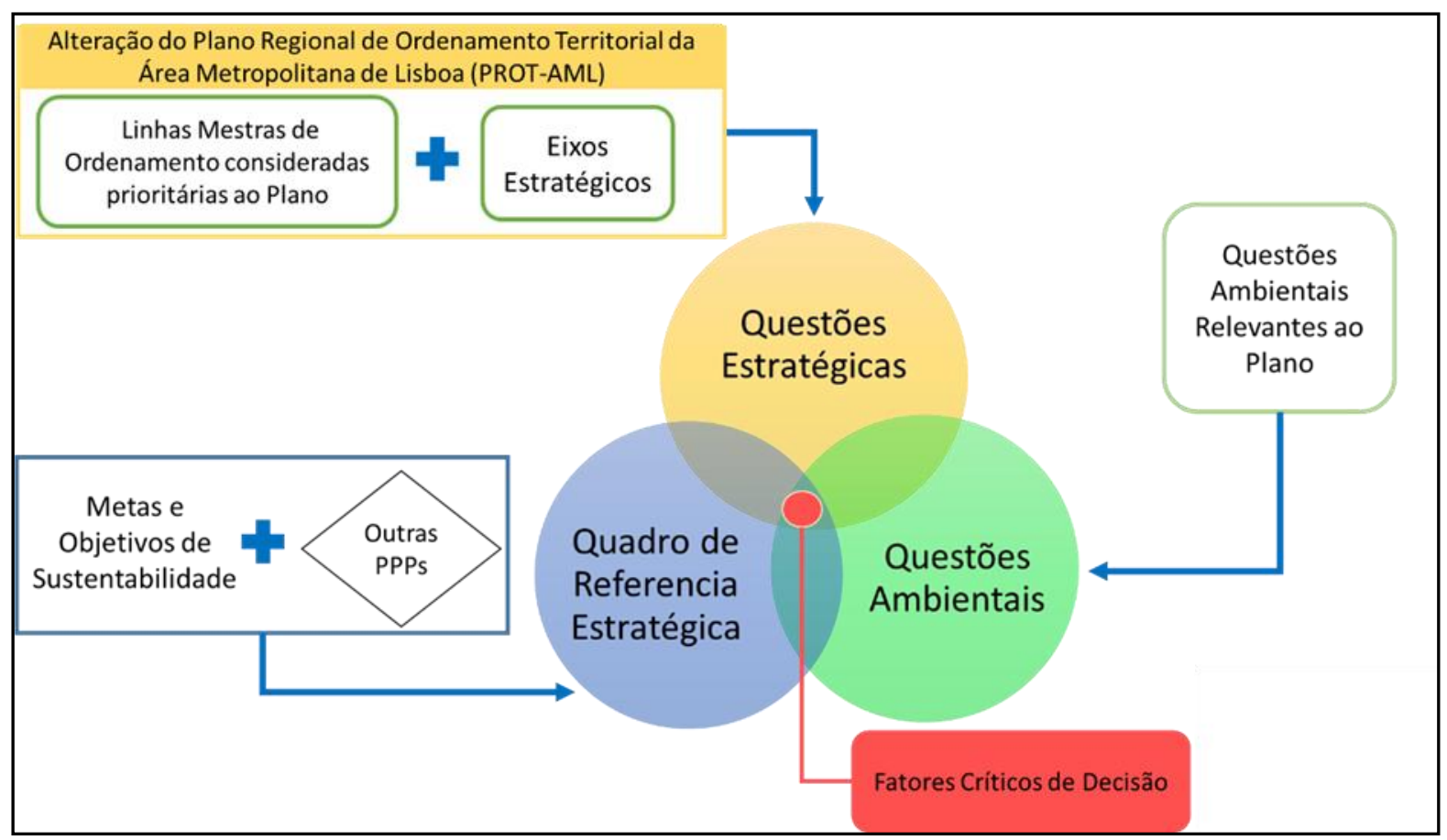

Figura 36 - Integração dos "Elementos Chave” para a formulação dos Fatores Críticos de Decisão

Inicialmente, as "Questões Estratégicas" são formuladas tendo como base o objeto da AAE, que permite identificar os aspectos (estratégicos) importantes no âmbito da alteração do PROT-AML em termos das linhas mestras de ordenamento do território e os eixos estratégicos estabelecidos para a sua implementação, e sobre os quais a AAE se desenvolverá.

Em seguida, são levantadas as "Questões Ambientais", que se referem a temas ambientais previamente estabelecidos (normalmente a partir da regulamentação aplicável), e direcionados a aspectos relevantes para o plano. Finalmente, tem-se a configuração do "Quadro de Referência Estratégica", elaborado a partir da análise de políticas, planos e programas e 
identificação de objetivos e metas de sustentabilidade com influência direta sobre a ação estratégica.

A análise integrada destes elementos permite estabelecer os "Fatores Críticos de Decisão", que refletem os temas que estruturam a avaliação e correspondem aos pontos fundamentais a serem considerados no processo de tomada de decisão, uma vez que consideram as tendências, as opções estratégicas do plano e as ações que as implementam. Portanto a definição destes fatores críticos é parte essencial do processo de avaliação, bem como da elaboração do plano.

O Quadro 4 a seguir permite verificar as diferenças entre os objetivos estabelecidos inicialmente para a ação estratégica (a partir da identificação das Questões Estratégicas) e aquilo que a AAE insere como essencial a partir de seus objetivos (descritos pelos Fatores Críticos de Decisão).

Quadro 4 - Objetivos de ação estratégica e os Objetivos de AAE para o caso 3

\begin{tabular}{|c|}
\hline Objetivos de Ação Estratégica \\
\hline $\begin{array}{l}\text { - Impulsionar a globalização e a internacionalização regional; } \\
\text { - } \quad \text { Apostar na Investigação \& Desenvolvimento Tecnológico (I\&DT) } \\
\text { - } \text { Promover a sustentabilidade (no sentido da civilização pós-carbono); } \\
\text { - } \quad \text { Privilegiar a polarização/concentração/poli nucleação/compactação; } \\
\text { - Recentrar a AML em torno do Estuário do Tejo; } \\
\text { - Reformular as mobilidades; } \\
\text { - Reordenar e requalificar as periferias. }\end{array}$ \\
\hline Objetivos de AAE \\
\hline $\begin{array}{l}\text { Promover a consideração das tendências de desenvolvimento decorrentes das opções } \\
\text { estratégicas da alteração do PROT-AML na estrutura de governo, de decisão e na articulação } \\
\text { institucional na região, nas questões relacionadas com a criação e utilização de conhecimento, } \\
\text { bem como nos padrões de especialização produtiva regional, nas condições de atratividade } \\
\text { territorial à fixação destas atividades, e nas estratégias de articulação dos agentes tendo presente } \\
\text { a afirmação internacional da região. }\end{array}$ \\
\hline $\begin{array}{l}\text { Atender aos aspectos relacionados com a dinâmica demográfica, natural e migratória, com a } \\
\text { coesão social, as tensões e desafios da multiculturalidade, bem como com a criação de elevados } \\
\text { padrões de qualidade de vida em termos de saúde, habitação, lazer e elementos de uma } \\
\text { identidade regional. }\end{array}$ \\
\hline $\begin{array}{l}\text { Abordar a dinâmica de fluxos de pessoas e bens a nível regional, nacional e internacional, os } \\
\text { padrões sustentáveis de mobilidade e a gestão integrada do sistema de transportes numa } \\
\text { perspectiva de sustentabilidade e internacionalização da Região. }\end{array}$ \\
\hline
\end{tabular}


Dirigir-se à estruturação do sistema territorial regional, polarizado pelo estuário do Tejo, considerando questões relacionadas com a coesão territorial, assim como a requalificação e revitalização dos núcleos urbanos e suas periferias, atendendo igualmente a aspectos de qualidade física do ambiente

Abordar a sustentabilidade energética, a eficiência da gestão energética e a utilização de fontes endógenas de recursos renováveis, como fator de competitividade e de sustentabilidade regional, tendo como linha de força principal as iniciativas de adaptação e mitigação das alterações climáticas

Compreender a estrutura ecológica regional, os valores naturais e as funcionalidades associadas aos serviços dos ecossistemas, bem como a gestão integrada destes recursos, vistos segundo as perspectivas de conectividade, compromissos e valor acrescentado em termos de competitividade.

Caso 4: Avaliação Ambiental Estratégica do Plano de Desenvolvimento de Clare County -

\section{1-2017 (Irlanda).}

“Clare County Development Plan 2011 -2017/Environment Appraisal of the Plan/Part

\section{I: Strategic Environmental Assessment (SEA)"}

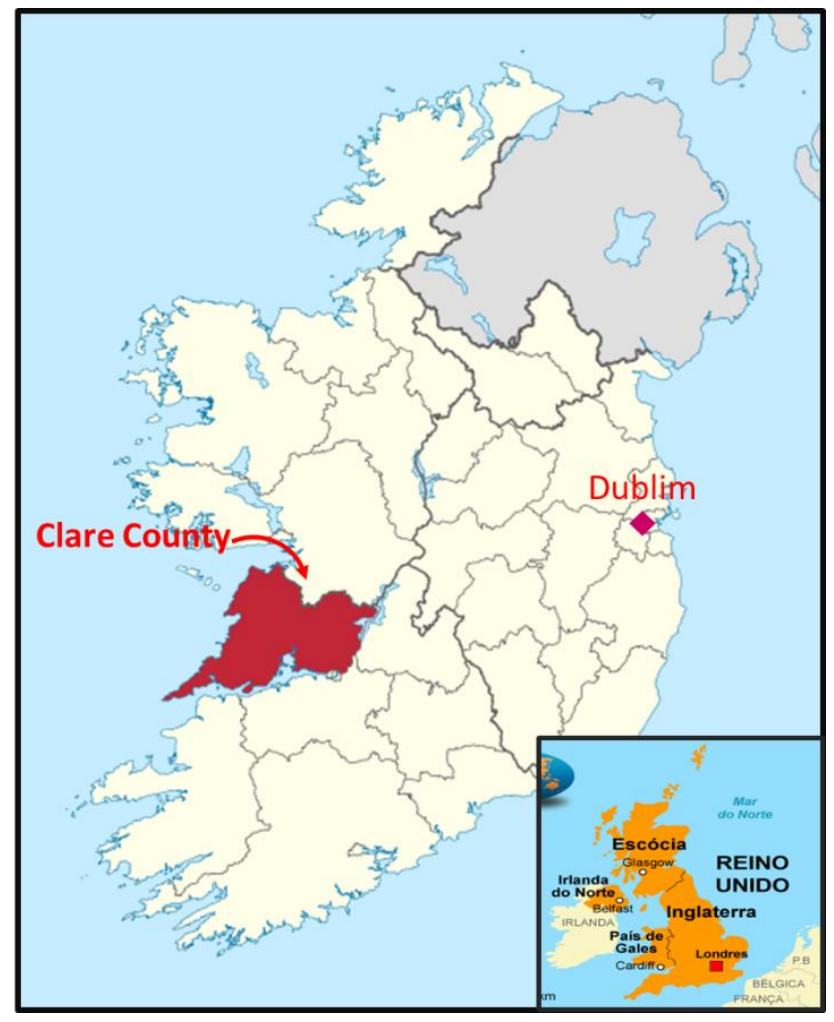

Figura 37 - Localização do Condado de Clare na Irlanda

Clare (Clare County) é um condado irlandês com cerca de 100 mil habitantes e se localiza na província de Munster na porção meio-oeste do país, como assinala a figura acima. 
Neste país os condados tradicionais são, em geral, a base para ações de planejamento do governo local, e de desenvolvimento da comunidade.

Assim, os "County Development Plan" (CPD) se tornam o principal documento político de planejamento do território que refletem as intenções estratégicas de nível superior e ao mesmo tempo são a base para ações de nível local. De forma geral, trata-se de planos que procuram incluir políticas para o uso do solo através do controle de desenvolvimentos dentro dos condados (Counties) e ainda fornecer um direcionamento/zoneamento local para os tipos de uso do solo (JONES et al., 2005).

As diretrizes legais irlandesas indicam que deve haver uma integração completa entre o desenvolvimento de um CPD e os processos de AAE e de Avaliação da Diretiva Habitats (Habitats Directive Assessment - HDA $)^{11}$.

A função destes dois processos, em especial a AAE, é a de informar a ação estratégica sobre as considerações ambientais desde o início, e como prescrito pelo relatório ambiental, é de fazer com que os responsáveis pela preparação do plano compreendam:

$\checkmark$ as questões ambientais existentes na localidade;

$\checkmark$ que os efeitos significantes no ambiente são resultados da implementação do futuro plano;

$\checkmark$ que tais impactos devem ser reduzidos e monitorados;

$\checkmark$ que as metas e objetivos ambientais estratégicos formulados devem fazer parte do futuro plano.

Neste sentido o Plano de Desenvolvimento 2011-2017 do Condado Irlandês de Clare, tem por objetivo central promover de forma sustentável seu desenvolvimento econômico e social tendo como mecanismo chave a AAE, devido à sua capacidade de identificar, avaliar e descrever os efeitos significativos do ambiente frente às disposições da ação estratégica.

Assim, a Figura 38 esquematiza como os diversos elementos do processo de AAE se articularam para formulação dos "Objetivos Ambientais Estratégicos" a partir das considerações iniciais do plano.

\footnotetext{
${ }^{11}$ Diretiva dos Habitats ou Diretiva Habitats é o nome pelo qual é conhecida a Directiva 92/43/CEE do Conselho, de 21 de Maio de 1992, relativa à preservação dos habitats naturais e da fauna e da flora selvagens.
} 


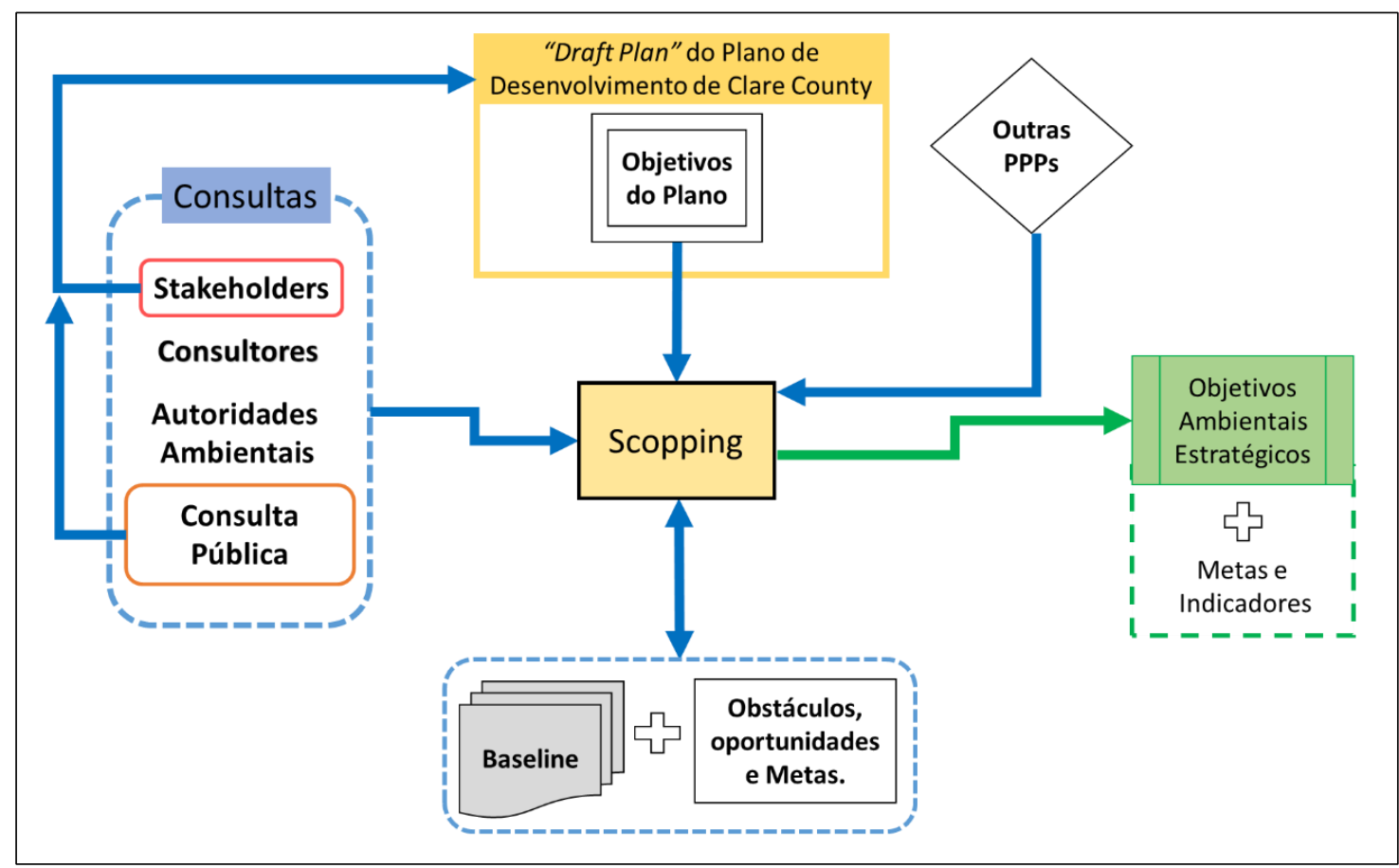

Figura 38 - Organização dos elementos responsáveis pela definição de objetivos ambientais estratégicos

A condução da etapa de scoping foi acompanhada de diversos tipos de consulta, que incluíram as "Autoridades Ambientais", referente aos órgãos e entidades ambientais que podem influenciar sobre o plano; os "Consultores" responsáveis pelo desenvolvimento da avaliação; os stakeholders, atores sociais com capacidade de influência sobre avaliação e elaboração do plano; a participação por meio da "Consulta Pública", aqui compreendida como a participação da sociedade em geral. Vale destacar que estes dois últimos grupos, também apresentam papel fundamental no momento de definição do "Draf Plan".

No caso em questão, o Draf Plan contém as intenções iniciais da ação estratégica, ou seja, os "Objetivos do Plano". A este elemento integram-se as informações de baseline (cujos conteúdos são predefinidos legalmente), e os inputs recebidos a partir de procedimentos específicos de consultas junto aos stakeholders e ao público, realizado durante a etapa de scoping. Tais inputs permitem que a baseline seja interpretada de modo a apresentar os principais “Obstáculos, Oportunidades e Metas” a serem observados.

A estes elementos, a etapa final do scoping integra a consideração de outras políticas planos e programas (PPPs) com influência direta sobre a ação estratégica, a fim de verificar a sobreposição ou a falta de ações ligadas às estratégias do futuro plano.

Ao final, apresentam-se os Objetivos de AAE ou, no caso, "Objetivos Ambientais Estratégicos". O produto desta etapa pode ser conferido no quadro a seguir, em que inicialmente se apresentam as intenções iniciais do "Draft Plan" e a partir da organização dos elementos 
definidos ao longo da elaboração do scoping são gerados 38 objetivos que refletem as principais preocupações ambientais às quais a ação estratégica deve atentar.

Quadro 5 - Objetivos do Draft Plane os Objetivos Ambientais Estratégicos do caso 4

\begin{tabular}{|l} 
Objetivos do "Draft Plan" \\
\hline Por uma Clare County que impulsione o crescimento local e regional através do \\
aproveitamento do potencial da sua localização privilegiada, qualidade de vida, recursos \\
naturais e outras vantagens competitivas. \\
Por uma Clare County em que tenha as áreas urbanas e rurais fortemente equilibradas, e que \\
prestam serviços essenciais e uma boa qualidade de vida, de modo que as pessoas tenham a \\
opção de viver na área de onde elas são. \\
Por uma Clare County com Habitações de alta qualidade em locais apropriados em todo o \\
concelho, garantindo o desenvolvimento de uma gama de tipos de casas, tamanhos e posses \\
para acomodar as diferentes necessidades do agregado familiar, promover comunidades \\
sustentáveis, com integração e inclusão social e facilitando um sentido de lugar. \\
Por uma Clare County em que o crescimento sustentável do Concelho seja desenvolvido e \\
integrado as demais comunidades, instituições educacionais e culturais, onde através de um \\
compromisso com a igualdade, acessibilidade e inclusão social, o condado desenvolva-se \\
como uma localização única com uma melhor qualidade de vida para os seus cidadãos e \\
visitantes. \\
Por uma Clare County em que postos de trabalho e as pessoas se reúnam e onde o crescimento \\
do emprego e de atividades econômicas sejam de forma proativa em todos os setores da \\
economia e em todo o concelho.
\end{tabular}

Objetivos Ambientais estratégicos

- Conservar, proteger e evitar a perda da diversidade e da integridade dos habitats designados, as características geológicas, as espécies ou dos seus recursos sustentáveis em locais designados;

- Evitar impactos adversos significativos, incluindo os de influência direta, os cumulativos e indiretos, de habitats relevantes, de características geológicas, de espécies ou de recursos sustentáveis .

- Proteger e valorizar sítios naturais segundo o artigo 6. ${ }^{\circ}$ da Diretiva Habitats

- Conservar, proteger e evitar a perda da diversidade e da integridade dos habitats nãodesignados de características geológicos, de espécies ou onde seus recursos sustentáveis em sítios ecológicos não são designados a proteção.

- Impedir a perda de corredores ecológicos, redes ou partes que forneçam significante conectividade entre áreas de biodiversidade local.

- Designar novos sítios de importância geológica

- Prover o desenvolvimento de zonas ribeirinhas

- Proteger os habitats (terrestre e aquática) de espécies invasivas

- Melhorar a qualidade de vida das pessoas com base em ambientes de vida de alta qualidade, a partir de trabalhos em instalações de lazer

- Proteger a saúde humana contra os riscos ou perturbações resultantes da exposição a novas formas, ou formas incompatíveis, de uso do solo.

- Aderir ao Plano de Emergência County e outros objetivos de relevância para a saúde humana

- Disponibilizar espaços verdes para as comunidades 
- Maximizar o desenvolvimento sustentável a partir da reutilização de terrenos industriais abandonados e uso do espaço construído existente e reduzir a diminuição de zonas verdes

- Manter e conservar as áreas de perfil natural do solo com os seus constituintes, bem como, a flora e fauna. Além da preservação dos perfis deformados em áreas a serem usadas para agricultura

- Implementar planos de proteção do aquífero

- Conservar, proteger e manter a diversidade e integridade de áreas alagáveis no Concelho, bem como manter livre de novos desenvolvimentos áreas de planícies de inundação existentes

- Prevenção de interferência na morfologia águas interiores pela evolução e alterações nas formas de uso do solo

- Manter e melhorar a qualidade do ar

- Minimizar as emissões de gases do efeito estufa para cumprir a legislação / padrão nacional e internacional

- Reduzir a dependência da utilização de carros dentro do County por meio de incentivando a mudança de modal carro para formas mais sustentáveis de transporte público e estímulo aos desenvolvimentos não dependentes do transporte privado

- Fornecer uma rede de transportes públicos adaptados e melhorados

- Reduzir o desperdício de energia, promover o uso de fontes renováveis de energia e apoio a iniciativa de conservação

- Desenvolver uma infraestrutura de transportes sustentável e que reduza a necessidade de viagens para o cumprimento da jornada

- Minimizar a produção de resíduos e poluição, bem como a introdução de práticas sustentáveis de gestão de resíduos

- Promover a produção e reutilização de agregados de resíduos da construção civil em projetos na região

- Servir os novos desenvolvimentos no County com água potável e saudável

- Melhorar a eficiência na operação e gerenciamento da infraestrutura de abastecimento de água, promover a conservação da água e reduzir o nível global de perdas de água no abastecimento público

- Servir os novos desenvolvimentos com o tratamento adequado de águas residuais

- Melhorar a infraestrutura de plantas de tratamento de águas residuais existente

- Reduzir a utilização de fossas sépticas e monitorar a sua manutenção

- Promover o uso de sistemas e tecnologias de energias renováveis

- Promoção da conservação de energia em todos os setores. Promover o desenvolvimento de baixo carbono comércio e edifícios

- Promover as melhores práticas na conservação do património e gestão

- Promover a conservação do património cultural como serviço

- Identificação e proteção de novos patrimônios arqueológicos

- Promover a proteção de paisagens designadas, de vistas panorâmicas, rotas e de características da paisagem de valor local 
- Sempre que possível incorporar noções de desenho urbano sustentável em projetos relacionados a paisagem

- Conservar e melhorar as paisagens e as características históricas e culturais

\section{Análise dos casos selecionados - procedimentos aplicados para definição do scoping}

Levando-se em conta a caracterização do processo de estabelecimento dos objetivos das AAEs realizada na etapa anterior, os casos são analisados a partir da aplicação dos elementos orientadores definidos para a compreensão dos procedimentos aplicados para o estabelecimento do scoping. São eles:

$\checkmark$ Considerações sobre a participação dos agentes envolvidos - (stakeholders, participação pública e consultores);

$\checkmark$ Considerações sobre a forma de apresentação das informações contextuais sobre o objeto de avaliação;

$\checkmark$ Considerações sobre a análise de outras Políticas, Planos e Programas - PPPs;

$\checkmark$ Considerações sobre a importância da etapa de baseline e definição de indicadores;

$\checkmark$ Considerações sobre como ocorre a promoção de aspectos voltados à sustentabilidade.

As Tabelas de 8 a 13 apresentam as considerações efetuadas. 
Tabela 8 - Considerações sobre a participação dos agentes envolvidos - (Stakeholders, participação Pública e Consultores)

Participação dos agentes envolvidos - (Stakeholders, participação Pública e Consultores)

\begin{tabular}{|c|c|}
\hline Caso 1 & $\begin{array}{l}\text { Os agentes envolvidos se associam em três momentos com os demais } \\
\text { elementos do processo. Primeiramente, estes agentes são tidos como } \\
\text { fundamentais para a formulação das "Key messages" isto é, as questões } \\
\text { chaves que definem o contexto da estratégia. Em seguida são responsáveis } \\
\text { pela definição das "Questões de Sustentabilidade" e, finalmente, opinam na } \\
\text { definição dos objetivos de AAE/AS. Portanto apresentam relação com quase } \\
\text { todas as etapas, com exceção da etapa de baseline, elaborada basicamente } \\
\text { pelos consultores. }\end{array}$ \\
\hline Caso 2 & $\begin{array}{l}\text { É destacado a presença dos stakeholders em todos os momentos para o } \\
\text { estabelecimento dos objetivos - desde o estabelecimento do Relatório de } \\
\text { Questões Principais, passando pela elaboração da baseline e verificação de } \\
\text { outras PPPS. Deste modo, considera-se que os stakeholders são influentes } \\
\text { também no momento de definição dos Objetivos de AAE. Cabe destacar que } \\
\text { participação e consulta pública, isto é, da população influenciada, é } \\
\text { mencionada como importante apenas no momento de se elaborar o relatório } \\
\text { de questões principais, que se desenvolve fora do processo de AAE. }\end{array}$ \\
\hline Caso 3 & $\begin{array}{l}\text { O relatório não evidencia como se deu a participação e envolvimento dos } \\
\text { diversos agentes no momento de "Focalização" do escopo da AAE. No } \\
\text { entanto, destaca em sua metodologia a necessidade de cumprir a } \\
\text { regulamentação legal, que indica o dever de dispor informações do processo } \\
\text { de avaliação para a consulta de instituições e para o público em geral. } \\
\text { Portanto, não é possível compreender como se deu a participação dos agentes. }\end{array}$ \\
\hline Caso 4 & $\begin{array}{l}\text { O relatório cita o envolvimento dos stakeholders, consultores, autoridades } \\
\text { ambientais e a realização de consulta pública no momento de definição do } \\
\text { scoping. O relatório também cita o envolvimento dos stakeholders e da } \\
\text { consulta pública, no momento de estabelecimento da Draf Plan. }\end{array}$ \\
\hline
\end{tabular}




\begin{tabular}{l|l}
\hline Síntese & $\begin{array}{l}\text { Nota-se que nos casos em que houve maior transparência em relação à } \\
\text { participação dos agentes envolvidos, independentemente do momento ou } \\
\text { objeto de avaliação, houve maior compreensão acerca dos produtos } \\
\text { desenvolvidos e também sobre como se deu a definição dos objetivos de AAE. } \\
\text { Por exemplo, os casos } 1 \text { e } 2 \text { onde os stakeholders participam no } \\
\text { desenvolvimento de todas as etapas, se compreende melhor os produtos } \\
\text { apenas no momento da definição dos objetivos de AAE, os produtos são } \\
\text { facilmente compreendidos. Diferentemente do caso 3, em que a participação } \\
\text { é apenas citada de maneira geral e sem detalhamento das contribuições, e } \\
\text { portanto não é possível identificar claramente qual a relevância desta } \\
\text { participação. }\end{array}$ \\
\hline
\end{tabular}

Tabela 9 - Considerações sobre forma de apresentação das informações contextuais sobre o objeto de avaliação

\section{Apresentação das informações contextuais sobre o objeto de avaliação}

\begin{tabular}{l|l}
\hline Caso 1 & $\begin{array}{l}\text { Surge com o nome de Draf Plan, que apresenta os objetivos iniciais da } \\
\text { proposta e contém informações contextuais sobre o objeto de análise. Após } \\
\text { uma apreciação pelos stakeholders e pela análise de outras PPPs, se apresenta } \\
\text { como Key messages, que significa um refinamento daquilo que a avaliação } \\
\text { deve se desenvolver. }\end{array}$ \\
\hline Caso 2 & $\begin{array}{l}\text { Se apresenta com o nome de Relatório de Questões Principais, no qual se } \\
\text { encontram informações culturais, sociais, ambientais e econômicas sobre a } \\
\text { localidade, bem como retrata a visão política, as questões prioritárias, as } \\
\text { Portanto se refere a um momento inicial de formulação daquilo que será } \\
\text { avaliado, e que passará pelo crivo das demais etapas. }\end{array}$ \\
\hline
\end{tabular}




\begin{tabular}{|c|c|}
\hline Caso 3 & $\begin{array}{l}\text { No caso, as descrições contextuais são nomeadas como "Questões } \\
\text { Estratégicas", que se especificam a partir do que é chamado de "Eixos } \\
\text { Estratégicos" e "Linhas Mestras de Ordenamento", que portanto são } \\
\text { designações bem definidas sobre qual deve ser objeto da AAE. Logo, as } \\
\text { "Questões Estratégicas" se apresentam como um detalhamento das questões } \\
\text { que devem ser avaliadas, que em seguida serão sobrepostas aos demais } \\
\text { elementos do processo de Focalização. }\end{array}$ \\
\hline Caso 4 & $\begin{array}{l}\text { Apresenta-se como "Draf Plan", o documento que contêm as intenções e } \\
\text { objetivos iniciais da estratégia. A definição sobre quais questões devem ser } \\
\text { objeto da AAE, se desenvolve após a análise dos stakeholders e da consulta } \\
\text { pública. }\end{array}$ \\
\hline Síntese & $\begin{array}{l}\text { Apesar de apresentar diferentes nomenclaturas, em todos os casos o aspecto } \\
\text { contextual se apresenta como uma definição do que a ação estratégica tem } \\
\text { como objetivo e, também, como um documento que apresenta características } \\
\text { gerais sobre o que a AAE deverá se debruçar. Trata-se de um aspecto } \\
\text { contextual relevante, que é ponto de partida para as demais etapas do processo } \\
\text { de AAE. }\end{array}$ \\
\hline
\end{tabular}

$\underline{\text { Tabela } 10 \text { - Considerações sobre a análise de outras Políticas, Planos e Programas - PPPs }}$ A análise de outras Políticas, Planos e Programas - PPPs

\begin{tabular}{l|l}
\hline Caso 1 & $\begin{array}{l}\text { São confrontadas diretamente com o contexto da ação estratégica - “Key } \\
\text { messages”, não havendo ligações com outros elementos da etapa. Visa uma } \\
\text { verificação inicial dos objetivos do plano, evitando a sobreposição ou o } \\
\text { conflito de objetivos. }\end{array}$ \\
\hline Caso 2 & $\begin{array}{l}\text { Apresenta uma associação direta com o documento de contexto da ação } \\
\text { estratégica, o Relatório de Questões Principais. Ao ser traduzida em diretrizes } \\
\text { para a AAE, revela sobretudo os "Objetivos de Proteção Ambiental" a serem } \\
\text { considerados no escopo das avaliações, que incluem objetivos de diversas } \\
\text { escalas. }\end{array}$ \\
\hline
\end{tabular}




\begin{tabular}{|c|c|}
\hline Caso 3 & $\begin{array}{l}\text { Surge como um levantamento que visa estabelecer a influência de outras PPPs } \\
\text { sobre os objetivos do plano. Tal levantamento orienta a definição de Metas e } \\
\text { Objetivos de Sustentabilidade, que irão compor o Quadro de Referência } \\
\text { Estratégica para o estabelecimento dos Fatores Críticos de Decisão. }\end{array}$ \\
\hline Caso 4 & $\begin{array}{l}\text { Se desenvolve com o objetivo de verificar a sobreposição ou a falta de ações } \\
\text { ligadas às estratégias do futuro plano, para eventual inclusão diretamente ao } \\
\text { escopo da AAE. }\end{array}$ \\
\hline Síntese & $\begin{array}{l}\text { Nos casos } 1,2 \text { e } 3 \text {, percebe-se que a verificação de outras PPPs ocorre no } \\
\text { sentido de promover o aprimoramento das questões iniciais antes de serem } \\
\text { integradas ao escopo da AAE ou aplicadas para a determinação de seus } \\
\text { objetivos. Por sua vez, no estudo Irlandês (Caso 4) esta integração é feita } \\
\text { diretamente ao escopo. } \\
\text { De maneira geral, independente do momento de realização, a análise de outras } \\
\text { PPPs destina-se a verificar possíveis sobreposições ou conflitos entre os } \\
\text { objetivos de ações estratégias, o que pode resultar em maior amplitude das } \\
\text { questões abordadas. }\end{array}$ \\
\hline
\end{tabular}

Tabela 11 - Considerações sobre a importância da Baseline e a definição de Indicadores de AAE

A importância da etapa de Baseline e a definição de indicadores de AAE

\begin{tabular}{l|l}
\hline & $\begin{array}{l}\text { Se define a partir do trabalho dos consultores, tendo como } \\
\text { fundamento as especificações legais e as informações contextuais. } \\
\text { Os aspectos levantados pela Baseline são utilizados no } \\
\text { estabelecimento das "Questões de Sustentabilidade" e no momento } \\
\text { de definição dos objetivos e indicadores da AAE. }\end{array}$ \\
\hline Caso 2 & $\begin{array}{l}\text { Se desenvolve tendo como base as informações contextuais do } \\
\text { "Relatório de questões principais". No entanto, é a partir da } \\
\text { apreciação dos stakeholders que se definem quais são os problemas } \\
\text { ambientais mais significantes, o que contribui para um melhor } \\
\text { direcionamento desta etapa. }\end{array}$ \\
\hline
\end{tabular}




\begin{tabular}{|c|c|}
\hline Caso 3 & $\begin{array}{l}\text { Neste caso a baseline é referenciada como "Questões Ambientais", } \\
\text { exclusivamente a partir de temas pré-definidos legalmente, para os } \\
\text { quais o processo de avaliação define a pertinência de sua } \\
\text { consideração, quais os fatores a serem considerados (amplitude) e } \\
\text { com qual nível de detalhamento (profundidade). }\end{array}$ \\
\hline Caso 4 & $\begin{array}{l}\text { A baseline integra conteúdos pré-definidos legalmente, que são } \\
\text { associados às demais etapas do scoping para a definição dos } \\
\text { principais "Obstáculos, Oportunidades e Metas" a serem } \\
\text { considerados. }\end{array}$ \\
\hline Síntese & $\begin{array}{l}\text { Apesar de não ser apresentado de forma de clara como se dá a } \\
\text { definição dos temas a serem analisados e sua elaboração, percebe- } \\
\text { se que seu desenvolvimento é baseado nas informações contextuais } \\
\text { e orientado pelos aspectos institucionais da AAE em cada caso. Esta } \\
\text { etapa se caracteriza como ponto de partida para o desenvolvimento } \\
\text { dos objetivos de AAE. }\end{array}$ \\
\hline $\begin{array}{c}\text { Sobre a definição } \\
\text { de Indicadores de } \\
\text { AAE }\end{array}$ & $\begin{array}{l}\text { Em todos os casos verificados não há um explicação sobre } \\
\text { procedimentos que definem os indicadores de AAE, apresentando- } \\
\text { se apenas a sua indicação junto aos objetivos de AAE. Verifica-se } \\
\text { uma clara influência da baseline, corroborando o referencial } \\
\text { teórico. }\end{array}$ \\
\hline
\end{tabular}


Tabela 12 - Considerações sobre como ocorre a consideração de aspectos voltados à promoção da sustentabilidade

\section{A promoção da sustentabilidade}

No Caso 1 houve um destaque especifico para a promoção da sustentabilidade, tendo em vista a utilização, no sistema inglês de planejamento, de instrumento específico para esta finalidade (Sustainability Appraisal). Desta forma, destaca-se neste caso a realização do levantamento das chamadas "Questões de sustentabilidade", que evidenciam questões locais que necessitam de uma solução sustentável e que, por sua vez, são levadas em consideração pelos demais elementos que integram o scoping, na formulação dos objetivos de AAE.

No caso 3 a promoção da sustentabilidade decorreu essencialmente da Síntese observação de outras PPPs que se correlacionam com os objetivos da ação estratégica, não sendo identificados outros procedimentos relacionados. Fruto desta abordagem, os objetivos de sustentabilidade apresentados ao final constituem referências genéricas e vagas para o direcionamento da sustentabilidade na ação estratégica que está sendo avaliada.

Nos demais casos a promoção da Sustentabilidade é assumida como um objetivo intrínseco ao processo de AAE, ou seja, os procedimentos aplicados devem necessariamente buscar esta promoção. Nestes casos, a promoção da sustentabilidade, e evidentemente a proteção ambiental, pode ser compreendida como consequência do processo de AAE.

\section{Conexões e interrelações identificadas}

A análise efetuada permitiu identificar as relações entre os elementos e ações que ocorrem dentro do processo de estabelecimento do Scoping, apresentadas na Tabela 13 a seguir. 
Tabela 13 - Relações verificadas entre os elementos do processo de scoping

\begin{tabular}{|c|c|c|c|c|c|}
\hline \multirow{2}{*}{$\begin{array}{c}\text { Casos } \\
\text { analisados }\end{array}$} & \multicolumn{5}{|c|}{ Elementos do processo de scoping } \\
\hline & stakeholders & baseline & $\begin{array}{l}\text { Informações } \\
\text { contextuais }\end{array}$ & Outras PPPs & $\begin{array}{c}\text { Promoção da } \\
\text { sustentabilidade }\end{array}$ \\
\hline Caso 1 & $\begin{array}{l}\text { Se conectam com } \\
\text { todas as ações } \\
\text { desenvolvidas, exceto } \\
\text { no desenvolvimento } \\
\text { da baseline. }\end{array}$ & $\begin{array}{l}\text { Tem influência na } \\
\text { definição das "Questões } \\
\text { de sustentabilidade" e na } \\
\text { formulação dos Objetivos } \\
\text { de AAE/SA. Contudo os } \\
\text { aspectos que a embasam } \\
\text { surgem das informações } \\
\text { contextuais. }\end{array}$ & $\begin{array}{l}\text { São objeto de discussão } \\
\text { junto aos stakeholders, à } \\
\text { participação pública e } \\
\text { utilizadas também na } \\
\text { análise de outras PPPs. } \\
\text { Subsidiam a baseline, o } \\
\text { desenvolvimento de } \\
\text { aspectos de } \\
\text { sustentabilidade e a } \\
\text { formulação dos Objetivos } \\
\text { de AAE. }\end{array}$ & $\begin{array}{l}\text { Apenas se conectam às } \\
\text { informações contextuais }\end{array}$ & $\begin{array}{l}\text { A sua formulação é } \\
\text { derivada da junção de } \\
\text { todos os elementos do } \\
\text { scoping. }\end{array}$ \\
\hline Caso 2 & $\begin{array}{l}\text { Se conectam com } \\
\text { todos os elementos do } \\
\text { processo de scoping. }\end{array}$ & $\begin{array}{l}\text { É fundamentada pelos } \\
\text { aspectos contextuais e } \\
\text { influencia diretamente na } \\
\text { formulação dos objetivos } \\
\text { de AAE, metas e } \\
\text { indicadores. }\end{array}$ & $\begin{array}{l}\text { Relacionam-se } \\
\text { diretamente na } \\
\text { formulação da baseline e } \\
\text { dos objetivos de AAE. } \\
\text { Apresenta uma conexão } \\
\text { mútua com a verificação } \\
\text { de outras PPPs, ou seja, } \\
\text { as duas construções são } \\
\text { dependentes. }\end{array}$ & $\begin{array}{l}\text { Se relaciona de forma } \\
\text { mútua com os aspectos } \\
\text { contextuais e influencia } \\
\text { diretamente no } \\
\text { estabelecimento dos } \\
\text { objetivos de AAE. }\end{array}$ & $\begin{array}{l}\text { Não há menção sobre o } \\
\text { desenvolvimento deste } \\
\text { aspecto. }\end{array}$ \\
\hline Caso 3 & $\begin{array}{l}\text { Apresentam-se como } \\
\text { responsáveis diretos } \\
\text { no desenvolvimento } \\
\text { de todas as } \\
\text { movimentações que } \\
\text { ocorrem no no }\end{array}$ & $\begin{array}{l}\text { A sua construção define } \\
\text { as "Questões Ambientais" } \\
\text { e é levada em } \\
\text { consideração, junto a } \\
\text { outros elementos, para o } \\
\text { desenvolvimento dos }\end{array}$ & $\begin{array}{l}\text { A sua definição formula } \\
\text { as “Questões } \\
\text { Estratégicas" e é levada } \\
\text { em consideração, junto a } \\
\text { outros elementos, no } \\
\text { desenvolvimento dos }\end{array}$ & $\begin{array}{l}\text { A sua construção } \\
\text { formula o "Quadro de } \\
\text { referência estratégica" e } \\
\text { também é levada em } \\
\text { consideração, junto a } \\
\text { outros elementos, no }\end{array}$ & $\begin{array}{l}\text { A sua construção é } \\
\text { realizada a partir da } \\
\text { observação de "Outras } \\
\text { PPPs" e integra o } \\
\text { "Quadro de referência } \\
\text { estratégica", que se }\end{array}$ \\
\hline
\end{tabular}




\begin{tabular}{|l|l|l|l|l|l|}
\hline & $\begin{array}{l}\text { momento da } \\
\text { "Focalização" }\end{array}$ & $\begin{array}{l}\text { "Fatores Críticos de } \\
\text { Decisão". }\end{array}$ & $\begin{array}{l}\text { "Fatores Críticos de } \\
\text { Decisão". }\end{array}$ & $\begin{array}{l}\text { desenvolvimento direto } \\
\text { dos "Fatores Críticos de } \\
\text { Decisão". }\end{array}$ & $\begin{array}{l}\text { conecta diretamente ao } \\
\text { estabelecimento dos } \\
\text { "Fatores Críticos de } \\
\text { Decisão". }\end{array}$ \\
\hline Caso 4 & $\begin{array}{l}\text { Conectam-se } \\
\text { diretamente à } \\
\text { formulação dos } \\
\text { objetivos iniciais do } \\
\text { plano. }\end{array}$ & $\begin{array}{l}\text { A baseline influencia } \\
\text { diretamente na elaboração } \\
\text { do scoping, mas esta } \\
\text { apenas se firma a partir } \\
\text { do estabelecimento de } \\
\text { "Objetivos, oportunidades } \\
\text { e metas" quando da } \\
\text { finalização do escopo. } \\
\text { Logo, é uma relação de } \\
\text { construção mutua. }\end{array}$ & $\begin{array}{l}\text { Relacionam-se } \\
\text { diretamente à etapa de } \\
\text { scoping, na definição de } \\
\text { objetivos de AAE, metas } \\
\text { e indicadores. }\end{array}$ & $\begin{array}{l}\text { Relacionam-se } \\
\text { diretamente no } \\
\text { momento de elaboração } \\
\text { do scoping. }\end{array}$ & $\begin{array}{l}\text { Nesenvolvimento dos } \\
\text { indicadores. }\end{array}$ \\
\hline
\end{tabular}


A análise realizada permitiu caracterizar o processo de scoping a partir do detalhamento do papel desempenhado pelos elementos que o integram e da identificação das relações existentes entre eles. O produto da análise realizada nesta etapa da pesquisa pode ser sintetizado em um diagrama que ilustra, a partir dos inputs de cada caso analisado, o modo como o escopo da AAE foi desenvolvido na prática.

Nota-se que os elementos destacados se colocam de modo independente, sem sequenciamento de ações ou relações de interdependência entre si, uma vez que tal característica também foi percebida nos casos analisados, de modo que não há necessariamente um ponto de partida para o desenvolvimento da etapa de scoping. Considera-se, portanto, que estes elementos são necessários para o desenvolvimento do scoping, embora não tenham sido verificados em todos os casos. As relações indicadas pelo diagrama constituem todas as relações identificadas nos casos analisados e refletem, sobretudo, a capacidade de adaptação e a flexibilização que o instrumento pode adquirir nos diferentes sistemas de AAE.

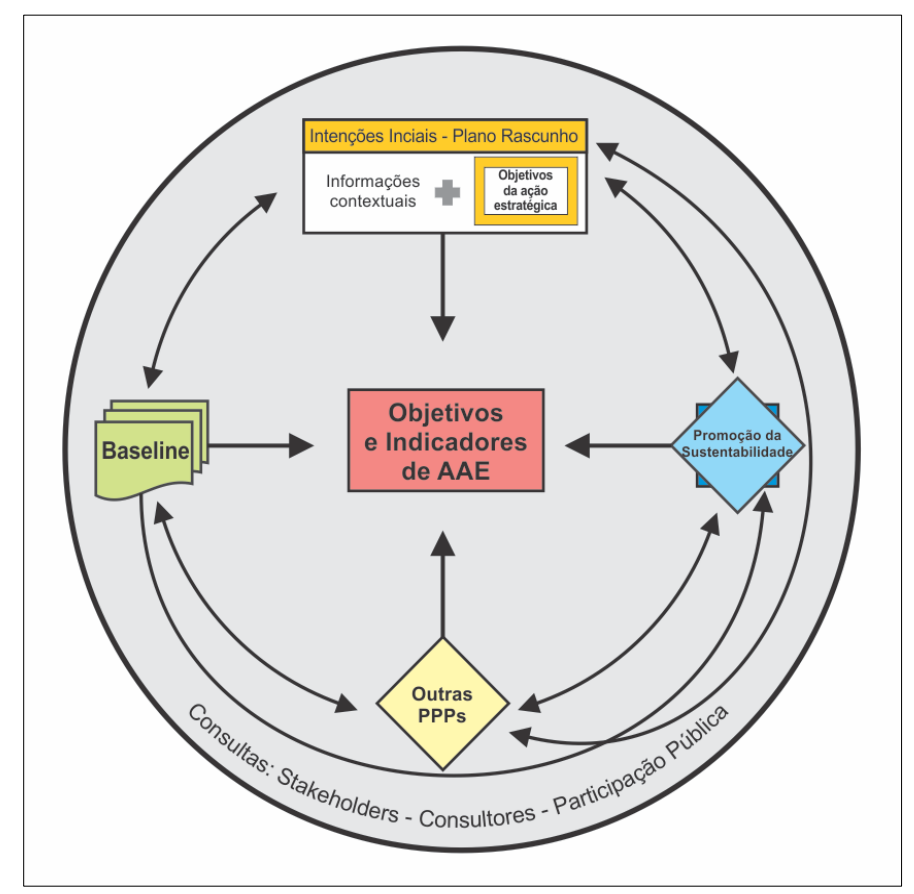

Figura 39 - Modelo síntese representativo para o estabelecimento da etapa de Scoping segundo os casos analisados 
Dessa maneira, as descrições aqui desenvolvidas caracterizam como o momento de scoping pode ser concebido a partir da prática da AAE aplicada ao planejamento do uso do solo.

\subsection{Discussões - os aspectos conceituais e práticos para a formulação do escopo da} AAE

As discussões aqui desenvolvidas procuram relacionar os aspectos conceituais trabalhados durante a revisão bibliográfica e aqueles identificados a partir da análise dos quatro casos da prática.

\section{A função da $A A E$ segundo a teoria e a prática.}

O conceito de AAE vem evoluindo nas últimas décadas, mas como já retratado anteriormente, sofreu alterações e interpretações decorrentes de mudanças na visão do propósito de aplicação do instrumento.

Por exemplo Therivel (2010) define a AAE como um processo que visa integrar as considerações ambientais e de sustentabilidade na tomada de decisão. Enquanto que Partidário (2012), argumenta que a proposta da AAE é ajudar a entender o contexto de desenvolvimento da estratégia, para apropriadamente identificar os problemas, as potencialidades, a abordar as principais tendências e avaliar a opções viáveis em termos ambientais e sustentáveis que permitiriam atingir os objetivos estratégicos.

As diferentes conceituações do objetivo da AAE têm reflexos diretos sob a forma como a AAE é desenvolvida na prática. Em contraposição, é valido lembrar que não há conceituação sem ação e evidentemente o conceito de AAE está em constante mutação.

A literatura também ressalta os benefícios da aplicação da AAE, como por exemplo, enquanto um instrumento integrador dos aspectos ambientais na ação estratégica, além de orientador da proteção ambiental e do desenvolvimento sustentável, promotor da participação efetiva dos envolvidos, que pode contribuir para tornar o processo de tomada de decisão menos sujeito a manipulações políticas, e que se posiciona de forma flexível ao processo de decisão, favorecendo a hierarquização de valores ambientais ao longo dos níveis estratégicos de ação (SADLER, 2005; DESMOND, 2007; FISCHER, 2007; THERIVEL, 2010; PARTIDÁRIO, 2012).

Contudo, ao se observar como os casos analisados apresentam a função da AAE (Tabela 14) é possível verificar que a relação entre o papel e os benefícios da AAE se 
misturam. Por exemplo, todos os casos admitem que o papel da AAE está relacionado, de alguma forma, à promoção da questão ambiental e também indicam a capacidade de promoção da sustentabilidade, sendo este apontado pela literatura como um benefício do instrumento.

Tabela 14 - A função da AAE segundo os casos analisados.

\begin{tabular}{|c|c|}
\hline $\begin{array}{c}\text { Casos } \\
\text { analisados }\end{array}$ & Função da Avaliação Ambiental Estratégica \\
\hline $\begin{array}{l}\text { Caso } 1- \\
\text { Inglaterra }\end{array}$ & $\begin{array}{l}\text { - Promover o desenvolvimento sustentável; } \\
\text { - Assegurar um elevado nível de proteção do ambiente; } \\
\text { - Integrar a sustentabilidade e as considerações ambientais na elaboração de } \\
\text { planos e programas; } \\
\text { - Fornecer um mecanismo para assegurar que a sustentabilidade através de } \\
\text { objetivos se traduzam em políticas de planejamento sustentável; } \\
\text { - Refletir preocupações globais, nacionais, regionais e locais; } \\
\text { - Fazer parte integrante de todas as fases da elaboração do plano. }\end{array}$ \\
\hline $\begin{array}{l}\text { Caso } 2 \text { - } \\
\text { Escócia }\end{array}$ & $\begin{array}{l}\text { - Proporcionar um elevado nível de proteção do meio ambiente; } \\
\text { - Tornar as considerações ambientais de modo integrado na preparação de } \\
\text { planos e, bem como, a sua adoção; } \\
\text { - Promover o desenvolvimento sustentável; } \\
\text { - Aumentar a participação pública nas tomada de decisão ambiental. }\end{array}$ \\
\hline $\begin{array}{l}\text { Caso } 3 \text { - } \\
\text { Portugal }\end{array}$ & $\begin{array}{l}\text { - Direcionar a formulação do plano a partir da consideração de opções } \\
\text { estratégicas e de um contexto de sustentabilidade. }\end{array}$ \\
\hline $\begin{array}{l}\text { Caso } 4 \text { - } \\
\text { Irlanda }\end{array}$ & $\begin{array}{l}\text { - Compreender as questões ambientais existentes na localidade; } \\
\text { - Compreender que os efeitos significantes no ambiente são resultados da } \\
\text { implementação do futuro plano; } \\
\text { - Reduzir e monitorar os impactos; } \\
\text { - Formular metas e objetivos ambientais estratégicos que façam parte do futuro } \\
\text { plano. }\end{array}$ \\
\hline
\end{tabular}

Dessa maneira é possível compreender que a evolução conceitual da função da AAE decorre diretamente do conhecimento acumulado com a prática do instrumento e que se rebate no modo como são definidos os aspectos institucionais que orientam a sua aplicação. Também se compreende, a partir do exposto, como a construção teórica e conceitual do instrumento evolui como um reflexo das ações práticas.

\section{A promoção da sustentabilidade na AAE e a etapa de scoping.}

A perspectiva de promoção da sustentabilidade através da AAE é retratada na literatura como um movimento decorrente do aumento de foco em relação ao alcance do instrumento, estendendo-o aos pilares da sustentabilidade (FISCHER, 2007; WALLINGTON, 2007). White \& Noble (2012) indicam que a capacidade de promover 
a sustentabilidade é uma condição contextual, sobretudo quando estes princípios estão bem estabelecidos, e Wallington (2007) considera que este aspecto é decorrente do foco estratégico estabelecido, ou seja, o sucesso da sustentabilidade a partir da AAE é um fator muito mais circunstancial do que dependente de uma estrutura metodológica.

Neste sentido o momento de elaboração do escopo da AAE é tido como aquele que reúne condições amplamente favoráveis para se discutir, dentre outras questões, se/como o processo avaliativo deverá buscar a incorporação dos aspectos relativos à sustentabilidade. Durante a revisão bibliográfica foi possível compreender que é neste momento que se inicia este debate, que pode se desenvolver de modo simples - ainda que correndo o risco de ser vago - por meio da observação de outras PPPs ou mesmo de marcos legais voltados à promoção da sustentabilidade e que tenham relação direta com o objeto da AAE.

Tal perspectiva também é visível no conjunto de casos analisados, ainda que se manifestem de diferentes modos. Por exemplo Caso 3 - Portugal, a questão da sustentabilidade foi integrada ao processo de scoping basicamente a partir da observação de outras PPPs, ao passo que no Caso 1 - Inglaterra, os procedimentos aplicados ao scoping sugerem uma preocupação mais elevada com esse aspecto ao discutir a sustentabilidade da ação estratégica a partir de outros elementos que não somente as demais PPPs - incluindo as considerações formuladas na baseline e por meio da participação pública, por exemplo.

Assim, afastando a perspectiva de algo opcional, facultativo, relacionado à promoção da sustentabilidade pelo processo de AAE, reitera-se as colocações de White $\&$ Noble (2012), no sentido de que assumir essa responsabilidade é um dos principais desafios colocados para o desenvolvimento da AAE.

\section{As abordagens metodológicas e a integração da AAE na tomada de decisão estratégica.}

Como verificado por meio da revisão bibliográfica, a literatura apresenta e discute diferentes abordagens para a condução do processo de AAE, com perspectivas distintas para o papel deste instrumento na tomada de decisão estratégica. A Figura 40 apresenta duas concepções distintas - segundo Partidário (2012) e Fischer (2007) - a respeito de como o processo de AAE pode ser desenvolvido. 


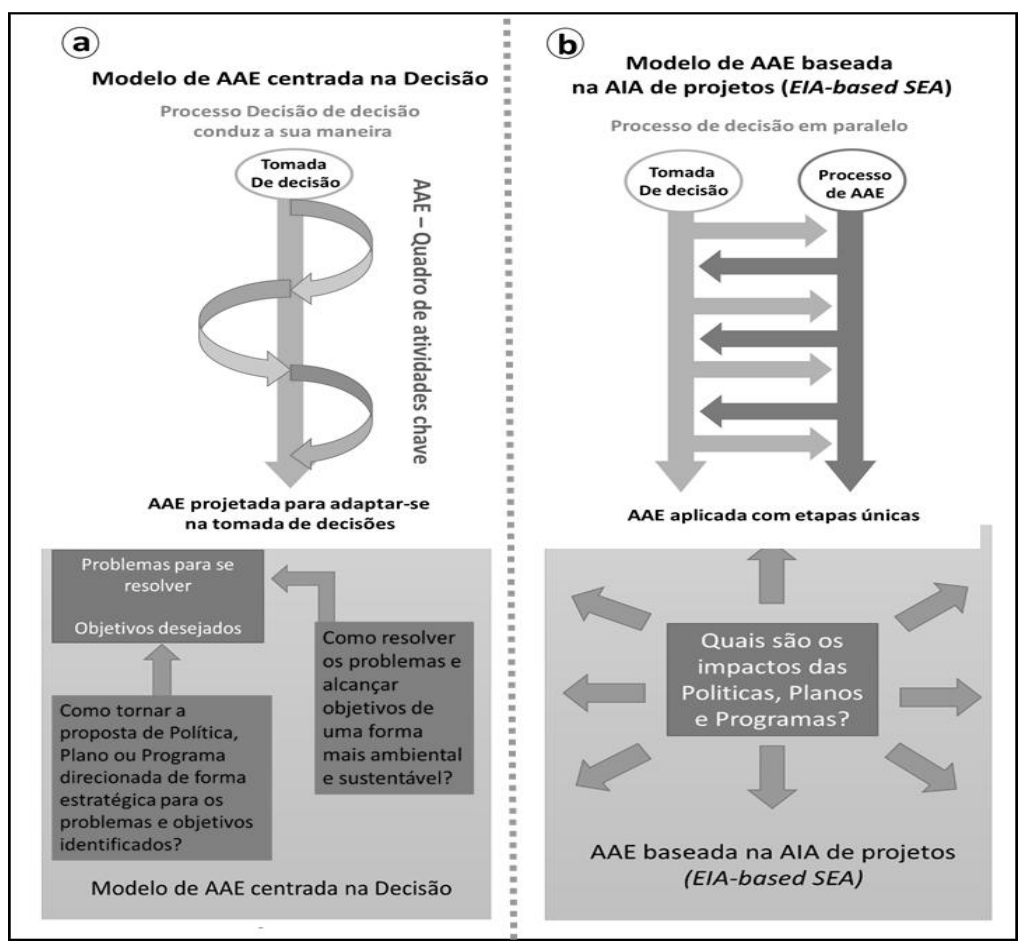

Figura 40 - O modelo de AAE centrada na decisão (a) e o modelo de AAE baseado na AIA de projetos (b).

Partidário (2012), destaca que a integração da AAE ao processo de tomada de decisão, em termos teóricos, pode se dar:

1. De forma totalmente separada, com uma única oportunidade de se desenvolver, podendo correr o risco perder o timing para influenciar a decisão;

2. De forma paralela, com equipes separadas que, de modo coordenado, se correspondem no desenvolvimento da ação estratégica e da avaliação ambiental e, assim, ambos devem ocorrer no mesmo tempo;

3. De forma integrada, com a mesma coordenação, sem qualquer distinção de equipes, mas que produzem, em geral, relatórios finais diferentes. Esta forma teria como desvantagem o fato de não possibilitar a identificação clara dos papéis desempenhados por cada um dos instrumentos;

4. De forma centrada na decisão, cujas características essenciais são a capacidade de se moldar e corresponder à ação estratégica, de acordo com as especificidades de cada ação estratégica. É apontada pela autora como a que melhor promove o caráter estratégico da AAE. 
Segundo a autora, os dois primeiros modelos têm suas raízes na AIA de projetos, enquanto que os seguintes estão voltados a abordagens de AAE integradas e estratégicas. A Figura 41 a seguir ilustra o exposto.

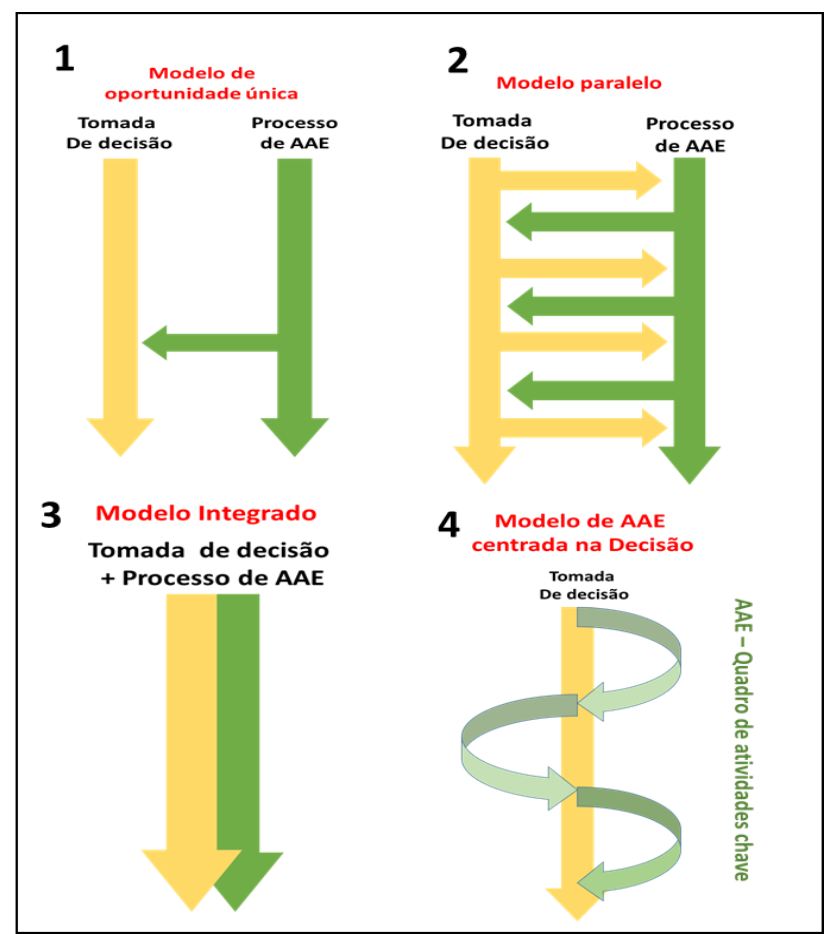

Figura 41 - Modelos de integração da AAE a tomada de decisão segundo Partidário (2012)

Com relação aos casos analisados, a maneira de integração do processo de AAE à tomada de decisão estratégica é apontada na Tabela 15 a seguir.

Tabela 15 - Formas de integração da AAE a tomada de decisão nos casos analisados

\begin{tabular}{|c|c|c|c|c|}
\hline $\begin{array}{c}\text { Casos } \\
\text { analisados }\end{array}$ & Caso 1 - Inglaterra & Caso 2 - Escócia & $\begin{array}{l}\text { Caso } 3 \text { - } \\
\text { Portugal }\end{array}$ & Caso 4 - Irlanda \\
\hline $\begin{array}{c}\text { Descrição } \\
\text { da } \\
\text { integração } \\
\text { da AAE }\end{array}$ & $\begin{array}{c}\text { A AAE/SA ocorre } \\
\text { junta ao "Draft Plan", } \\
\text { que por sua vez serve } \\
\text { de base para a } \\
\text { elaboração do Quadro } \\
\text { de Desenvolvimento } \\
\text { local. }\end{array}$ & $\begin{array}{l}\text { A AAE se } \\
\text { reflete na } \\
\text { elaboração do } \\
\text { Relatório de } \\
\text { Questões } \\
\text { Principais - } \\
\text { "Main Issues } \\
\text { Report”, que } \\
\text { serve de base } \\
\text { para construção } \\
\text { da ação } \\
\text { estratégica }\end{array}$ & $\begin{array}{c}\text { Processo } \\
\text { ocorre de modo } \\
\text { centrado à } \\
\text { tomada de } \\
\text { decisão e, } \\
\text { aparentemente, } \\
\text { presente em } \\
\text { todos os } \\
\text { momentos da } \\
\text { ação } \\
\text { estratégica. }\end{array}$ & $\begin{array}{c}\text { Sugere haver } \\
\text { integração entre o } \\
\text { desenvolvimento da } \\
\text { tomada de decisão e } \\
\text { as avaliações que } \\
\text { ocorrem. }\end{array}$ \\
\hline
\end{tabular}


Não constitui propósito do presente trabalho classificar os casos analisados em relação às diferentes perspectivas apontadas por Partidário (2012) ou qualquer outra referência. Tal classificação só poderia ser levada a cabo, evidentemente, com uma análise detalhada do processo de tomada de decisão, e não apenas baseado nas informações prestadas pelo relatório de AAE e alguns poucos documentos associados.

Ainda assim, tomando-se como base as colocações da autora, é possível visualizar diferentes possibilidades de integração da $\mathrm{AAE}$ ao processo decisório, nos casos analisados. Tal fato permite resgatar a necessidade do instrumento se colocarem de modo mais proativo em relação à tomada de decisões, ainda que não haja evidências que permitam justificar um ou outro modelo ou abordagem, como fazem Lobos \& Partidário (2014). Ainda assim, é importante ficar atento ao paradoxo da $A A E$, conforme apontado por Bidsturp \& Hansen (2014), segundo o qual haveria uma ambiguidade metodológica que tende a tornar a prática do instrumento cada vez menos estratégica.

\section{O processo de scoping segundo a teoria e a prática.}

Durante o desenvolvimento da etapa de revisão bibliográfica e na análise da desenvolvida sobre o scoping nos quatro casos selecionados, foi possível elaborar um diagrama síntese e representativo de ambas as perspectivas - teórica e prática (Figura 42).

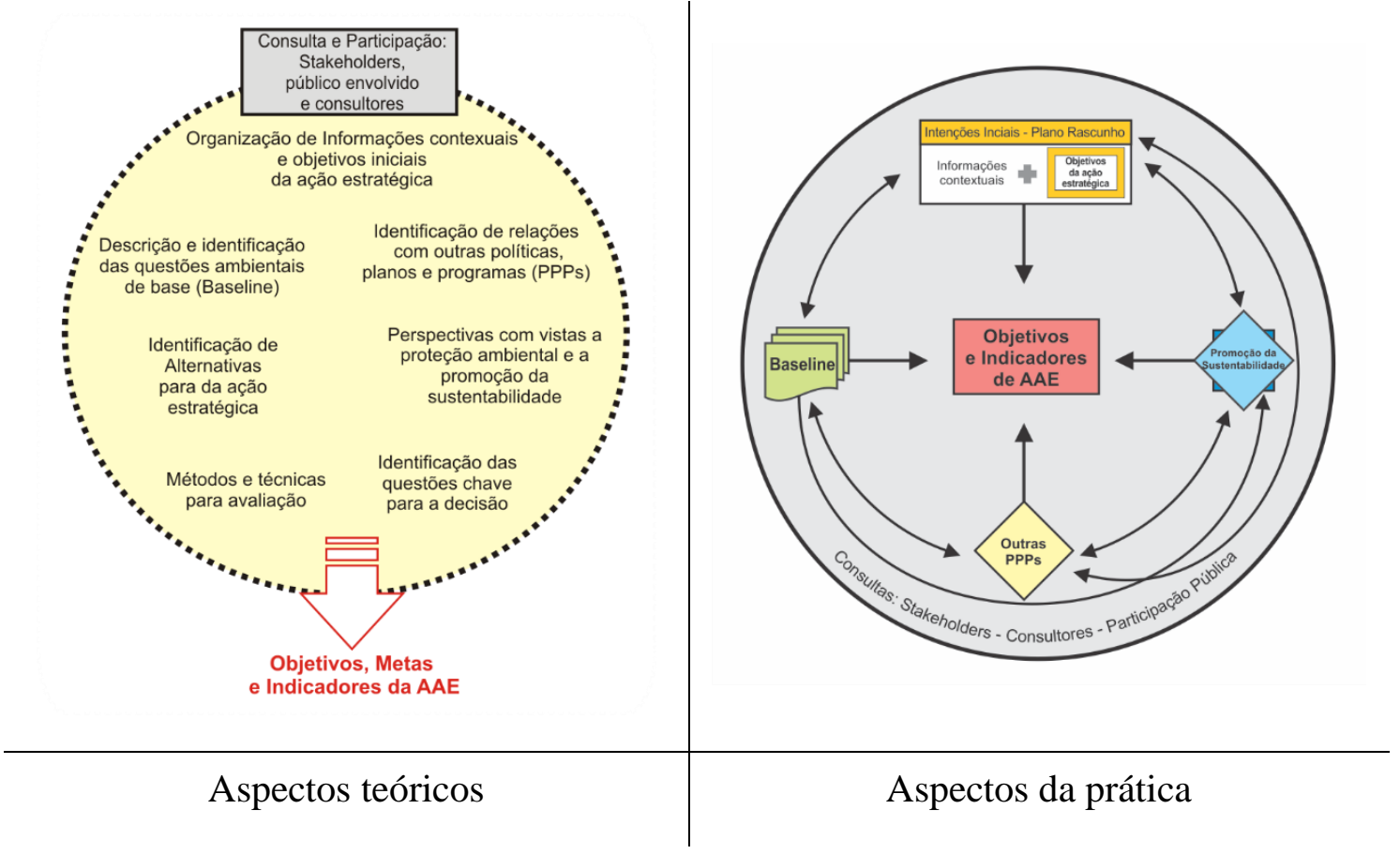

Figura 42 - Diagramas síntese da formulação teórica e prática da etapa de scoping. 
As diferenças e similaridades entre os dois diagramas permitem observar os aspectos da relação entre teoria e prática, ou seja, como os elementos citados na teoria se refletem sobre o conjunto de casos da prática de AAE para o uso do solo.

Neste sentido, foi possível identificar em todas as aplicações analisadas a presença da maior parte dos elementos descritos pela base teórica, que constituem o principal ponto em comum entre as duas esferas:

1. As informações contextuais;

2. A etapa de Baseline;

3. A verificação de outras PPPs;

4. O desenvolvimento de uma perspectiva de sustentabilidade.

Ou seja, estes elementos podem ser considerados como os pilares da prática da AAE em relação ao processo de scoping.

Por sua vez, aqueles elementos descritos teoricamente que não foram identificados em todos os casos analisados, ou em nenhum deles, sugerem que estão mais suscetíveis ao contexto de aplicação do instrumento. São eles:

1. A definição explícita de métodos e técnicas para a avaliação;

2. A identificação de alternativas para a ação estratégica;

3. A identificação de questões-chave para a decisão.

Destes, apenas a definição de "métodos e técnicas para a avaliação" não foi visualizada em nenhum dos casos.

As conexões entre os diferentes elementos que constituem o processo de scoping nos casos analisados são aspectos vinculados às abordagens metodológicas adotadas em cada situação. Assim, perceber a interatividade entre os elementos pode ser entendido como a principal contribuição do presente trabalho para a compreensão do processo de scoping em AAEs aplicadas ao planejamento urbano e do uso do solo.

A Figura 43 apresenta por meio de um diagrama a síntese entre os aspectos teóricos e aqueles identificados ao longo do presente trabalho. Finalmente, a Tabela 16 descreve o significado de cada elemento gráfico, permitindo compreender o diagrama. 


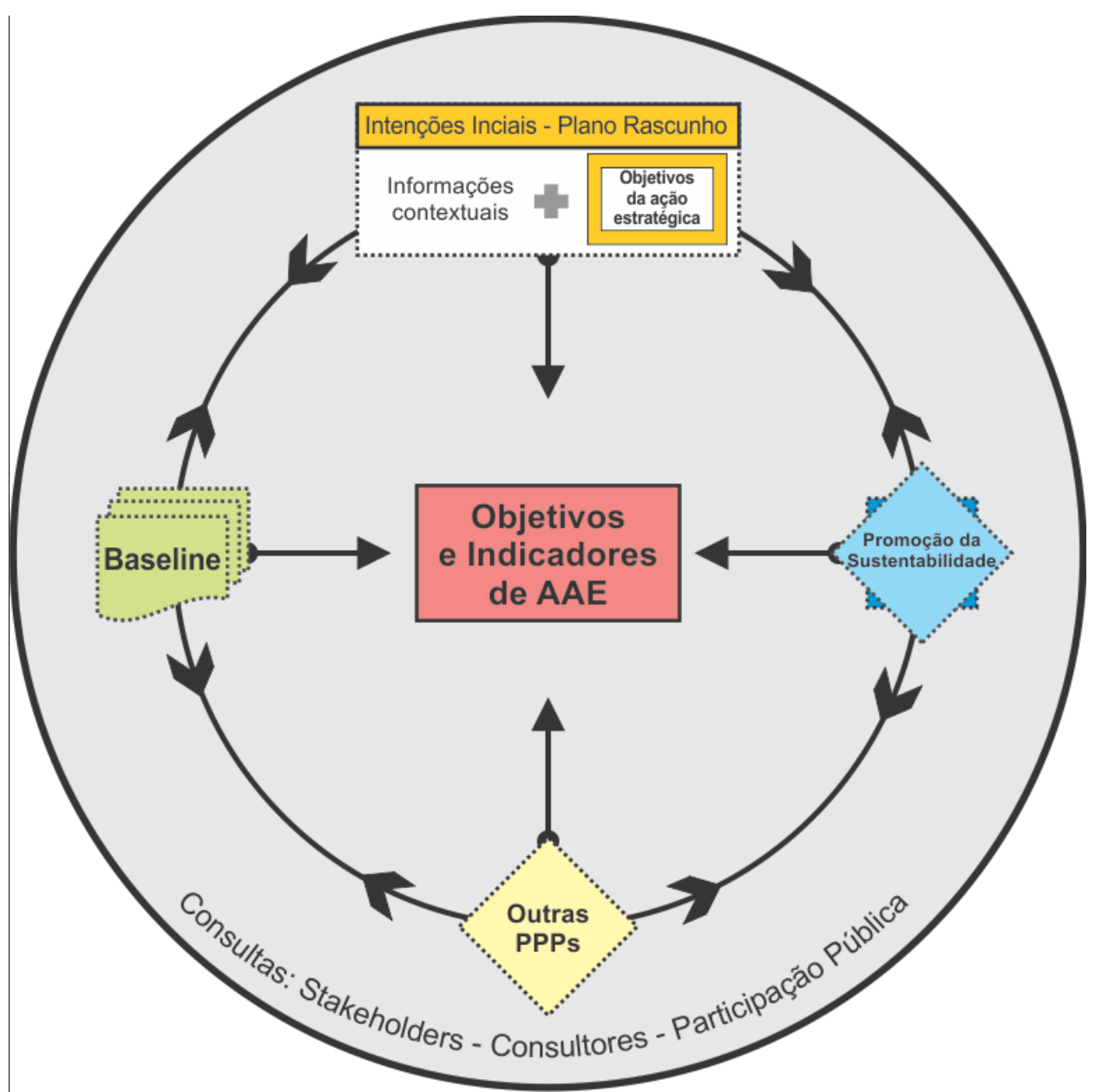

Figura 43 - Diagrama síntese das concepções teóricas e práticas para o estabelecimento do scoping

Tabela 16 - Características dos elementos envolvidos no momento de scoping segundo o conjunto de casos analisados.

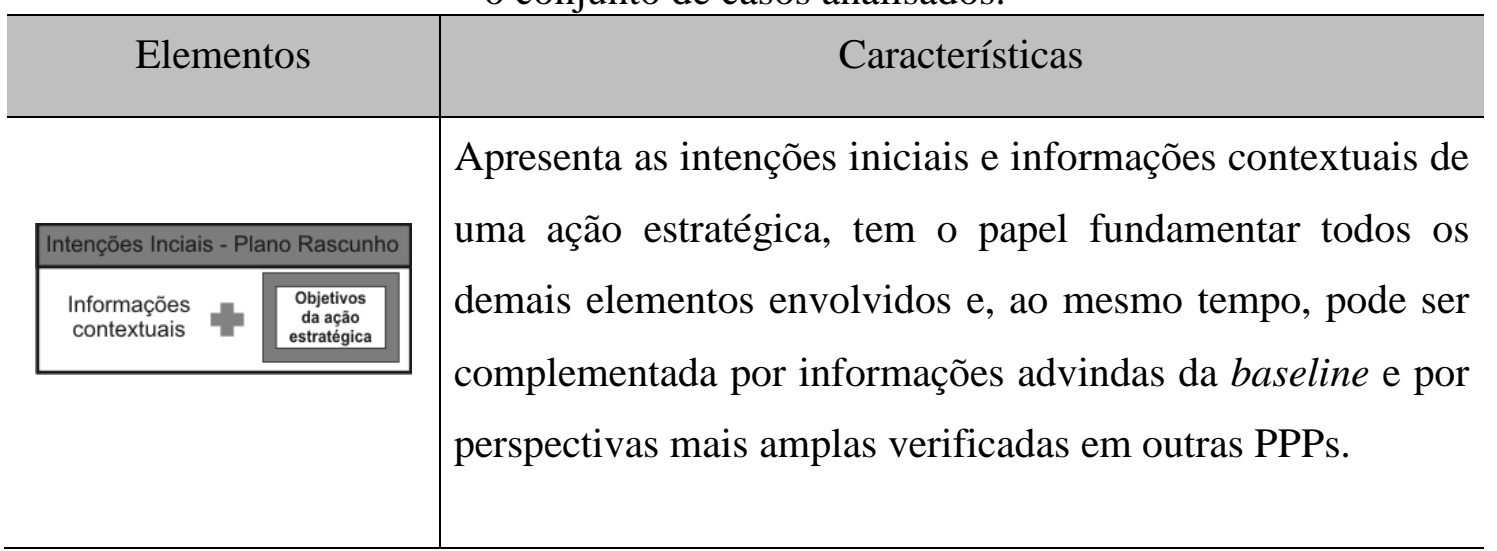




Apesar dos conteúdos desta etapa estarem geralmente
vinculados a aspectos legais, como a Diretiva Europeia de
AAE, os principais insumos advêm essencialmente das
informações contextuais.
Ao mesmo tempo, as informações de base permitem ampliar
o campo de verificação de outras PPPs relacionadas, que por
sua vez também pode indicar à baseline a necessidade de
novas observações.




\begin{tabular}{l|l}
\hline Este elemento compreender aquele que integra os demais, a \\
fim de identificar as questões pertinentes à ação estratégica e \\
procurar alternativas a partir de uma perspectiva sustentável. \\
Podem ser consideradas as informações contextuais, as de \\
Baseline, bem como as perspectivas de outras PPPs. \\
Sustentabilidade
\end{tabular} \mid $\begin{aligned} & \text { Ao mesmo tempo, a busca por respostas mais sustentáveis } \\
& \text { pode realimentar a etapa de informações contextuais e, } \\
& \text { consequentemente, os objetivos iniciais da ação estratégica, } \\
& \text { ou seja, o processo de AAE se inicia com visão mais ampla e } \\
& \text { sustentável. } \\
& \text { Quanto à etapa de verificação de outras PPPs, esta pode ser } \\
& \text { condicionada com base nos apontamentos de promoção da } \\
& \text { sustentabilidade. } \\
& \text { Vale ressaltar que, a definição de sustentabilidade é relativa e } \\
& \text { especifica a cada caso, situação ou contexto. Neste esquema, } \\
& \text { a promoção da sustentabilidade deve ser compreendida como } \\
& \text { o momento de visualizar as questões pertinentes a partir de } \\
& \text { uma perspectiva própria do que seria a sustentabilidade. }\end{aligned}$




\begin{tabular}{|c|c|}
\hline & $\begin{array}{l}\text { A etapa de Consultas se define a todo o processo com o qual } \\
\text { se promove a participação, consulta e comunicação dos } \\
\text { envolvidos e influenciados pela ação estratégica. }\end{array}$ \\
\hline Consultas & $\begin{array}{l}\text { Neste caso incluem-se os stakeholders, agentes sociais } \\
\text { diretamente ligados à ação estratégica, os consultores, os }\end{array}$ \\
\hline $\begin{array}{l}\text { Stakeholders } \\
\text { Participação } \\
\text { Pública } \\
\text { Consultores }\end{array}$ & $\begin{array}{l}\text { como a Participação Pública como um todo, na qual envolve } \\
\text { aqueles que direta e indiretamente são afetados pelo } \\
\text { desenvolvimento da ação estratégica. }\end{array}$ \\
\hline & $\begin{array}{l}\text { No modelo síntese a etapa de consulta se faz presente em } \\
\text { todas as etapas e se torna essencial para o estabelecimento de } \\
\text { cada uma delas, assim como para o estabelecimento dos } \\
\text { objetivos de AAE. }\end{array}$ \\
\hline $\begin{array}{l}\text { Objetivos } \\
\text { e Indicadores } \\
\text { de AAE }\end{array}$ & $\begin{array}{l}\text { A definição dos objetivos e indicadores de avaliação } \\
\text { ambiental estratégica pode ser condicionada pelas } \\
\text { contribuições do produto de cada etapa desenvolvida. No } \\
\text { entanto, a sobreposição destes só se desenvolve com sucesso } \\
\text { se for trabalhada em conjunto com os inputs do processo de } \\
\text { Consulta, ou seja, da participação dos diretamente afetados e } \\
\text { envolvidos. }\end{array}$ \\
\hline Conexס̃es & $\begin{array}{l}\text { As conexões possíveis entre os elementos do Scoping, podem } \\
\text { e devem ocorrer de acordo com a necessidade do processo } \\
\text { avaliativo, de modo a permitir a sua integração para o } \\
\text { estabelecimento dos Objetivos, Indicadores e Metas de AAE. }\end{array}$ \\
\hline
\end{tabular}


Esta construção torna possível definir em que consiste a etapa de scoping nas AAEs avaliadas no presente trabalho. Trata-se do momento de estabelecimento do foco do processo de AAE em relação ao seu objeto de análise, sendo necessário desenvolver um conjunto de elementos processuais que permitam melhor compreender a relação entre os propósitos da ação estratégica e os seus efeitos ambientais.

Dentre estes elementos, encontram-se a organização das informações contextuais iniciais da ação estratégica, o desenvolvimento da etapa de Baseline ou de pré-organização de informações sobre o estado corrente do ambiente, a visualização de outras PPPs com relação direta sobre a ação estratégica e a configuração de um quadro de referência para a promoção da sustentabilidade nas ações a serem desenvolvidas.

Para o desenvolvimento destas ações é fundamental a participação do público envolvido, dos consultores e dos stakeholders, além de ser essencial o estabelecimento de conexões e interrelações que permitam a integração de cada um dos elementos em direção ao estabelecimento dos objetivos, metas e indicadores da Avaliação Ambiental Estratégica. 


\section{ILUSTRAÇÃO DO POTENCIAL DE CONTRIBUIÇÃO DA AAE AOS PLANOS DIRETORES MUNICIPAIS}

Com o intuito de ilustrar a potencial contribuição da AAE em relação à promoção da sustentabilidade como elemento estratégico na elaboração de Planos Diretores de Desenvolvimento Urbano no Brasil, o presente capítulo adota como objeto de discussão o caso do município de São Carlos (SP).

Desta maneira, pode-se discutir a perspectiva de inserção da AAE (e seus fundamentos) no processo de elaboração e revisão dos Planos Diretores municipais, levando-se em consideração seu contexto de aplicação no Brasil. Evidentemente, não encontra-se entre as pretensões deste capítulo discutir ou sequer sugerir a efetividade do instrumento caso aplicado no país, muito embora outros trabalhos já tenham apontado para esta perspectiva indicando a necessidade de introdução da AAE como mecanismo de promoção da variável ambiental no planejamento urbano.

Primeiramente, é necessário compreender o contexto de elaboração dos PDs e em que momento a AAE poderia ser inserida. A possibilidade inserção da AAE se estabelece, de modo amplo, devido ao fato do Estatuto das Cidades compreender que as municipalidades brasileiras apresentam realidades únicas e assim estas são livres para, como quiserem, elaborarem os seus PDs. Ou seja, os municípios podem empregar diversas metodologias para desenvolverem os seus PDs, desde que o processo garanta o diálogo entre a população e a administração pública e também que esse processo seja transparente em suas ações, como disposto no artigo 40 do Estatuto das Cidades:

" $4^{\circ}$ No processo de elaboração do plano diretor e na fiscalização de sua implementação, os Poderes Legislativo e Executivo municipais garantirão:

I - a promoção de audiências públicas e debates com a participação da população e de associações representativas dos vários segmentos da comunidade;

II - a publicidade quanto aos documentos e informações produzidos;

III - o acesso de qualquer interessado aos documentos e informações produzidas."

Assim, a situação evidenciada por Costa, Campante e Araújo (2011) sobre a subutilização dos instrumentos de planejamento urbano em prol das questões ambientais na gestão dos espaços urbanos ganha ainda mais destaque, visto que por mais benéfica 
que possa ser compreendida esta abertura oferecida pelo Estatuto, ela permite a continuidade da situação identificada pelos autores.

Em outras palavras, a autonomia existente permite uma elaboração flexível e contextualizada mas, ao mesmo tempo, abre espaço para o surgimento de ineficiências que são reforçadas por fatores de ordem política, econômica e social.

No entanto, a mesma flexibilidade oferecida pelo Estatuto permite entender que a inserção da AAE no processo de elaboração dos Planos Diretores constitui uma possibilidade concreta, sobretudo pelo alinhamento entre os princípios deste instrumento (caráter antecipatório, transparente e participativo) e os fatores mínimos de desenvolvimento dos PDs pelo Estatuto.

A figura 44 a seguir ilustra a situação atual, em que a tomada de decisão estratégica associada à elaboração de Planos Diretores ocorre sem a influência da AAE e como, de maneira genérica, o processo poderia incluir a AAE.

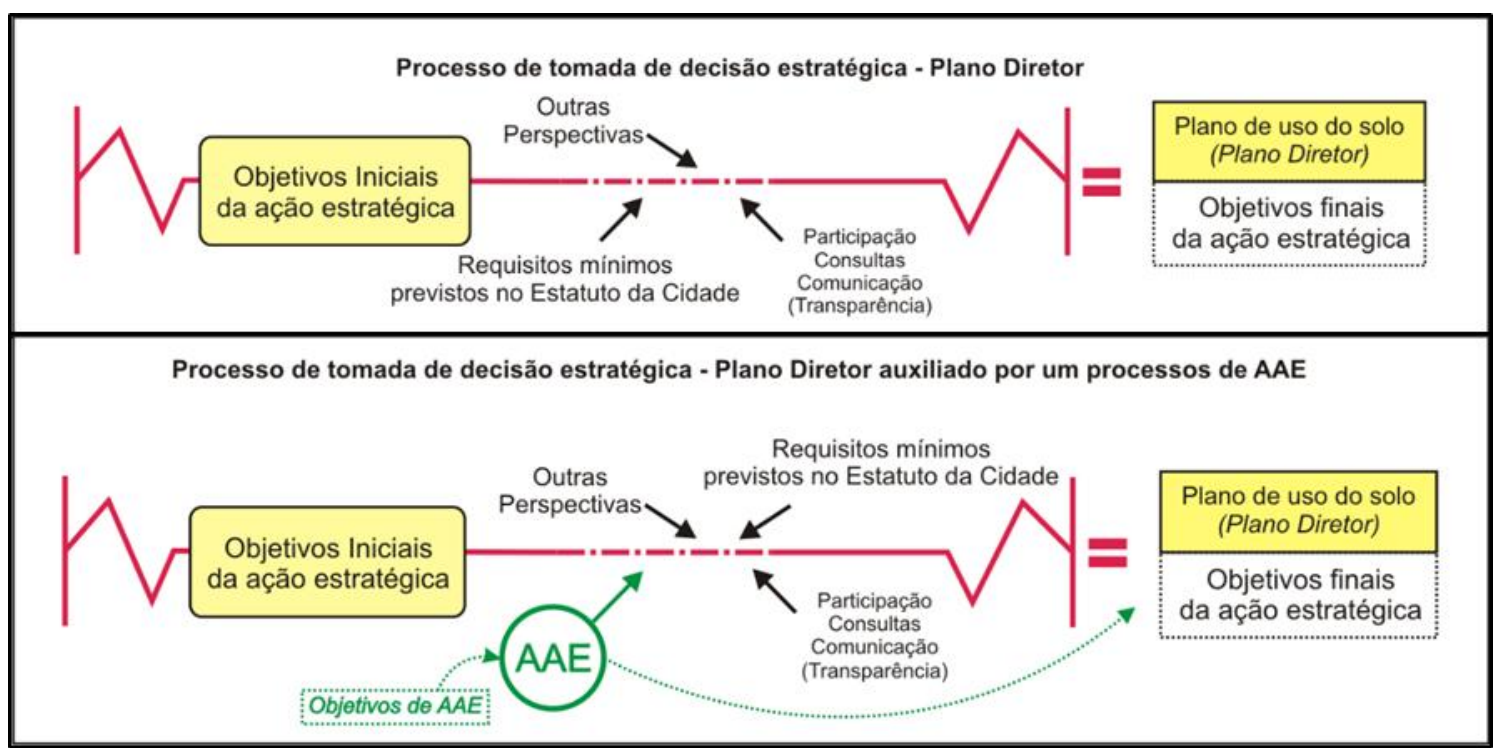

Figura 44 - Ilustração de como se desenvolveria o processo de tomada de decisão para o desenvolvimento de planos diretores municipais considerando a aplicação da AAE

Em uma integração hipotética do processo de AAE na tomada de decisão de Planos Diretores, entende-se que o processo permitiria a elevação e debate das questões ambientais e de sustentabilidade em um mesmo patamar de discussão das questões sociais e econômicas, além de outras vantagens acarretadas pela integração, como discutem Therivel (2004) e Fischer (2007).

Diante disto, a potencial contribuição da AAE como instrumento de elevação das questões ambientais e de sustentabilidade é desenvolvida a partir das seguintes 
discussões: a contribuição da AAE na promoção da sustentabilidade no Plano Diretor de São Carlos, e os elementos que orientariam o processo de scoping desta AAE.

O município de São Carlos está localizado na região central do Estado de São Paulo, a $230 \mathrm{~km}$ da capital paulista, possuindo uma área de $1.140,92 \mathrm{~km}^{2}$, sendo $67,25 \mathrm{~km}^{2}$ (6\% da área total) considerada urbana e atualmente, segundo o censo do IGBE-2010, possui cerca de 220 mil habitantes.

O município faz parte um dos eixos dinamizados pela força propulsora das Regiões Metropolitanas de São Paulo e de Campinas, no qual se caracteriza como um dos principais polos tecnológicos do Estado de São Paulo, abrigando um número significativo de indústrias de alta tecnologia e logística e, também, como centro de pesquisa e ensino universitário.

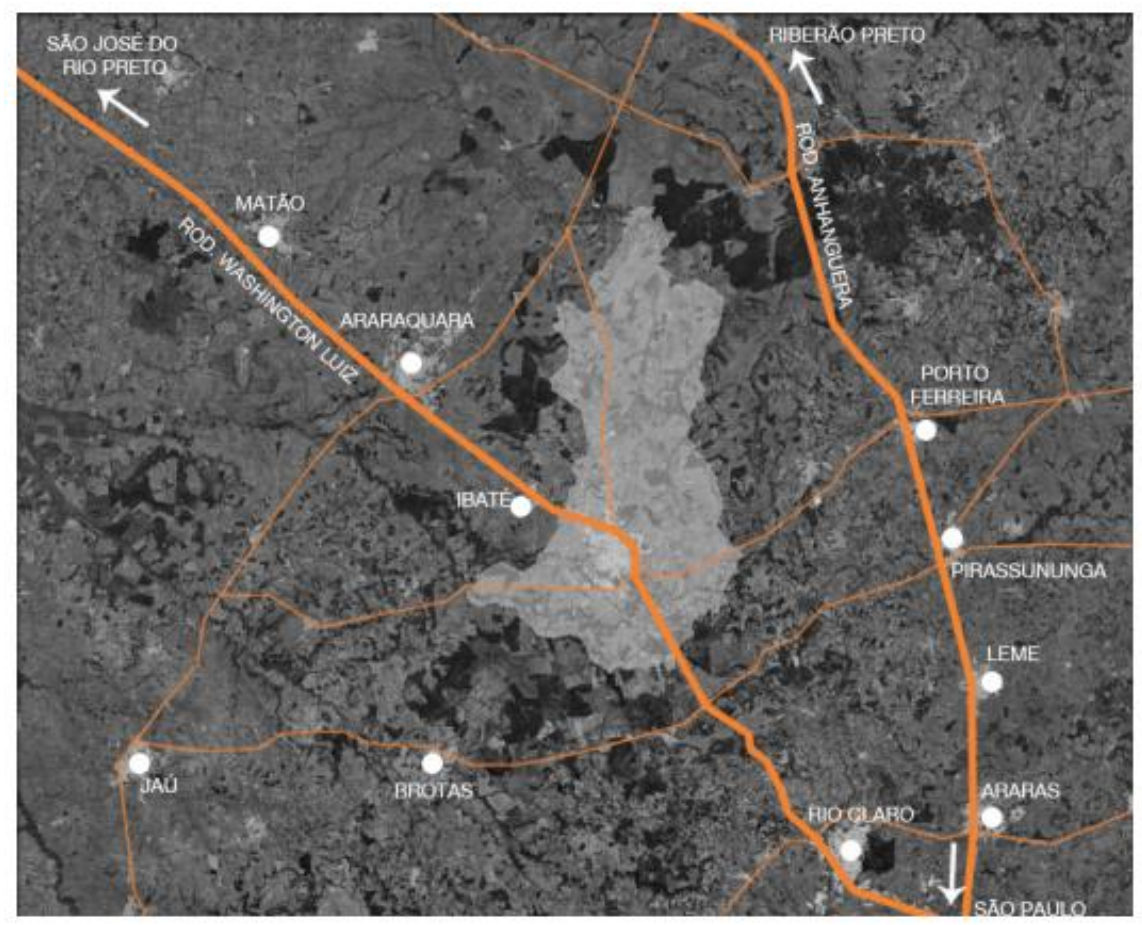

Figura 45 - Localização do município de São Carlos em sua microrregião

Ademais, o município possui importante base industrial formada, apresentando uma grande quantidade de indústrias médias e pequenas dos mais diversos setores de produção, constituindo também um polo comercial regional e produtor de leite, cana, laranja, frango, carne bovina e milho.

Como em outras cidades médias do Estado de São Paulo, a formação desta base econômica veio acompanhada por intensificações nos processos migratórios e pelo 
surgimento de assentamentos urbanos precários e informais ocupados pela população de baixa renda. Deste modo a cidade se expandiu gerando sérios problemas urbanos e ambientais.

Segundo Lima (2007), o processo de expansão do município iniciou no século XIX, a partir diferentes períodos de expansão (Tabela 17). Entre o final da década de 1960 e início dos anos 2000 a área urbanizada do Município praticamente duplica, passando de 2.140 ha para 4.080 ha.

Tabela 17 - Expansão da área urbanizada do município de São Carlos (1857 - 2011)

\begin{tabular}{|c|c|c|c|c|}
\hline \multirow{2}{*}{ Período } & \multirow{2}{*}{$\begin{array}{c}\text { Área urbanizada } \\
\text { no período (ha) }\end{array}$} & $\begin{array}{c}\text { Área } \\
\text { urbanizada } \\
\end{array}$ & & \multicolumn{2}{|c|}{ Crescimento (\%) } \\
\cline { 4 - 5 } & & 247,0 & total & $\begin{array}{c}\text { média por } \\
\text { década)(2) }\end{array}$ \\
\hline $\mathbf{1 8 5 7 - 1 8 8 8}$ & 247,0 & 364,0 & 47,37 & - \\
\hline $\mathbf{1 8 8 9 - 1 8 9 3}$ & 117,0 & 381,0 & 4,67 & - \\
\hline $\mathbf{1 8 9 4 - 1 9 2 9}$ & 17,0 & 423,5 & 11,15 & - \\
\hline Sem data (1) & 42,5 & 1351,1 & 254,62 & 87,8 \\
\hline $\mathbf{1 9 3 0 - 1 9 5 9}$ & 927,6 & 2140,9 & 58,45 & 34,3 \\
\hline $\mathbf{1 9 6 0 - 1 9 7 7}$ & 789,8 & 3108,6 & 45,2 & 41,0 \\
\hline $\mathbf{1 9 7 8 - 1 9 8 9}$ & 967,7 & 4080,2 & 31,25 & 26,0 \\
\hline $\mathbf{1 9 9 0 - 2 0 0 2}$ & 971,6 & 5051,7 & 23,81 & 29,7 \\
\hline $\mathbf{2 0 0 3 - 2 0 1 1}$ & $971,5(3)$ & & & \\
\hline
\end{tabular}

Fonte: Lima (2007, Pg.56),

(1) Trata-se de loteamentos que constam nos registros da Prefeitura como loteamentos "espontâneos, " sem data especificada, implantados entre 1857 e 1929.

(2) Estimativa calculada a partir de uma regra de três: \% do crescimento total do período X10 X1/ número de anos do período.

(3) Inclui empreendimentos implantados, em implantação, aprovados e em análise.

A autora explica que, neste período, a especulação imobiliária responde à demanda de uma periferia em crescimento, espalhando loteamentos pela cidade, de modo a prevalecer uma expansão urbana chamada de "padrão periférico", com precária ou nenhuma infraestrutura e ainda com a atuação conivente do poder público a serviço dos interesses do setor imobiliário.

Além disso, a ocupação urbana avançou áreas inadequadas, áreas de encostas, mananciais e com graves problemas de erosão e drenagem. Sendo assim, a partir dos anos de 1970, se acentuam os conflitos entre expansão urbana e áreas ambientalmente frágeis, principalmente com a implantação de vias marginais e a invasão de áreas de preservação ambiental à beira de córregos.

As informações destacadas indicam o rápido adensamento populacional da cidade e ao mesmo tempo representa a sua expressiva urbanização. Neste período o município 
praticamente ignora o ordenamento de sua expansão, sendo embasado apenas em códigos de conduta e leis de parcelamento do solo e de zoneamento urbano.

Seu atual Plano Diretor foi promulgado em 2005, elaborado à esteira do processo de adequação dos municípios à nova legislação urbana pós-promulgação do Estatuto das Cidades. Atualmente, encontra-se em andamento o seu primeiro processo de revisão.

A revisão do PDSC visa cumprir as determinações do Estatuto da Cidade, e é entendida como parte do processo de planejamento urbano, logo, o foco de suas análises e proposições deverá ser a efetividade de seus instrumentos tanto em relação a seus objetivos como em relação às atuais dinâmicas populacionais, econômicas e sociais do Município.

De acordo com a Prefeitura Municipal de São Carlos, a revisão do PD visa analisar e avaliar o uso e ocupação solo, as tendências de expansão, a definição de zonas de ocupação e a demarcação das diretrizes viárias, bem como outras medidas voltadas ao ordenamento do desenvolvimento urbano do município (PREFEITURA DE SÃO CARLOS, 2011).

Devido à inexistência de informações atuais relacionadas às propostas de revisão do Plano Diretor ${ }^{12}$, o presente trabalho utiliza como fonte de informações os seguintes documentos técnicos elaborados em 2011:

- Etapa 1: Atualização da Leitura Técnica do Município de São Carlos;

- Etapa 2: Análise dos instrumentos legais instituídos e regulamentados a partir da aprovação do Plano Diretor e da capacidade institucional de planejamento;

- Etapa 3: Definição dos eixos estratégicos da revisão do Plano Diretor;

- Etapa 4: Propostas para a Revisão do Plano Diretor do Município de São Carlos.

\footnotetext{
${ }^{12}$ Atualmente, as informações dos documentos elaborados em 2011 passam por um processo de atualização, e as proposições dispostas à época vêm sendo revistas por comissão interna no âmbito do Poder Público municipal. No momento de elaboração da presente dissertação, o processo de revisão do Plano Diretor de São Carlos encontrava-se em rumo incerto. Após um longo período sem divulgar informações, o Poder Público municipal havia iniciado o que chamou de consultas públicas para orientar o processo de revisão, quando foi interpelado pelo Ministério Público que questionou a legitimidade do processo, sobretudo pelo baixo espaço destinado à participação da sociedade em procedimentos efetivos de tomada de decisão.
} 


\subsection{A contribuição dos Objetivos de AAE ao atual Plano Diretor de São Carlos.}

O Plano Diretor de São Carlos foi instituído no ano de 2005, fundamentado pelas disposições do Estatuto da Cidade. Para o alcance de seus objetivos, previu-se a necessidade de articulação entre os seus diversos instrumentos - políticos, jurídicos, fiscais e de planejamento - junto à atuação de seus agentes institucionais, como exemplifica a figura a seguir.

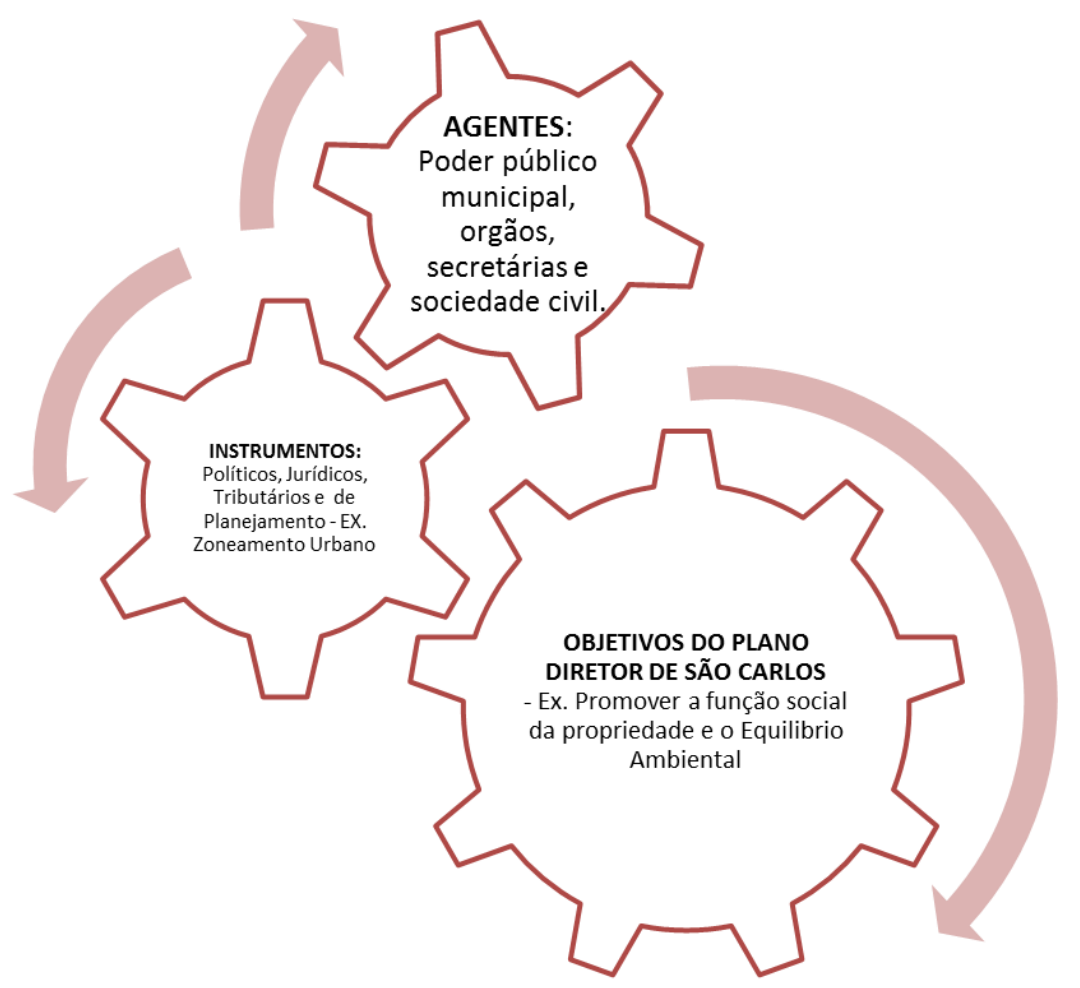

Figura 46 - Esquema geral de articulações do Plano Diretor de São Carlos

Este esquema de articulações entre objetivos, instrumentos e agentes do plano diretor é produto do seu processo de tomada de decisão, no qual os objetivos representam os anseios e necessidades que precisam ser respondidas pelo plano por meio da implementação dos instrumentos.

Neste sentido, de forma análoga à análise desenvolvida sobre os Objetivos de AAE da prática internacional, foram identificados os objetivos e direcionamento temático estabelecido pelo Plano Diretor. Sendo assim, observando-se os procedimentos metodológicos aplicados na análise da prática internacional de AAE, um total de 89 objetivos puderam ser agrupados de acordo com seus respetivos temas, cuja distribuição pode ser observada no gráfico a seguir. 


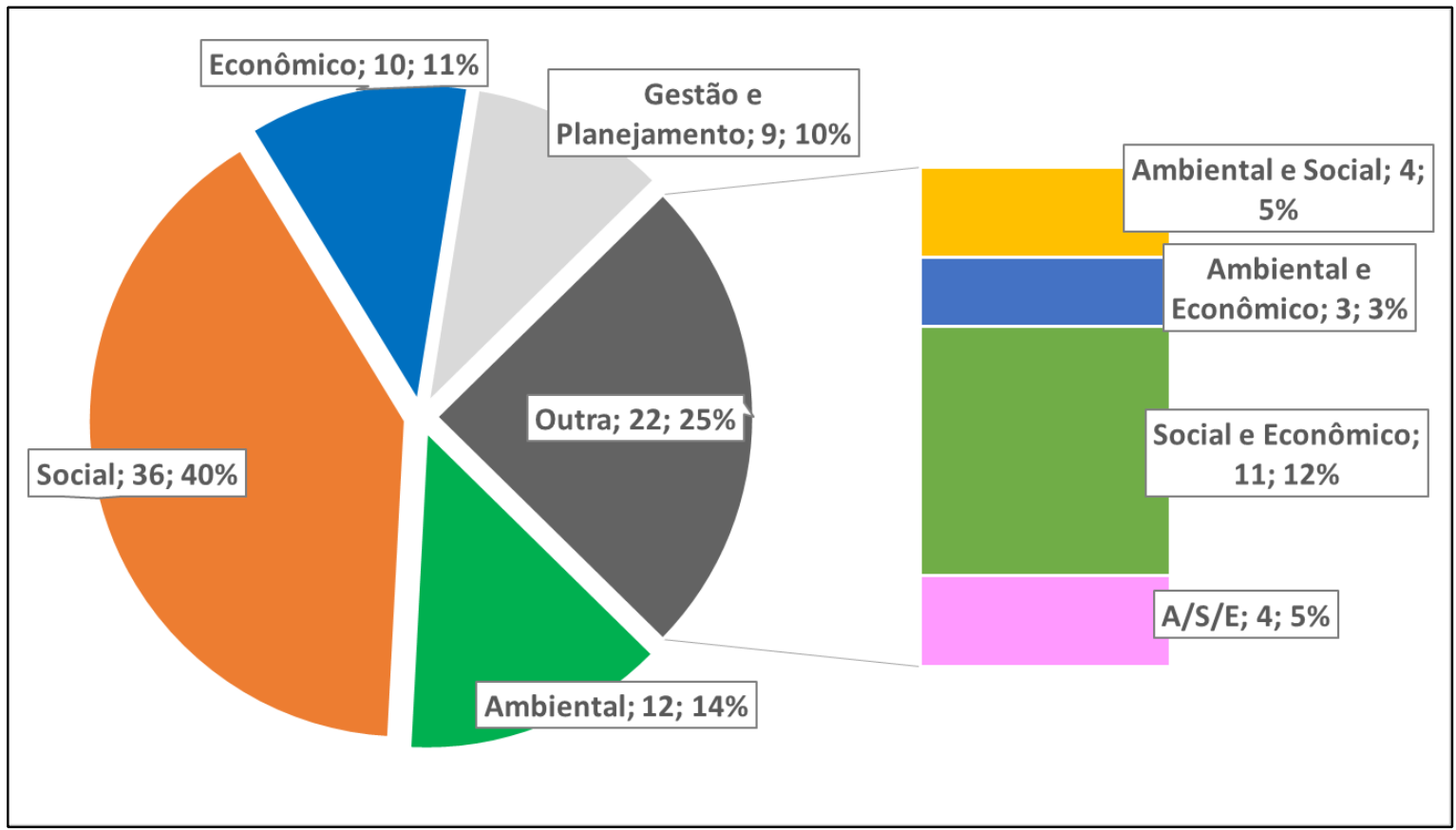

Gráfico 8- Temas dos objetivos do Plano Diretor de São Carlos.

Em seguida, se dispôs os temas dos objetivos do Plano Diretor de São Carlos (PDSC) frente aos temas dos objetivos de AAE do conjunto de práticas analisadas anteriormente, como indica o Gráfico 8 a seguir.

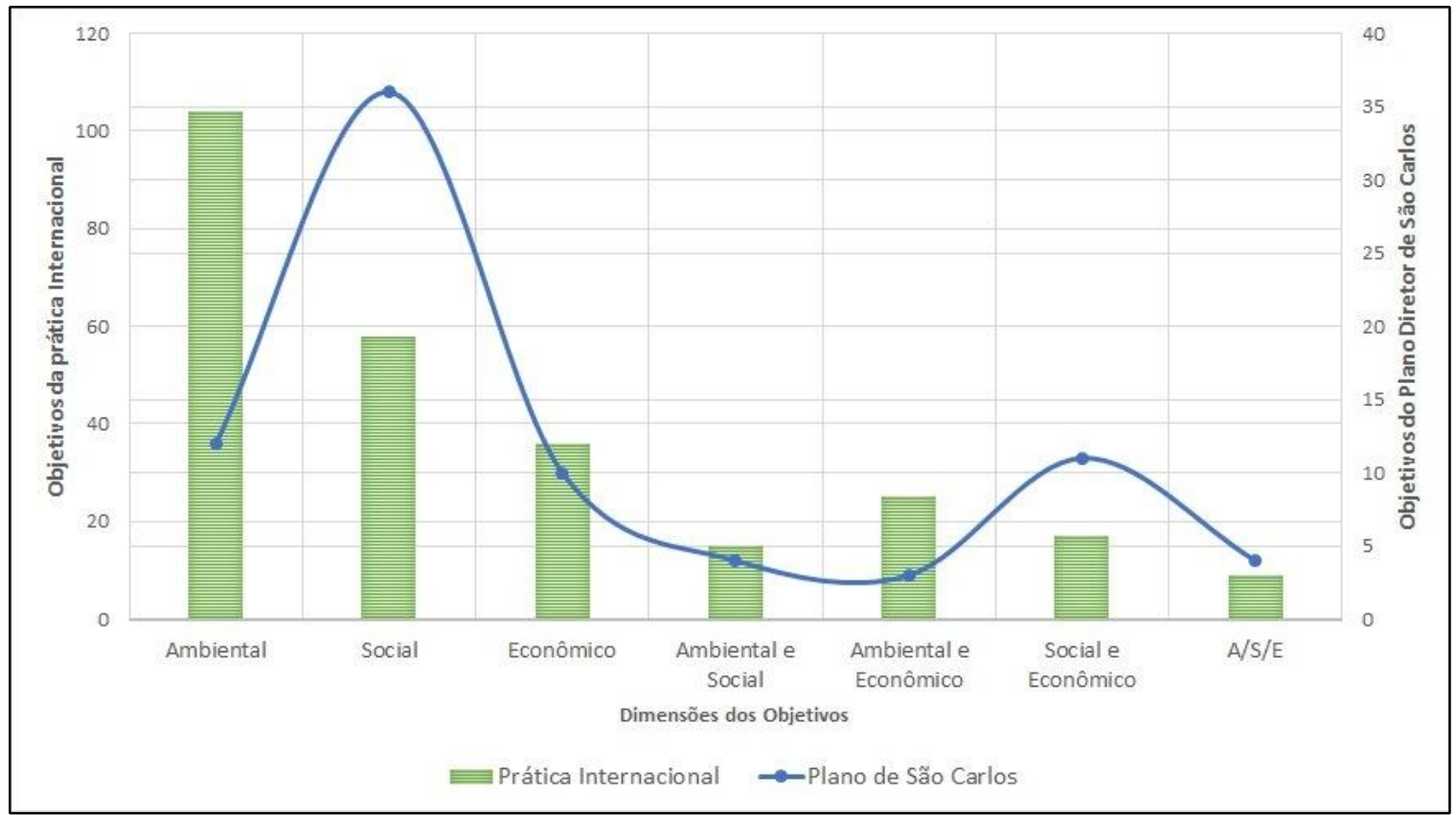

Gráfico 9 - Comparação dos objetivos de AAE segundo a prática internacional, frente aos objetivos do plano diretor de São Carlos. 
A análise deste gráfico não deve partir de uma perspectiva quantitativa, no entanto, por um viés qualitativo pode-se observar que os temas para os quais se voltam os objetivos do atual Plano Diretor de São Carlos, indicam que o foco das ações estabelecidas estão concentradas em questões sociais, seguido de uma presença equilibrada de questões ambientais e econômicas, enquanto há pouca presença de objetivos de interface (ambiental/social, ambiental/econômico, etc.). Cabe destacar que estes objetivos refletem uma tomada decisão que, independente de como ocorreu, indica as prioridades adotadas no plano. Sendo um plano voltado para o desenvolvimento urbano, entende-se que a prevalência de aspectos sociais e socioeconômicos dentre os objetivos estabelecidos indica a baixa disposição dos planejadores em promover a variável ambiental a um patamar significativo de relevância para a decisão. No caso das questões ambientais, o que se verifica é essencialmente uma compilação de aspectos obrigatórios já estabelecidos pela legislação (como a delimitação de áreas de preservação permanente) e ações de caráter ambiental de competência municipal (gestão de resíduos sólidos, drenagem, esgotamento sanitário).

A prática internacional revela que os temas trabalhados pelos processos de $\mathrm{AAE}$ apresentam um direcionamento maior às questões ambientais e sociais e econômicas e em suas interrelações. Esta configuração indica a finalidade da AAE, que é a de afirmar as questões ambientais em um mesmo nível que as demais no processo de tomada de decisão (FISCHER, 2007).

Além disto, a distribuição dos temas dos Objetivos de AAE sobre o gráfico permite resgatar as considerações de Fischer (2007) e White \& Bram (2012) sobre a capacidade do instrumento em promover a sustentabilidade devido à capacidade de integração de diversas questões. Esta integração de diversos temas em paralelo às questão ambiental pode contribuir para qualificar as questões ambientais, eleva-las ao mesmo nível que as demais (figura 47) e tornar mais racional o alcance dos objetivos de uma determinada ação estratégica. 


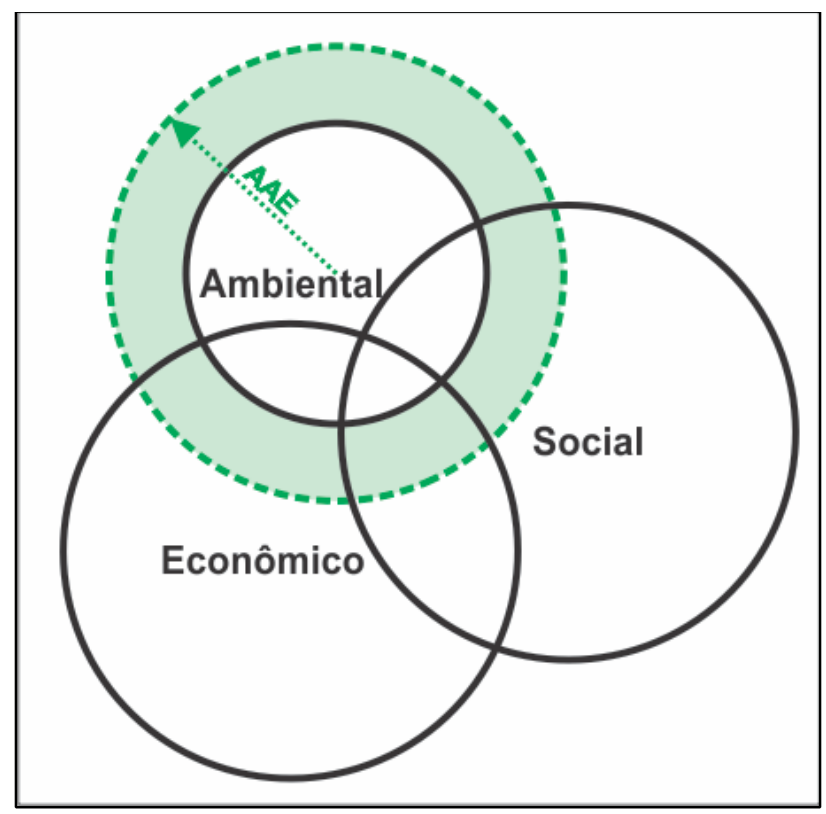

Figura 47 - A promoção dos aspectos ambientais pela AAE.

Neste sentido, os fundamentos conceituais e seu rebatimento sobre a prática verificada da AAE permite entender que, caso houvesse uma aplicação de um processo de AAE na elaboração do plano diretor de São Carlos, ou em sua revisão, a distribuição dos objetivos do plano apresentaria um padrão diferente do verificado no Gráfico 9, na medida da influência dos objetivos de AAE na construção do plano diretor. Ou seja, o suporte desenvolvido por um processo de AAE sugere priorizar as questões ambientais como inputs para a discussão dos objetivos do plano.

Ao se analisar os conteúdos relatados nos objetivos voltados à temática ambiental existentes no atual Plano Diretor de São Carlos (PDSC) frente aos objetivos ambientais integrados às AAEs da prática internacional, observa-se que:

$\checkmark$ Em relação aos objetivos do atual PDSC

o Os objetivos voltados à temática ambiental se apresentam de forma ampla e com pouco detalhamento sobre as questões almejadas. Constituem, portanto, diretrizes e intenções vagas com baixa perspectiva de prevalecerem diante de qualquer conflito com as agendas sociais e econômicas. Por exemplo, tomemse os seguintes objetivos:

- "II - proteção, valorização e uso adequado do meio ambiente natural e construído e da paisagem urbana e rural; (art. 7o)

- VII-assegurar a integração entre as áreas de preservação ambiental, rural e urbana visando o desenvolvimento ambiental sustentável; (art. 80 ) 
- XII - preservar e recuperar o meio ambiente natural e construído, do patrimônio cultural, histórico, artístico e paisagístico, em especial as áreas de interesse ambiental localizadas no perímetro de proteção aos mananciais; (art.9o)

- VII- assegurar a integração entre as áreas de preservação ambiental, rural e urbana visando o desenvolvimento ambiental sustentável; (art.9o)

- XIII - complementar a ação dos órgãos federais e estaduais responsáveis pelo controle ambiental; (art.9o)"

o Além destes, os demais objetivos referem-se a apenas aspectos ambientais ligados aos recursos hídricos, o saneamento ambiental, os resíduos, os solos, as áreas verdes, a poluição do ar e a vegetação. Para tais aspectos, há uma visão de que estes devem ser demarcados, preservados, protegidos e serem utilizados de forma sustentável. Além disto é destacado que a compatibilização do desenvolvimento municipal frente à preservação do meio ambiente deve ser empreendida por mecanismos de controle do uso dos recursos;

o O PDSC incorpora um discurso de promoção da sustentabilidade e proteção ambiental, mas no entanto, não se posiciona especificamente em relação a esta dimensão. Os objetivos do PDSC se colocam como um conjunto de regras a serem respeitadas, e não como metas a serem perseguidas. Corroborando as palavras de Therivel (2004), apresentam-se como um caça palavras cuja dica não é clara sendo possível encaixar qualquer resposta (THERIVEL, 2004).

o Esta característica indecisa dos objetivos do PDSC confirma as questões retratadas por Saboya (2013), de que os objetivos nos PDs aparecem de forma indireta, indicando apenas um alcance futuro e não um objetivo concreto e definido. Para o autor, esse caráter é o que provoca ações incertas, pois o plano não indica como alcançar um objetivo e nem mesmo os limites a se atingir, além disso, favorece a perda da credibilidade do plano já que este não transmite uma referência efetiva.

$\checkmark$ Em relação aos objetivos da prática internacional de AAE:

a. Os objetivos da temática ambiental identificados nas práticas de AAEs analisadas revelam-se detalhados e concisos sobre aquilo que desejam alcançar. Os temas trabalhados por esses objetivos são os mesmos inscritos na chave de indicadores elaborada nesta pesquisa, visto que se trata do mesmo 
conjunto de relatórios analisados. Logo, os objetivos voltados à temática ambiental referenciam-se a aspectos como biodiversidade, recursos hídricos, a qualidade dos solos, a qualidade do ar, os efeitos das mudanças climáticas, entre outros já discutidos anteriormente. Deve-se relembrar que os objetivos de AAE constituem um dos resultados do processo de scoping e, portanto, caracterizam-se por serem detalhados e específicos porque foram construídos a partir de evidencias (dadas pela baseline), e discussões entre os diretamente envolvidos (stakeholders).

Os objetivos descritos relatam situações diferentes, pois os objetivos da temática ambiental do atual PDSC referem-se à construção final de um processo de tomada de decisão, enquanto que os objetivos da temática ambiental do conjunto de AAEs analisadas se referem a um momento intermediário da tomada de decisão, visto que estes serão trabalhados pelo processo AAE e as considerações do processo serão relatadas e incorporadas no desenvolvimento da ação estratégica, como ilustra a figura44.

A amplitude com a qual o atual PDSC trata os objetivos da temática ambiental é semelhante ao que fora observado nos objetivos iniciais das ações estratégicas relatados nos casos descritos anteriormente no estudo sobre o processo de scoping na prática internacional da AAE. Tal fato indica que é justamente em questões amplas como a presente nos objetivos iniciais dos casos trabalhados (vide os quadros de 2 a 5) e também presente no atual Plano Diretor de São Carlos que os processos de AAE se pautam e assim, podem torna-los mais específicos e detalhados.

\subsection{O estabelecimento dos elementos da etapa de Scoping frente ao PD de São de} Carlos.

Durante o desenvolvimento deste trabalho foi destacada a importância conceitual da etapa de scoping e como ela tem se desenvolvido em alguns casos da prática da AAE para planejamento do uso do solo.

Neste sentido, com o propósito de indicar a potencialidade desta etapa em uma circunstância hipotética de desenvolvimento da AAE, apresenta-se a seguir uma esquematização do diagrama síntese das concepções teóricas e práticas para o estabelecimento do scoping (figura 43).

Trata-se de uma demonstração de como poderia ser a composição do scoping aplicado ao contexto de elaboração/revisão do PD de São Carlos, procurando-se 
demonstrar quais elementos contextuais estariam envolvidos na discussão e promoção de objetivos de sustentabilidade pela AAE.

Demonstrar estes elementos contextuais torna explicita a possibilidade de emprego da AAE, indicando que esta poderia obter êxito em seus propósitos. Tal fato é reforçado pelas colocações de Wirustkulshai (2011), ao destacar a importância que os aspectos contextuais têm para o sucesso e progresso da implementação da AAE no contexto de planejamento da Tailândia, em que as particularidades contextuais e, sobretudo, a estrutura governamental exerceram influência substancial na incorporação da AAE.

Sendo assim, a Figura 48 apresentada a seguir esquematiza, a partir do diagrama síntese desenvolvido nesta pesquisa, como se daria a composição do scoping para o contexto de planejamento no município de São Carlos. 

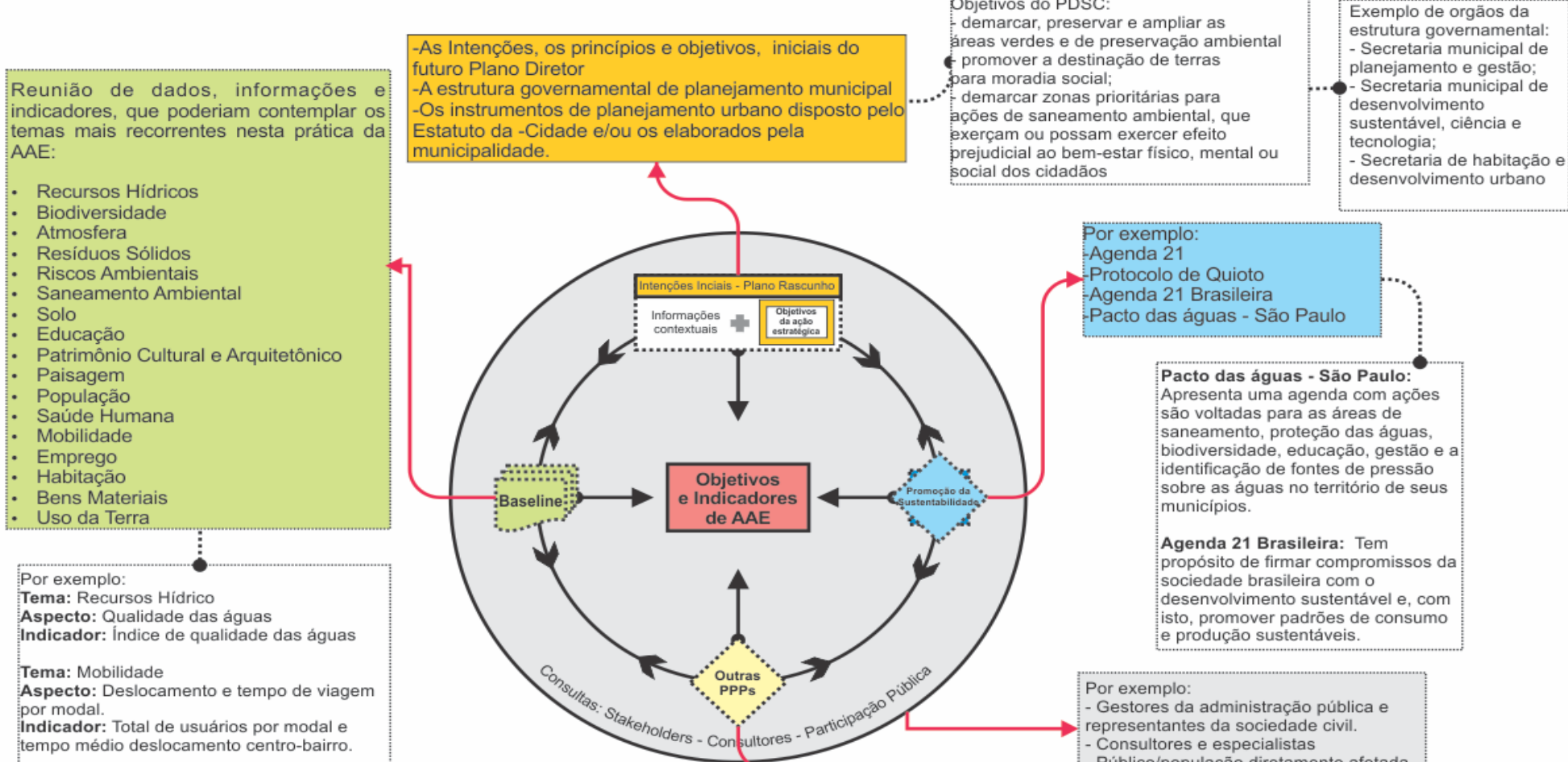

io Cultural e Arquitetônico

Indicador: Total de usuarios por modal e

tempo medio deslocamento centro-bairro.

Exemplo de objetivos de PPPs:
Programa Minha Casa Minha Vida: é um
programa habitacional do Governo Federal do
Brasil que visa promover o financiamento da
habitaçăo
Plano de Bacia Tietê Jacaré: são planos
diretores, de natureza estratégica e operacional,
que têm por finalidade fundamentar e orientar a
implementaçăo da Politica Estadual de Recursos
Hidricos,
Programa de microbacias: possibilita o
investimento de recursos em incentivos para que
os agricultores paulistas adotem práticas
conservacionistas e tenham uma produçăo
ecologicamente adequada.

A verificação de outras Politicas, Planos e Programas em esfera superior ou inferior de

planejamento, com influencia direta e indireta sobre o desenvolvimento do PD.

Por exemplo as seguintes PPPs:

Política Nacional de Residuos Sólidos

- Politica Nacional de Recursos Hidricos

Política Nacional de Mobilidade Urbana

Plano Plurianual de Desenvolvimento Regional do Estado de São Paulo.

Planode Bacia Tie JacarecBHín Re

Prano nacional de Saneamento básico

Programa de Microbacia

- Programa Município Verde Azul

Figura 48 - Composição do elementos do scoping de uma AAE ao caso de São Carlos. 
A composição dos elementos que poderiam compor o scoping para o caso de São Carlos permite visualizar possíveis elementos que seriam identificados e discutidos em conjunto com as proposições da ação estratégica e, além disso, poderiam influenciar e se conectar a outros elementos desenvolvidos, conforme indicado na Tabela 18 a seguir.

Tabela 18 - características dos elementos do scoping de uma AAE aplicada ao caso de São Carlos.

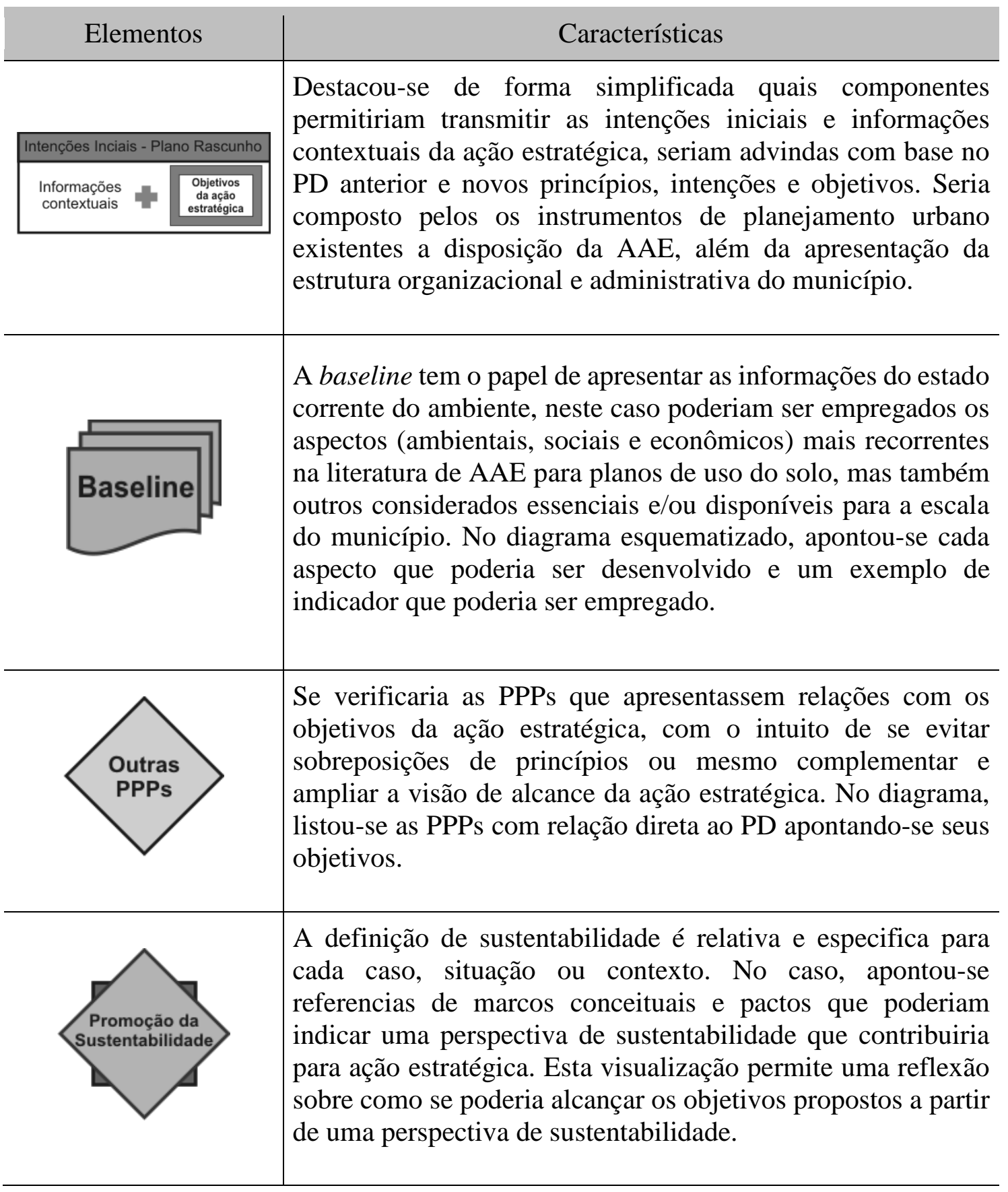




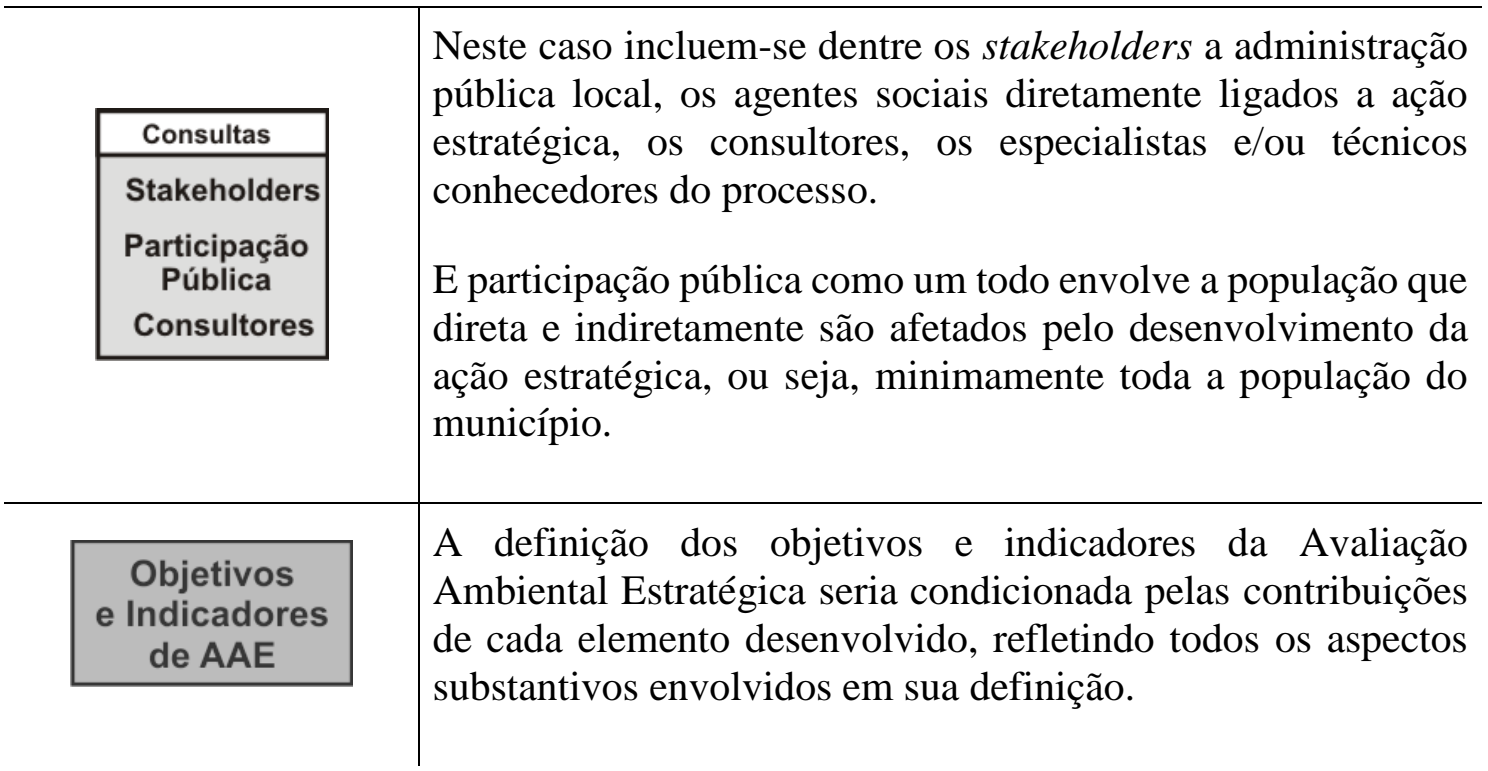

Vale destacar que o papel desta composição é apenas ilustrar uma possível forma de conduzir esta etapa, pois o detalhamento do que realmente seria levantado, discutido, as relações possíveis de se desenvolver e toda estrutura procedimental que envolveria a aplicação da AAE no caso de São Carlos não se encontra dentre os objetivos do presente trabalho. O que se pretende é demonstrar que existem conteúdos, informações, referências, outras PPPs influentes, elementos orientadores da sustentabilidade e, principalmente, intenções/objetivos suficientes para se discutir e desenvolver a AAE no âmbito do planejamento do desenvolvimento urbano no Brasil.

Dessa maneira, o exercício de aplicação realizado para o município de São Carlos ilustra o potencial dos inputs derivados da AAE de contribuir para a construção de objetivos de uma ação estratégica, bem como em relação à tomada de decisão como um todo.

$\mathrm{O}$ que se procurou apresentar aqui foi o caminho percorrido entre $\mathrm{o}$ estabelecimento de fundamentos conceituais e a aplicação concreta, baseada em uma situação real. É evidente que a real verificação destas potencialidades só se constrói pela prática, isto é, a integração e desenvolvimento do instrumento junto aos elementos contextuais de uma aplicação concreta. 


\section{8 . CONSIDERAÇÕES FINAIS}

A pesquisa teve como objetivo geral apresentar e discutir procedimentos e aspectos metodológicos que envolvem a definição de objetivos e indicadores a serem empregados em uma Avaliação Ambiental Estratégica voltada ao planejamento do desenvolvimento urbano no contexto brasileiro.

Para seu desenvolvimento os procedimentos metodológicos empregados consistiram em averiguar e relacionar os aspectos teóricos e práticos da AAE a partir de uma perspectiva qualitativa, de modo que se estabeleceu como ponto central da pesquisa a etapa de revisão bibliográfica para, em seguida, averiguar e discutir as dimensões construídas na prática. Ou seja, a trajetória da pesquisa desenvolveu-se pela comparação entre os aspectos teóricos e práticos.

A etapa de revisão bibliográfica se estabeleceu como estruturadora de todas as atividades da pesquisa, isto é, forneceu a base para fomentar as metodologias desenvolvidas e, principalmente, discutir os resultados obtidos.

Em relação à AAE, a revisão se pautou se pautou nas características, princípios, abordagens e procedimentos envolvidos em sua prática corrente, em específico ao que se refere à etapa de scoping, sintetizada por meio de um diagrama das representações conceituais que possibilitou discutir os aspectos essenciais desta etapa em relação à prática. Quanto a temática relacionada aos instrumentos de planejamento urbano no Brasil, buscou-se abordar as características conceituais dos Planos Diretores Municipais e a sua importância para a inserção dos aspectos ambientais no planejamento das cidades. Tal construção subsidiou as discussões relacionadas ao caso do PD de São Carlos e o potencial de inserção de sustentabilidade e a questão ambiental pela AAE.

A análise dos objetivos de AAE realizada sobre o conjunto de documentos identificou quais temas têm sido empregados como inputs da AAE para a tomada de decisão estratégica, o que permitiu identificar o direcionamento e amplitude temática ambiental, social, econômica e interfaces - para a qual se voltam os objetivos de AAE, tendo sido verificado empiricamente que este instrumento tem contribuído para a promoção do aspecto ambiental em equilíbrio com os sociais e econômicos.

Foram coletados 550 Indicadores de AAE divididos e agrupados nas dimensões Ambiental, Social, Econômica e em suas interfaces, que foram posteriormente identificados e categorizados em 14 temas: Recursos Hídricos, Biodiversidade, Atmosfera, Resíduos Sólidos, Riscos Ambientais, Saneamento Ambiental, Solo, 
Educação, Patrimônio Cultural e Arquitetônico, Saúde Humana, Bens Materiais, Emprego, Habitação e Uso do Solo.

Os aspectos descritos se pautam como um referencial para futuras construções de indicadores para esta modalidade de AAE, pois sugerem de forma direta questões primordiais a serem abordadas e, também, em um contexto favorável para a promoção da sustentabilidade.

Os procedimentos metodológicos adotados no desenvolvimento da pesquisa permitiram identificar elementos em comum entre as perspectivas teóricas e práticas, destacando-se os principais elementos para o desenvolvimento da etapa de scoping: (i) as informações contextuais do plano; (ii) a baseline; (iii) a visualização de outras PPPs; (iv) a construção de uma perspectiva de sustentabilidade; (v) o papel dos stakeholders; (vi) os objetivos e indicadores de AAE; e (vii) as interconexões possíveis de se desenvolver.

A construção dos diagramas que representavam o paralelo entre as concepções teóricas e práticas para o estabelecimento do scoping (Figura 43) permitiu, em relação aos casos analisados, definir uma síntese do que representaria esta etapa.

Esta pode ser definida, de forma resumida, como o momento em que a avaliação ambiental estabelece seu foco em relação ao seu objeto de análise, o qual se desenvolve por meio de um conjunto de elementos processuais e que esclarecem e ainda ampliam as relações entre os propositos da ação estratégica e os seus efeitos ambientais.

A pesquisa ilustrou a potencial contribuição da AAE para a promoção da sustentabilidade como um elemento estratégico na elaboração de Planos Diretores municipais no contexto brasileiro, tendo como pano fundo o caso do município de São Carlos (SP), destacando-se. O resultado deste exercício foi a ilustração de elementos contextuais que favorecem a discussão e o desenvolvimento dos potenciais inputs derivados da AAE na construção de objetivos da ação estratégica.

Entende-se que os resultados obtidos permitiram ilustrar o potencial da AAE em relação à promoção da sustentabilidade como elemento estratégico na elaboração de Planos Diretores de Desenvolvimento Urbano no Brasil.

Como aspectos que limitam a generalização dos resultados e proposições, entende-se que estão relacionados ao conjunto restrito de documentos e relatórios de casos da prática da AAE utilizados para embasamento das análises, bem como a falta de informações referentes às especificidades dos processos de tomada de decisão. Sendo assim, futuras pesquisas relacionadas ao tema devem explorar a representatividade da amostragem para a escolha de casos práticos de AAE, e, sobretudo que seu 
desenvolvimento seja realizado por meio de informações mais detalhadas sobre o modo como se desenvolveu o scoping nos casos analisados.

Por fim, por abordar a relação entre a teoria e prática da AAE, o presente trabalho não deve ser visto de forma estática, ou encerrada, visto que seu objeto se encontra em constante evolução, devendo ser compreendido como um exercício de aproximação entre a AAE e os instrumentos de planejamento urbano aplicados no contexto brasileiro, conforme a lacuna de pesquisa evidenciada inicialmente. 


\section{REFERENCIAS BIBLIOGRÁFICAS}

ANGELIERI, , C. C. S. Biodiversidade e planejamento de uso e ocupação do solo: estudo de caso Brotas/SP. Dissertação (Mestrado). Escola de Engenharia de São Carlos. São Carlos. 2011.

APA. Guia da Avaliação Ambiental dos Planos Municipais de Ordenamento do Território. Agência Portuguesa do Ambiente. [S.1.]. 2008.

BELLEN, H. M. V. Indicadores de Sustentabilidade: uma análise comparativa. Rio de Janeiro: FGV, 2006.

BIDSTRUP, M.; HANSEN, A. M. The paradox of strategic environmental assessmen. Environmental Impact Assessment Review, n. 47, p. 29-35, 2014.

BINA, O. A critical review of the dominant lines of argumentation on the need for SEA.. Environmental Impact Assessment Review, n. 27, p. 585- 606, 2007.

BRASIL. Lei $\mathrm{n}^{\circ} \mathbf{1 0 . 2 5 7}$, de 10 de Julho de 2001. Regulamenta os arts. 182 e 183 da Constituição Federal, estabelece diretrizes gerais da política urbana e dá outras providências. Brasilia, DF: Diário Oficial da União, 2001.

BRASIL. Estatuto da Cidade: guia para implementação pelos municípios e cidadãos. Brasília: Câmara dos Deputados, Coordenação de Publicações, 2002.

BROWN, A. L.; THERIVEL, R. Principles to guide the development of strategic environmental assessment methodology. Impact Assessment and Project Appraisal, v. 18, n. 3, p. 183 - 189, 2000 .

BUCKLEY, R. Strategic environmental assessment of policies and plans: legislation and implementation. Impact Assessment and Project Appraisal, p. 209-215, Mar 2000.

CAAS (ENVIRONMENTAL SERVICES). Appropriate Assessment Of Draft Galway County Development Plan 2009, 2009. Disponivel em: <http://www.galway.ie/en/Services/Planning/DevelopmentPlans/GalwayCountyDevelopmentPl an2009-2015/CountyDevelopmentPlan2009-2015/>. Acesso em: 10 Dez 2012.

CAIRNGORMS National Park - Deposit Local Plan Strategic Environmental Assessment/ Environmental Report, $2007 . \quad$ Disponivel em: <http://cairngorms.co.uk/resource/docs/publications/06072007/CNPA.Paper.489.Deposit\%20Lo cal\%20Plan\%20-\%20Non-Technical\%20Summary.pdf>. Acesso em: 24 Mar 2013.

CLARE COUNTY COUNCIL. Clare County Development Plan 2011-2017 - Environment Appraisal of the Plan /Part I: Strategic Environmental Assessment (SEA) , 2011. Disponivel em: $<$ http://www.clarecoco.ie/planning/publications/clare-county-development-plan-2011-2017volume-3-strategic-environmental-assessment-environmental-report-9181.pdf $>$. Acesso em: 25 Mai 2013.

CNUMAD - (CONFERÊNCIA DAS NAÇÕES UNIDAS SOBRE MEIO AMBIENTE E DESENVOLVIMENTO). Agenda 21. CNUMAD. São Paulo. 1992.

COMUNE DI ACERRA. Comune di Acerra Piano Urbanistico Comunale - Valutazione ambiental estrategica - Rapporto Ambientale, 2008. Disponivel em: <http://www.cartografia.regione.lombardia.it/sivas/jsp/procedimenti/procedimentiChiusiVa.jsf> . Acesso em: 15 Jul 2013. 
COMUNE DI ROMANO DI LOMBARDIA. Comune di Romano di Lombardia - Valutazione Ambientale Strategica (VAS) del Piano di Governo del Territorio (PGT), 2008. Disponivel em: <http://www.cartografia.regione.lombardia.it/sivas/jsp/procedimenti/procedimentiChiusiVa.jsf> . Acesso em: 20 Jun 2013.

COMUNI DI BERGAMO. Comuni di Bergamo - Valutazione Ambientale Strategica (VAS) del Piano di Governo del Territorio (PGT), 2008. Disponivel em: <http://www.cartografia.regione.lombardia.it/sivas/jsp/procedimenti/procedimentiChiusiVa.jsf> . Acesso em: 20 Jun 2012.

CORK COUNTY COUNCIL - PLANNING POLICY UNIT. Cork County Council Planning Policy Unit - Strategic Environmental Assessment - Environmental Report, 2007. Disponivel em: $<$ http://www.corkcoco.ie/co/web/Cork\%20County\%20Council/Departments/Planning/Planning \%20Policy\%20Unit\%20(PPU)/>. Acesso em: 11 Dez 2012.

COSTA, H. S. D. M.; CAMPANTE, A. L. ; ARAÚJO, R. P. Z. D. A dimensão AmbientAl nos planos diretores de municípios brasileiros: um olhar panorâmicosobre a experiência recente. In: JUNIOR, O. A. D. S.; MONTANDON, D. T. Os planos diretores municipais pós-estatudo da cidade: balanço crítico e perspectivas. Rio de Janeiro: Observatório das Cidades: IPPUR/UFRJ, 2011. Cap. VI, p. 296.

DESMOND, M. Strategic environmental assessment (sea): A tool for environmental decisionmaking. Irish Geography, 2007. 63 - 78.

DGOTDU. Guia da Avaliação Ambiental dos Planos Municipais de Ordenamento do Território. Direcção -Geral do Ordenamento do Território e Desenvolvimento Urbano. [S.1.], p. 137. 2008. (ISBN: $978-972-8569-44-0$ ).

DONNELLY, A. et al. Decision-support framework for establishing objectives, targets and indicators for use in strategic. Impact Assessment and Project Appraisal, n. 24:2, p. 151-157, 2006.

DONNELLY, A. et al. Selecting environmental indicator for use in strategic environmental assessment. Environmental Impact Assessment Review, n. 27, p. 161-175, 2007.

DONNELLY, A.; O'MAHONY, T. Development and Application of Environmental Indicators in SEA. In: SADLER, B., et al. Handbook of Strategic Enrionmental Assessment. Londres: Earthscan, 2011. Cap. 21.

DONNELLY, A.; PRENDERGAST, T.; HANUSH, M. Examinig Quality of Environvmental Objetives, targests and Indicators in Environmental Reports Prepared for Strategic Environmental Assessment. Journal Of Environmental Assessment an Management, Dezembro 2008. 381401.

EEA. EEA core set of indicators - Guide. EEA- European Environment Agency. Luxembourg, p. 38. 2005. (ISSN 1725-2237).

ELLING, B. Integration of strategic environmental assessment into regional spatial planning. Impact Assessment and Project Appraisal, n. 18, p. 233-243, Mar 2000. ISSN doi: 10.3152/147154600781767367.

EPA. Review of Effectiveness of SEA in Ireland - Key Findings \& Recommendations. Environmental Protection Agency (Ireland). [S.1.]. 2012. 
EUROPEAN COMMISSION ENVIRONMENT. SEA Directive (2001/42/CE). <http: //eurlex.europa.eu/LexUriServ/LexUriServ.do?uri=OJ:L:2001:197:0030:0037:EN:PDF>, 2001. Acesso em: 01 mar. 2013.

EZEQUIEL, S.; RAMOS, T. B. The State and Role of indicators Use in SEA. Impact Assessment and Responsible Development for infrastucture, Business and Industry - 31 IAIA, Puebla, México, Jun 2011.

FABBRO NETO, F. A. A avaliação ambiental estratégica para planos de uso e ocupação do solo: um estudo sobre o plano diretor municipal. Dissertação (Mestrado). Escola de Engenharia de São Carlos. São Carlos. 2010.

FABBRO NETO, F. A. A avaliação ambiental estratégica e o planejamento de uso e ocupação do solo: o caso do litoral norte do Estado de São Paulo. Tese (Doutorado). Escola de Engenharia de São Carlos. São Carlos. 2013.

FACULDADE DE CIÊNCIAS E TECNOLOGIA - UNIVERSIDADE DE NOVA LISBOA. Avaliação Ambiental Estratégica do Plano Regional de Ordenamento do Território dos Açores, 2008. Disponivel em: <http://www.azores.gov.pt/NR/rdonlyres/E3CF392B-07E3-4CEB-85A18752D2FDFECB/419799/RA_PROTA_Final_Parte1.pdf>. Acesso em: 15 Jan 2013.

FERNANDES, E. O Estatuto da Cidade e a ordem jurídico-urbanística. In: CARVALHO, C. S.; ROSSBACH, A. O Estatuto da Cidade Comentado. São Paulo: Ministério das Cidades: Aliança das Cidades, 2010.

FISCHER, T. B. Strategic environmental assessment in post-modern times. Environmental Impact Assessment Review, p. 155 - 170, 2003.

FISCHER, T. B. The Theory and Practice of Strategic Environmental Assessment: towards a more systematic approach. Londres: Earthscan, 2007.

FISCHER, T. B. Reviewing the quality of strategic environmental assessment reports for English spatial plan core strategies. Environmental Impact Assessment Review, 2009.

GAO, J.; KORNOV, L.; CHRISTENSEN, P. Do indicators influence communication in SEA? Experience from the chinese practice. Environmental Impact Assessment Review, n. 43, p. 121-128, 2013.

GAO, J.; KØRNØV, L.; CHRISTENSEN, P. Do indicators influence communication in SEA? Experience from the chinese pratice. Environmental Impact Assessment Review, n. 43, p. 121 $-123,2013$.

GAZZOLA, P. What appears to make SEA efective in different planning systems. Journal of Environmental Assessment Policy and Management, v. 10, n. 1, p. 1-24, Mar 2008.

GLASGOW CITY COUNCIL. The Local Development Plan for Glasgow - Main issues report Interim Environmental Report, 2010. Disponivel em: <http://www.glasgow.gov.uk/CHttpHandler.ashx?id=13036\&p=0>. Acesso em: Mar 2013.

HACKING, T.; GUTHRIE, P. Sustainable development objectives in impact assessment: Why are they needed and where do they come from? Journal of Environmental Assessment Policy and Management, v. 8, n. 3, p. 341-371, Set 2006.

HOGAN, D. J. A qualidade ambiental urbana: oportunidades para um novo salto. Fundação SEADE, São Paulo, 1995. 
HYDER CONSULTING (UK). The London Borough of Barking and Dagenham - Local Implementation Plan - Strategic Environmental Assessment/ Environmental Report , 2005. Disponivel em: 〈http://www.lbbd.gov.uk/Pages/Home.aspx>. Acesso em: 16 Abr 2013.

IAIA; INTERNATIONAL ASSOCIATION FOR IMPACT ASSESSMENT. Strategic Environmental Assessment Performance Criteria. Special Publication Series, 2002.

IBGE - INSTITUTO BRASILEIRO DE GEOGRAFIA E ESTATÍSTICA. Pesquisa de Informações Básicas Municipais - Perfil dos Municípios Brasileiros 2013. IBGE. Rio de Janeiro. 2014.

IBGE. Instituto Brasileiro de Geografi a e Estatística - IBGE. Indicadores de Desenvolvimento Sustentável - BRASIL 2010, Rio de Janeiro, 2010.

INSTITUTO SUPERIOR TÉCNICO. Avaliação Ambiental Estratégica do Plano Regional de Ordenamento do Território dos Oeste e Vale do Tejo., 2008. Disponivel em: <http://consultaprotovt.inescporto.pt/plano-regional/avaliacao-ambiental-estrategica/RNT_PROTOVT.pdf $>$. Acesso em: 16 Jan 2012.

INSTITUTO TÉCNICO SUPERIOR. Avaliação Ambiental Estratégica da Alteração do Plano Regional de Ordenamento do Território da Área Metropolitana de Lisboa, 2010. Disponivel em:

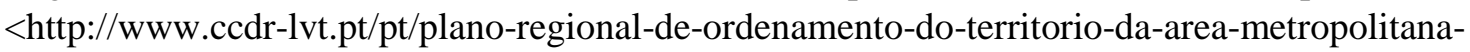
de-lisboa/54.htm>. Acesso em: 10 Ago 2012.

JACKSON, T.; ILLSLEY, B. An analysis of theoretical rationale for using strategic environmental assessment to deliver environmental justice in th ligth of the Scottish Environmental Assessment Act. Environmental Impact Assessment Review, n. 27, p. 607-623, 2007.

JONES, C. et al. Strategic Environmental Assessment and Land Use Planning: an international evaluation. London - UK: Earthscan, 2005.

LEE, Y.-J.; HUANG, C.-M. Sustainability index for Taipei. Environmental Impact Assessment Review, n. 27, p. 505-521, 2007.

LEMOS, C. C. Avaliação Ambiental Estratégica como instrumento de planejamento do turismo. Dissertação (Mestrado) - Escola de Engenharia de São Carlos, Universidade de São Paulo. São Carlos, p. 184. 2007.

LEMOS, C. C. Avaliação ambiental estratégica para o setor de turismo: uma proposta para aplicação no Brasil. Tese (Doutorado) - Escola de Engenharia de São Carlos, Universidade de São Paulo. São Carlos, p. 260. 2011.

LEMOS, C. C.; FISCHER, T. B.; SOUZA, M. P. Strategic environmental assessment in tourism planning - Extent of application and quality of documentation Original Research Article. Environmental Impact Assessment Review, v. 35, p. 1 - 10, 2012.

LENG NG, K.; OBBARD, J. P. Strategic environmental assessment in Hong Kong. Environment International, n. 31, p. 483 - 492, 2005.

LIMA, R. P. O Processo e o (Des) Controle da expansão urbana de São Carlos (1857-1977). Dissertação (Mestrado) - Escola de Engenharia de São Carlos, Universidade de São Paulo. São Carlos. 2007.

LOBOS, ; PARTIDARIO,. Theory versus practice in Strategic Environmental Assessment (SEA). Environmental Impact Assessment Review, 2014. 34-46. 
LONDON. Sustainability Appraisal of Regional Spatial Strategies and Local Development Documents - Guidance for Regional Planning Bodies and. The Office of the Deputy Prime Minister. London. 2005.

MAlVESTIO, A. C. Análise da efetividade da Avaliação Ambiental Estratégica como instrumento de política ambiental no Brasil. Dissertação (Mestrado) - Escola de Engenharia de São Carlos, Universidade de São Paulo. São Carlos, p. 198. 2013.

MALVESTIO, A.; MONTAÑO, M. Effectiveness of strategic environmental assessment applied to renewable energy in Brazil. Journal of Environmental Assessment Policy and Management, v. 15, 2013.

MINISTÉRIO DO MEIO AMBIENTE. Agenda 21 brasileira : resultado da consulta nacional / Comissão de Políticas de Desenvolvimento Sustentável e da Agenda 21 Nacional. Ministério do Meio Ambiente. Brasilia, , p. p. 158. 2004.

MMA; MINISTÉRIO DO MEIO AMBIENTE. Avaliação Ambiental Estratégica. MMA/SQA. Brasília:, p. 92. 2002.

MOLDAN, ; JANOUSKOVÁ, ; HÁK,. How to understand and measure environmental sustainability: Indicators and targets. Ecological Indicators , v. 17, p. 4 - 13, 2012.

MONTAÑO, M. et al. Current state of the SEA System in Brazil: A comparative Study. Journal of Environmental Assessment Policy and Management, 2014.

MONTAÑO, M.; MALVESTIO, A. C.; OPPERMANN , P. A. Institutional learning by SEA practice in Brazil. UVP Report, v. 4+5, p. 201-206, 2013.

MORRISON-SAUNDERS, A.; FISCHER, T. B. What is wrong with EIA and SEA anyway? A sceptic's perspective on sustainability assessment. ournal of Environmental Assessment Policy and Management, v. 8, p. 19 - 38, 2006.

OECD - ORGANISATION FOR ECONOMIC CO-OPERATION AND DEVELOPMENT. Applying Strategic Environmental Assessment: Good Practice Guidance for Development Co-Operation. Organisation for Economic Co-Operation and Development. [S.1.]. 2006.

OECD. OECD Glossary od Statistical Terms. OECD Publishing. [S.1.], p. 605. 2008. (doi:10.1787/978926405508).

OLIVEIRA, , I. S. D.; MONTAÑO, M.; SOUZA, M. P. Strategic Environmental Assessment to improve infrastructure impact assessments in Brazil. Journal of Environmental Protection, v. 4, p. 87-95, 2013.

OLIVEIRA,. Alternativas para a implementação da avaliação ambiental estratégica no Brasil. Tese (Doutorado). Escola de Engenharia de São Carlos. São Carlos. 2008.

OLIVEIRA, I. S. D.; MONTAÑO, M.; SOUZA, M. P. Avaliação Ambiental Estratégica. São Carlos: Suprema Gráfica e Editora, 2009.

OPPERMANN, P. Estudo da Avaliação Ambiental Estratégica no Brasil em perspectiva comparada. Dissertação (Mestrado). Escola de Engenharia de São Carlos, Universidade de São Paulo. São Carlos, p. 108. 2012.

OXFORD CITY COUNCIL. Oxford City Council - Scoping Report for the Local Development Framework, 2011. Disponivel em: <http://www.oxford.gov.uk/PageRender/decP/Sustainability_Appraisal_occw.htm>. Acesso em: 25 Abr 2013. 
PARTIDÁRIO, M. D. R. Guia de boas práticas para a Avaliação Ambiental Estratégica: orientações metodológicas. Amadora: Agência Portuguesa do Ambiente. [S.1.]. 2007.

PARTIDÁRIO, M. D. R. Guia de melhores práticas para Avaliação Ambiental Estratégica orientações metodológicas para um pensamento estratégico em AAE. Agência Portuguesa do Ambiente. Lisboa - Portugal. 2012. (978-972-8577-63-6).

PARTIDÁRIO, M. R. Strategic Environmental Asseement: Key issues emerging from recet pratice. Environ Impact Assess Rev, v. 16, p. 31-55, 1996.

PARTIDÁRIO, M. R. Elements of an SEA framework - improving the added-value of SEA. Environmental Impact Assessment Review, v. 20, p. 647 -663, 2000.

PARTIDÁRIO, M. R. Scales and associated data - what is enough for SEA needs? Environmental Impact Assessment Review, 2007. 460 - 478.

PLANING PRACTICE GUIDANCE (DEPARTMENT FOR COMMUNITIES AND LOCAL GOVERnMENT). Informações. Planning Practice Guidance, 2014. Disponivel em: <http://planningguidance.planningportal.gov.uk/about/>. Acesso em: 12 nov. 2014.

POPE, J.; ANNANDELE, D.; MORRISON-SAUNDERS, A. Conceptualising sustanability assessment. Environmental Impact Assessment Review, n. 24, p. 595 - 616, 2004.

PREFEITURA DE SÃO CARLOS. LEI No 13.691/2005 que institui o Plano Diretor do Município. São Carlos. 2005.

PREFEITURA DE SÃO CARLOS. REVISÃO DO PLANO DIRETOR DO MUNICÍPIO DE SÃO CARLOS - ETAPA 2 - Análise crítica dos instrumentos urbanísticos e da capacidade institucional da SMHDU/PMSC. PMSC/FUSC. São Carlos, p. 47. 2012.

PREFEITURA DE SÃO CARLOS. REVISÃO DO PLANO DIRETOR DO MUNICÍPIO DE SÃO CARLOS - ETAPA3 - Definição dos eixos estratégicos da revisão do Plano Diretor. PMSC/FUSP. São Carlos, p. 22. 2012.

PREFEITURA DE SÃO CARLOS. REVISÃO DO PLANO DIRETOR DO MUNICÍPIO DE SÃO SÃo CARLOS - ETAPA 4 - Propostas para a Revisão do Plano Diretor do Município de São Carlos. PMSC/FUSP. São Carlos, p. 46. 2012.

PREFEITURA MUNICIPAL DE SÃO CARLOS. REVISÃO DO PLANO DIRETOR DO MUNICÍPIO DE SÃO CARLOS - PRODUTO 1 -Atualização da Leitura Técnica do Município. PMSC/FUSP. São Carlos - SP, p. 141. 2011.

RIBEIRO, W. C. Cidades ou sociedades sustentáveis? In: ALESSANDRI CARLOS, A. F.; CARRERAS, C. Urbanização e Mundialização: estudos sobre a metropole. 1. ed. São Paulo: Contexto, 2010. Cap. VI, p. 60 -70.

ROLNIK, R. Ten year of City Statute in Brazil: from the struggle for urban reform to the World Cup cities. International Journal of Urban Sustainable Development, v. 1, p. 1-11, 2013.

ROMANELLI, C. Avaliação ambiental estratégica como instrumento para implantação de programas habitacionais - um estudo sobre o Minha Casa Minha Vida. Dissertação (Mestrado). Escola Politécnica. [S.1.]. 2013.

SABOYA, R. T. Planos diretores como instrumento de orientação das ações de desenvolvimento urbano, Jul 2006. ISSN ISSN 1809-6298. Disponivel em: <http://www.vitruvius.com.br/revistas/read/arquitextos/07.074/338>. Acesso em: 21 Mar 2013. 
SADLER, B.; VERHEEM, R. Strategic Environmental Assessment: status, challegens and future directions. In: The Hague: Netherlands: Minitry of Housing, Spatial Planning and the

Environment. [S.1.]: [s.n.], v. (Report n.53), 1996.

SÁNCHEZ, L. E. Avaliação de Impacto Ambiental - conceitos e métodos. [S.1.]: Oficina de Textos, 2006.

SANTOS,. A Urbanização Brasileira. São Paulo: Hucitec. [S.1.]: [s.n.], 1993.

SANTOS, R. F. Planejamento Ambiental: teoria e prática. São Paulo: Oficina de Textos, 2004.

SANTOS, S. M. E. A. O escopo da Avaliação Ambiental Estratégica. Anais do V Congresso Nacional de Excelência em Gestão., Niterói, RJ, Brasil:, 2009. [s.n.].

SCOTT WILSON PLANNING ENVIRONMENT \& DESIGN. (SEA) / (SA) of Thurrock Council - Local Development Framework /Scoping Report 2005, 2005. Disponivel em: <http://www.thurrock.gov.uk/planning/strategic/content.php?page=strategic_assessment $>$. Acesso em: 20 Abr 2013.

SCOTTISH GOVERNMENT. Aberdeenshire Local Development Plan 2009 Strategic Environment Assessment: Interim Environmental Report. scotland.gov, 2009. Disponivel em: <http://www.aberdeenshire.gov.uk/planning/plans_policies/plan.asp>. Acesso em: 20 mar 2013.

SHEPHERD, A.; ORTOLANO, L. Strategic Environmental Assessment for Sustainable Urban Development. Enrionmental Impact Assessment Review, New York, n. 16, p. 321-335, 1996.

SILVA, A. W. L. D.; SELIG, P. M.; MORALES, A. B. T. Indicadores de Sustentabilidade em Processos de Avaliação Ambiental Estratégica. Ambiente \& Sociedad, São Paulo, v. XV, n. n.3, p. 75 - 96, set-dez 2012.

SILVA, J. A. Direito Urbanisco Brasileiro. 4a . ed. São Paulo: Malheiros Editora, 2006.

SILVA, L. S. E.; TRAVASSOS, L. Problemas ambientais urbanos:desafios para a elaboração de políticas públicas integradas. Cadernos metrópole, n. 19, p. 27-47, 2008.

SNELL, T.; COWELL, R. Scoping in environmental impact assessment: Balancing precaution and efficiency? Environmental Impact Assessment Review, n. 26, p. 359 - 376, 2006.

SOUZA, C. M. M. Avaliação Ambiental Estratégica como subsídio para o planejamento urbano. Tese (Doutorado). UFSC. [S.1.]. 2003.

SPÓSITO, M. E. B. O embate entre as questões ambientais e sociais no Urbano. In: ALESSANDRI, A. F.; LEMOS, A. I. G. Dilemas Urbanos - Novas abordagens sobre a cidade. [S.l.]: Ed. Contexto, 2003.

TAO, T.; TAN, Z.; HE, X. Integrating environment into land-use planning though strategic environmental assessment in China: Towards legal framework an operational procedures. Environmental Impact Assessment Review, n. 27, p. 243-265, Nov 2007. ISSN 10.1016/j.eiar.2006.10.002.

TEIXEIRA, I. M. V. O uso da Avaliação Ambiental Estratégica no planejamento da oferta de blocos para exploração e produção de petróleo e gás natural no Brasil: proposta. Tese (Doutorado) - Universidade Federal de Rio de Janeiro - COPPE, Rio de Janeiro, 2008. 308.

TETLOW, M. F.; HANUSCH ,. Strategic environmental assessment: the state of the art. Impact Assessment and Project Appraisal, 2012. 15-24. 
THERIVEL,. Strategic Environmental Assessment in action. 2a Edição. ed. London: Earthscan, 2010.

THERIVEL, R. Strategic enviromental assessment in action. London:Earthscan: [s.n.], 2004.

THERIVEL, R.; MINAS, P. Ensuring effective sustainability appraisal. Impact Assessment and Project Appraisal, p. 81 - 91, Fev 2002.

UNITED NATIONS ECONOMIC COMMISSION FOR EUROPE. Resource Manual to Support Application of the Protocol on Strategic Environmental AssessmentResource Manual to Support Application of the Protocol on Strategic Environmental Assessment. Nova York e Genebra. 2013.

VERHEEM, R. A. A.; TONK, J. A. M. N. Strategic environmental assessment: one concept multiple forms. Impact Assessment and Project Appraisal, 2000. 177-182.

VILLAÇA, F. Dilemas do Plano Diretor. In: CEPAM, F. P. F. L.- O município no século XXI: cenários e perspectivas. São Paulo: Cepam, 1999. p. 384.

WALLINGTON, ; BINA, O.; THISSEN,. Theorising strategic environmental assessment: Fresh perspectives and future challenges. Environmental Impact Assessment Review, 2007. 569584.

WANG, Y. et al. Developing an indicar system to foster sustainability in strategic planning in China: A case study of Pundong nwe Area, Shanghai. Ecological Indicators, v. 29, p. 376-389, 9 Jan 2013.

WHITE, L.; BRAM, N. F. Strategic environmental assessment for sustainability: Review of a decade of academic research. Environmental Impact Assessment Review, 2012.

WIRUTSKULSHAI, U.; SAJOR, E.; COOWANINTWONG, N. Importance od Context in adoption and progress in application of strategic environmental assessment: Experience of Thailand. Environmental Impact Assessment Review, n. 31, p. 352-259, Feb 2011. ISSN 10.1016/j.eiar.2011.01.001. 


\section{ANEXOS}

\section{LISTA DE FONTES}

Lista de relatórios de AAE utilizados nesta pesquisa.

CAAS (ENVIRONMENTAL SERVICES). Appropriate Assessment Of Draft Galway County Development Plan 2009, 2009. Disponivel em: <http://www.galway.ie/en/Services/Planning/DevelopmentPlans/GalwayCountyDevelopmentPl an2009-2015/CountyDevelopmentPlan2009-2015/>. Acesso em: 10 Dez 2012.

CAIRNGORMS National Park - Deposit Local Plan Strategic Environmental Assessment/ Environmental Report, 2007. Disponivel em: $<$ http://cairngorms.co.uk/resource/docs/publications/06072007/CNPA.Paper.489.Deposit\%20Lo cal\%20Plan\%20-\%20Non-Technical\%20Summary.pdf>. Acesso em: 24 Mar 2013.

CLARE COUNTY COUNCIL. Clare County Development Plan 2011-2017 - Environment Appraisal of the Plan /Part I: Strategic Environmental Assessment (SEA), 2011. Disponivel em: $<$ http://www.clarecoco.ie/planning/publications/clare-county-development-plan-2011-2017-

volume-3-strategic-environmental-assessment-environmental-report-9181.pdf >. Acesso em: 25 Mai 2013.

COMUNE DI ACERRA. Comune di Acerra Piano Urbanistico Comunale - Valutazione ambiental estrategica - Rapporto Ambientale, 2008. Disponivel em: <http://www.cartografia.regione.lombardia.it/sivas/jsp/procedimenti/procedimentiChiusiVa.jsf> . Acesso em: 15 Jul 2013.

COMUNE DI ROMANO DI LOMBARDIA. Comune di Romano di Lombardia - Valutazione Ambientale Strategica (VAS) del Piano di Governo del Territorio (PGT), 2008. Disponivel em: <http://www.cartografia.regione.lombardia.it/sivas/jsp/procedimenti/procedimentiChiusiVa.jsf> . Acesso em: 20 Jun 2013.

COMUNI DI BERGAMO. Comuni di Bergamo - Valutazione Ambientale Strategica (VAS) del Piano di Governo del Territorio (PGT), 2008. Disponivel em: 〈http://www.cartografia.regione.lombardia.it/sivas/jsp/procedimenti/procedimentiChiusiVa.jsf> . Acesso em: 20 Jun 2012.

CORK COUNTY COUNCIL - PLANNING POLICY UNIT. Cork County Council Planning Policy Unit - Strategic Environmental Assessment - Environmental Report, 2007. Disponivel em: <http://www.corkcoco.ie/co/web/Cork\%20County\%20Council/Departments/Planning/Planning \%20Policy\%20Unit\%20(PPU)/>. Acesso em: 11 Dez 2012.

FACULDADE DE CIÊNCIAS E TECNOLOGIA - UNIVERSIDADE DE NOVA LISBOA. Avaliação Ambiental Estratégica do Plano Regional de Ordenamento do Território dos Açores, 2008. Disponivel em: <http://www.azores.gov.pt/NR/rdonlyres/E3CF392B-07E3-4CEB-85A18752D2FDFECB/419799/RA_PROTA_Final_Parte1.pdf>. Acesso em: 15 Jan 2013.

GLASGOW CITY COUNCIL. The Local Development Plan for Glasgow - Main issues report Interim Environmental Report, 2010. Disponivel em: <http://www.glasgow.gov.uk/CHttpHandler.ashx?id=13036\&p=0>. Acesso em: Mar 2013.

HYDER CONSULTING (UK). The London Borough of Barking and Dagenham - Local Implementation Plan - Strategic Environmental Assessment/ Environmental Report , 2005. Disponivel em: <http://www.lbbd.gov.uk/Pages/Home.aspx>. Acesso em: 16 Abr 2013. 
INSTITUTO SUPERIOR TÉCNICO. Avaliação Ambiental Estratégica do Plano Regional de Ordenamento do Território dos Oeste e Vale do Tejo., 2008. Disponivel em: <http://consultaprotovt.inescporto.pt/plano-regional/avaliacao-ambiental-estrategica/RNT_PROTOVT.pdf>.

Acesso em: 16 Jan 2012.

INSTITUTO TÉCNICO SUPERIOR. Avaliação Ambiental Estratégica da Alteração do Plano Regional de Ordenamento do Território da Área Metropolitana de Lisboa, 2010. Disponivel em: $<$ http://www.ccdr-lvt.pt/pt/plano-regional-de-ordenamento-do-territorio-da-area-metropolitanade-lisboa/54.htm>. Acesso em: 10 Ago 2012.

OXFORD CITY COUNCIL. Oxford City Council - Scoping Report for the Local Development Framework, 2011. Disponivel em: <http://www.oxford.gov.uk/PageRender/decP/Sustainability_Appraisal_occw.htm>. Acesso em: 25 Abr 2013.

SCOTT WILSON PLANNING ENVIRONMENT \& DESIGN. (SEA) / (SA) of Thurrock Council - Local Development Framework /Scoping Report 2005, 2005. Disponivel em: <http://www.thurrock.gov.uk/planning/strategic/content.php?page=strategic_assessment>. Acesso em: 20 Abr 2013.

SCOTTISH GOVERNMENT. Aberdeenshire Local Development Plan 2009 Strategic Environment Assessment: Interim Environmental Report. scotland.gov, 2009. Disponivel em: <http://www.aberdeenshire.gov.uk/planning/plans_policies/plan.asp>. Acesso em: 20 mar 2013. 